\title{
Lower respiratory tract infections in general practice : aetiology, diagnosis, management and prgnosis
}

Citation for published version (APA):

Hopstaken, R. M. (2005). Lower respiratory tract infections in general practice : aetiology, diagnosis, management and prgnosis. [Doctoral Thesis, Maastricht University]. Universitaire Pers Maastricht. https://doi.org/10.26481/dis.20050909rh

Document status and date:

Published: 01/01/2005

DOI:

10.26481/dis.20050909rh

Document Version:

Publisher's PDF, also known as Version of record

\section{Please check the document version of this publication:}

- A submitted manuscript is the version of the article upon submission and before peer-review. There can be important differences between the submitted version and the official published version of record.

People interested in the research are advised to contact the author for the final version of the publication, or visit the DOI to the publisher's website.

- The final author version and the galley proof are versions of the publication after peer review.

- The final published version features the final layout of the paper including the volume, issue and page numbers.

Link to publication

\footnotetext{
General rights rights.

- You may freely distribute the URL identifying the publication in the public portal. please follow below link for the End User Agreement:

www.umlib.nl/taverne-license

Take down policy

If you believe that this document breaches copyright please contact us at:

repository@maastrichtuniversity.nl

providing details and we will investigate your claim.
}

Copyright and moral rights for the publications made accessible in the public portal are retained by the authors and/or other copyright owners and it is a condition of accessing publications that users recognise and abide by the legal requirements associated with these

- Users may download and print one copy of any publication from the public portal for the purpose of private study or research.

- You may not further distribute the material or use it for any profit-making activity or commercial gain

If the publication is distributed under the terms of Article $25 \mathrm{fa}$ of the Dutch Copyright Act, indicated by the "Taverne" license above, 


\section{Lower respiratory tract infections in general practice}

aetiology, diagnosis, management and prognosis 
Rogier Hopstaken, Maastricht 2005

ISBN: $90-5278-474-4$

Coverillustration: 'Direct auscultation' by an anonymous artist; lithograph from the private collection of Rogier Hopstaken

Layout: Tiny Wouters

Production: Datawyse | Universitaire Pers Maastricht

The studies in this thesis were financed by the Care and Public Health Research Institute.

Printing of this thesis was financially supported by Stichting Gezondheidscentra Eindhoven, Axis-Shield PoC, Clindia Benelux B.V., Mediphos Medical Supplies B.V. and $\mathrm{CZ}$ Actief in Gezondheid. 


\title{
Lower respiratory tract infections in general practice
}

\section{aetiology, diagnosis, management and prognosis}

\author{
PROEFSCHRIFT \\ ter verkrijging van de graad van doctor \\ aan de Universiteit Maastricht, \\ op gezag van de Rector Magnificus, Prof. mr. G.P.M.F. Mols, \\ volgens het besluit van het College van Decanen, \\ in het openbaar te verdedigen \\ op vrijdag 9 september 2005 om 12.00 uur
}

door

Rogier Hopstaken

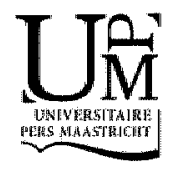


Promotor

Prof. Dr. G.J. Dinant

Co-promotores

Dr. E. E. Stobberingh

Dr. P. Nelemans

Dr. J.W.M. Muris

Beoordelingscommissie

Prof. dr. F. Sturmans (voorzitter)

Prof. dr. C.A.M. Bruggeman

Prof. dr. F. Buntinx

Prof. dr. H. Melbye, University of Tromsø, Noorwegen

Dr. G. Wesseling 
Voor mijn moeder

Ter herinnering aan mijn vader Aan Vanessa 



\section{Contents}

Chapter 1 Introduction 9

Chapter 2 Contributions of symptoms, signs, erythrocyte sedimentation rate, and Creactive protein to a diagnosis of pneumonia in acute lower respiratory tract infection

Chapter 3 Inter-observer variation in the interpretation of chest radiographs for pneumonia in community-acquired lower respiratory tract infections

Chapter 4 Clinical items not helpfull in differentiating viral from bacterial lower respiratory tract infections in general practice

Chapter 5 Is roxithromycin better than amoxicillin in the treatment of acute lower respiratory tract infections in general practice? A double-blind randomised controlled trial

Chapter 6 Do clinical findings in lower respiratory tract infection help general practitioners prescribe antibiotics appropriately? An observational cohort study in general practice

Chapter 7 Prognostic factors and clinical outcome in acute lower respiratory tract infections; a prospective study in general practice

Chapter 8 Implementing findings of diagmostic research in everyday general practice; the paradox of evidence and practice in the example of lower respiratory tract infections

Chapter 9 General discussion

Summary

Samenvatting

Dankwoord

Publications

About the author 



\section{Chapter 1}

Introduction

t)

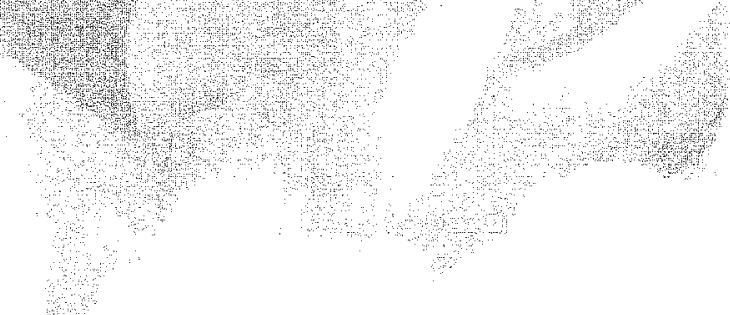




\section{Background and research questions}

Lower respiratory tract infection (LRTI) is a collective term for infections below the larynx. It includes bronchial infections and pneumonia in a broad variety of clinical presentations and severity. The present thesis deals with community-acquired LRTI in adults, as presented, diagnosed and managed in general practice. The outpatient setting is pre-eminently the field in which this common illness is routinely diagnosed and treated. Antibiotics are frequently prescribed, despite their questionable additional value in most cases. In fact, it is probable that most antibiotic prescriptions do not outweigh the risks and the exposure to adverse events. Above all, unjustified antibiotic prescribing leads to growing bacterial resistance rates. Practice-based studies are of eminent importance to assess the occurrence and presentation of LRTI in primary care and to provide answers that may help to slow down the pace of the emerging problem of bacterial resistance worldwide. However, there is a striking lack of knowledge on all major aspects of LRTI in the community. The many unanswered research questions discussed below have stimulated us to initiate this LRTI project. The aim of our study was formulated as follows:

\section{Study aim}

To examine the aetiology, diagnosis, management and prognosis of LRTI in general practice, in the hope of contributing to the development of rational diagnostic and therapeutic strategies, ultimately leading to a reduction of unnecessary antibiotic prescribing.

In daily general practice, the clinical diagnosis of LRTI is relatively rare - unlike that of upper respiratory tract infection. Instead, general practitioners diagnose a chest infection or they tend to subdivide LRTI into two major, and clinically relevant, subcategories: acute bronchitis and pneumonia. The same distinction is used in the International Classification of Primary Care (ICPC). ${ }^{1}$ Most computerised patient information systems in general practice have adopted the codes of this classification system to label patients' illnesses and complaints. The ICPC definition for acute bronchitis is: presence of a combination of (a) cough, and (b) scattered or generalised abnormal chest signs: wheeze, coarse or moist sounds. Pneumonia is defined as: evidence of pulmonary consolidation shown by one of the following: (a) typical $x$-ray appearance, or (b) clinical signs of at least three of the following: (I) diminished air entry; (II) dullness to percussion; (III) bronchial breath sounds; (IV) fine crepitations (or crackles); and (V) increased vocal fremitus and resonance.

Eighty percent of LRTI patients are estimated to have acute bronchitis (with an incidence of 24-46 per 1000 patients per year) and $20 \%$ to have community- 
acquired preumonia (with an incidence of 5-11 per 1000 patients per year). ${ }^{2}$ The recently performed Second National Study on complaints and disease in general practice in the Netherlands indicates incidences of 21.5 for acute bronchitis (95\% confidence interval (CI) 18.5-24.5) and 6.3 for pneumonia ( $\mathrm{Cl}$ 5.2-7.4). ${ }^{3}$ This cluster (i.e., LRTI) is the fourth most frequently presented iliness in Dutch general practice (after common cold, neck and back complaints and urinary tract infection). Theoretically, the distinction between acute bronchitis and pneumonia has important implications for the management of the illness. Evidence is growing that acute bronchitis is self-limiting and rarely requires antibiotic treatment. Systematic reviews of randomised controlled trials of treatment for patients with acute bronchitis have concluded that the possible modest beneficial effect hardly outweighs the harm caused by antibiotic treatment. By contrast, antibiotic treatment is considered obligatory for community-acquired pneumonia. However, it is not known whether or not general practitioners (GPs) succeed in selecting the right persons, i.e. pneumonia patients, for antibiotic treatment. This resulted in the following research question:

1. What is the diagnostic value of clinical symptoms, signs and blood tests for the diagnosis of pneumonia in LRT?

In combination with clinical suspicion, chest radiography is the acknowledged reference standard for the diagnosis of pneumonia. Classical lobar pneumonia with uniform shadowing on the chest radiograph is easy to diagnose. However, pneumonia in ambulant patients in the community is mostly less extensive and may show more discrete radiographic shadowing. Hence, the interpretation of chest radiographs of pneumonia outpatients by radiologists may well show greater variability. This resulted in the following research question:

2. What is the inter-observer variation in the interpretation of chest radiographs for pneumonia in community-acquired LRTI?

LRTI is caused by microbial agents, and may be of chemical or mechanical origin in cases of aspiration. ${ }^{4}$ Although a predominant pathogen can not always be identified, bacterial and viral pathogens, including the so-called atypical bacteria Chlamydia pneumoniae. Mycoplasma pneumoniae and Legionella pneumophila, are generaily believed to be the cause of almost all LRTI in the community. Aspiration pneumonia is not subject of this thesis. Repeated incentives by the pharmaceutical industry and reports of increasing occurrences of newly emerging pathogens like these so-called atypical bacteria may be relevant for antibiotic prescribing behaviour in daily general practice.5.6 However, the frequency distribution of the micro-organisms involved in LRTI in the community is largely unknown. This resulted in the following research question: 
3. What is the frequency distribution of the mioro-organisms most frequenty involved in LRTI in the community?

Evidence of an additional value of macrolide antibiotics in the communty setting is required before it can be decided to advise GPS to change their antibiotic prescribing behaviour from the reliable first-choice antibiotics amoxicillin and doxycycline to the use of newer and expensive antimicrobial drugs. This resulted in the following research question:

4. Is the macrolide antibiotic roxithromycin more effective than amoxicillin in the treatment of LRTI?

Clinical identification of viral and bacterial LRTI would be helpful; but, remarkably, we were unable to find diagnostic studies on the clinical prediction of viral or bacterial LRTI in general practice. High C-reactive protein (CRP) values may be predictive of bacterial infections, although evidence is poor and conflicting: ${ }^{7-12}$ This resulted in the following research question:

5. What is the diagnostic value of clinical symptoms, signs and blood tests for the diagnosis of viral and bacterial LRTI?

Unnecessary antibiotics use leads to growing bacterial resistance rates. ${ }^{13 \cdot 16}$ The impact of antibiotic overprescribing in primary care is huge, and can be expressed in the following percentages, which I call the " $4 \times 80^{\text {" data": }}$

$-80 \%$ of all antibiotic prescriptions are handed out in primary care; 17,18

$-80 \%$ of the antibiotic prescriptions are for respiratory tract infections; $17,19.20$

- $80 \%$ of the LRTI patients are treated with antibiotics despite the fact that it is beneficial only in a small minority of cases; 17,21

- $80 \%$ of the LRTI patients have acute bronchitis, which is a self-limiting disease, rarely requiring antibiotic treatment.22,23

* rounded percentages

Diagnostic uncertainty and various non-medical factors like time pressure, patient expectations and perceived patient expectations have been identified in questionnaire and qualitative studies as reasons for antibiotic overprescribing. $24,2.5$ In these studies, GPs were asked about their perceptions of the reasons behind this overprescription. There have been no studies to identify actual history and examination findings that predict antibiotic prescribing rates for LRTI. Moreover, the appropriateness or otherwise of these prescribing decisions has never been prospectively studied. This resulted in the following research question: 
6. How do the general practitioners history and examination findings influence antibiotic prescribing rates for LRT, and to what extent do these clinical findings predict appropriate antibiotic prescribing?

Patients suffering from LRTI are often told that they should reconsult if the symptoms get worse or last for more than a week. This period of one week is often chosen because it coincides with the last day of the antibiotic course that they usually receive. This implies that the LRTI is usually expected to be cured within one week. However, evidence for this assumption has not been found. This resulted in the following research question:

7. How long does it take to recover from LRTI according to GPS and patients, taking possible antibiotic treatment and various subgroups into consideration?

Regardless of whether or not antibiotics are prescribed, about one in three patients reconsults for similar symptoms within the next 28 days. ${ }^{26}$ Two-thirds of the patients initially treated with antibiotics who reconsult receive another antibiotic, despite the lack of evidence of infection. ${ }^{27}$ It may well be that the burden of LRTI and the impact of the illness on daily activities and work productivity are underestimated. This resulted in the following research question:

8. To what extent does LRTI impair the patients' daily activities?

Before the discovery of the first sulphonamides in 1938, and then penicillin in 1944, pneumonia was a major threat to the population. It was called captain of the man of death' and later 'the old man's friend', both referring to the pivotal role of (pneumococcal) pneumonia in morbidity and mortality. 4,28 But even today, pneumonia is one of the leading causes of death, albeit often as a terminal event in some underlying illness. However, most studies on the outcome of pneumonia are hospital-based, and their results can not be generalized to primary care. because the severity of the suspected pneumonia is lower and the illness is mostly at an earlier stage at the time of presentation. Primary care studies on the prognosis of LRTI, including representative samples of both pneumonia and acute bronchitis patients, have been rare. Moreover, subgroups of patients with particular clinical characteristics or co-morbidity may be more prone to a poor prognosis or a slow recovery from the illness. This resulted in the following research question:

9. Is it possible to identify subgroups of patients with patient and clinical characteristics indicating that they are prone to a poor prognosis or a
prolonged clinical course?

Answers to these questions are expected to help us understand the complex issues encountered in LRTI. This could lead to recommendations for better and more rational patient care and ultimately to the reduction of bacterial resistance. 
However, implementation of study results to daily general practice is often hampered by various factors, especially as regards findings of diagnostic studies. This resulted in the following - LRTI-oriented - research question:

10. Why is implementation of diagnostic research in daily general practice often not achieved, and how can it be improved?

In order to answer the above research questions, patient-centred studies were designed, consisting of one observational study and one experimental study. The study was performed in the general practice setting, and involved $25 \mathrm{GPS}$ and their practice assistants in the Dutch province of Limburg in the years 1998 and 1999. Data of 247 adult patients with acute cough and additional symptoms and signs of LRTI were recorded during regular consultation hours. Additional study procedures, except for chest radiography but including the collection of biological samples, took place at the GPs' surgeries on the same day. 


\section{Outline of the thesis}

Chapters $2-8$ comprise a series of seven published or submitted manuscripts. Some overlap in contents between these chapters was inevitable, since it had to be possible to read each article independently.

Chapter 2 describes an assessment of the diagnostic value of a large set of clinical items, the GPS' clinicall diagnosis, erythrocyte sedimentation rate (ESR) and Creactive protein (CRP) for pneumonia. It also derives a prediction rule for the presence of pneumonia, and identifies a llow-risk group of patients who do not require antibiotic treatment.

Chapter 3 reports on the inter-observer variation in the interpretation of chest radiographs of patients with pneumonia versus those without pneumonia. The radiologists of three hospitals routinely assessed the chest radiographs for each recruited LRTI patient. The radiographs were blindly re-assessed for the presence or absence of infiltrates by one independent radiologist. Various measures of interobserver agreement are reported.

Chapter 4 evaluates findings on history taking, physical examination and relevant blood tests for their value to predict viral or bacterial LRTI. It also presents frequencies of the isolated respiratory tract pathogens in community-acquired LRTI.

Chapter 5 reports the results of a double-blind randomised controlled medication trial in LRTI patients who needied antibiotic treatment according to their GP. The efficacy and safety of roxithromycin was compared with that of amoxicillin in a 10 day treatment regimen.

Chapter 6. The negative consequences of overprescribing of antibiotics for LRTI are well-known. In earlier questionnaire-based and qualitative studies, clinicians were asked about their perceptions of the reasons behind overprescribing of antibiotics. This chapter describes the actual findings on history and physical examination that predict antibiotic prescribing for LRTI and explores the appropriateness or otherwise of these prescribing decisions.

Chapter 7 describes the duration of the clinical course and the clinicall outcome of LRTI, as reported by GPS and patients, as well as the impact of LRTi on patients" daily activities. Differences are presented between the following subgroups: (a) patients who were prescribed an antibiotic compared to those who were not; (b) patients who were suffering from pneumonia compared to those who were not; and (c) patients who went through a viral infection compared to patients with a bacterial infection and compared to patients with an infection of microbiologically 
unexplained aetiology. Furthermore, it describes the patient characteristics and history and examination findings that contribute to delayed symptom resolution.

Chapter 8 discusses issues relating to the implementation of diagnostic research findings in daily general practice and the difficulties encountered in this implementation. Our research project on LRTI in general practice is used to illustrate important issues of the paradox of evidence and practice.

Chapter 9 considers the methodological strengths and limitations of the study and discusses the implications of the study results for general practice, as well as directions for future research. 


\section{References}

1. WONCA CCo. ICHPPC-2-Defined International Classification of Health Probilems in Primary Care). Oxford, Oxford University Press, 1986.

2. Okkes IM, Oskam $S K$, Lamberts H. Van Klacht naar diagnose: episodegegevens uit de huisartspraktijk. [From complaint to diagnosis: Disease episodes in general practice]. Bussum, Couthino, 1998.

3. van der Linden MW, Westert GH, de Bakker DH, Schellevis $F$ G. Tweede Nationale Studie naar ziekten en verrichtingen in de huisartspraktijk. Klachten en aandoeningen in de bevolking en in de huisartspraktijk. Utrecht/Bitthoven. NIVEL/RIVM, 2004.

4. Bartlett JB. Management of Respiratory tract infections. Baltimore, Williams\&Wilkins, 1997:1-117.

5. Fang GD, Fine M, Orloff J, Arisumi D, Yu VL, Kapoor W, Grayston JT, Wang SP, Kohler R, Muder RR et al. New and emerging etiologies for community-acquired pneumonia with implications for therapy.A prospective multicenter study of 359 cases. Medicine Baltimore. 1990;69:307-16.

6. Marrie TJ, Peeling RW, Fine MJ, Singer DE, Coley CM, Kapoor WN. Ambulatory patients with community-acquired pneumonia: the frequency of atypical agents and clinical course. Am J Med. 1996;101:508-15.

7. BTS Guidelines for the Management of Community Acquired Pneumonia in Adults. Thorax. 2001;56 S4:1-64.

8. Holmberg $H$, Bodin L, Jonsson I, Krook. A. Rapid aetiological diagnosis of pneumonia based on routine laboratory features. Scand J Infect Dis. 1990;22:537-45.

9. Korppi $M$, Kroger L. Creactive protein in viral and bacterial respiratory infection in children. Scand J Infect Dis. 1992;25:207-13.

10. Hjortdahl $P$, Landaas $S$, Urdal $P$, Steinbakk $M$, Fuglerud $P$, Nygaard $B$. C-reactive protein: a new rapid assay for managing infectious disease in primary health care. Scand J Prim Health Care. 1991;9:3-10.

11. Virkki R, Juven T, Rikalainen H, Svedstrom E, Mertsola J, Ruuskanen O. Differentiation of bacterial and viral pneumonia in children. Thorax. 2002;57:438-41.

12. Soderstrom M, Blomberg $J$, Christensen $P$. Hovelius B. Erythromycin and phenoxymethylpenicillin (penicillin $W$ ) in the treatment of respiratory tract infections as related to microbiological findings and serum Creactive protein. Scand I Infect Dis. 1991:23:347.54.

13. Magee JT, Pritchard EL, Fitzgerald KA, Dunstan FD, Howard A. Antibiotic prescribing and antibiotic resistance in community practice: retrospective study, 1996-8. BMJ. 1999;319:1239-40.

14. Jacoby GA. Prevalence and resistance mechanisms of common bacterial respiratory pathogens. Clin Infect Dis. 1994;18:951-7.

15. Swartz MN. Use of antimicrobiall agents and drug resistance. N Engl J Med. 1997;337: 491.2.

16. Neu HC. The crisis in antibiotic resistance. Science. 1992;257:1064-73.

17. Kuyvenhoven MM, Var Ballen FA, Verheij TJ. Outpatient antibiotic prescriptions from 1992 to 2001 in The Netherlands. J Antimicrob Chemother. 2003;52:675-8.

18. Wise R. Hart T, Cars O, Streulens M, Helmuth R, Huovinen P, Sprenger M: Antimicrobial resistance. Is a major threat to public health. BMJ. 1998;317:609-10.

19. Melker de RA. [Efficacy of antibiotics in frequently occurring airway infections in family practice] Effectiviteit van antibiotica bij veelvoorkomende luchtweginfecties in de huisartspraktijk. Ned Tijdschr Geneeskd. 1998;142:452-6. 
20. Gonzales $R$, Steiner JF, Lum $A_{p}$ Barrett $P H$. Decreasing antibiotic use in ambulatory practice - Impact of a multidimensional intervention on the treatiment of uncomplicated acute bronchitis in adults. JAMA. 1999;281:151229.

21. Holmes WF. Macfarlane JT, Macfarlane RM, Hubbard R. Symptoms, signs, and prescribing for acute lower respiratory tract illness. Bi J Gen Pract. 2001;51:177-81.

22. Smucny J, Fahey $T$, Becker L, Glazier R. Antibiotics for acute bronchitis (Cochrane review): The Cochrane Library. Issue 1, 2004. Chichester, UK, John Wiley \& Sons, Ltd. 2004.

23. Fahey $T$, Stocks $N$, Thomas T. Quantitative systematic review of randomised controlled trials comparing antibiotic with placebo for acute cough in adults. BMJ. 1998;316: 906-10.

24. Coenen $S_{n}$ Van Royen $P$, Vermeire $E$, Hermann I, Denekens J. Antibiotics for coughing in general practice: a qualitative decision analysis. Fam Pract. 2000;17:380-5.

25. Butler CC, Rallnick S, Pill R, Maggs Rapport F, Stott N. Understanding the culture of prescribing: qualitative study of general practitioners' and patients" perceptions of antibiotics for sore throats. BMJJ. 1998;317:637-42.

26. Holmes WF, Macfarlane JT, Macfarlane RM, Lewis S. The influence of antibiotics and other factors on reconsultation for acute lower respiratory tract ill ness in primary care. Br J Gen Pract. 1997;47:815-8.

27. Macfarlane J, Prewett J, Rose D, Gard P, Cunningham R, Saikku P, Euden S, Myint S. Prospective case-control study of role of infection in patients who reconsult after initial antibiotic treatment for lower respiratory tract infection in primary care. BMJ. $1997 ; 315: 1206-10$.

28. Macfarlane JT. Pneumonia and other acute infections. Acute respiratory infections in adults, in Brewis RAL, Corrin B, Geddes DM, Gibson GJ. Respiratory Medicine. Londion, W.B. Saunders Company Ltd, 1995;1:705-46. 


\section{Chapter 2}

Contributions of symptoms, signs, erythrocyte sedimentation rate, and C-reactive protein to a diagnosis of pneumonia in acute lower respiratory tract infection

RM Hopstaken, JWM Muris, JA Knottnerus, ADM Kester, PELM Rinkens, GJ Dinant

British Journal of General Practice 2003;5:358-64

Huisarts en Wetenschap 2004;47:9-15

Evidence-Based Medicine 2004;9:55 


\title{
Abstract
}

\section{Background}

Diagnastic tests enabling general practitioners (GPS) to differentiate rapidly between pneumonia and other lower respiratory tract infections (LRTIs) are needed to prevent increase of bacterial resistance by unjustified antibiotic prescribing.

\begin{abstract}
Aims
To assess the diagnostic value of symptoms, signis, erythrocyte sedimentation rate (ESR), and C-reactive protein (CRP) for pneumonia; to derive a prediction rule for the presence of pneumonia; and to identify a low-risk group of patients, who do not require antibiotic treatment.
\end{abstract}

\section{Design of study \\ Cross-sectional.}

\author{
Setting \\ Fifteen GPs' surgeries in the southern part of The Netherlands.
}

\section{Method}

Twenty-five GPs recorded clinical information and diagnosis in 247 adult patients presenting with LRTI. Venous blood samples for CRP and ESR were taken and chest radiographs (reference standard) were made. Odds ratios, describing the relationships between discrete diagnostic variables and reference standard (pneumonia or no pneumonia) were calculated. Receiver operating characteristic analysis of ESR, CRP, and final models for pneumonia was performed. Prediction rules for pneumonia were derived from multiple logistic regression analysis.

\section{Results}

Dry cough, diarrhoea and recorded temperature of $\geq 38^{\circ} \mathrm{C}$ were independent and statistically significant predictors of pneumonia, whereas abnormal pulmonary auscultation and clinical diagnosis of pneumonia by the GPs were mot. ESR and CRP had higher diagnostic odds ratios than any of the symptoms and signs. Adding CRP to the final 'symptoms and signs' model significantly increased the probability of correct diagnosis. Applying a prediction rule for low-risk patients, including CRP of $<20 \mathrm{mg} / \mathrm{I}, 80$ of the 193 antibiotic prescriptions could have been prevented with a maximum risk of $2.5 \%$ of missing a pneumonia case.

\section{Conclusion}

Most symptoms and signs traditionally associated with pneumonia are not predictive of pneumonia in general practice. The prediction rule for low risk patients presented here, including a CRP of $<20 \mathrm{mg} /$, can considerably reduce unjustified antibiotic prescribing. 


\section{Background and research questions}

The main diagnostic challenge of general practitioners (GPS) facing patients with acute community-acquired lower respiratory tract infections (LRTIs) is selecting the right patients for antibiotic treatment. In contrast with acute bronchitis, where antibiotics are rarely indicated because the infection is mostly self-limiting: 1.2 in pneumonia it is considered bad practice to withhold antibiotic treatment from a patient. GPs have the difficult task of balancing the fear of missing the diagnosis of pneumonia against their duty not to contribute to the growing problem of bacterial resistance by routine prescription of antibiotics. 310 Therefore, it would be useful to have diagnostic tools in general practice that enabled GPs to differentiate between pneumonia and other LRTIs rapidly, i.e., during one consultation, without the need to refer a patient for chest radiography or laboratory tests. ${ }^{14}$ However, diagnostic studies on LRTIs in general practice are very rare. Classical symptoms and signs of pneumonia, derived from hospital studles, are of limited value in everyday general practice, because of the lower incidence and smaller extent of disease found there. Owing to this lower pre-test probabillty of pneumonia, the predictive value of a positive symptom or sign (for example, crackles on auscultation) for pneumonia will automatically be lower, assuming equal diagnostic skills of the doctors involved. ${ }^{12-14}$ Additional use of erythrocyte sedimentation rate (ESR) and C-reactive protein (CRP) tests might be helpful. ${ }^{15-17}$

Despite the diagnostic uncertainties, the incidence of acute bronchitis has been estimated at 24-46 per 1000 patients per year. ${ }^{18-21}$ The annual incidence of community-acquired pneumonia is approximately five to 11 per 1000 patients. 18.21 The present study evaluated the diagnostic value of symptoms, signs, ESR, and CRP for pneumonia in adult patients presenting to a GP with LRTI. A rule to predict the probability of pneumonia was derived to "dentify a group of patients with a low risk of pneumonia.

\section{Methods}

\section{Patients and procedures}

Consecutive patients in the southern part of the Netherlands, who presented to their GP with symptoms and signs of LRTI (defined as a new or increasing cough, combined with other clinical characteristics), were eligtible to enter the study. Inclusion criteria are llisted in Box 2.1. Exclusion criteria were: pregnancy and lactation; history of hypersensitivity to penicillin or macrolide antibiotics: concomitant treatment with ergot alkalloids and/or terfenadine during the study period; other severe clinical disease; treatment with antibiotics within the preceding 14 days; and a hospital stay for a respiratory complaint during the previous four 
weeks. Some of the exclusion criteria were relevant to a randomised clinical trial, which was running in parallel to the diagnastic study. 22

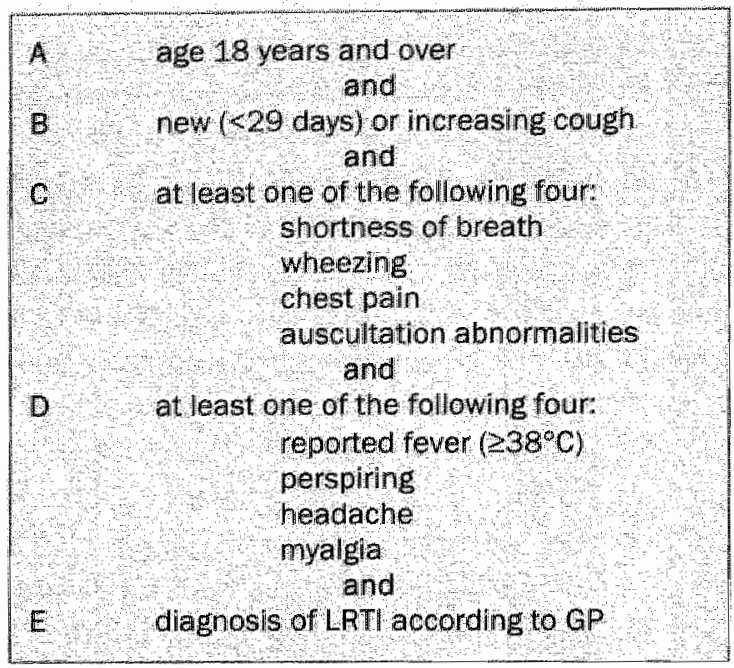

Box 2.1. Inclusion criteria for the studly.

The GPS performed and recorded an extensive, standardised medical history and physical examination, and stated a clinical diagnosis of either pneumonia or other LRTI, summarised for the purpose of the present study as acute bronchitis. The GPS applied and interpreted the diagnostic tests (symptoms and signs) in their usual way, and were not trained in any sense. This was done to increase the generalisability of the study results to everyday general practice. In addition, venous blood samples for CRP and ESR analysis were taken and submitted to the Haematology and Clinical Chemistry laboratories of the University Hospital Maastricht on the same day and were analysed using standard procedures. ${ }^{23}$

\section{Reference standard}

Chest radiographs (lateral and postero-anterior) were made of every patient on the third day after inclusion, the third day being chosen to ensure that possible infiltrates were detectable on the chest radiograph. 24 The radiologist was asked to rate infiltrates or other abnormalities. The radiographs were then re-assessed for the presence or absence of infiltrates by an independent senior radiologist at the University Hospital Maastricht, blinded to the first radiologist's results for conclusions. If the first and second radiologists disagreed, a third senior radiologist of the University Hospital Maastricht conducted an independent, decisive assessment. The radiologists were blinded to the clinical status of the patient. The 
conclusive finding of an infiltrate was regarded as evidence of pneumonia and served as the reference standard for the diagnostic analysis. All other outcomes were considered to represent "no pneumonia'. The GPS were only informed by the radiologist about the results of the radiographs after the study had been completed.

\section{Statistical analysis}

The data were analysed in several steps, using SPSS 9.0 and Stata 7 software. Sensitivities, specificities, positive and negative predictive values (PV+, PV-) and diagnostic odds ratios (ORs) with $95 \%$ confidence intervals (95\% Cls) were calculated from $2 \times 2$ tables, comparing the outcomes of all discrete diagnostic variables with the reference standard ('pneumonia' or 'no pneumonia'). Receiver operating characteristic (ROC) analysis was used to describe the association between sensitivity and specificity of the blood tests (ESR and CRP) at different cutoff values. To compare the overall diagnostic power of ESR and CRP, the respective areas under the curve (AUCS) were calculated. Differences between the AUCs were tested for significance by the DeLong equality test. 25

The independent diagnostic contributions of symptoms and signs to the prediction of pneumonia were assessed using multiple logistic regression analysis. However, the number of available variables was too large to have ten cases per variable. ${ }^{26}$ Therefore, three criteria had to be met for a variable to enter the model. First, each variable had to be positive in at least ten patients. Secondly, each variable had to be positive in at least five patients with pneumonia. Thirdly, the association of the variables with the presence or absence of pneumonia ( $2 \times 2$ tables) had to have a $p$ value $<0.10$ ( $\chi^{2}$ or Fisher's exact test). Multiple logistic regression analysis (backward elimination with $p>0.05$ for exclusion) was performed with the selected variables from history taking and physical examination, resulting in the final "symptoms and signs' model. Several potentially relevant interaction terms were included in the model and removed again if they did not contribute to the diagnostic accuracy. This allowed a rule to be derived predicting the probability of pneumonia in each individual case. In accordance with everyday practice, where additional blood tests are performed after information has been acquired from history taking and physical examination, logistic regression analysis was repeated for the 'symptoms and signs" model, adding ESR or CRP at different cut-off points and as numerical variables. ROC curves were constructed to visualise the diagnostic performance of the final models. The AUCs of these models were calculated and tested mutually for significance. 25 


\section{Results}

\section{Patients and univariate analysis of symptoms and signs}

Between January 1998 and April 1999, 25 GPs from 15 practices included 247 patients in the study, with a mean age of 52 years (range $=18-89$ years). Radiographic pneumonia was present in 32 (13\%) patients. Chest radiographs were missing in four patients. The frequencies of the symptoms and signs presented and the GPs" diagnostic conclusions are shown in Table 2.1. The corresponding ORs show that the presence of nausea and diarrhoea at least doubled the probability of pneumonia. 'Recent cough for $\leq 2$ days' and mental confusion, present in only 11 and elght patients respectively, were highly specific, their presence almost tripling the probability of pneumonia. The lower limit of the confidence interval of the OR of mental confusion, however, equalled $\mathbb{1}$.0.

The classical symptoms and signs of pneumonia, i.e. dyspnoea, thoracic pain, fever (ais recalled by the patient), respiratory rate $>20 / \mathrm{min}$, percussion dullness, and crackles, were not discriminative for pneumonia. A clinical diagnosis of pneumonia by the GPS was associated with a very modest, non-significant increase in the probability of pneumonia, from $13 \%$ (prior probability) to $19 \%$ (PVt, posterior probability). The GPs could not exclude pneumonia with more certainty (PV - 87\%) than before their clinical judgment, since the prior probability of not having pneumonia was $87 \%$.

\section{ROC analysis of ESR and CRP}

ESR and CRP at various cut-off points were compared with the reference standard and ROC curves were constructed (Figure 2.1). The figure shows ORs, with confidence intervals, for three clinically relevant cut-off values per blood test. In general. ESR and CRP were elevated $(>10)$ in $97 \%$ of the patients with radiographic pneumonia. Both tests had much higher ORs than variables from history and physical examination. The overall diagnostic performance of CRP was significantly better than that of ESR $(p=0.02)$.

\section{Multivariable analysis of symptoms and sigins}

Logistic regression analysis was performed with six selected variables from history taking and physical examination, adding the variable age (as a numerical variable). This was the 'symptoms and signs' model. The variables dry cough, diarrhoea and temperature $\geq 38^{\circ} \mathrm{C}$ had statistically significant ORs (final 'symptoms and signs' model, Table 2.2). This allowed the predicted probability of pneumonia for individual patients to be calculated. 
Table 2.1 Diagnostic value of symptoms, signs and clinical diagnosis in pneumonia, Univariate analysis $(n=243)$.

\begin{tabular}{|c|c|c|c|c|c|}
\hline & \multirow[b]{2}{*}{ N } & \multirow[b]{2}{*}{8} & \multicolumn{3}{|c|}{ Freumonia (prior probability $13.2 \%$ ) } \\
\hline & & & OR $(95 \% \mathrm{Cl})$ & $\mathrm{PV}+\mathrm{M})$ & $P V(k)$ \\
\hline \multicolumn{6}{|l|}{ Symptoms } \\
\hline Age 65 years or older & 70 & 28.8 & $1.3(0.6-3.0)$ & 15.7 & 870 \\
\hline Recent cough 52 days & 11 & 51 & $38(1.0-13.8)^{4}$ & 364 & 86.9 \\
\hline Dry cough & 58 & 23.9 & $22(1,0-4.7)$ & 20.7 & 89,2 \\
\hline Sputum purulence & 133 & 54.7 & $12(0.6=2.6)$ & 14.3 & 882 \\
\hline Dyspnoea & 188 & 77.4 & $0.710 .3-1.61$ & 122 & 83.6 \\
\hline Thoracic pain & 145 & 59.7 & $1.3(0.6>2.9)$ & 14.5 & 88.8 \\
\hline Fever & 85 & 35.0 & $1.8(0.8-3.8)$ & 176 & 89.2 \\
\hline Chills' & 122 & 50.2 & $2.4(1,1,5.4)$ & 18.0 & 947 \\
\hline Confusion & 8 & 3.3 & $43(10-18.8)^{2}$ & 375 & 877 \\
\hline Nausea & 39 & 16.0 & $2,9(1,2-6.6)^{4}$ & 25.6 & 892 \\
\hline Diarmoeat & 19 & 78 & $3: 5(1.2-10.0)^{3}$ & 31.6 & 88.4 \\
\hline Smoking & 81 & 33.3 & $0.8(0.3-1.7)$ & 11.1 & 85.8 \\
\hline Smoking in the past & 150 & 61.7 & $1,0(0,5-2.2)$ & 13.3 & 871 \\
\hline \multicolumn{6}{|l|}{ Comorbidity } \\
\hline Asthma & 47 & 19.3 & $12(0.5=3.0)$ & 14.9 & 872 \\
\hline COPDS & 32 & 13.2 & $1.3(0.4-3.6)$ & 156 & 872 \\
\hline \multicolumn{6}{|l|}{ Physical signs } \\
\hline General impression: moderate/severe lliness! & 65 & 26.7 & $28(13-61)$ & 23,1 & 90.4 \\
\hline Respiration rate $>20 / \mathrm{min}$, & 9 & 3.7 & $0.8(0.1-6.8)$ & 111 & 86.8 \\
\hline Percussion duliness & 11 & 45 & (4) & 4 & 100 \\
\hline Auscultation abnormality & 204 & 840 & $20(0.6-69)$ & 142 & 923 \\
\hline Bronchial breathing & 64 & 263 & $1.4(0.7-3.4)$ & 172 & 878 \\
\hline Crackles & 50 & 20.6 & $1.5(0.7-3,7)$ & 180 & 87.6 \\
\hline Temperature $238^{\circ} \mathrm{C}$ & 58 & 23.9 & $2.5(1.2-5.5)$ & 22.4 & 89.7 \\
\hline Clinical diagnosis of pneumonia & 21 & 8.6 & $1.6(0.5-5.2)$ & 19.0 & 87.4 \\
\hline
\end{tabular}

"Variable selected for multiple logistic regression analysis.

2 Number rounded to 1.0 , but in reality less than 1.0

3 Measured less than 24 hours previously

4 Statistically significant $(p<0.05)$

s Chronic olbstructive pulmonary disease

\section{Multivariable analysis 'symptoms and signs + ESR/CRP value'}

The diagnostic value of the variables in the final 'symptoms and signs' model with added ESR or CRP value is also shown in Table 2.2. The AUCs of the 'symptoms and signs + ESR/CRP' models were higher than those of the 'symptoms and signs' model, and rose further at higher cut-off values of ESR and CRP. A CRP cut-off value of 50 led to the highest OR (18) upon addition of CRP to the final "symptoms and signs' model, leading to non-significant ORs for all other variables. 


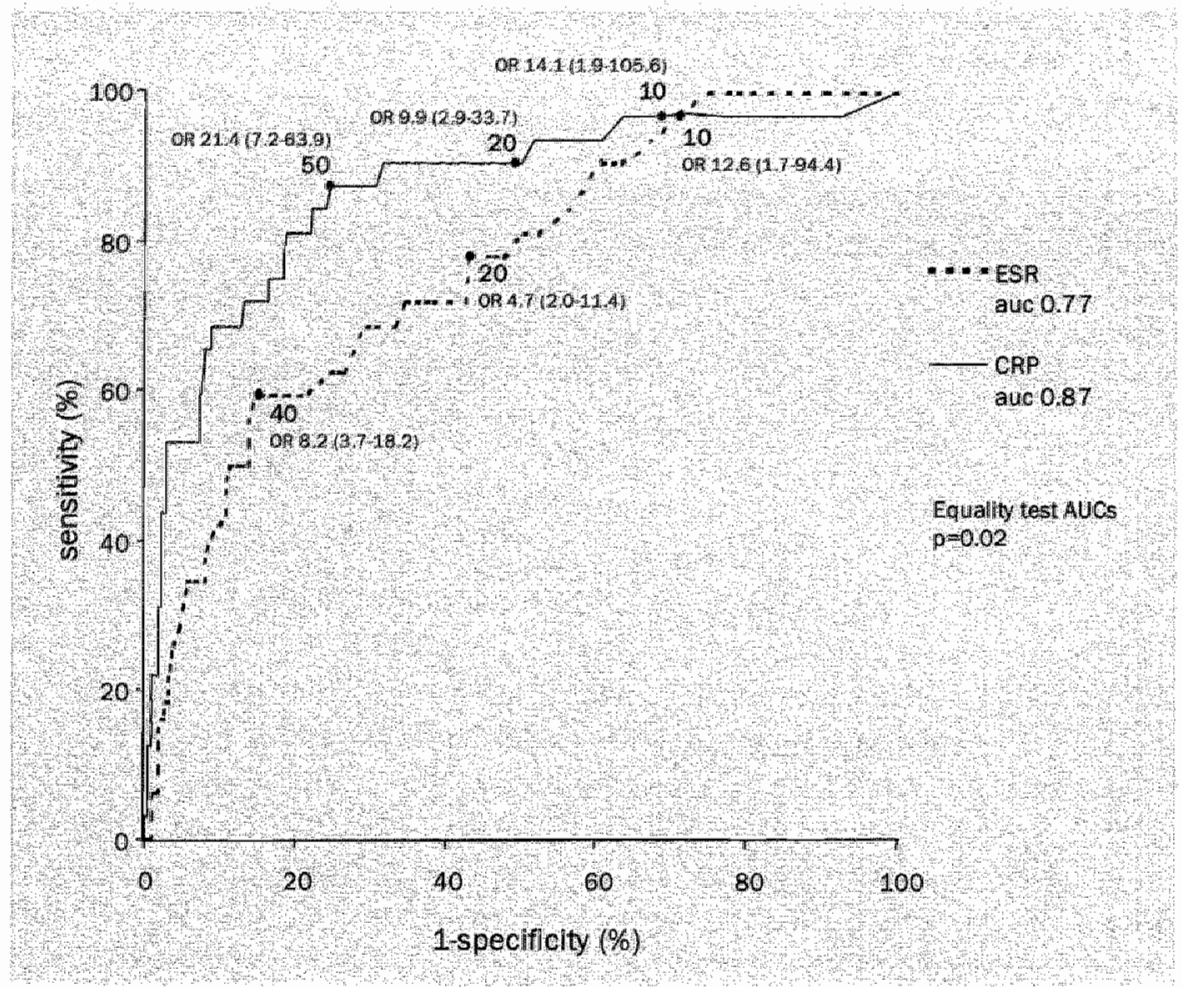

Figure 2.1 ROC curves of erythrocyte sedimentation rate (ESR) and C-reactive protein (CRP) for pneumonia $(n=243$ ), with various cut-off points and corresponding diagnostic odds ratios (ORs).

\section{ROC analysis of final models}

The diagnostic performances of the final models with ESR and CRP as numerical values were visualised in ROC curves (Figure 2.2). Both the 'symptoms and signs + ESR' model and the "symptoms and signs + CRP" model predicted the probability of pneumonia significantly better than the 'symptoms and signs' model ( $p=0.004$ and $p<0.001$, respectively). In addition, the 'symptoms and signs + CRP' model was also significantly better than the "symptoms and signs + ESR' model $(p=0,012)$. 
Table 2.2 Diagnostic value of "symptoms and signs" (SS). "symptons and signs + erythrocyte sedimentation rate (SS + ESR) and "symptoms and signs + C-reactive protein" (SS + CRP) at different cut-off points in the reduced logistic regiression madels.

\begin{tabular}{|c|c|c|c|c|c|c|c|}
\hline & & & & OR $195 \%$ CI) & & & \\
\hline & ss & SS + ESR 10 & SS + ESR 20: & $S S+$ ESR 40 & SS + CRP 10 & S5 + CRP 20 & SS - CRP 50 \\
\hline Histony & & & & & & & \\
\hline oncoush & 277 & 2.64 & 2.65 & $2.66^{2}$ & 284 & 288 & 2,48 \\
\hline & $(1,19644)$ & $10,2021)$ & $(1,14631)$ & 100608 : & $(1206,73)$ & 1140094 & 10976,17 \\
\hline crills & +4 & 3 & *ै। & अ०० & 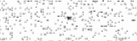 & 3 & $3+4$ \\
\hline Nausee & & 8 & & 3 & 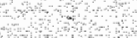 & & 8 \\
\hline oiarmosea & 590 & 5.57 & 5.25 & 392 & 497 & 435 & 2,74 \\
\hline & $(4898.49)$ & $(7,1 / 1809)$ & $(158.1799)$ & $(1.12 \cdot 3.66)$ & $(455 \times 495)$ & $(333,1429)$ & 10,70964 \\
\hline Physical examination & & & & & & & \\
\hline General lmpression & & & & & & & \\
\hline moderate/severe iling & & & & . & 2 & & 4 \\
\hline Temperaturo $>38^{\circ} 6$ & 308 & 2.53 & 2.86 & 271 & 238 & 2214 & 1900 \\
\hline & $(135702)$ & 1095,85 & $(1,226,70)$ & $(1,12666)$ & $(1,03553)$ & 1093,621 & $(076.7 .7)$ \\
\hline Blood test: & & & & & 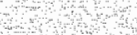 & & 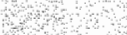 \\
\hline ESR $10 / 20 / 40$ & 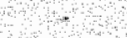 & 10.52 & 4.29 & 6.81 & 4 & & 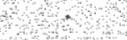 \\
\hline 10 & & $(4397973)$ & $(17410 \mathrm{~s} 9)$ & $(2,96-15,65)$ & & 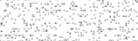 & \\
\hline CRP $10 / 20 / 50$ & & & & & 4170 & 848 & 1762 \\
\hline & & & & & $(15588664)$ & $(2.45 .2939)$ & $(5.77 .53 .85)$ \\
\hline constant & 274 & 4.73 & 3.88 & 329 & 4,79 & 4,18 & 4.15 \\
\hline Area Under curve (aud) & 0.70 & 076 & 078 & 0.80 & 0.77 & 0,80 & 0.87 \\
\hline
\end{tabular}

${ }^{1}$ Non-significant test result

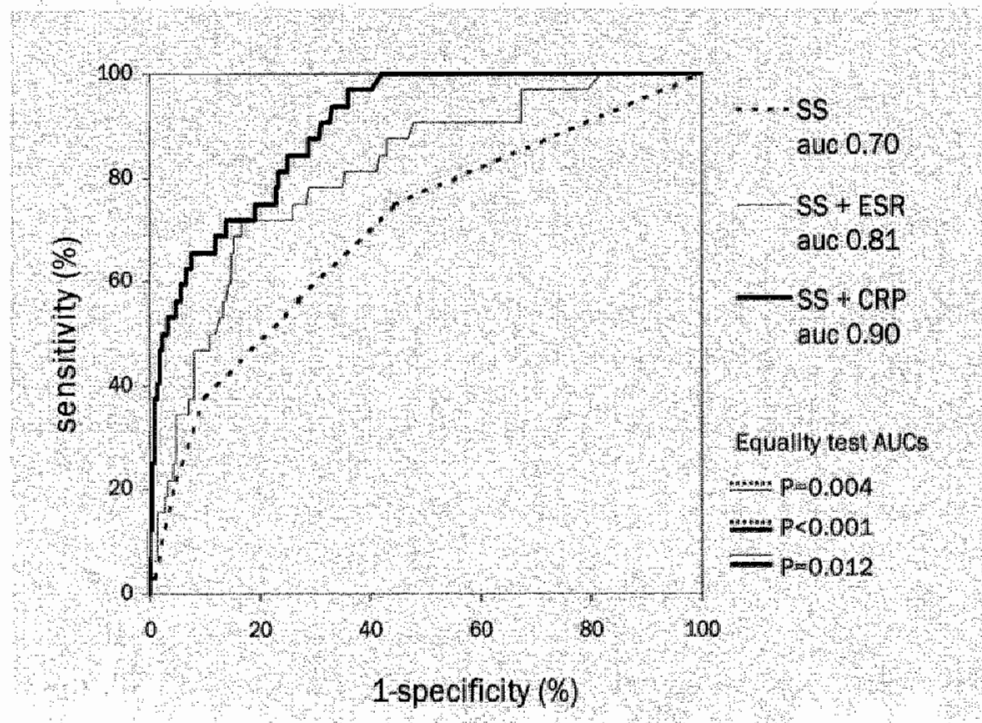

Figure 2.2 Multiple logistic regression analysis. ROC curves of the three finall madels: 'symptoms and signs' model (SS), 'symptoms and signs + ESR' model (SS+ESR) and 'symptoms and signs * CRP' model (SS+CRP). The AUCs of the models were calculated and tested mutually for significance by DeLong equality tests. 
The predicted probatility of pneumonia for each individual patient can be calculated from the equation:

$$
P \sin (1+y)
$$

in which

$$
y=a+b x_{1}+b_{2} x_{2}+b_{3} x_{3}
$$

where is the codficient of the constant in the model; $b_{1,4} b_{2}$ and $b$ are the regression coeficients of the variables in the model.

Caldulatons for the firal 'symptoms and signs' model and one of the final 'symptoms and signs + ESR/CRP' models are given bestow.

"Symptoms and silgris" model

$$
y=-2.74
$$

+1.02 when dry cough was present; +1.78 when diarrhoea was present: +1.13 when temperature $\geq 38^{\circ} \mathrm{C}$

\section{Examples:}

A patient with dry cough, ditarthoea and temperature $\geq 38^{6}$ c has a prediction score of $-2.74+1.02+1.78+1.13=$ 1.19, resulting in a probability of $76 \%$ (Cl $42 \% 93 \%$ ) of having pneumonia. Simlarly, a patient with dry cough and temperature $\geq 38^{\circ} \mathrm{C}$, but no diarrhoea, has a probability of $36 \%$ (Cl 19\%-56\%) of having pmeumonia. A patient without any of these three ltems has a probability of $6 \%(\mathrm{Cl} 3 \% 11 \%)$ of having pneumonia.

'Symptoms and signs + CRP cul-off value $20^{\circ}$ madell

$$
y=4.18
$$

4.1 .06 when dry cough was present; +1.4 .7 when diarrhoea was present; +0.79 when temperature $\geq 38.0^{\circ} \mathrm{C}$;

$$
+2.14 \text { when } C R P \geq 20
$$

\section{Examples:}

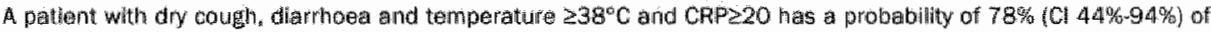
having pneumobles. Similenly, a petient with the maximum of one positivo score on the three items dry cough, darrhoer and temperature $238^{\circ} \mathrm{C}$, and with $\mathrm{CRP} 20$ (the low-1sk grouph, has a probability of $3 \%(\mathrm{Cl} 1 \%-8 \%$ ) having pneumonim. A patient without any of these items has a probability of $2 \%(\mathrm{Cl} 0 \% 5 \%)$ of hawing pneumonia.

The $95 \%$ confidence interval (C) can be calculated from the interval:

$$
y \pm[1.96 \times \operatorname{SE}(\gamma)]
$$

of the predicted log odds.

Box 2.2 Derivation of probability test for pneumonia. 


\section{Low-risk groups}

A review of the equations (Box 2.2), resulting in diagnostic trees with all possible predicted (posterior) probabilities of pneumonia, allowed a group of patients to be identified with a low risk of having pneumonia after history taking, physical examination and measurement of CRP, compared with the (prion) probability of pneumonia at the start of the consultation (13\%). This low-risk group $(n=107)$ consisted of patients with a maximum of one positive score on the three items diarrhoea, dry cough, and temperature $\geq 38^{\circ} \mathrm{C}$, and with CRP<20 $\mathrm{mg} / \mathrm{l}$. The combined PV in this low-risk group of not having pneumonia was $97 \%(95 \%$ $\mathrm{Cl}=92 \%$ to $99 \%$ ). When an ESR value of $<20 \mathrm{~mm} /$ hour was used instead of CRP<20 $\mathrm{mg} / \mathrm{l}$, the combined PV in this group $(n=121)$ of not having pneumonia was $95 \%(95 \% \mathrm{Cl}=89 \%$ to $98 \%)$. If the prediction rule for low-risk patients, including CRP<20 mg/l, was applied to the patients who received antibiotic treatment, 80 prescriptions $(41 \%)$ could have been avoided, with a risk of $2.5 \%$ (i.e., the risk of missing two patients with pneumonia). Applying the rule to the patients who did not receive antibiotic treatment $(n=50), 27$ patients would not receive an antibiotic with a risk of $4 \%$ (i.e., the risk of missing one patient with pneumonia). According to the reference standard, five of the 50 patients who did not receive antibiotic treatment had pneumonia. Thus, the GPS" decision not to prescribe antibiotics comprised a risk of $10 \%$ of missing pneumonia.

\section{Discussion}

The need for better diagnostic tools enabling GPs to differentiate between pneumonia and other LRTIs was obvious from the GPS" clinical assessment: there was no relation between their assessment that pneumonia was present and pneumonia actually being found subsequently. However, this finding needs to be treated with caution, because it assumes that the widely acknowledged reference standard used (the finding of an infiltrate on chest radiographs by two radiologists) is $100 \%$ accurate, which is not the case. To gain more insight into the acceptability of chest radiography as a reference standard, the outcomes of the chest radiographs were compared with the microbiological test results, assuming - although both acute bronchitis and pneumonia are infectious diseases - a higher probability of pathogens in pneumonia than in other LRTIs: pathogens were found in $77 \%$ of the 'infiltrate' group, compared with $44 \%$ of the 'no infiltrate' group $(\mathrm{OR}=4.2,95 \% \mathrm{Cl}=1.7$ to 10.3$)$, which was in accordance with our expectations.

Diagnostic studies on LRTIs have rarely been performed, and especially not with a population of LRTI in general practice, so it was considered too early to start the present study with promising variables from other studies alone. The drawback is a potential introduction of paradoxical associations, when the number of diagnostic 
variables is high. As a result of the applied restrictions for entering the logistic regression analysis a satisfactory strong reduction in variables was acquired, although, statistically, an even stronger reduction of variables would have been preferable.

In this practice-based study we have tried to remain as close as possible to daily practice: different GPS diagnosing illnesses with their own interpretations of history taking and physical examination, who were not trained in any sense but who followed strict study criteria to define the study population and to facilitate comparisons with other studies performed, and future studies. The chosen approach increases generalisability of the study results. For the same reason, additional blood tests were added to the logistic regression model after analysis with symptoms and signs only.

Significant predictors of pneumonia in multivariate logistic regression analysis were dry cough, diarmoea, and a temperature of $\geq 38^{\circ} \mathrm{C}$. In the present study population, all patients coughed (inclusion criterion). One of the main characteristics of patients with acute bronchitis is that they have productive cough. In pneumonia, productive cough may well be present, but not necessarily so, and it is often not an early symptom. 27 So it is not obvious to look for primarily inflamed bronchi with subsequent high sputum production in pneumonia patients, unllike that seen in acute bronchitis. Dry cough was a predictor of pneumonia in one other study known to us. ${ }^{28}$ Diarrhoea is probably a para-infectious symptom of pneumonia, caused by the rellease of cytokines and other inflammation mediators, which lead to malabsorption in the intestines, combined with an adrenergic stress reaction. ${ }^{29}$ it is present in $10 \%$ to $30 \%$ of patients with community-acquired pneumonia. 30 Originally described as a common symptom in pneumonia caused by Legionella pneumophila, Chlamydia pneumoniae, and Mycoplasma pneumoniae, it later became clear that diarrhoea occurs in both types of pneumonia. Moreover, the specific clinical pictures of these so-called atypical pneumonias are less common than previously thought. ${ }^{31,32}$ Therefore, it is now accepted to consider instead the atypical pathogens as bacteria. A recorded temperature of $\geq 38^{\circ} \mathrm{C}$ was identified as an independent predictor in all the published diagnostic studies on communityacquired pneumonia that were consulted.28,33-38 However, fever, as recalled by the patient, was not a good substitute for the actual recording of rectal temperature in this study. Mental confusion seemed highly specific for pneumonia, but the small number of cases in the present study presumably was not enough to achieve statistical significance.

Most symptoms and signs traditionally associated with pneumonia, including abnormal pulmonary auscultation, did not contribute to the diagnosis of pneumonia in the present study. Other studies have also found that crackles, in particular, are not discriminative, ${ }^{33,34,38,39}$ or not sufficient to rule in or rule out pneumonia. ${ }^{35.37}$ 
Antibiotics were prescribed to 196 of the 247 patients, while a cinical diagnosis of pneumonia was made in only 21 patients. Leaving out these 21 patients with presumed pneumonia, this means that antibiotics were prescribed in $175 / 226$ patients $(77 \%)$ with presumed acute bronchitis, which is in accordance with earlier studies ${ }^{40-42}$ The high percentage of antibiotic prescriptions is probably owing to a strong belief in the efficacy of antibiotics for acute bronchitis, as well as by the negative consequences of missing a diagnosis of pneumonia, in terms of the patient's morbidity and possible damage to the doctor-patient relationship, in addition to various other doctor- and patient-related factors. 43

The identified prediction rule for low-risk patients, including a CRP<20 $\mathrm{mg} /$, can help GPS reduce their fear of missing pneumonia, and can serve as a supportive argument in negotiations with patients about whether or not to prescribe antibiotics. In addition to the identification of a low-risk patient, a scheduled reattendance at the surgery the next day, for example, may be timely enough to recognise potential dangers for the patient, using time as a diagnostic tool. However, the final prediction models and the rule for low-risk patients may be too optimistic for clinical use, since they were derived from this study population. They should therefore be tested in a new, similar set of patients in general practice, to obtain external validation of the results. ${ }^{44}$ Internal validation procedures, such as split-half or bootstrap methods are both inferior to validation in a new study population and statistically not advisable, because of the relatively simall sample size. As the exclusion criteria, which were not needed for this diagnostic study, mainly consisted of pregnant or breastfeeding women and patients with rare conditions, there is no indication that they have hampered the generalisability of the study results.

Dutch GPs generally have the opportunity to measure ESR in their surgeries, but it is hardly used for LRTIs. The need for a venous blood sample, and the time delay of one hour before the test result is obtained. may contribute to the choice of prescribing antibiotics instead of selecting the right patients for antibiotic treatment. A CRP point of care test, which requires only a finger prick and a few minutes, may prevent this course of action, and thus potentially reduce antibiotic prescriptions in general practice. Introduction in routine practice seems to be justified, since the test has been proved to be accurate, robust and costeffective. $15,17.45,46$

To the best of our knowledge, the present study is the first complete, diagnostic study on the full scope of LRTIs in general practice. Dry cough, diarrhoea, a temperature of $\geq 38^{\circ} \mathrm{C}$ and elevated ESR and CRP values were significant predictors of pneumonia. Safely withholding LRTI patients from antibiotic treatment was possible, if the patient satisfied the criteria of the prediction rule for low-risk patients, including a CRP value of $<20 \mathrm{mg} / \mathrm{l}$. A new primary care study is necessary to accept or reject our findings and to validate this prediction rule. 


\section{References}

1. Smucny JJ, Becker LA, Glazier RH. Mclsaac W: Are antibiotics effective treatment for acute bronchitis? A meta-analysis. I Fam Pract. 1998;47:453-60.

2. Macfarlane J, Holmes W, Gard P, Macfarlane R, Rose D, Weston V, Leinonen M, Saikku P. Myint S; Prospective study of the incidence, aetiology and outcome of adult lower respiratory tract illness in the community. Thorax. 2001;56:109-14.

3. Felmingham D, Gruneberg RN. The Alexander Project 1996-1997: latest susceptibility data from this international study of bacterial pathogens from community-acquired lower respiratory tract infections. J Antimicrob Chemother. 2000;45:191-203.

4. Friedland IR, Mccracken GH Jr. Management of infections caused by antibioticresistant Streptococcus pneumoniae. N Engl J Med. 1994:331:377-82.

5. Jacoby GA. Prevalence and resistance mechanisms of common bacterial respiratory pathogens. Clin Infect Dis. 1994;18:951-7.

6. Schwartz $B$, Bell DM, Hughes JM. Preventing the emergence of antimicrobial resistance. A call for action by clinicians, public health officials, and patients. JAMA. 1997:278:944 5.

7. Seppala $H_{*}$ Klaukka $T$, Vuopio-Varkila $J$, Muotiala $A, H e l e n i u s ~ H$, Lager $K$, Huovinen $P$. The effect of changes in the consumption of macrolide antibiotics on erythromycin resistance in group A streptococci in Finland. Finnish Study Group for Antimicrobial Resistance. N Engl J Med. 1997;337:441-6.

8. Swartz MN. Use of antimicrobial agents and drug resistance. N Engl J Med. 1997;337: 491-2.

9. Magee JT, Pritchard EL, Fitzgerald KA, Dunstan FD, Howard AJ. Antibiotic prescribing and antibiotic resistance in community practice: retrospective study, 1996-8. BMJ. 1999:319:1239-40.

10. Priest P, Yudkin P, McNulty C, Mant D. Antibacterial prescribing and antibacterial resistance in English general practice; cross sectional study. BMJ. 2001;323:1037-41.

11. Keeley D. Guidelines for managing community acquired pneumonia in adults. BMJ. 2002;324:436-7.

12. Knottnerus JA. Interpretation of diagnostic data: an unexplored field in genera! practice. I R Coll Gen Pract. 1985;35:270-4.

13. Knottnerus JA. Medical decision making by general practitioners and specialists. Fam Pract. 1991:8:305-7.

14. Knottnerus $J A_{r}$ Leffers $P$. The influence of referral patterns on the characteristics of diagnostic tests. I Clin Epidemiol. 1992;45:1143-54.

15. Dinant GJ, de Kock $C A$, van Wersch JW. Diagnostic value of Creactive protein measurement does not justify replacement of the erythrocyte sedimentation rate in dailly general practice. Eur J Clin Invest. 1995;25:353-9.

16. Dinant $G J$, Knottherus $J A$, van Wersch JW. Discriminating ability of the erythrocyte sedimentation rate: a prospective study in general practice. Br J Gen Pract. 1991;41: $365-70$.

17. Hjortdahl P. Landaas $S$, Urdal $P$, Steinbakk $M_{1}$ Fuglerud P, Nygaard B. C-reactive protein: a new rapid assay for managing infectious disease in primary health care. Scand J Prim Health Care. 1991;9:3-10. 
18. Okkes IM, Oskam SK, Lamberts H. Van Klacht naar diagnose, episodegegevens uit de huisartspraktjk. [From complaint to diagnosis: Disease episodes in general practice]. Bussum " Couthino, 1998.

19. van der Velden J, De Bakker DH, Claessens AAMC, Schellevis FG. Dutch National Survey of General Practice. Morbidity in General Practice. Utrecht, NIVEL, 1992.

20. Woodhead MA, Macfarlane JT, McCracken JS, Rose DH. Finch RG. Prospective study of the aetiology and outcome of pneumonia in the community. Lancet. 1987;1:671 4 .

21. Jokinen $C$. Heiskanen $L$, Juvonen $H$, Kallinen $S$, Karkola K, Korppi M, Kurki $S$, Ronnberg $\mathrm{PR}$, Seppa A, Soimakallio $S$ et al. Incidence of community-acquired pneumonia in the population of four municipalities in eastern Finland. Am J Epidemiol. 1993;137: 977-88.

22. Hopstaken RM Nelemans P. Stobberingh EE, Muris JWM, Rinkens PELM, Dinant GJ. Is roxithromycin better than amoxicillin in the treatment of acute lower respiratory tract infections in primary care? A double-blind randomized controlled trial. I Fam Pract. 2002:51:329-36.

23. Isenberg HD. Clinical micrabiology procedures handbook. Washington; D.C. American Society for Microbiology, 1994.

24. Bartlett JG, Mundy LM. Community-acquired pneumonia. N Engl J Med. 1995;333: 1618-24.

25. DeLong ER, DeLong DM, Clarke Pearson DL. Comparing the areas under two or more correlated receiver operating characteristic curves: a nonparametric approach. Biometrics. 1988;44:837-45.

26. Harrell FE Jr, Lee KL, Mark DB. Multivariable prognostic models: issues in developing models, evaluating assumptions and adequacy, and measuring and reducing errors. Stat Med. 1996;15:361-87.

27. Baldwin DR, Macfarlane JT. Community-Acquired Pneumonia, in Foulsham $R$ and Whitehouse R: Infectious Diseases. London, Furn, R., 1999, vol. 1.

28. Melbye $\mathrm{H}$. Straume B, Aasebo U, Dale K. Diagnosis of pneumonia in adults in general practice. Relative importance of typical symptoms and abnormal chest signs evaluated against a radiographic reference standard. Scand J Prim Health Care. 1992;10:226-33.

29. Powell DW. Approach to the patient with diarrhea, in Yamada T: Textbook of gastroenterology. Philadelphia, J.B. Lippincott Company, 1995;1:815-22.

30. Marrie TJ. Community acquired pneumonia. Clin Infect Dis. 1994;18:501-15.

31. Marrie TJ, Peeling RW. Fine MJ, Singer DE, Coley CM, Kapoor WN. Ambulatory patients with community-acquired pneumonia: the frequency of atypical agents and clinical course. Am J Med. 1996;101: 508-15.

32. Helms CM, Viner JP, Sturm RH, Renner ED, Johnson W. Comparative features of pneumococcal, mycoplasmal, and Legionnaires' disease pneumonlas. Ann hntern Med. 1979;90:543-7.

33. Melbye $H$, Straume B, Aasebo U, Brox J. The diagnosis of adult preumonia in general practice. The diagnostic value of history, physical examination and some blood tests. Scand J Prim Health Care. 1988;6:111-7.

34. Diehr $P_{n}$ Wood RW, Bushyhead J, Krueger L, Wolcott B, Tompkins RK Prediction of pneumonia in outpatients with acute cough-a statistical approach. J Chronic Dis. 1984; $37: 215-25$.

35. Singal BM, Hedges JR, Radack KL. Decision rules and clinical prediction of pneumonia: evaluation of low-yield criteria. Ann Emerg Med. 1989;18:13-20.

36. Gonzalez Ortiz MA, Carnicero Bujarrabal M, Varela Entrecanales M. Prediccion de la presencia de neumonia en el adiulto con fiebre. [Prediction of the presence of pneumonia in adults with fever]. Med Clin (Barc). 1995;105:521-4. 
37. Heckerling PS, Tape $\pi G$, Wigton RS, Hissong KK. Leikin JB, Ornato JP, Cameron JL, Pacht EM. Clinical prediction rule for pulmomary infiltrates. Ann Intern Med. 1990;113: 664-70.

38. Gennis $P$, Gallagher $J$, Falvo $C$, Baker $S$, Than $W$. Clinical criteria for the detection of pneumonia in adults: guidelines for ordering chest roentgenograms in the emergency department I Emerg Med. 1989;7:263-8.

39. Melbye $H$, Straume $B, B r o x ~ J$. Laboratory tests for pneumonia in general practice: the diagnostic values depend on the duration of illness. Scand J Prim Health Care. $1992 ; 10: 234-40$.

40. Kuyvenhoven MM, Verheif $\mathrm{T} J$, de Melker RA, van der Velden $\mathbb{U}$. Antimicirobial agents in lower respiratory tract infections in Dutch general practice. $\mathrm{Br} J$ Gen Pract. 2000;50: 133-4.

41. Oeffiriger KC, Snell LM, Foster BM, Panico KG, Archer RK. Treatment of acute bronchitis in adults. A national survey of family physicians. I Fam Pract. 1998;46:469-75.

42. Macfarlane J, Lewis $S A$, Macfarlane $R$. Holmes $W$. Contemporary use of antibiotics in 1089 adults presenting with acute lower respiratory tract illness in general practice in the U.K.: implications for developing management guidelines. Respir Med. 1997;91: 427-34.

43. Coenen $S$, van Royen $P$, Vermeire $E$, Hermann I, Denekens $J$. Antibiotics for coughing in general practice: a qualitative decision analysis. Fam Pract. 2000;17:380-5.

44. Knottnerus JA, wan Weel C, Muris JWM. Evaluation of diagnastic procedures. BMJ. 2002:324:477-80.

45. Dahler Eriksen BS, Lassen JF, Petersen PH, Lund ED, Lauritzen T, Brandslund I. Evaluation of a near-patient test for C-reactive protein used in daily routine in primary healthcare by use of difference plots. Clin Chem. 1997;43:2064-75.

46. Dahler Eriksen BS, Lauritzen T, Lassen JF, Lund ED, Birandslund I. Near-patient test for C-reactive protein in general practice: assessment of clinical, organizational, and economic outcomes. Clin Chem. 1999;45:478-85. 


\section{Chapter 3}

Inter-observer variation in the interpretation of chest radiographs for pneumonia in community-acquired lower respiratory tract infections

RM Hopstaken, T Witbraad, JMA van Engelshoven, GJ Dinant

Clinical Radiology 2004;59:743-52 


\section{Abstract}

Aim

To assess interobserver variation in the interpretation of chest radiographs of individuals with pneumonia versus those without pneumonia.

\section{Materials and methods}

Chest radiographs of outpatients with a lower respiratony tract infection (LRT) were assessed for the presence of Infiltrates by radiologists from three local hospitals and were reassessed by one university hospital radiologist. Various measures of inter-observer agreement were calculated.

\section{Results}

The observed proportional agreement was 218 in 243 patients ( $89.7 \%$ ). Kappa ( $k$ ) was 0.53 (moderate agreement) with a $95 \%$ confidence interval of 0.37 to 0.69 . The observed positive agreement (59\%) was much lower than for negative agreement (94\%). Kappa was considerably lower, if chronic obstructive pulmonary disease was present $(\kappa=0.20)$ or Streptococcus pneumoniae $(k=0.29)$ was the infective agent.

\section{Conclusion}

The overall inter-observer agreement adjusted for chance was moderate. Inter-observer agreement in cases with pneumonia was much worse than the agreement in negative (i.e., non-pneumonia) cases. A general practitioner's selection of patients with a higher chance of having pneumonia for chest radiography would thus not improve the observer agreement of radiologists. 


\section{Introduction}

Whereas the British Thoracic Society considers general investigations, including chest radiography, not necessary for the majority of outpatients with suspected community-acquired pneumonia (CAP), ${ }^{1}$ the American Thoracic Society and the Infectious Diseases Society of America recommend chest radiography as part of the routine evaluation of patients in whom pneumonia is considered a likely diagnosis. ${ }^{2.3}$ The cited guidelines agree that chest radiography is the diagnostic test of choice, if additional investigations are needed. Moreover, chest radiography is, in combination with clinical suspicion, widely acknowledged as the reference standard for scientific studies on acute lower respiratory tract infections (LRTI) in the community. 2.3 Although the results of chest radiography may have important implications for the management of community-acquired LRTI, i.e. the prescription of antibiotics or hospital admission, surprisingly little is known about the interobserver agreement in the radiographic diagnosis of pneumonia in adults, in general practice in particular. We know of only one outpatient study from Norway of patients with $\mathrm{LRTI}$, in which moderate agreement between one radiologist, two radiology residents, one pulmonologist, and an expert panel was found. ${ }^{4}$ Strikingly, the agreement when pneumonia was diagnosed by (one of) the interpreters and the expert panel was considerably lower than when no pneumonia was diagnosed. In daily practice, general practitioners (GPS) in the UK and the Netherlands usually select for chest radiography only those patients who do not respond to initial treatment strategies or whose condition worsens. ${ }^{1,5}$ This selection increases the proportion of patients with pneumonia undergoing chest radiography. If the Norwegian findings of worse agreement in positive cases are reproducible, it supports the idea that a GP's selection of patients for chest radiography will not improve, and possibly increase inter-observer variation. We studied a sample of LRTI patients, representative of daily general practice. The variability in assessment of chest radiographs between the radiologists at the local site and a second radiologist at a university hospital was determined using various measures of agreement.

\section{Methods}

\section{Patients and procedures}

Within the framework of a prospective study on aetiology, diagnosis and treatment of LRTI in general practice, ${ }^{6.7}$ consecutive adult patients with symptoms and signs of LRTI were eligible to enter the study. The patients were selected by 25 general practitioners (GPs) from 15 practices in the southern part of the Netherlands. The inclusion criteria were: a new or increasing cough combined with at least one of four respiratory criteria: dyspnoea, wheezing, chest pain and auscultation 
abnormalities; and at least one of four general illness criteria: fever $\left(\geq 38^{\circ} \mathrm{C}\right)$, perspiring, headache and myalgia. Furthermore, the GP had to be convinced of the diagnosis LRTI.

The GPS performed and recorded an extensive, standardised medical history and physical examination, A sputum sample, oral washing and nasopharyngeall swab were taken for bacteriological examination, as well as venous blood samples for Creactive protein (CRP), erythrocyte sedimentation rate (ESR) and initial titres of viral pathogens, Mycoplasma pneumoniae and Legionella pneumophila. All samples were submitted to the laboratories of Haematology, Clinical Chemistry and Medical Microbiology of the University Hospital Maastricht on the same day, and were analysed using standard procedures. ${ }^{8}$

\section{Chest radiography}

Posterior-anterior and lateral chest radiographs were taken of every patient on the third day after inclusion, the third day being chosen to increase the likelihood that infiltrates were detectable on chest radiography. ${ }^{9}$ The patient was referred to the nearest hospital as in usual care. The radiologists of the three participating hospitals in Sittard, Geleen and Maastricht (A) were informed of the nature of the study and were asked to interpret the chest radiographs in a routine manner. They received a specific radiography application form with the following information: date, patient's name and birth date, acknowledgment of 'Participation in the LRTI study' and the query 'Presence of an infiltrate and possible other abnormalities?' The presence of an infiltrate was defined radiographically as diffuse, focal or alveolar shadowing, with or without air bronchograms or sillhouette sign on the posterior-anterior and lateral film. Comparison with previous radiographs (if available) was made as in usual care. The presence of an infiltrate together with the clinical diagnosis of LRTI (in all included patients) was regarded as evidence of pneumonia. The query "possible other abnormalities' was added to give the radiologists the opportunity to state other possibly relevant radiographic abnormalities (e.g., pleural effusion) or incidental abnormalities (e.g., density suspicious of lung canceir). The radiographs were collected and reassessed for the presence or absence of infiltrates by one blinded, independent senior radiologist (B) of the University Hospital Maastricht. In addition to this dual judgment, subject to the present study, a third senior radiologist (C) of the University Hospital Maastricht conducted an independent, decisive assessment if the first $(A)$ and second $(B)$ radiologists disagreed. The conclusive finding of an infiltrate was regarded as evidence of pneumonia and was used as reference standard in a diagnostic study, which was running parallel to the present study. ${ }^{7}$ All other outcomes were considered to represent 'no pneumonia'. 


\section{Statistical analysis}

The observed proportional inter-observer agreement rate for the presence or absence of a radiographic infiltrate was calculated by summing the proportions of equal interpretations of radiologists $A$ and $B$. The kappa statistic $(x)$, a measure of inter-observer relliability that adjusts for agreement by chance; and its $95 \%$ confidence interval $(\mathrm{Cl})$ were calculated. A $\kappa<0.20$ indicates poor agreement, a $k$ of 0.21-0.40 fair, a $\kappa$ of $0.41-0.60$ moderate, a $\kappa$ of $0.61-0.80 \mathrm{good}$, and a $\kappa$ of $0.81-1.00$ indicates very good agreement between two observers ${ }^{10}$ for better understanding of the results, the performance of the observers in both positive (pneumonia) and negative (no pneumonia) decisions was calculated by dividing the total number of agreed positive (or negative) cases by half the combined subtotall of positive (or negative) cases of radiologists $A$ and $B^{11,12}$ (Figure 3.1). This was called the proportional agreement in positive (or negative) cases. Clinically relevant patient characteristics possibly affecting agreement rates were separately compared for the two radiologists. The kappa statistic for the presence and for the absence of a particular patient characteristic was calculated. All statistical analyses were performed with Statistical Package for the Social Sciences software, version 11.0 .

\section{Results}

\section{Patient characteristics}

Between January 1998 and April 1999, 247 ambulatory LRTI patients with a mean age of 52 years (range 18-89) entered the study. Posterior-anterior and lateral chest radiographs were performed in 243 patients. Four patients did not comply with the request to visit the Radiology Department of the participating hospitals. In Table 3.1 the characteristics of the 243 patients whose radiographs were read by radiologists $\mathrm{A}$ and $\mathrm{B}$ are shown. In addition to an acute cough, frequently occurring symptoms and signs were dyspnoea, wheezing, chest pain, and rhonchi on auscultation. In approximately one quarter of the patients the GP recorded that the LRTI was moderately severe. Although pneumonia was clinically diagnosed in $8.6 \%$ of the patients, the vast majority $(79.4 \%)$ received antibiotics at the end of the consultation. None of the patients had received antibiotic treatment for this illness episode before study entry. All patients were treated in an outpatient setting. In almost half of the study population an aetiologic diagnosis was made, viral and bacterial micro-organisms evenly divided. After radiographic imaging and additional investigations, concomitant pulmonary cancer was found in four patients. 


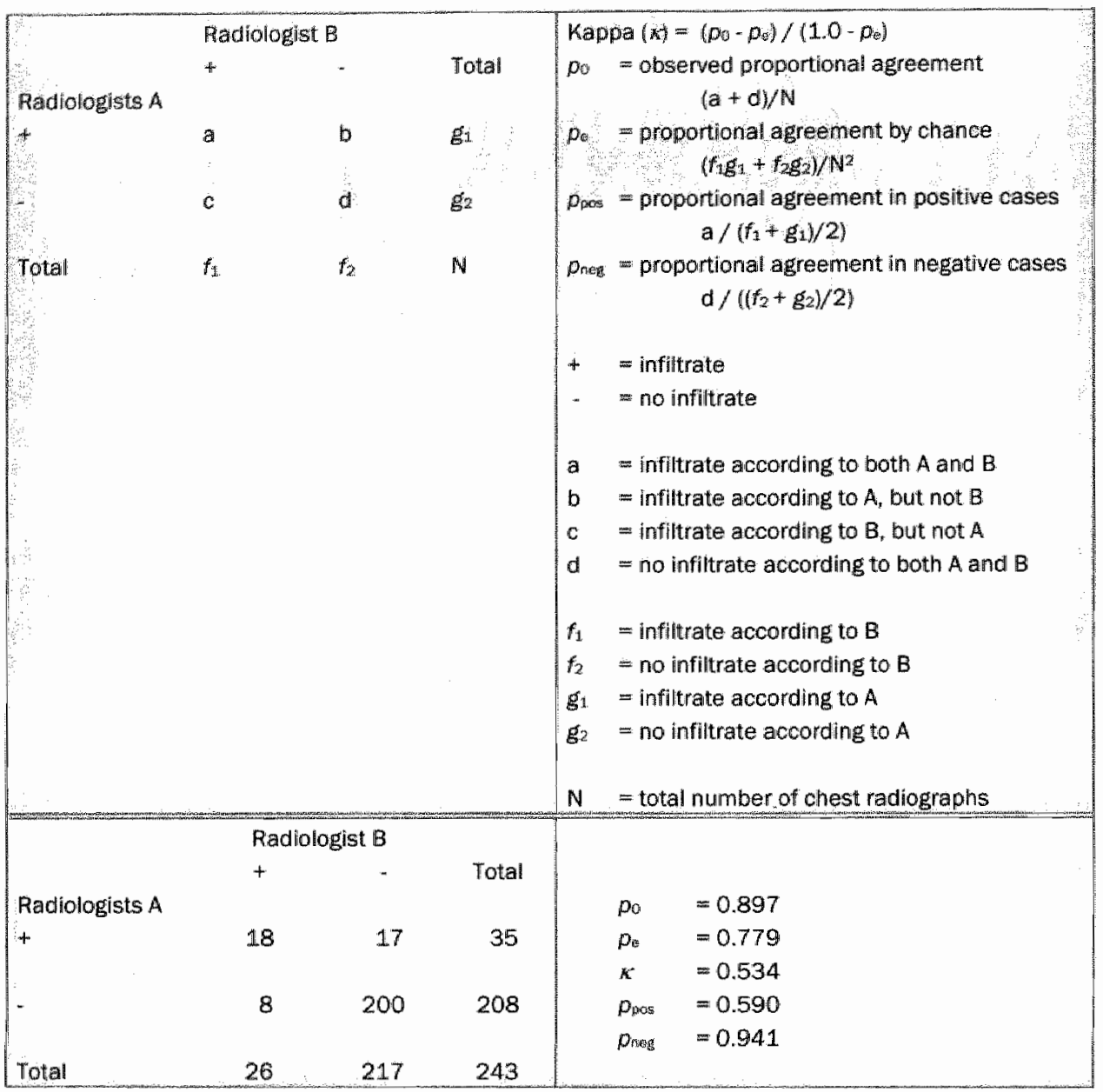

Figure 3.1 Measures of inter-obserwer agreement used, followed by the actual numbers of pulmonary infiltrates judged by radiologists $\mathrm{A}$ and $\mathrm{B}$, including calculated measures of agreement.

\section{Inter-observer variation}

The observed proportional agreement ( $p_{0}$ ) in radiographic judgment of pneumonia by radiologists $A$ and $B$ was $218 / 243$ (89.7\%, Figure 3.1 ). The proportional agreement by chance ( $p_{\mathrm{e}}$ ) was $77.9 \%$, resulting in a moderate $\kappa$ of 0.53 with a $95 \%$ confidence interval of 0.37 to 0.69 . The proportional agreement in positive cases $\left(p_{p o s}, 59 \%\right)$ was lower than the proportional agreement in negative cases (pneg; $94 \%)$. 
Table 3.1 Demographic and clinical characteristics of the study population.

\begin{tabular}{|c|c|c|c|}
\hline \multirow{2}{*}{ Number of patients ${ }^{2}$} & & & $N\left(\mathrm{H}_{3}\right)$ \\
\hline & & & 243 \\
\hline \multirow[t]{4}{*}{ Bemographic data } & Nate & & $115(47.3)$ \\
\hline & Age years & 1840 & $59(24.3)$ \\
\hline & & 41-65 & $114(46.9)$ \\
\hline & & $>65$ & $70(28.8)$ \\
\hline \multirow{3}{*}{ Study site location } & Sittard & & $45(19.1)$ \\
\hline & Geleen & & $143(60.9)$ \\
\hline & Malastricht & & $47(20.0)$ \\
\hline \multirow[t]{5}{*}{ Symptoms } & Recent cou & & $223(91.8)$ \\
\hline & Productive & & $194(79.8)$ \\
\hline & Dyspnoea & & $188(77.4)$ \\
\hline & Wheezing & & $155(63.8)$ \\
\hline & Chest pain & & $145(59.7)$ \\
\hline Risk factors & Current cig & te smoking & $81(33.6)$ \\
\hline \multirow[t]{3}{*}{ Comorbidity } & Asthma & & $47(19.6)$ \\
\hline & Chranic ob & ctive pulmonary disease & $32(13.3)$ \\
\hline & Heart failu & & $8(3.3)$ \\
\hline \multirow[t]{7}{*}{ Signs } & Moderate/ & are illlness & $65(26.7)$ \\
\hline & Respiration & $>20 / \min$ & $9(3.7)$ \\
\hline & Percussion & iness & $11(4.5)$ \\
\hline & Bronchial b & thing & $64(26.3)$ \\
\hline & Crackles & & $50(20.6)$ \\
\hline & Rhonchil & & $153(83.0)$ \\
\hline & Body temp & ure $\geq 38.0^{\circ} \mathrm{C}$ & $58(23.9)$ \\
\hline \multicolumn{3}{|c|}{ Clinical diagnosis of pneumonia } & $21(8.6)$ \\
\hline \multicolumn{3}{|c|}{ Antibiotic treatment } & $193(79.4)$ \\
\hline \multirow[t]{3}{*}{ Laboratory tests } & C-reactive & ein, median (range) & $52(2-312)$ \\
\hline & Erythrocyte & dimentation rate, median (range) & $27(1-121)$ \\
\hline & Leukacytes & edian (range) & $8.7(3.8-19.7)$ \\
\hline \multicolumn{3}{|c|}{ Number of patients with ettiologic diagnosis $(\%)$} & $111(48.1)$ \\
\hline \multirow[t]{11}{*}{ Micro-organisms } & Haemophil & bara-) influenzae & $38(15.8)$ \\
\hline & Streptocac & pneumoniae & $12(5)$ \\
\hline & Moraxella & rrhalis & $7(29)$ \\
\hline & Mycoplasm & neumoniae & $3(1.3)$ \\
\hline & Leglonella & umophila & $1(0.4)$ \\
\hline & Influenza $A$ & & $32(13.9)$ \\
\hline & Influenza B & & $11(4.7)$ \\
\hline & Parainfluer & $1,2,3$ & $9(3.9)$ \\
\hline & Adenowirus & & $11(4.7)$ \\
\hline & Respirator & cytial virus & $5(2.2)$ \\
\hline & Other & & $9(3.8)$ \\
\hline
\end{tabular}

Valiues are numbers (percentages) unless otherwise stated. Percentages are based on number of patients for each variable.

${ }^{1}$ Chest radiographs were missing in four patients. 
The radiologists at the local hospital (A) judged 26 patients of having a pulmonary infiltrate corresponding to the diagnosis of pneumonia (Figure 3.2). Reassessment by radiologist $B$ resulted in 35 cases of pneumonia. Eighteen cases were judged as pneumonia by both radiologists $A$ and $B$. An illustrative example of agreement is shown in Figure 3.3. In 25 cases radiologists $A$ and $B$ disagreed. An example of disagreement is shown in Figure 3.4. In these cases, a re-judgement by radiologist C took place, which resulted in another 14 cases of pneumonia and 11 cases of "no pneumonia'. As a result, pneumonia was diagnosed in 32 of the 243 patients (13.2\%) according to the reference standard. The frequencies of the radiographic patterns of the pulmonary infiltrates, judged after the study by radiologist $\mathrm{C}$, are shown in Table 3.2. Lobar pneumonia was not identified in any case.

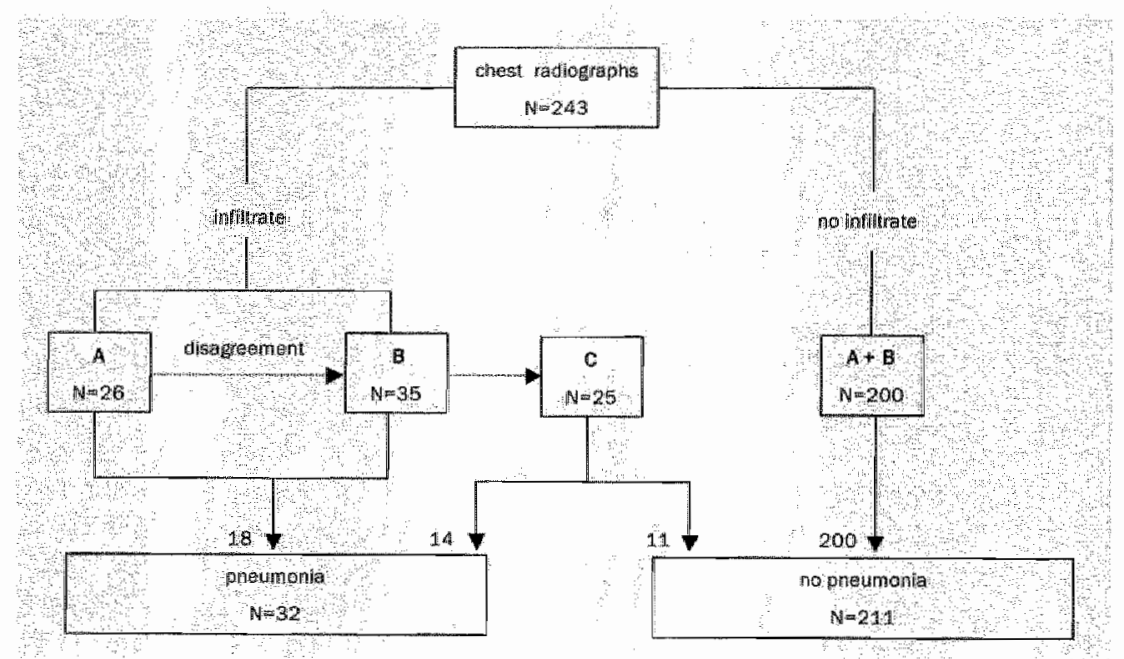

Figure 3.2 Conclusions of pulmonary imfiltrate by the radiologists and final diagnosis of pneumonia in 243 patients with LRTI.

A $=$ radiologists at the local hospital; $n=26$, pulmonary infiltrates

$B=$ radiologist who re-assessed the chest radiographs; $n=35$ pulmonary infiltrates

$C=$ radiologist who re-assessed the chest radiographs in cases of disagreement $(n=25)$ between $A$ and $B$

118 mumber of chest radiographs judged by both $A$ and $B$ as showing pulmonary infiltrates

$14=$ number of pulmonary infiltrates according to $C$

11 number of "no pulmonary infiltrate" according to $C$ 

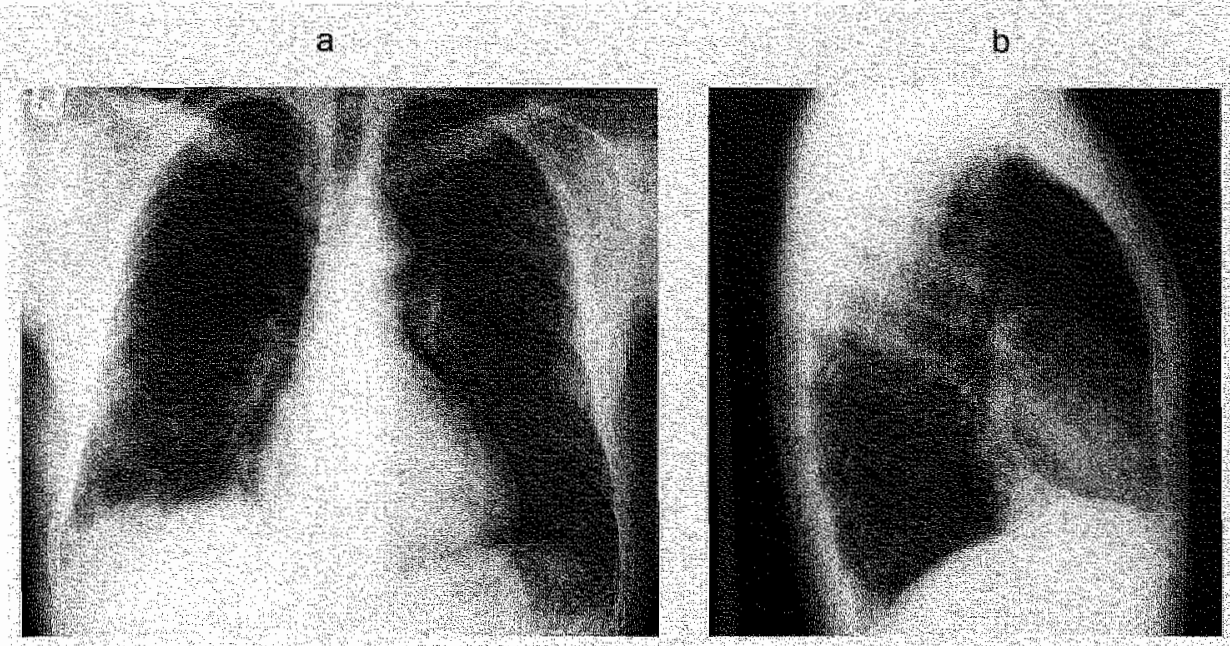

Community-acquired pneumonia in a 39 year-old man with dry cough, various feverish symptoms, tonsillary exsudate, rhonehi on auscultation and temperature $372 \circ$. The patient was ellinically diagnosed as suffering from acute bronchitis, Laboratory test tesults ESR 82, CRP 234, leveocytes 14.4. Haemophilus para-influenzae was cultured in sputum, in vitro resistant to the antibiotic prescribed (roxithromycin). The patient was cured clinically after 10 days despite bacterial resistance in vitro. The chest radiograph after 28 days showed complete resomption of the infiltrate.

Figure 3.3 Chest radiography (AP and Lat). Ill-defined consolidation in the right lower lobe with air bronchograms and a silhouette sign with the right hemi-diaphragm.

Table 3.3 shows the results of separate analyses of inter-observer variation between radiologists $A$ and $B$ per selected, clinically relevant variable. Large differences in $\kappa$ were found, if chronic obstructive pulmonary disease (COPD) was present $(\kappa 0.20, \mathrm{Cl}-0.27$ to 0.67$)$ compared with the absence of COPD $(\kappa-0.60, \mathrm{Cl}$ 0.41 to 0.74$)$, or if Streptococcus pneumoniae was present $(\kappa-0.29, \mathrm{Cl}-0.58$ to 0.01 ) compared with absent ( $\kappa 0.69, \mathrm{Cl} 0.50$ to 0.88 ). The negative $\kappa$ indicates that the observed agreement was worse than the agreement expected by chance. An example of pneumococcal pneumonia is shown in Figure 3.5: radiologist A suspected a malignancy (which was excluded after additional investigations), while radiologist $\mathrm{B}$ and $\mathrm{C}$ concluded 'pulmonary infiltrate'.

Pulmonary infiltrates according to radiologists $\mathrm{A}$ and $\mathrm{B}$ were mostly localised in the lower lobe, both in the right and left lung (Table 3.4). The higher frequency of pulmonary infiltrates found by radiologist $\mathrm{B}$ was primarily due to extra-detected infiltrates in the left lower lobe (11 versus four of radiologist A). Three of these 11 $(27 \%)$ infiltrates of radiologist B were finally judged as false-positives by radiologist C. compared with one of four (25\%) infiltrates of radiologist A. 
a

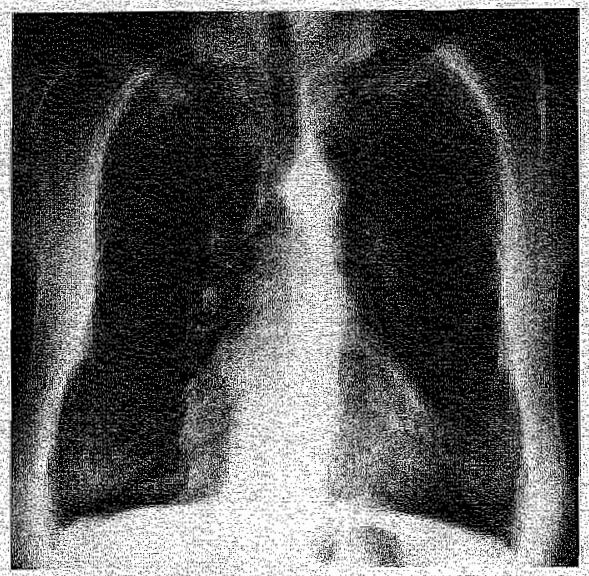

b

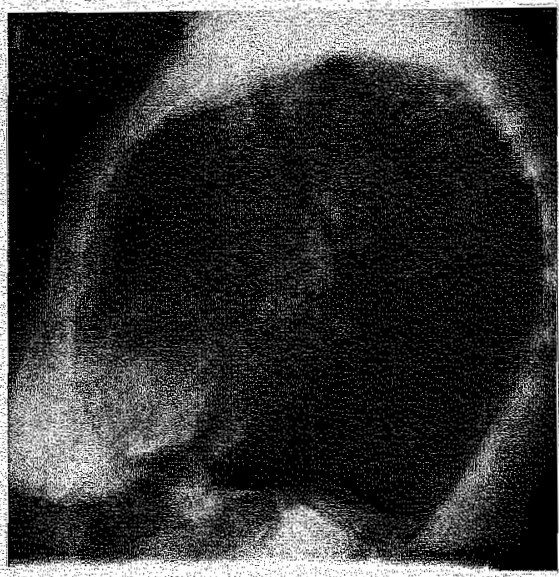

Disagreement between radiologist A (probable infiltrate right lower lobe) and radiologist B (no Infiltrate), inally consic ered as pneumania after judgement by radiologist $c$ in a 89 -year-old female COPD patient with dry cough, dysprioea (respiratory rate $>20 / \mathrm{min}$ ) fever $\left(38,1^{\circ} \mathrm{C}\right.$, percussion duliness in the ight lower lobe and crepitations in the left upper and lower lobe. The patient was Clincally diagnosed as suffering rrom severe pneumonia Laboratony test results: ESR 56, CRP 145 leveocytes 10;2. The patient was empiricaly treated with amoxicillin without knowing the results of the sputum qulture after 10 days (Pseudomonas aeruginosa). The patient was clinically cured after 10 days. The chest radiograph after 28 days showed total resorption of the infiltrate.

Figure 3.4 Chest radiography (AP and Lat). III-defined opacities without air bronchograms located in the middle lobe, but hardly visible on the lateral chest radiograph.

Table 3.2 Pattem of radiographic pulmonary infiltrates in 32 pneumonia patients.

\begin{tabular}{|c|c|}
\hline Infiluate dharecteristic & Number $(\%)$ \\
\hline Alr brongho gram & $24(75)$ \\
\hline silhouette sign & $18(56)$ \\
\hline Pleural effusion & $4(13)$ \\
\hline Type of infilirate - elveolar & $11(34)$ \\
\hline (4) diffuse & $16(50)$ \\
\hline 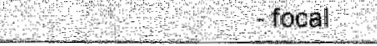 & $5(16)$ \\
\hline
\end{tabular}


Table 3.3 Inter obsener reliabily for the presence or absence of pumonany untluates for selected clinical variables.

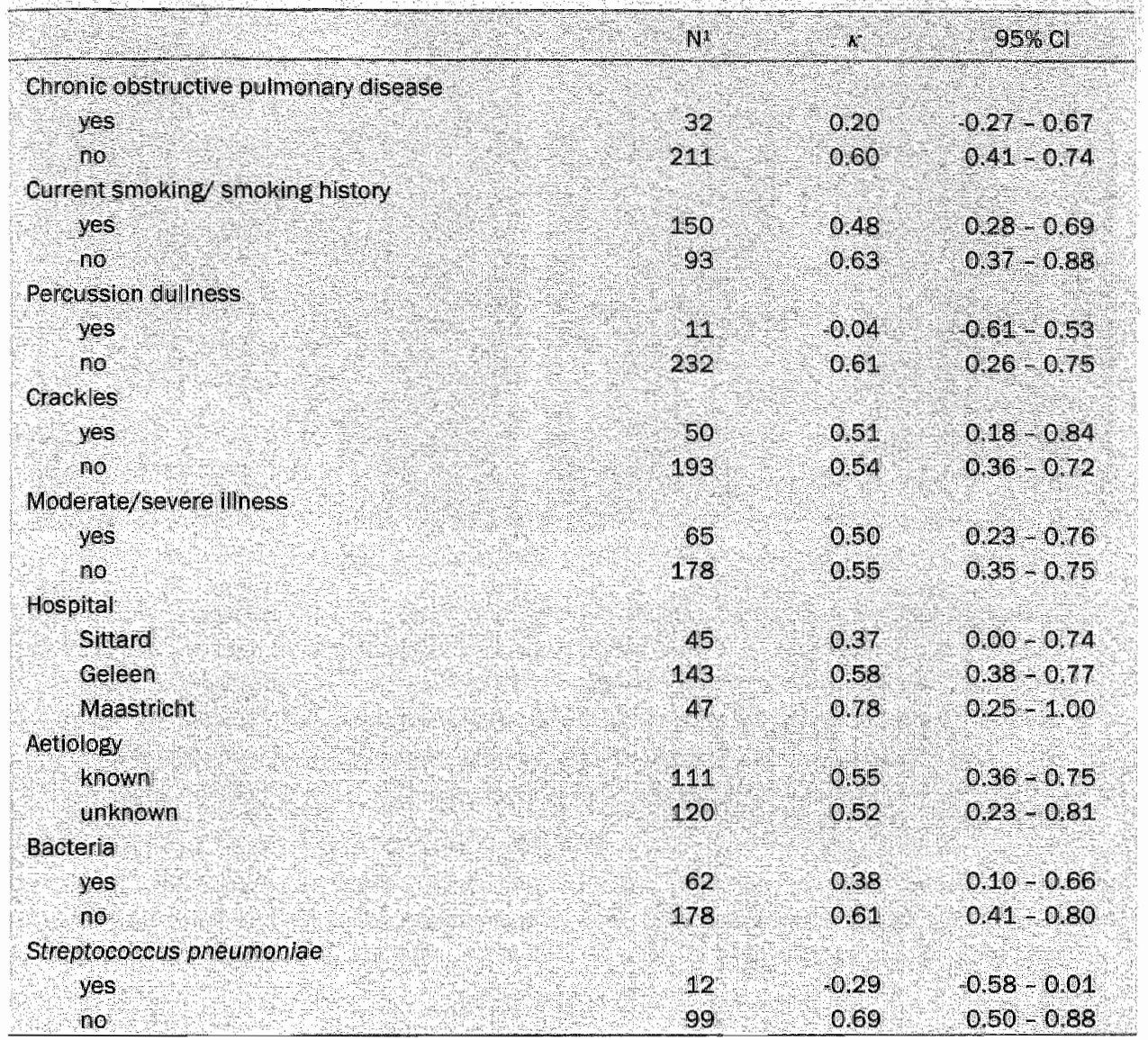

1 number of patients with particular wariable

Table 3,4 Localisation pulmonary infiltrates according to the radiologists at the local hosphtal (A) and the radiologist, who reassessed the radiographs $(B)$.

\begin{tabular}{|c|c|c|}
\hline 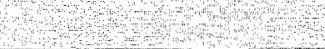 & Radiologists A & Radiologist B \\
\hline Number of patients & 243 & 243 \\
\hline Pulmonary infiltrate & 26 & 35 \\
\hline Locallisation & & \\
\hline Right 4 upper lobe & 1 & 2 \\
\hline ९ै। middle lobe & 7 & 5 \\
\hline lower lobe & 8 & 9 \\
\hline Left upper lobe & 1 & 3 \\
\hline $4+$ lower lobe & 4 & 11 \\
\hline $4+4$ lingual & 1 & 3 \\
\hline Other locallsatlon & 4 & 2 \\
\hline
\end{tabular}


a

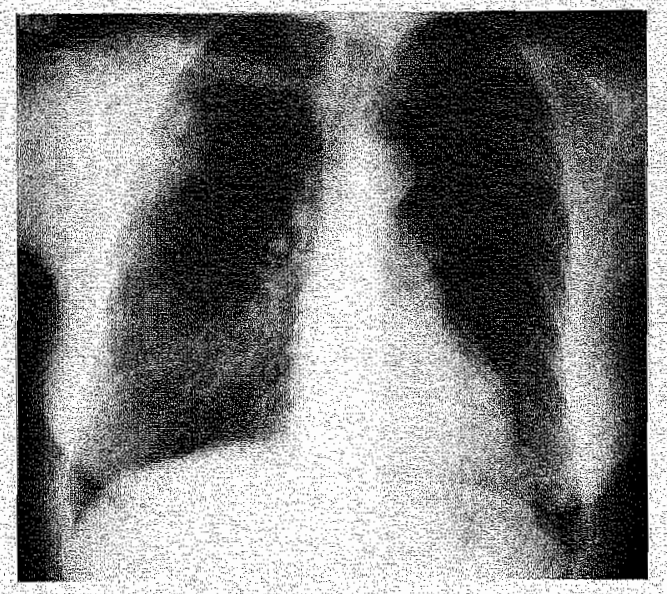

b

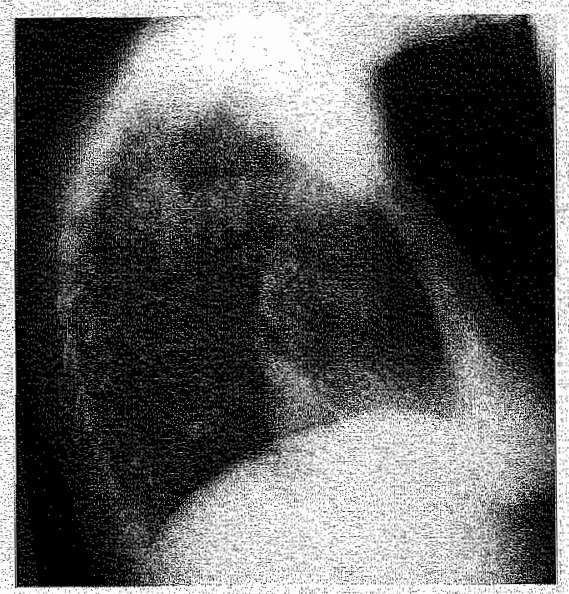

Suspleion of mallgnancy in right upper region (radiologist A), Judged as infiltrate by both radialogists $\mathrm{B}$ and $\mathrm{C}$. 69 yearold, moderately ill woman with productive cough lasting more than wo weeks, fever $138.8^{\circ} \mathrm{C}$, end honchi In left upper and lower reglon, dinically diagnosed as acute bronchitis. ESR 29 , CRP 122, leucocytes missing streptococcus pneumoniae was cultured in sputum, resistant to antibiotlo prescribed (roxithronycin, A mailgnancy was exeluded after additional examinations by the pulmonologlst. The patient was clinically cured after 10 days. The chest radiograph after 21 days showed complete resombtion of the infiltrate.

Figure 3.5 Chest radiography (AP and Lat). Large inhomogeneous density with ill-defined borders and without air bronchograms in the upper lobe of the right lung, invisible on the lateral film.

\section{Discussion}

The percentage of pneumonia in 243 patients with community-acquired LRTI, according to the radiographic reference standard used, was $13.2 \%$. This corresponds with earlier epidemiological data in general practice. ${ }^{13-15}$ Although inter-observer agreement was apparently high (89.7\%), the agreement adjusted for chance, expressed as $\kappa$, was moderate $(0.53)$.

Slightly lower agreement rates were found in one other outpatient study known to us, comparing the routine judgement of the radiologist with one pulmonologist $(\kappa 0.49)$ and two residents in radiology ( $\kappa \quad 0.43$ and 0.44 respectively). ${ }^{4}$ in a multicentre study with ambulatory and hospitalised patients with radiographic pneumonia two radiologists reviewed copies of radiographs which all showed radiographic evidence of pneumonia as determined by a local study site radiologist. The overall agreement rate between the two radiologists was $85.4 \%$ with a corresponding fair $\kappa$ of 0.37 .16 However, awareness of the very high percentage of 
radiographic pneumonia most probably led to a context bias the observers were more likely to consider a radiograph abnormal because it was reviewed in a specially assembled sample with high disease prevalence 17 The same applies to a study on the inter-observer variation in 15 hospitalised patients with radiographic pneumonia. ${ }^{18}$ Agreement rates ( $\kappa$ not provided) between groups of students. residents and radiologists compared to a panel of radiologists (reference standard) were variable $(55-87 \%)$ and did not increase substantially with increasing experience. In the present study initial, routine judgement of the chest radiograplis was performed in a representative sample of LRTI patients in the community with a relatively low percentage of pneumonia. The applicability of the study results to daily practice is best approximated in this way.

Secondary analyses were performed to compare inter-observer variation for the presence and absence of selected clinical variables. In seven of eight selected variables the inter-observer variation was lower. when a particular variable was present. In particular, judgement of the presence or absence of radiographic pneumonia in COPD patients is problematic. This may be due to the variable radiographic image of COPD ranging from completely normal to increased vascular markings with accentuated bronchial walls (tram lines), which can simulate discrete alveolar opacities. Although the numbers are small, the very low interobserver agreement in patients with LRTI caused by $S$ pneumoniae ( $\kappa-0.29$ ) was striking. This is in apparent contradiction to the generally taught classical and clear radiographic picture of lobar pneumococcal pneumonias. However, this typical picture seems to be less frequently present in the community, which may explain the low inter-observer agreement we found. The four radiographic images of pneumonila during this study were variable ranging from homogeneous air space consolidation very near to the visceral pleura to some discrete patchy infiltrates.

Inter-observer agreement on individual radiographic patterns (ail bronchogram, silhouette sign, etc) was not determined in this study, because the radiologists at the local hospitals judged and reported the chest radiographs as in usual care, without systematically using these terms. Although the overall agreement for the presence or absence of pneumonia was clinically acceptable, greater variation in these radiographic patterns would probably have been recorded, as reported in previous studies. ${ }^{16,18}$

The main diagnostic challenge of the GP in LRTI patients is to select patients with pneumonia who need antibiotic treatment. In most $L R T$, antibiotics are rarely indicated because the infection is self-limiting. 19.20 However, the accuracy of an initial clinical diagnosis of community-acquired pneumonia is not hight and probably the lowest in general practice where the illness is often milder than in hospitalised populations, classical symptoms and signs of pneumonia are less prominent or do not occur often. Diagnostic uncertainty and anxiety about missing pneumonia, accompanied by various patient-doctor related factors, ${ }^{21.23}$ are responsible for thigh antibiotic prescription rates. The present practice-based study 
was wustrative of this phenomenon: pnewmonia was clinically diagnosed in $8.6 \%$, but antibiotics were prescribed in about $80 \%$ of patients. According to the guidelines from the American Thoracic Society, the Infectious Diseases Society of America and the Canadian Community-acquired Pneumonia Working Group chest radiography is regarded as essential for (almost) every patient with suspected CAP.23:24 However, the present study and earlier stucies show that a single radiologist's interpretation of a pair of posterior-anterior and lateral chest radiographs in patients with LRTI reveals considerable variation for the diagnosis of pneumonia. 4 , 18 It would seem more rational to refer for chest radiography those patients, in whom the test results wll be expected to have important consequences for the management of the Illness, and who do not timely respond to initial treatment strategies. However, according to the two outpatient studies performed (including the present study), the inter-observer agreement in positive cases (t.e. pneumonia) is much less than the agreement in negative (i.e. non-pneumonia) cases. An increase in the proportion of patients with pneumonia through $\mathrm{GPS}^{3}$ selection of patients for chest radiography - in accordance with daily genera! practice in the UK and the Netherlands - will thus not improve, and probably decrease observer agreement. The additional diagnostic value of chest radiography after diagnostic "screening" by the GP is therefore questionable. Guidelines on indications for chest radiography in LRTI patients may need to be reconsidered. Theoretically, it would be better to advise an independent second and - in cases of disagreement - third radiographic judgement to increase accuracy of chest radiography. However, practical and financial consequences of such a strategy are prohibitive. CT of the thorax may be a more rational and up-to-date alternative, but the cost-effectiveness of CT in suspected pneumonia has not yet been fully evaluated. 25 


\section{References}

1. British Thoracic Society Standards of Care Committee. BTS Guidelines for the Management of Community Acquired Pneumonia in Adults. Thorax. 2001;56 Suppl 4: $1-64$.

2. Niederman MS, Mandell LA, Anzueto A, Bass JB, Broughton WA, Campbell GD, Dean N, File T, Fine MJ, Gross PA et al. Guidelines for the management of adults with community-acquired pneumonia. Diagnosis, assessment of severity, antimicrobial therapy, and prevention. Am J Respir Crit Care Med. 2001;163:1730-54.

3. Bartlett JG, Dowell SF, Mandell LA, File Jr TM, Musher DM. Fine M.. Practice guideines for the management of community-acquired pneumonia in adults. Infectious Diseases Society of America. Clin Infect Dis. 2000;31:347-82.

4. Melbye $H$, Dale $K$. Inter-observer variability in the radiographic diagnosis of adult outpatient pneumonia. Acta Radiol. 1992;33:79-81.

5. Verheij TJM, Salomé PL, Bindels PJ, Chavannes AW, Ponsioen BP, Sachs APE, Thiadens HA, Romeijnders ACM, Van Balen JAM. NHG-Standaard Acuut hoesten. [Dutch College of General Practitioners Guidelines on Acute Cough]. Huisarts Wet. 2003;46:496-506.

6. Hopstaken RM, Nelemans P, Stobberingh EE, Muris JWM, Rinkens PELM, Dinant GJ. Is roxithromycin better than amoxicilin in the treatment of acute lower respiratory tract infections in primary care? A double-blind randomized controlled trial. J Fam Pract. 2002;51:329-36.

7. Hopstaken RM, Muris JWM, Knottnerus JA, Kester ADM, Rinkens PELM, Dinant GJ. Contributions of symptoms, signs, erythrocyte sedimentation rate and C-reactive protein to a diagnosis of pneumonia in acute lower respiratory tract infection. $\mathrm{Br} J$ Gen Pract. 2003;53:358-64.

8. Isenberg HD. Clinical microbiology procedures handbook. Washington, D.C., American Society for Microbiology, 1994.

9. Bartlett JG. Mundy LM. Community-acquired pneumonia. N Engl J Med. 1995;333: 1618-24.

10. Altman DG. Practical statistics, for medical research. London, Chapman \& Hall, 1997.

11. Feinstein AR, Cicchetti DV. High agreement but low kappa: I. The problems of two paradoxes. J Clin Epidemiol. 1990;43:543-9.

12. Cicchetti DV. Feinstein AR. High agreement but low kappa: II. Resolving the paradoxes. $J$ Clin Epidemiol. 1990:43:551-8.

13. van der Velden J, De Bakker DH, Claessens AAMC, Schellevis FG. Dutch National Survey of General Practice. Morbidity in General Practice. Utrecht, NIVEL, 1992.

14. Woodhead MA, Macfarlane JT, McCracken JS, Rose DH, Finch RG. Prospective study of the aetiology and outcome of pneumonia in the community. Lancet. 1987;1: 671-4.

15. Jokinen $\mathrm{C}$, Heiskamen $\mathrm{L}$, Juvonen $\mathrm{H}$, Kallinen $\mathrm{S}$, Karkola $\mathrm{K}$, Korppi M, Kurki S, Ronnberg

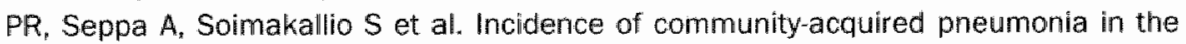
population of four municipalities in eastern Finland. Am $₫$ Epidemiol. 1993;137: 977-88.

16. Albaum MN, Hill LC, Murphy M, Li YH, Fuhrman CR. Britton CA, Kapoor WN, Fine MJ. Inter-observer reliability of the chest radiograph in community-acquired pneumonia. PORT Investigators. Chest. 1996:110:343-50.

17. Egglin TK, Feinstein AR. Context bias. A problem in diagnostic radiology. JAMA. 1996:276:1752-5.

18. Young $M$, Marrie TJ. Interobserver variability in the interpretation of chest roentgenograms of patients with possible pneumonia. Arch Intern Med. 1994;154: 2729-32. 
19. Smucny 11, Becker LA, Glazier PH, Mclsaac W. Are antibiotics effective treatment for acute bronchitis? A meta-analysis $\perp$ Fam Pract 1998,47:453-60.

20. Mactarlane J, Holmes $W$, Gard P, Macfarlane $R_{\text {, Rose }}$, Weston , Leinonen $M$, Saikk P. Myint S. Prospective study of the incidence, aetiology and outcome of adult lower respiratory tract IIness in the community. Thorax $200156: 109-14$.

21. Butler CG, Rollnick $S$, Kinnersley $P$, Jones A, Stott N Reducing antibiotics for respiratory tract symptoms in primary care consolidating why' and considering 'how'. Br J Gen Pract $1998,48 \times 1865-70$

22. Little $P$. Where next with antibiotics and respiratony tract infections? J Fam Pract. 2002; $51.337-8$.

23. Coenen $S$, Van Royen P, Vermeire E, Hermann J. Denekens J. Antibiotics for coughing in general practice: a qualitative decision analysis. Fam Pract. 2000;17: 380-385.

24. Mandell LA, Marrie TJ, Grossman RF, Chow AW, Hyland RH. Canadian guidelines for the initial management of community-acquired pneumonia: an evidence-based update by the Canadian Infectious Diseases Society and the Canadian Thoracic Society. The Canadian Community-Acquired Pneumonia Working Group. Clin Infect Dis. 2000;31: $383 \div 421$.

25. Syrjala H. Broas M, Suramo I, Ojala A, Lahde S. High-resolution computed tomography for the diagnosis of community-acquired pneumonia. Clin Infect Dis. 1998; 27:358-63. 


\section{Chapter 4}

Clinical items not helpful in differentiating viral from bacterial lower respiratory tract infections in general practice

RM Hopstaken, EE Stobberingh, JA Knottnerus, JWM Muris, P Nelemans, PELM Rinkens, GJ Dinant

Journal of Clinical Epidemiology 2005:58:175-83

Huisarts en Wetenschap, accepted for publication 


\section{Abstract}

\section{Objective.}

Incorrect and unnecessany antibiotic prescribing enhancing bacterial resistance rates might be reduced if viral and bacteriall lower respiratory tract infections (LRT) could be differentiated clinically. Whether this is possible is often doubted, but has rarely been studied in general practice.

\section{Study design and setting}

Observational cohort study in 15 general practice surgeries in the Netherlands.

\section{Results}

Etiologic diagnoses were obtained in 112 of 234 patients with complete data (48\%). Viral pathogens were found as often as bacterial pathogens. Haemophilus (para-) influenzae was most frequently found None of the symptoms and signs correlated statistically significantly with viral or bacterial LRTI. Erythrocyte sedimentation rate $>50$ (Odds Ratio [OR] 2.3 to 3.3 ) and C-reactive protein (CRP) $>20 \mathrm{mg} / /$ (OR 2.1 to 4.6) were independent predictors for viral LRTI and bacterial LRTI when compared with microbiologically unexplained LRT!.

\section{Conclusion}

Extensive history-taking and physical examination did not provide items that predict viral or bacterial LRTI in adult patients, in daily general practice. We could not confirm CRP to differentate between viral and bacterial LRTI. 


\section{Introduction}

Bacterial resistance rates are rising with increasing antibiotic consumption. 18 The magnitude of the problem varies widely between countries. Defensive prescription behaviour, busy consultation hours, repeated incentives by the phamaceutical industry, and reports of increasing occurrences of newly emerging pathogens are a constant threat to a rational or evidence-based approach (e.g. antibiotic prescribing in indicated cases only) by the physician toward a patient with a respiratory tract infection. 4,9-12 Furthermore, the physician's diagnostic uncertainty increases the likelihood of unnecessary antibiotic prescribing 13 This is especially true in lower respiratory tract infections (LRTI), with a diagnosis in general practice of 30-55 new episodes per thousand patient per year; 14.17 the infrequently occurring pneumonias ( $20 \%$ of all LRTI) are clinically misclassified in most cases. ${ }^{18}$ 20 Acute bronchitis almost exclusively accounts for the remainder ( $80 \%$ ) of the LRTI cases. Antibiotics are prescribed in $80 \%$ of the cases, 2123 despite the fact that acute bronchitis is mostly self-limiting 24,25 and often viral. In pneumonia it is considered to be malpractice to withhold antibiotic treatment from a patient.

General practitioners (GPS) can theoretically postpone the decision whether or not to prescribe antibiotics by taking sputum samples for microbiologicall culture. However, the time delay before receiving the test result and (false-) negative test results in more than half of the samples ${ }^{26-28}$ restrain the GP from more frequently submitting samples to the laboratories. ${ }^{29}$ From a clinical point of view, GPs would be better off by having a viral instead of a bacteriological diagnosis confirmed. This would enable them to select at least those patients who do not need antibiotics. However, waiting for seroconversion (approximately four weeks) before knowing whether or not the patient suffered from a viral infection is (of course) no option. As a result, the GP usually decides empirically, after history-taking and physicall examination, whether or not to prescribe antibiotics to the patient. Correctly predicting specific pathogens on clinical grounds in pneumonia patients seems to be difficult in most cases. ${ }^{30.31}$ Moreover, the GPS' clinical assessment that an infection warranting antibiotics was present and bacterial infection being found were not related in a community-based study in the United Kingdom. 32 Diagnostic studies on clinical prediction of viral or bacterial LRTI in daily general practice could not be found. High C-reactive protein (CRP) values might be predictive for bacterial infections, although evidence is poor and conflicting.33-38 In summary, the diagnostic value of the clinical tools GPS have at their disposal to manage LRTI is largely unknown. The present study evaluated the predictive value of symptoms, signs, leukocyte count, erythrocyte sedimentation rate (ESR) and CRP for viral and bacterial LRTI, including pneumonia, in adult patients presenting with LRTI to a GP. 


\section{Methods}

\section{Patients and procedures}

Adult patients presenting with the following symptoms and signs of LRTI to 25 GPS from 15 practices in the south of The Netherlands were eligible for the study: a new or increasing cough combined with at least one of the four respiratory criteria: dyspnoea, wheezing, chest pain, auscultation abnormalities; and at least one of the four general criteria fever $\left(238^{\circ} \mathrm{C}\right)$, perspiring, headache, myalgia. The GP had to be convinced of the diagnosis LRTI. Exclusion criteria were: pregnancy and lactation, history of hypersensitivity to penicillin or macrolide antibiotics, concomitant treatment with ergot alkaloids or terfenadine during the study period, other severe clinical disease, treatment with antibiotics within the preceding 14 days, and hospital stay for respiratory complaints in the previous four weeks. Some of the exclusion criteria were relevant to a randomised clinical trial, which was running in parallel to the diagnostic study. 28

The GPs performed and recorded an extensive, standardised medical history and physical examination. Venous blood samples for leukacyte count, CRP, and ESR were taken and submitted to the laboratories of Haematology and Clinical Chemistry of University Hospital Maastricht, and were analysed on the same day. Chest radiographs (lateral and postero-anterior) were made on the third day after inclusion. The radiographs were assessed blindly for the presence or absence of infiltrates by two independent radiologists. If the two radiologists disagreed, a third radiologist conducted an independent, decisive assessment. The conclusive finding of a pulmonary infiltrate was regarded as evidence of pneumonia.

\section{Reference standard}

The reference standard was composed of generally accepted microbiological tests 39 routinely used in laboratories for microbiology. Venous blood samples were taken at baseline and around 28 days later for serological testing of the viruses Influenza $A$, Influenza $B$, Parainfluenza $1 / 2 / 3$, Adenovirus and Respiratory syncytial virus, and the bacteria Mycoplasma pneumoniae and Legionella pneumophila. Criteria for a serological diagnosis were an initial titre of at least 1:64 or a fourfold or more increase in titre between the two samples. Sputum samples for standard microbiological analysis were taken at baseline, before possible antibiotic treatment, and ten days later ${ }^{40}$ Oral washings were used, when sputum could not be obtained. 41 Criteria for laboratory diagnosis of infection with Streptococcus pneumoniae, Haemophilus influenzae, Moraxella catarrhalis, and other bacteria were defined as the isolation of these micro-organisms as predominant from sputum samples or oral washings. ${ }^{41}$ Nasopharyngeal swabs were taken for detection of Chlamydia pneumoniae using polymerase chain reaction (PCR) as previously described. 42 


\section{Statistical analysis}

Patients with a diagnosis of viral LRTI according to the reference standard were compared with patients with various combinations of 'other $\angle R T I$, (e.g*, bacterial LRTI, mixed viral-bacterial LRTI and microbiologically unexplained LRTI) with respect to the presence or absence of symptoms and signs, leukocyte count, CRP, and ESR. Diagnostic accuracy was expressed in terms of sensitivity, specifficity, positive and negative predictive values, and diagnostic odds ratios (OR) with $95 \%$ confidence intervals (Cl). Receiver Operating Characteristic (ROC) analysis was used to describe the association between sensitivity and specificity of the blood tests (ESR, CRP and leukocytes) at different cut-off values. To compare the overall diagnostic power of ESR, CRP, and leukocytes, we calculated the respective areas under the curve (AUC). 43

The independent diagnostic contributions of symptoms and signs to the prediction of viral LRTI were simultaneously assessed using multiple logistic regression analysis. The number of availlable variables was too large, however, to have ten cases per variable. ${ }^{44}$ Therefore, two criteria had to be met for a variable to enter the model. First, the variable had to be positive in at least five patients with viral LRTI. Second, the p-value for the association of the variables with the presence or absence of viral LRTI ( $2 \times 2$ tables) had to be $<0.1$ ( $\chi^{2}$ or Fisher"s exact test). Multiple logistic regression analysis (backward elimination with $p>0.05$ for exclusion) was performed with the selected independent variables from history taking and physical examination. Logistic regression analysis was repeated, ardding ESR, CRP, or leukocytes at different cut-off points. All statistical analyses were performed with SPSS 11.0.

\section{Results}

\section{Patients and etiologic diagnosis}

Between January 1998 and April 1999, 247 LRTI patients 18-89 years of age (mean age 52) were included. One or more test results of 13 patients were missing; 11 blood samples for serologic analysis (first or second sample) and two sputum samples. An etiologic (microbiological) diagnosis was obtained in 112 of the 23.4 remaining patients $(48 \%)$ (Table 4.1$)$. Viral LRTI $(n=49,21 \%)$ was found as often as bacterial LRTI $(n=48,21 \%)$. $H$ (para-) influenzae was the most common bacterial micro-organism found $(16 \%)$.

Influenza $A$ virus accounted for most of the viral infections. Influenza virus (A and $B$ together) was the most common pathogen found. The so-called "atypical" microorganisms were present in four patients onlly (M pneumoniae in three patients, $L$ pneumophila in one patient). C pneumoniae was not found. A respiratory virus was found in 49 patients (21\%). In four of these patients two viral pathogens were 
isolated in the following pairs: Influenza $A$ together with Influenza $B$, and Parainfluenza 3 together with Influenza $A_{1}$ Respiratory syncytial virus and adenovirus once each. Viral and bacterial respiratory pathogens occurred together in 15 patients, the combination of Influenza virus with $H$ influenzae being most frequently found $(n=7)$. In four patients, a viral infection was followed by a bacterial infection after 10 days Influenza A by $M$ catarrhalis, influenza A by $H$ influenzae. influenza B by Hinfuenzae, and Adenovirus by gram-negative rods.

Table 4.1 Respiratory tract pathogens isolated in all LRTI patients with complete microbiological workup, and in the group of patients with pneumonia.

\begin{tabular}{|c|c|c|}
\hline Micro-organisms & $\begin{array}{l}\text { All patients } \\
\mathrm{N}=2341 \\
\mathrm{~N}(\%)\end{array}$ & $\begin{array}{c}\text { Pneumonia group } \\
N=30^{2} \\
N(8)\end{array}$ \\
\hline \multicolumn{3}{|l|}{ Vruses } \\
\hline Influenza A & $33(14)$ & $8(27)$ \\
\hline Infuenza B & $11(5)$ & $2(7)$ \\
\hline Perainfluenzae $1,2,3$ & $9(4)$ & $2(7)$ \\
\hline Adenovirus & $11(5)$ & $4(13)$ \\
\hline Respiratory syncytlal virus & $5(2)$ & \\
\hline Total viruses & $69(29)$ & $16(53)$ \\
\hline Patlents with wral LRTI & $49(21)$ & $9(30)$ \\
\hline \multicolumn{3}{|l|}{ Bacteria } \\
\hline Haemophilus (para) influenzae & $38(16)$ & $9(30)$ \\
\hline Streptococcus pneumoniae & $13(6)$ & $4(13)$ \\
\hline Moraxella catanhalls & $7(3)$ & मे \\
\hline Mycoplasma pneumonlae & 311 & 4 \\
\hline Legionella oneumophila & $1(0.4)$ & +3 \\
\hline S other ${ }^{3}+4$ & $9(4)$ & $1(3)$ \\
\hline Total bacterla & $71(30)$ & $14(47)$ \\
\hline Patients with bacteria/ LRTI & $48(21)$ & $8(27)$ \\
\hline Patients with mixed vira/bacterial LRT/ & $15(6)$ & $6(20)$ \\
\hline Patlents with etiologio dilagnosis & $112(48)$ & 23177 \\
\hline
\end{tabular}

113 pattents not included , because one or more test results were missing.

22 patients not included, because one or more test results were missing.

3 Enterobacteriaceae $(n=3)_{3}$ Staphylococcus aureus $(n=2)$, Streptococous windans $(n=1)$. Neisseria meningitidis $(n=1)$ Streptococcus milleri $(n=1)$, $\beta$ Haemolytic streptococcus group $B(n=1)$.

Table 4.1 also gives the frequencies of predominant respiratory pathogens for the subgroup of patients with radiographically proven pneumonia. The distribution of pathogens in this group is roughly the same as in the entire study population, with viral pathogens being identified as often as bacterial pathogens, Influenza virus being the most common pathogen, and $H$ (para-) influenzae being the most common bacterial pathogen found. Atypical pneumonia did not occur. 
Univariate analysis of symptoms, signs, and blood tests

Viral LRTI was compared with the following combinations of 'other LRTI'; with decreasing number of subjects: (I) bacterial LRTI and mixed viral-bacterial LRTI and microbiologically unexplained LRTI $(n=236) ;(11)$ bacterial LRTI and microbiologically unexplained LRTI ( $n=216)$; (III) microbiologically unexplained LRTI $(n=171)$; (IV) bacterial LRTI and mixed viral-bacterial LRTI $(n=112)$; (V) bacterial LRTI $(n=97$ ). The frequencies and diagnostic test characteristics of symptoms, signs and additional blood tests for the entire study population (except for 11 missing cases) (analysis 1) are shown in Table 4.2. None of the symptoms and signs correlated statistically significantly with viral LRTI. CRP $>50$ was the only additional blood test with a statistically significant $O R(O R 2.7, \mathrm{Cl} 1.4-5.2)$. ROCs were constructed to show the poor overall diagnostic value of the additional blood tests in predicting viral LRTI compared with bacterial/ microbiologically unexplained LRTI with and without mixed viral-bacterial LRTI (Figures $4.1-1$ and $4.1-11$ ), viral LRTI compared with microbiologically unexplained LRTI (Figure 4.1-III) and viral LRTI compared with bacterial LRTI with and without mixed viral-bacterial LRTI (Figure 4.1-IV and 4.1-V). Microbiologically unexplained LRTI was compared with bacterial/mixed viralbacterial LRTI (Figure 4.1-VI) to show that the AUCs of ESR and CRP were not only (moderately) raised in viral LRTI, but also in bacterial LRTI when compared with microbiologically unexplained LRTI.

\section{Multiple logistic regression analysis}

I Viral LRTI compared with bacterial and mixed viral-bacterial and microbiologically unexplained LRTI

Of the symptoms and signs, recent cough was the only variable selected for logistic regression analysis. It was not a statistically significant predictor of viral LRTI. CRP $>50$ was the only variable with a statistically significant $\mathrm{OR}$ (OR $2.7, \mathrm{Cl} 1.4-5.2$ ), when added to recent cough in the logistic regression model (Table 4.3).

\section{Viral LRTI compared with bacteria/ LRTI and microbiologically unexplained LRTI}

The variables recent cough, crackles, ESR, and CRP were selected for entering multiple logistic regression analysis. None of the clinical variables had a statistically significant $O R$, but ESR $>50 \mathrm{~mm} /$ hour and CRP $>50 \mathrm{mg} / 1$ were statistically significant predictors of viral LRT| (Table 4.3). 
Teible 4.2 Diagnostic value of symptoms, signs and blood tests in viral LRTI. Univariate analysis: viral LRTI versus bacterial/ mixed viral-bacterial/ microbiologically unexplained LRTI ( $n=236^{\text {? })}$

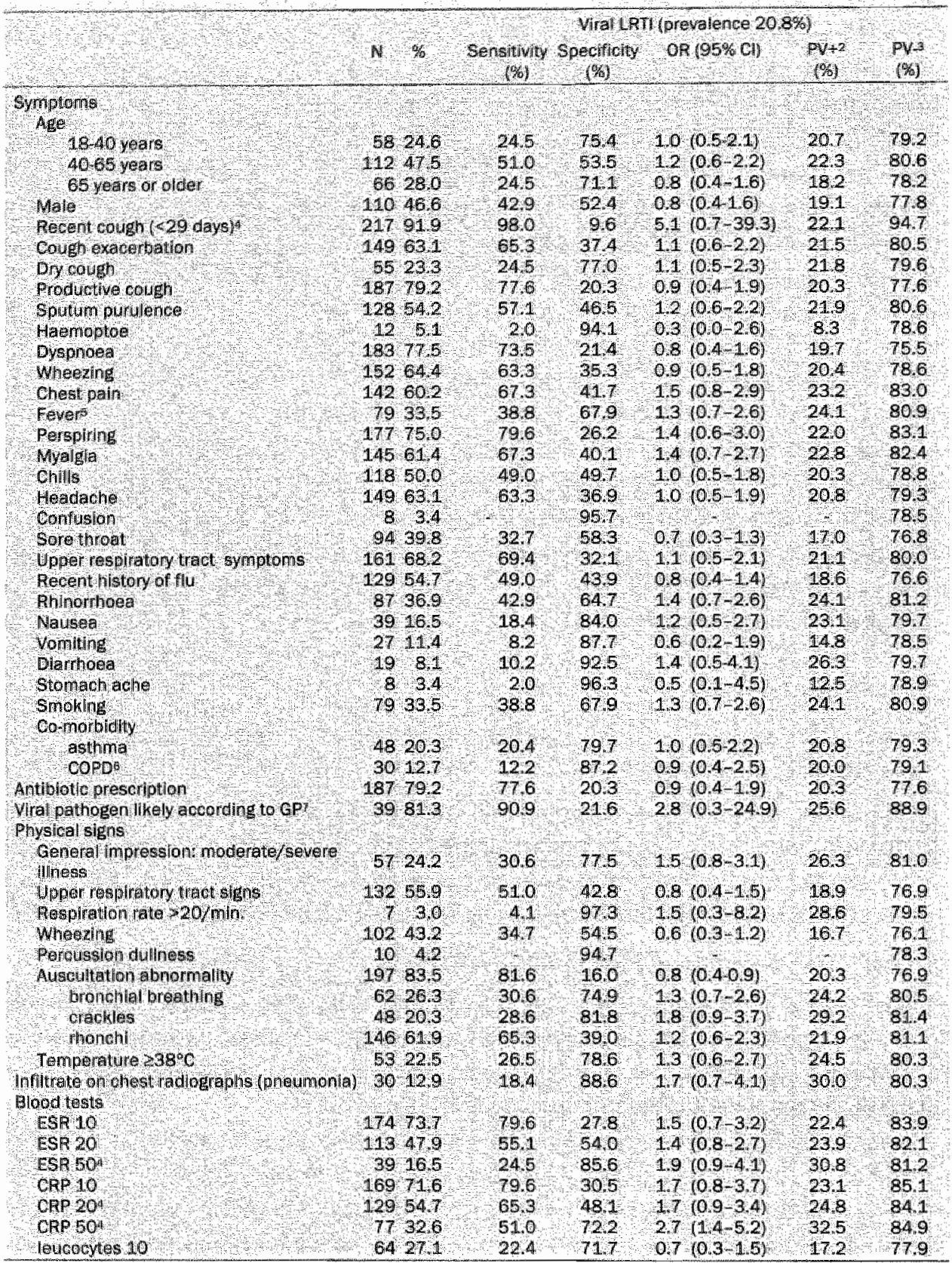

11 patients not included, because one or more for this analysis essential-test results were missing. Not essential was: 'virus missing, bacterium prestent' (n-2), because patient belonged to the reference group:

2 Posinive predictive walue; ${ }^{3}$ Negative predictive value; ${ }^{4}$ Variable selected for multiple logistic regression analysis;

s Measured less than 24 hours ago; in Chonic obstructiwe pulmonany disease; "In patients who were not prescribed antibiotics 

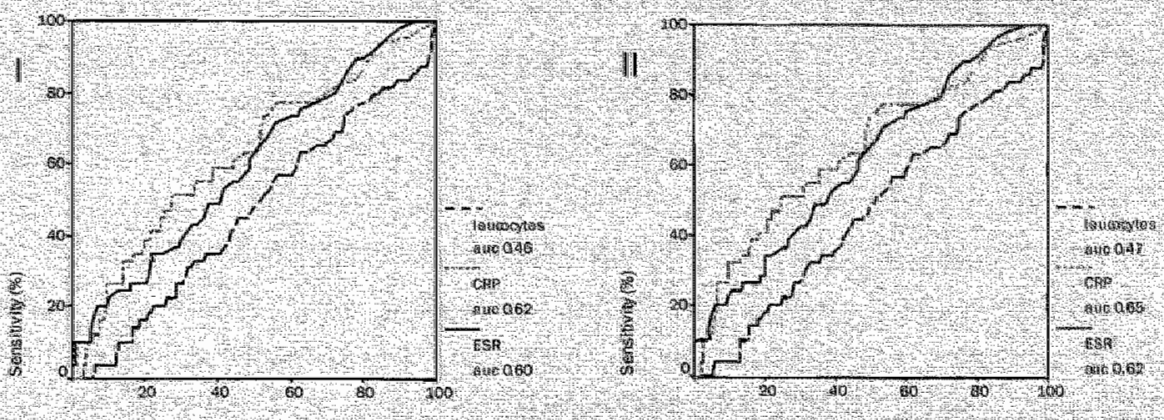

$1+\mathrm{sposifithit}$

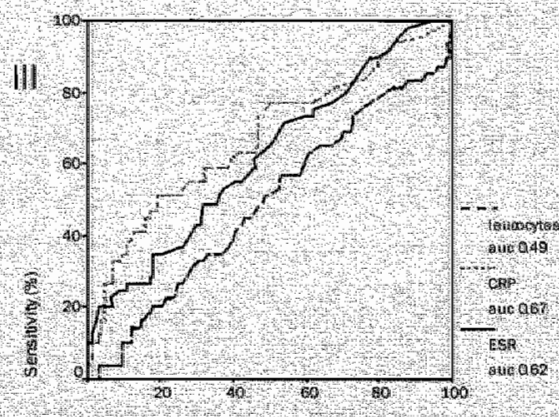

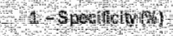

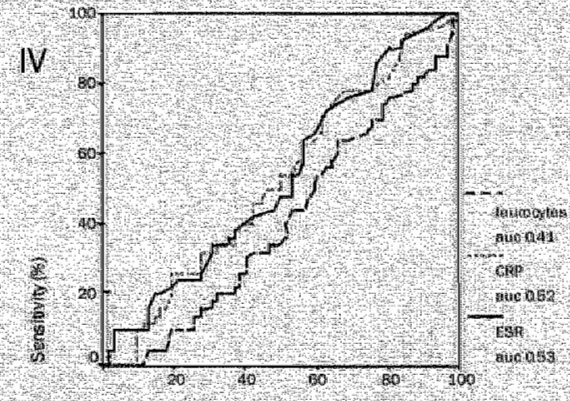

1, spescificitor

1 spocelneth $($ w)
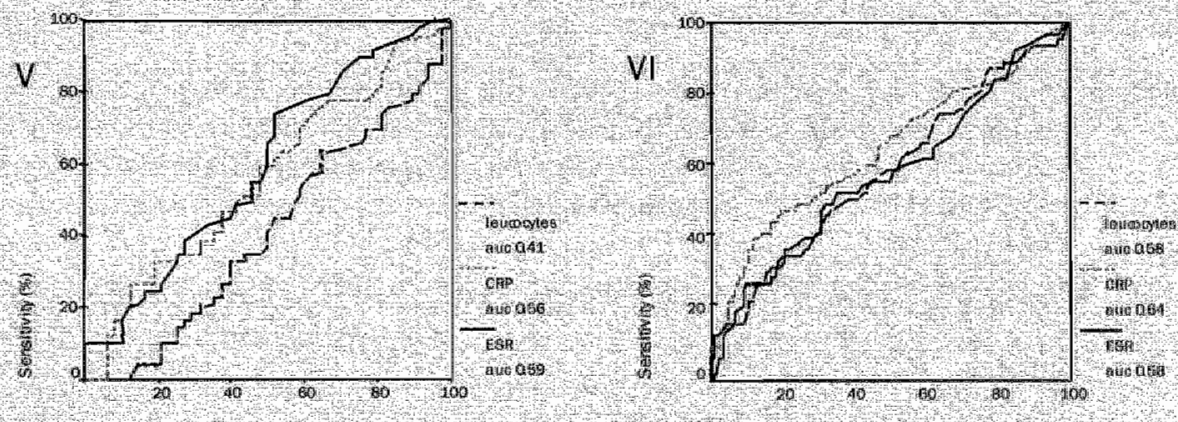

1-spenificty (d)

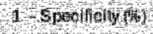

Figure 4.1 ROC curves of erythrocyte sedimentation rate (ESR), C-reactive protein (CRP) and leukocytes for wiral LRTI compared to various combinations of other LRTI, and for bacterlal// mlxed wiral. bacterial LRTI compared to microbiologically unexplained LRTH.

I: Viral LRTI wS. bacterial/ mixed viral-bacterial microbiologically unexplained LRTI ( $n=236$ );

II: Viral LRTI vs. bacterial/ microbiologically unexplained LRTI ( $n=216$ ):

III: Viral LRTI vs. microbiologically unexplained LRTI $(n=171)$;

IV: Viral LRTI vs. bacterial/ mixed wiral-bacterial LRTI $(n=112)$;

V: Viral LRTI ws. bacterial LRTI ( $n=97)$;

VI: Bacterial/ mixed viral-bacterial LRTI vs. microbiologically unexplained LRTI ( 


\section{Viral LRTI compared with microbiologically unexplained LRTI}

The variables chest pain, sore throat, ESR, and CRP were selected for entering multiple logistic regression analysis. None of the clinical variables was a statistically significant predictor of viral LRTI, but ESR $>50 \mathrm{~mm} / \mathrm{hour}$, CRP $>20 \mathrm{mg} / 1$ and CRP $>50 \mathrm{mg} / \mathrm{I}$ had statistically significant ORs (Table 4.3 ).

\section{Viral LRTI compared with bacterial LRTI and mixed viral-bacterial LRTI}

The variables chest pain, perspiring, and leucocytes were selected for entering multiple logistic regression analysis. None of the clinical variables had a statistically significant $O R_{\text {, }}$ but leucocytes $>10$ was a statistically significant negative predictor of viral LRTI (Table 4.3).

\section{Viral LRTI compared with bacterial LRTI}

The variables recent cough, perspiring, and smoking were selected for entering multiple logistic regression analysis. Perspiring was a statistically significant positive predictor of viral LRTI (OR 2.7, Cl 1.0-6.7). None of the additional blood tests were statistically significant (Table 4.3).

All analyses were repeated with the group microbiologically unexplained LRTI compared with all combinations of explained (viral/bacterial/mixed viral-bacterial) LRTI. High ESR and CRP were negative predilictors of microbiologically unexplained LRTI in all combinations (not shown).

Table 4.3 Multiple logistic regression analysis. Odds ratios (OR) and confidence intervals (Cl) of statistically significant, predictive symptoms and signs (A), and added blood tests (B) of viral LRTI compared to other LRTI: bacterial LRTI, mixed viral-bacterial LRTI, and microbiologically unexplained LRTI; different combinations with decreasing numbers $(N)$ and percentage $(\%)$ of 246 patients.

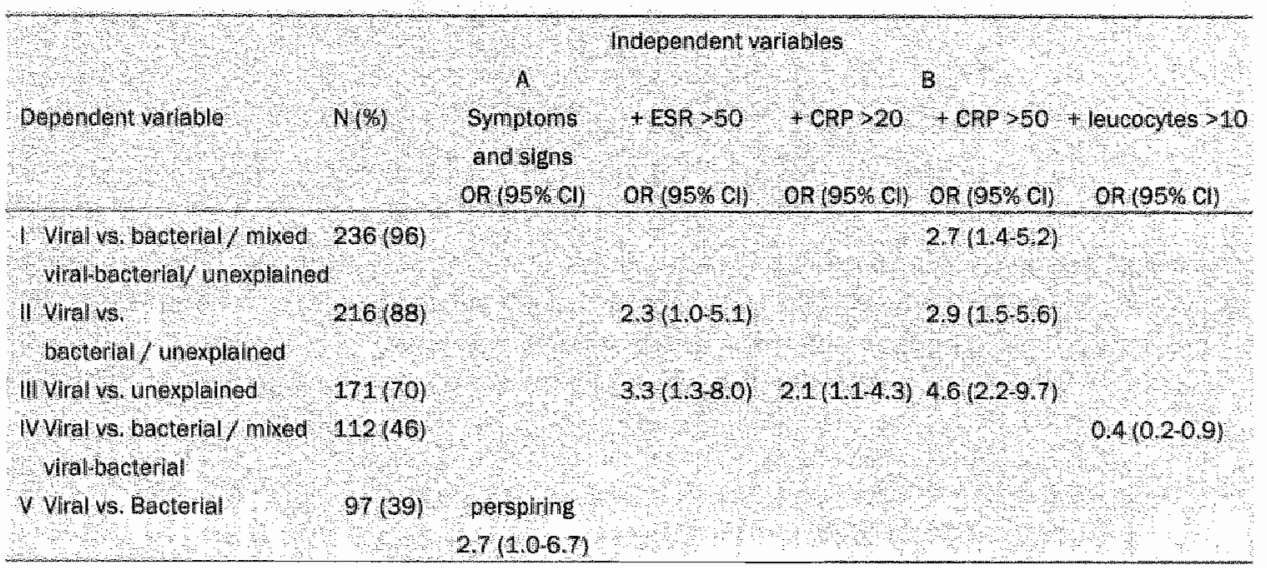




\section{Subgroup analysis}

All analyses were repeated for viral pneumonia compared with other pneumonia, including mixed virat-bacterial infections. Nine of 30 pneumonia cases (two missing) were of purely viral origin. In univariate analysis, the symptoms 'age 40-65 years', dry cough, and wheezing had p-values $<0.10$. In logistic regression analysis, none of these variables correlated statistically significantly with viral pneumonia.

\section{Discussion}

The present diagnostic study on LRTI provides evidence of an assumption which is often prematurely derived from hospital studies and guidelines on pneumonia: $12,30,33,45,46$ extensive history-taking and physical examination do not provide clinical items that are useful to predict viral or bacterial aetiology of LRTII in adult patients. Only in the theoretical situation of maximal contrast of the dependent variable in logistic regression analysis, proven viral versus proven bacterial LRTI, was perspiring found predictive of viral LRTI. The number of eligible subjects for this analysis was $97 / 236(41 \%)$ only, and the lower limit of the $95 \%$ confidence interval just over 1.0 (Cl 1.05-6.72). The significance of this finding could therefore be due to chance because of multiple testing.

High CRP values were predictive of viral LRTI in several analyses $(1,11$ and $I I$ in Table 4.3). However, this was only the case in analyses including patients with microbiologically unexplained LRTI. With a relatively increasing percentage of microbiologically unexplained LRTI, the predictive value of CRP rose, and lower cutoff values of CRP became predictive as well. The same pattern, although less pronounced, was present with high cut-off values $(>50)$ of ESR. It seems that the patients with unexplained LRTI were less ill, therefore less likely to show strong acute phase responses. It can be hypothesized that a certain proportion of this group did not suffer from LRTI, but from an upper respiratory tract infection (or other minor illness) instead. To test the plausibility of our explanations ('low ESR/CRP means less ill, means no detectable pathogen"), we repeated the analyses with the group microbiologically unexplained LRTI compared to all combinations of explained (viral/bacterial/mixed viral-bacterial) LRTI. Sore throat was indeed predictive of microbiologically unexplained LRTI in some of the combinations and again, high ESR and CRP were positive predictors of explained LRTI or (the other way around) negative predictors of microbiologically unexplained LRTI. In other words, in contrast to the acknowledged strength of CRP in its ability to predict and exclude pneumonia in general practice, ${ }^{20,47}$ we could not confirm CRP (or ESR) to be predictive of viral LRTI or bacterial LRTI. We only found these blood tests of value to discriminate microbiologically proven LRTI from microbiologically unexplained LRTI. 
A leukocyte count $>10$ decreased the probability of viral LRTI, when compared to bacterial/mixed viral-bacterial LRTI. If the mixed group was omitted from the analysis, the association was no longer significant. However, the clinical relevance is questionable both because of the poor magnitude of the effect and because of the practical limitation of inadmissible time delay before the test result is available in general practice.

In the present study the diagnosis of viral LRTI according to the reference standard was used as the dependent variable in the various logistic regression procedures, in comparison with various combinations of "other' LRTI, used as the so-called reference categories. The reason for this approach is the acknowledged low false positive rate of serology, whereas bacteriological sputum cultures may reveal considerable numbers of false positives. ${ }^{46.48}$ Positive sputum cultures were found as often in healthy subjects as in GP-patients with acute respiratory tract infections in an epidemiological study from the Netherlands. 49 Furthermore, patients with viral illnesses are less likely to have a (secondary) bacterial infection than those without virall illness. 50

This implies that the patients with a proven viral infection do not need antibiotic treatment and patients with a positive culture might benefit from antibiotics. In the relatively llarge group of patients with both negative culture and serology ('microbiologically unexplained LRTI') the need for antibiotics remains microbiologically unclear. Therefore, they were used as a reference group in the logistic regression procedure, as was the bacterial LRTI group. Nevertheless, regardless of speculations on the methodologically preferable choice of the dependant variable (viral or bacterial LRTI), the results would have been the same either way." extensive history-taking and physical examination did not provide items that predict viral or bacterial LRTI in adult patients.

Since diagnostic studies on LRTI have rarely been performed, especially not with general practice patients, it would have been presumptuous to start our study with promising variables from other studies alone. The drawback is a potential introduction of paradoxical associations, when the number of diagnostic variables is high. With the restrictions applied for entering variables into the logistic regression analysis a satisfactory strong reduction in variables was acquired, although from a statistical point of view an even stronger reduction of variables would have been preferable.

In $52 \%$ of the LRTI predominant pathogens could not be found. Other outpatient studies of acute bronchitis and LRTI have reported even higher percentages with unknown aetiology.26.27.51 Important reasons for the high percentage of unexplained LRTI are the $10 \%$ to $30 \%$ of patients $(21 \%$ in this study) with dry cough $^{52}$ and the inability of patients, partly due to older age and recent onset of the illmess, to produce sputum at the day of inclusion. If high quality sputum was absent, the results of the low sensitive oral washings were used. Moreover, the time delay between sputum production and transport to the hospital laboratory 
might have increased the number of false-negative cultures.52.53 The possibly considerable number of false-negative sputum cultures warrants the methodological approach in the present study to group microbiologically unexplained LRTI together with bacterial LRT, presuming that antibiotics might have been helpful in (at least) some of these patients.

More advanced (and expensive) methods focusing on antigen detection, like enzyme-linked immunosorbent assay (ELISA) and latex agglutination, and polymerase chain reaction (PCR) would possibly have resulted in higher bacteriological yields, with the drawback of increasing rates of false-positive test results. ${ }^{46.48}$ Moreover, it is very unlikely that the finding of some extra bacteria would have changed the results of the diagnostic analyses.

It is possible that 'new' micro-organisms which already play a role in the aetiology of LRTI might be discovered in the (near) future. Recently, it has been suggested that the Metapneumovirus might be responsible for a substantial part of the microbiologically unexplained LRTI.54

Almost half of the microbiologically proven LRTI were caused by viral pathogens, both in 'all LRTI' and in the pneumonia group. The proportion of viral infections is lower than mostly reported for acute bronchitis. The advice to be reluctant to prescribe antibiotics in acute bronchitis might therefore be better accompanied by the remark that acute bronchitis is mostly a self-limiting disease, instead by underlining the (viral) cause of the lliness. On the other hand for the pneumonia cases, the $30 \%$ proven viral pneumonias was higher than mostly reported. Generally, pneumonias in outpatients are milder than in hospitalised patients, which could explain the relatively high frequency of viral (non-pneumococcal) pneumonias. Moreover, a publication bias concerning reports on more virulent bacterial pathogens cannot be ruled out.

$S$ pneumoniae is the most frequently identified pathogen in most performed hospital studies. However, community studies have rarely been performed, ${ }^{48}$ which makes any conclusion on aetiology of LRTI in the community uncertain. In the present study $H$ influenzae was the most common bacteriological micro-organism found. Patients in the present study were recruited from a former miners' area with high prevalence of chronic obstructive pulmonary disease (COPD). In the present study $13 \%$ of the patients suffered from COPD. This may explain the high frequency of $H$ influenzae.

In this diagnostic study patients were recruited and diagnosed by GPS in their natural setting, maintaining regular care as much as possible. The GPs diagnosed LRTI with their own interpretations of history taking and physical examination, not trained in any sense, but with strict study criteria, derived from an important LRTI study by Macfarlane and others, ${ }^{27}$ to define the study population and to facilitate comparisons with other studies. The chosen approach increases generalisability of the study results. Nevertheless, generalization of our findings to everyday care may not be valid. To explore the degree of selection in our recruited patients, we 
compared the actual numbers of cases of LRTI in three practices (with a total of nine GPS and a total population of 13,269 ) with the numbers included in the present trial during one year of the inclusion period. Of the 463 presumably eligible patients, only $43(9 \%)$ were actually included. This proportion is similar to that in a recent study of randomised controlled trials in primary care in which less than $10 \%$ of the eligible population were recruited for the triall.55 Included patients did not differ from other eligible patients with regard to age, clinical diagnosis, severity of illness, and need for antibiotic treatment (according to the GPs).

We have no iridication that the clinical applicability of the study results may be jeopardised, since exclusion was restricted to pregnant or breastfeeding women and patients with rare conditions, However, clinical reality may differ from one research setting to another, and an internally valid model may have limited external validity. Therefore, the study should be repeated in a new, similar, set of patients in general practice to obtain external validation of the results. 56

Previously, we have shown that, despite alarming reports on the raise of so-called atypical infections and increasing bacterial resistance rates, LRTI caused by L pneumophila, M pneumoniae, or $C$ pneumoniae was rare in the community. Amoxicillin was found to be a reliable first-choice antibiotic in the treatment of LRTI in the community. ${ }^{28}$ Next, we have shown that GPS have great difficulty differentiating pneumonia from acute branchitis in LRTI patients. Clinical predictors of pneumonia were identified, which will contribute to better targeting of antibiotic treatment.20 But the most important question is which subgroup of patients, irrespective of initial infecting agent, will benefit from antibiotic treatment. 57 Therefore, it is time to shift focus from aetiology to prognosis, including the identification of patients at risk for a poor clinical outcome or prolonged course of the LRTI episode.

Diagnostic studies on common clinical illnesses are not frequently performed in clinical practice. Maybe practicing clinicians are reluctant to critically review their basic, clinical skills. The expertise of epidemiologists in designing and executing diagnostic studies like these in the future is welcome to get a better grip on the many, diagnostic uncertainties physicians face in daily clinical practice. 


\section{References}

1. Jacobs $M R_{n}$ Felmingham $D_{*}$ Appelbaum $P C_{n}$ Gruneberg $R N$, The Alexander Project $G$. The Alexander Project 1998-2000: susceptibility of pathogens isolated from community-acquired respiratory tract infection to commonly used antimicrobial agents. J Antimicrob Chemother. 2003;52:229-46.

2. Friedland $\mathbb{I R}$, McCracken GH Jr. Management of infections caused by antibioticresistant Streptococcus pneumoniae. N Engl 』Med. 1994:331:377-82.

3. Jacoby GA. Prevalence and resistance mechanisms of common bacterial respiratory pathogens. Clin Infect Dis. 1994;18:951-7.

4. Schwartz B. Preventing the spread of spiread of antimicrobial resistance among bacterial respiratory pathogens in industrialized countries: the case for judicious antimicrobial use. Clin Infect Dis. 1999;28:211-3.

5. Seppala H, Klaukka $T$, Vuopio-Varkila J, Muotiala A, Helenius $H$, Lager $K$, Huovinen P. The effect of changes in the consumption of macrolide antibiotics on erythromycin resistance in group A streptococci in Finland. Finnish Study Group for Antimicrobial Resistance. N Engl I Med. 1997;337:441-6.

6. Swartz MN. Use of antimicrobial agents and drug resistance. N Engl J Med. 1997;337: 491-2.

7. Magee JT, Pritchard EL, Fitzgerald KA, Dunstan FD, Howard AJ. Antibiotic prescribing and antibiotic resistance in community practice: retrospective study, 1996-8. BMJ. 1999;319:1239-40.

8. Priest $P$, Yudkin $P$, McNulty $C$, Mant $D$. Antibacterial prescribing and antibacterial resistance in English general practice: cross sectional study. BMJ. 2001;323:1037-41.

9. Butler CC, Rollnick S, Pill R, Maggs Rapport F. Stott N. Understanding the culture of prescribing: qualitative study of general practitioners' and patients' perceptions of antibiotics for sore throats. BMJ. 1998;317:637-42.

10. Falck G, Heyman L, Gnarpe $\downarrow$, Gnarpe H. Chlanydia pneumoniae (TWAR): a common agent in acute bronchitis. Scand J Infect Dis. 1994;26:179-87.

11. Marrie TJ, Peeling RW. Fine MJ, Singer DE, Coley CM, Kapoor WN. Ambulatory patients with community-acquired pneumonia: the frequency of atypical agents and clinical course. Am J Med. 1996;101:508-15.

12. Fang GD, Fine $M$, Orloff J, Arisumi D, Yu VL, Kapoor W, Grayston JT, Wang SP, Kohler R, Muder RR et al. New and emerging etiologies for community-acquired pneumonia with implications for therapy.A prospective multicenter study of 359 cases. Medicine Baltimore. 1990;69:307-16.

13. Coenen $S_{v}$ Van Royen $P$, Vermeire E, Hermann I, Denekens J. Antibiotics for coughing in general practice: a qualitative decision analysis. Fam Pract. 2000;17:380-5.

14. Okkes IM, Oskam SK and Lamberts H: Van klacht naar diagnose: episodegegevens uit de huisartspraktijk. [From complaint to diagnosis: Disease episodes in general practice]. Bussum, Couthino, 1998.

15. wan der Velden J, De Bakker DH "Claessens AAMC, Schellevis FG. Dutch National Survey of General Practice. Morbidity in General Practice. Ltrecht, NIVEL, 1992.

16. Woodhead MA, Macfarlane JT, McCracken JS, Rose DH, Finch RG. Prospective study of the aetiology and outcome of pneumonia in the community. Lancet. 1987;1:671.4.

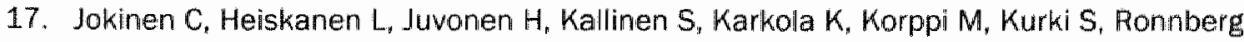
PR, Seppa A, Soimakallio $S$ et al. Incidence of community-acquired pneumonia in the population of four municipalities in eastern Finland. Am / Epidemiol. 1993;137: 977.88. 
18. Metlay JP, Kapoor WN, Fine MJ. Does this patient have community-acquired pneumonia? Diagnosing pneumonia by history and physical examination. IAMA. 1997; 278:1440-5.

19. Melbye H, Straume $B$, Aasebo U, Dale $K$. Diagnosis of pneumonia in aduits in general practice. Relative importance of typical symptoms and abnormal chest signs evaluated against a radiographic reference standard. Scand I Prim Health Care. 1992;10:226-33.

20. Hopstaken RM, Muris JWM, Knottherus JA, Kester ADM, Rinikens PELM, Dinant GJ. Contributions of symptoms, signs, enythrocyte sedimentation rate and C-reactive protein to a diagnosis of pneumonia in acute lower respiratory tract infection. Br J Gen Pract. 2003;53:358-64.

21. Kuyvenhoven MM, Verheij TJ, de Melker FA, van der Velden J. Antimiçrobial agents in lower respiratory tract infections in Dutch general practice. $\mathrm{Br} /$ Gen Pract. 2000;50: $133-4$.

22. Macfarlane J, Lewis SA, Macfarlame R, Holmes W. Contemporary use of antiblotics in 1089 adults presenting with acute lower respiratory tract illness in general practice in the U.K.: implications for developing management guidelines. Respir Med. 1997;91: $427-34$.

23. Huchon GJ, Gialdroni Grassi G, Leophonte P, Manresa F, Schaberg T, Woodhead M. Initial antibiotic therapy for lower respiratory tract infection in the community: a European survey. Eur Respir J. 1996:9:1590-5.

24. Smucny JJ. Becker LA, Glazier RH, Mclsaac W. Are antibiotics effective treatment for acute bronchitis? A meta-analysis. I Fam Pract. 1998;47:453-60.

25. Bent $S$, Saint $S$, Vittinghoff $E$, Grady D. Antibiotics in acute bronchitis: a meta-analysis. Am J Med. 1999:107:62-7.

26. Jonsson JS, Sigurdsson JA, Kristinsson KG, Guthnadottir $M$, Magnusson S. Acute bronchitis in adults. How close do we come to its aetiology in general practice? Scand J Prim Health Care. 1997;15:156-60.

27. Macfarlane JT, Colville A, Guion A, Macfarlane RM, Rose DH. Prospective study of aetiology and outcome of adult lower-respiratory-tract infections in the community. Lancet. 1993;341:511.4.

28. Hopstaken RM, Nelemans P, Stobberingh EE, Muris JWMI, Rinkens PELM, Dinant GJ. Is roxithromycin better than amoxicillin in the treatment of acute lower respiratory tract infections in primary care? A double-blind randomized controlled triall. I Fam Pract. 2002:51:329-36.

29. Woodhead M, Gialdroni Grassi G, Huchon GJ, Leophonte P, Manresa F, Schaberg T. Use of investigations in lower respiratory tract infection in the community: a European survey. Eur Respir J. 1996;9:1596-600.

30. Farr $\mathrm{BM}_{\text {; }}$ Kaiser $\mathrm{DL}$, Harrison $\mathrm{BD}$. Connolly $\mathrm{CK}$. Prediction of microbiall aetiology at admission to hospital for pneumonia from the presenting clinical features. Thorax. 1989:44:1031-5.

31. Cicchetti DV, Feinstein AR. High agreement but low kappa: II. Resolving the paradoxes. J Clin Epidemiol. 1990;43:551-8.

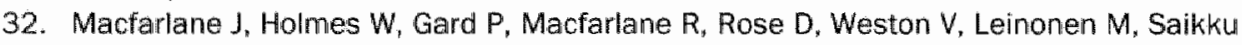
$P$. Myint S: Prospective study of the incidence, aetiology and outcome of adult lower respiratory tract illness in the community. Thorax. 2001;56:109-14.

33. British Thoracic Society Standards of Care Committee. BTS Guidelines for the Management of Community Acquired Pneumonia in Aduits. Thorax. 2001;56 54:1-64.

34. Holmberg $\mathrm{H}$. Bodin L, Jonsson I, Krook A. Rapid aetiological diagnosis of pneumonia based on routine laboratory features. Scand J Infect Dis. 1990;22:537-45. 
35. Korppi M. Kroger L. C-reactive protein in viral and bacterial respiratory infection in children. Scand I Infect Dis. 1992,25:207-13.

36. Hjortdahl $P$, Landaas $S$, Urdal $P$, Steinbakk $M$. Fuglerud $P$, Nygaard $B$. Creactive protein: a new rapid assay for managing infectious disease in primary health care. Scand I Prim Health Care. 1991;9:3-10.

37. Virkki $R$, Juven T, Rikalainen $H$, Svedstrom $E$, Mertsola J, Ruuskanen O. Differentiation of bacterial and viral pneumonia in children. Thorax. 2002;57:438-41.

38. Soderstrom $M$, Blomberg $J$, Christensen $P$. Hovelius B. Erythromycin and phenoxymethylpenicillin (penicillin $V$ ) in the treatment of respiratory tract infections as related to microbiological findings and serum C-reactive proteln. Scand $I$ Infect Dis. 1991:23:347-54.

39. Murray PR, Baron EJ, Pfaller MA, Tenower FC, Yolken R. Manual of Clinical Microbiology. Washington DC, ASM Press, 1999.

40. Isenberg HD. Clinical microbiology procedures handbook. Washington, D.C., American Society for Microbiology, 1994.

41. Sachs AP, van der Waaij $\mathrm{D}$, Groenier $\mathrm{KH}_{\mathrm{r}}$ Koeter $\mathrm{GH}$, Schiphuis J. Oropharyngeal flora in asthma and in chronic obstructive pulmonary disease. Indigenous oropharyngeal microorganisms in outpatients with asthma or chronic obstructive pulmonary disease. Am Rev Respir Dis. 1993;148:1302-7.

42. Tong $C Y$, Sillis $M$. Detection of Chlamydia pneumoniae and Chlamydia psittaci in sputum samples by PCR. J Clin Pathol. 1993;46:313-7.

43. DeLong ER, DeLong DM, Clarke Pearson DL. Comparing the areas under two or more correlated receiver operating characteristic curves: a nomparametric approach. Biometrics. 1988;44:837-45.

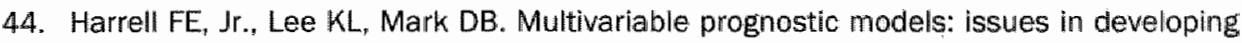
models, evaluating assumptions and adequacy, and measuring and reducing errors. Stat Med. 1996;15:361-87.

45. Niederman MS, Mandell LA, Anzueto A, Bass JB, Broughton WA, Campbell GD, Dean N, File T, Fine MJ, Gross PA, Martinez F, Marrie TJ, Plouffe JF, Ramirez J, Sarosi GA, Torres A, Wilson R, Yu VL; American Thoracic Society. Guidelines for the management of adults with community-acquired pneumonia. Diagnosis, assessment of severity, antimicrobial therapy, and prevention. Am J Respir Crit Care Med. 2001;163:1730-54.

46. Bartlett IG, Dowell SF, Mandell LA, File Jr TM, Musher DM, Fine MJ. Practice guidelines for the management of community-acquired pneumonia in adults. Infectious Diseases Society of America. Clim Infect Dis. 2000;31:347-82.

47. Melbye H. Straume B, Aasebo U. Brox J. The diagnosis of adult pneumonia in general practice. The diagnostic value of history, physical examination and some blood tests. Scand J Prim Health Care. 1988;6:111-7.

48. Bates $\mathrm{JH}$, Campbell GD, Barron AL, McCracken GA, Morgan PM, Moses EB, Davis CM. Microbial etiology of acute pneumonia in hospitalized patients. Chest. 1992;101: 1005-12.

49. van den Brandhor WE, Bartelds AIM, Peeters MF, Wilbrink B, Helinen MLA. ARI-EL: een case-controle onderzoelk naar Acute Respiratoire Infecties in de Eerste Lijn. Tussenrapportage over okt. $2000 \mathrm{t} / \mathrm{m}$ sept. 2001. Bilthoven, Rijksinstituut voor Volksgezondheid en Milieu (RIVM), 2001.

50. Byington $\mathrm{CL}$, Castillo $\mathrm{H}$, Gerber K, Daly JA, Brimley LA, Adams S, Christerison JC, Pavia AT. The effect of rapid respiratory viral diagnostic testing on antibiotic use in a children's hospital. Arch Pediatr Adolesc Med. 2002;156:1230-4. 
51. Boldy DA, Skidmore $5 J$. Ayres JG. Acute bronchitis in the community: clinical features, infective factors, changes in puinonary function and bronchial reactivity to histamine. Respir Med. 1990:84:377-85.

52. Bartlett JG, Mundy LM. Community-acquired pneumonia. N Engl J Med. 1995;333: 1618-24.

53. Huchon $\mathrm{G}$, Woodhead M. Management of adult community-acquired lower respiratory tract infections. Eur Respir Rev. 1998;8:391-426.

54. Schrijnemakers: EARSS Annual report 2001 Bithoven, The Netherlands, RIVM, 2001.

55. Wilson $S$, Delaney BC, Roalfe A, Roberts $L$, Redman $V$, Wearn AM, Hobbs FD. Randomised controlled trials in primary care: case study. BM1. 2000;321:24-7.

56. Knottnerus JA, van Weel $\mathrm{C}$, Muris JWM. Evaluation of diagnostic procedures. BMJ. $2002 ; 324: 477-80$.

57. Hopstaken R, Hay AD, Butler CC. Diagnosis of bacterial LRTI. Bir J Gen Pract. 2004; $54: 216$. 


\section{Chapter}

Is roxithromycin better than amoxicillin in the treatment of acute lower respiratory tract infections in general practice? A double-blind randomised controlled trial

RM Hopstaken, P Nelemans, EE Stobberingh, JWM Murs, PELM Rinkens PELM, GJ Dinant

Journal of Family Practice 2002;51:329-36

Huisarts en Wetenschap 2003;46:73-9 


\section{Abstract}

\section{Oblective}

To assess the efficacy of roxithromycin relative to amoxicillin.

\section{Methods}

We conducted a double-blind randomised controlled trial of oral $500 \mathrm{mg}$ amoxicillin three times per day us. oral $300 \mathrm{mg}$ roxithiromycin once a day for 10 days. We included 196 adults who had presented to a general practitioner with lower respiratory tract infection (LRTI) and, in the physician's opinion, needed antibiotic treatment. We measured clinical response after 10 and 28 days, defined in four ways: (1) decrease in LRTI symptoms" (2) complete absence of symptoms: (3) decrease in signs; and (4) complete absence of signs. Selfreported response included the decrease in symptoms and the time until resumption of impaired or abandoned daily activities on days 1 through 10,21 , and 27 .

\section{Results}

Clinical cure rates after the completion of antibiotic treatment ( 10 days) were not significantly different for the two groups. After 28 days, the roxithromycin group showed no increase in cure rate as evidenced by the decrease in symptoms, indicating a significantly lower cure rate. However, this difference did not alter physicians" overall conclusion after complete follow-up that $90 \%$ of patients, regardless of age, had been effectively treated with either amoxicillin or roxithromycin.

\section{Conclusion}

The surplus value of roxithromycin was not confirmed. Amoxicillin remains a reliable firstchoice antibiotic in the treatment of LRTI in general practice. 


\section{Introduction}

Acute community-acquired lower respiratory tract infections (LRT/S) in adults include acute bronchitis, pneumonia, and infectious episodes in patients with asthma or chronic obstructive pulmonary disease (COPD). In acute bronchitis and exacerbations of COPD, the value of antibiotic therapy is doubtful; in pneumonia, however, it is widely accepted. Because distinguishing between these disease entities on clinical grounds alone is often impossible, deciding which patients would benefit from antibiotic treatment remains difficult. ${ }^{1.6}$ In the Netherlands, as in the United States and Great Britain, antibiotics are prescribed for patients with acute bronchitis approximately $80 \%$ of the time. ${ }^{7.9}$

If a general practitioner (GP) decides to treat LRTI with antibiotics, amoxicillin is the drug of first choice in the Netherlands. ${ }^{10-13}$ However, amoxicillin is not effective in infections caused by atypical organisms such as Mycoplasma pneumoniae, Chlamydia pneumoniae, and Legionella pneumophila, which are responsible for $1 \%$ to $50 \%$ of cases of $L R T I .{ }^{14-20}$ Roxithromycin and the newer macrolide antibiotics are recommended as drugs of choice for the empirical treatment of communityacquired pneumonia in low-risk patients in the United States and Canada ${ }^{21-23}$ because those drugs cover both typical and atypical pathogens. Amoxicillin has long proved to be a reliable drug and one to which the resistance of common respiratory tract pathogens (Streptococcus pneumoniae and Haemophilus influenzae) in the Netherlands is $\| \mathrm{w}_{.}^{24-29}$

Community-based studies that evaluate treatment for LRTI are lacking. Also lacking are independent randomised controlled studies comparing amoxicillin with roxithromycin or other new macrolides for LRTI. Our double-blind randomised trial attempted to determine whether the preference for amoxicillin in the Netherlands is well founded. In the trial, patients with LRTI who in their GP's opinion needed antibiotic treatment were assigned to either amoxicillin or roxithromycin. We then compared the efficacy and safety of both drugs.

\section{Methods}

\section{Eligibility criteria and baseline characteristics}

Eligible study subjects were patients in the southern part of the Netherlands who presented with signs and symptoms of LRTI that their GPs believed warranted antibiotic therapy. Table 5.1 lists the inclusion and exclusion criteria.

Baseline data (at day 1) were obtained to evaluate the comparability of prognostic factors between the intervention groups. The GP performed an extensive medical history and physical examination. In addition, a sputum sample, oral washing, and nasopharyngeal swab were taken for bacteriologic examination. Venous blood 
samples were taken for blood chemistry, hematology, and serology (initial titers of viral pathogens, and $M$ pneumoniae and $L$ pneumophila).

Table 5.1 Checklist for patient elighility.

\begin{tabular}{|c|c|c|}
\hline \multicolumn{2}{|c|}{ Inclus/on criteria } & Exclusion Criteria \\
\hline A & Age 18 years or blder & Pregnant or present wish to become pregnant \\
\hline & AND & Breastreeding \\
\hline 8 & New or increasing cough & Terminal disease \\
\hline & $\mathrm{AND}$ & Drug or alcohol abuse \\
\hline c & At least onis of the following & History of hypersensitivity to penicillins or macrolides \\
\hline & dyspnoea & Hospital stay in prewious four weeks for respiratory \\
\hline & wheezing & complaints \\
\hline & chest pain & Treatment with antibiotics withlin preceding 14 days \\
\hline & euscultation abmormalities & Treatment with any other investige \\
\hline & AND & ehs before entry \\
\hline $\mathrm{D}$ & At least one of the following: & ed hepatic or renal function \\
\hline & fever $\left.238^{\circ} \mathrm{C}\right)$ & Mental condition renderi \\
\hline & persping & understand the nature, \\
\hline & theadache & consequences of the study or evidence of \\
\hline & 4 nyalgla & erative attitude \\
\hline & $\mathrm{AND}$ (P) & nability to attend follow up visits \\
\hline E & Dlagnosis of LRT according to GP & Inmunocompromised status \\
\hline & & mission to hospital \\
\hline F & Antibiotics required In GP's opinon) & $\begin{array}{l}\text { Concomitant treatment with ergot alkaloids or } \\
\text { terfenadine during the study period }\end{array}$ \\
\hline
\end{tabular}

1. Onset within the previous 28 days

LRTI denotes lower respiratory tract infection; GP, general practitioner

\section{Interventions}

Once the samples had been collected, patients were randomly assigned to oral treatment with either $500 \mathrm{mg}$ amoxicillin three times daily for 10 days or $300 \mathrm{mg}$ roxithromycin once daily for 10 days. A computer program using random permuted blocks of six prepared a randomisation list for each participating centre. Batches of drug packages, each provided with a unique trial code, had been sent in advance to the participating general practices. A double-dummy technique achieved blinding of patients, treating physicians, and investigators to the assigned medication. This was necessary because amoxicillin and roxithromycin have different dosing schedules (three times a day versus once daily) and are not identical in appearance (capsule versus tablet). All capsules and tablets had identical appearance and taste. All patients received both forms of their assigned medication. Compliance with medication regimens was measured by Medical Event 
Monitoring Systems (MEMS), an electronic recording system that compiles the dosing history of ambulatory patients taking oral medication. ${ }^{30}$

\section{Chest radiography}

Every patient underwent chest radiography. The radiographs were reassessed for the presence or absence of infiltrate by a blinded independent senior radiologist. If the first and second radiologist disagreed, a third senior radiologist made a final assessment.

\section{Follow-up}

Follow-up consultations similar to the examination on day 1 took place on days 10 and 28. During treatment (days 1 through 10 ) and on days 21 and 27 , follow-up was supplemented by a short diary in which patients recorded their symptoms and the times at which they resumed daily activities that they had abandoned or that had been impaired.

\section{Outcomes measured}

Efficacy was assessed by comparing the groups' clinical response on day 10 (the primary outcome measure) and day 28 and their bacteriologic response on day 10 . Satisfactory clinical response was defined in four ways: (1) decrease in symptoms of LRTI; (2) absence of symptoms of LRTI; (3) decrease in signs of LRTI; and (4) absence of signs of LRTI. All other outcomes were regarded as unsatisfactory responses.

Self-reported symptoms and time to resolution were compared between the two groups on days 1 through 10,21, and 27. The percentage of patients who had abandoned daily activities or whose participation in daily activities had been impaired by illness was followed over time. Bacteriologilc cure was defined as the absence of growth of a predominant bacterial pathogen (cultured at baseline) in a sputum sample taken on day 10.

We recorded patients' compliance rates, frequency of adverse events, and acquired bacterial resistance. Compliance was defined as the number of doses taken divided by the number of doses prescribed.

\section{Statistical analyses}

The efficacy of amoxicillin and roxithromycin was evaluated using an intention-totreat analysis. Differences were tested using a two-sided $\chi^{2}$ test ( $\alpha=0.05$ ). Multiple logistic regression analysis was performed to analyse the effect of differences in baseline characteristics between the randomised groups. Differences in symptoms, time to resolution of symptoms, and time to resumption of abandoned and impaired daily activities were tested in life table analyses using the Gehan test. All 
statistical analyses were performed with Statistical Package for the Social Sciences software, version 8.0 .

\section{Results}

\section{Patient population}

From January 1998 to April 1999, 25 GPs from 15 practices recruited 196 patients aged 18 years to 89 years. Of these patients, 99 received amoxicillin and 97 received roxithromycin (Figure 5.1). The two groups" demographic data, signs and symptoms, co-morbidities, identified pathogens, and radiographic abnormalities. were similar (Table 5.2). Multiple logistic regression analysis showed that none of the covariables altered the effects of the study medication.

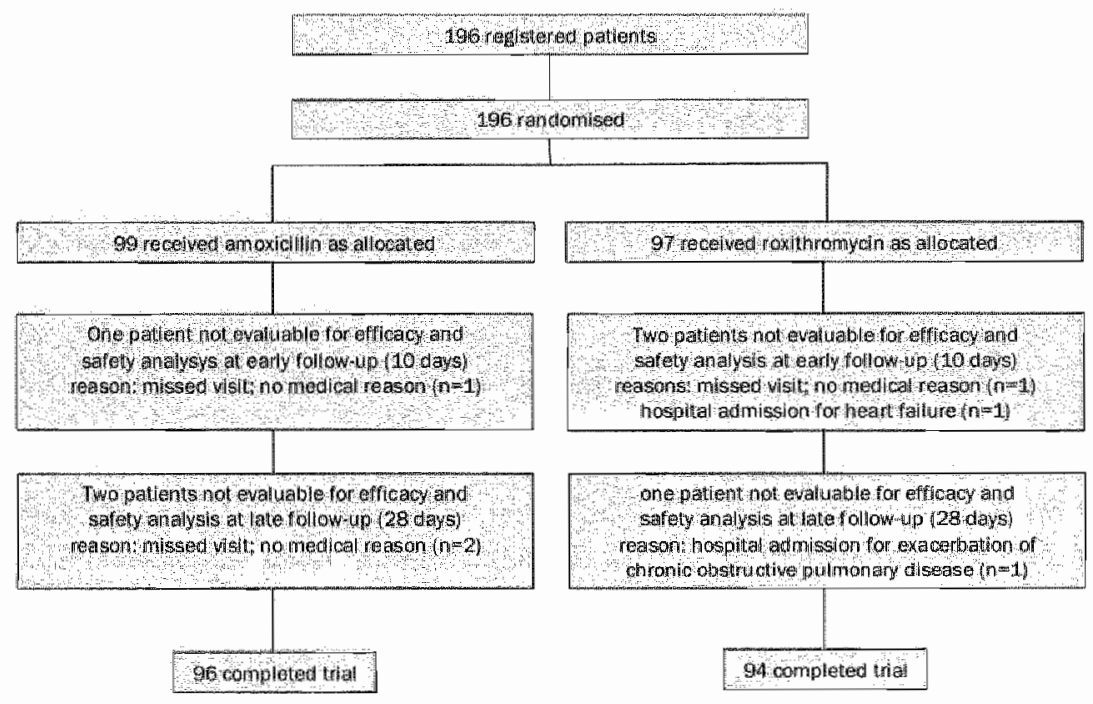

Figure 5.1 Distribution of patients for efficacy and safety analysis.

\section{Clinical cure}

\section{Early follow-up}

The rate of clinical cure, defined as the decrease in symptoms and signs at 10 days after randomisation, was high and not significantly different between both groups. Using the stricter definition of clinical cure as the complete absence of symptoms and signs led to the same conclusion. Absolute cure rates using this strict definition were low (Table 5.3). 
Physicians discontinued treatment with the study medication in two cases (one amoxicillin and one roxithromycin) because of unsatisfactory clinical response. Both patients recovered rapidly after alternative antibiotic treatment. In one case, the patient discontinued amoxicillin after eight days because of rash and urticaria and recovered quickly without further treatment.

Table 5.2 Findings on presentation.

\begin{tabular}{|c|c|c|}
\hline 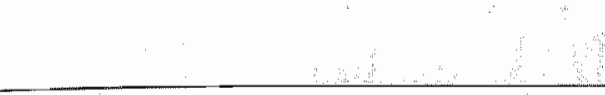 & $\begin{array}{c}\text { Amoxicillingroup } \\
N(\%)\end{array}$ & $\begin{array}{l}\text { Roxithromycin group } \\
\text { N(o) }\end{array}$ \\
\hline Number of patients & $99(51)$ & $97(49)$ \\
\hline \multicolumn{3}{|l|}{ Demographic data } \\
\hline Ratio of men to women & $46 / 53$ & $53 / 44$ \\
\hline Mean age in years $(\mathrm{SD})$ & $55(15)$ & $50(16)$ \\
\hline \multicolumn{3}{|l|}{ Symptoms } \\
\hline \multicolumn{3}{|l|}{ Recent cough in number of days } \\
\hline $1-7$ & $34(36)$ & $4143)$ \\
\hline $8-14$ & $31(33)$ & $25(26)$ \\
\hline $15-28$ & $22(23)$ & $23(24)$ \\
\hline No recent cough & $8(8)$ & $6(6)$ \\
\hline Productive cough & $77(78)$ & $84(88)$ \\
\hline Dyspnea & $78(79)$ & $76(79)$ \\
\hline Wheezing & $68(69)$ & $61 .(64)$ \\
\hline Risk factors & & 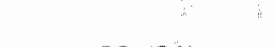 \\
\hline Cigarette smoking & $36(36)$ & $29(31)$ \\
\hline \multicolumn{3}{|l|}{ Co-morbidity } \\
\hline none & $55(56)$ & $48(52)$ \\
\hline asthma & $19(19)$ & $20(22)$ \\
\hline COPD & $17(17)$ & $11(12)$ \\
\hline heart failure & $3(3)$ & $4(4)$ \\
\hline diabetes mellitus & $2(2)$ & $3(3)$ \\
\hline other & $23(24)$ & $21(23)$ \\
\hline Asthma medication prescribed at start of study & $16(16)$ & $13(14)$ \\
\hline \multicolumn{3}{|l|}{ Signs } \\
\hline Auscultation abnormalities & $93(94)$ & $87(91)$ \\
\hline Body temperature $\geq 38.0^{\circ} \mathrm{C}$ & $25(26)$ & $22(24)$ \\
\hline Mild/moderate infection & 91 (93) & $89(93)$ \\
\hline Severe infection & $7(7)$ & $7(7)$ \\
\hline \multicolumn{3}{|l|}{ Laboratory tests } \\
\hline CRP median (irange) & $23(2-228)$ & $26(2-312)$ \\
\hline Erythrocyte sedimentation rate, median (range) & $21(1-104)$ & $19(1-121)$ \\
\hline Leukocytes, median (range) & $8.3(3.9-19.7)$ & $8.4(4.3-1.5 .4)$ \\
\hline Patients with pathogens & $45(45)$ & $46(47)$ \\
\hline Infiltrate on chest radiographs & $14(14)$ & 13 (14) \\
\hline
\end{tabular}

NOTE: Values are numbers (percentages) unless otherwise stated. Percentages are based on number of patients for each wariable. COPD denotes chronic obstructive pulmonary disease; CRP, C-reactive protein; ESR, enythrocyte sedimentation rate; SD, standard deviation. 
Table 5.3 Clinical cure rate at early (10-day) and late (28-day) follow-up.

\begin{tabular}{|c|c|c|c|}
\hline & $\begin{array}{l}\text { Amoxicillin } \\
\mathrm{N}(\%)\end{array}$ & $\begin{array}{l}\text { Roxithromycin } \\
\text { (N }(\%)\end{array}$ & $\begin{array}{l}\text { Relative Riskik } \\
(95 \% \text { Cl }\end{array}$ \\
\hline \multicolumn{4}{|l|}{ Decrease in symptoms and signs. } \\
\hline \multicolumn{4}{|l|}{ Day 10} \\
\hline symptoms & $84 / 96(88)$ & $90 / 95(95)$ & $2.38(0.87-6.48)$ \\
\hline signs (physical examination) & $85 / 98(87)$ & $89 / 95(94)$ & $210(0.83-5.30)$ \\
\hline \multicolumn{4}{|l|}{ Day 28} \\
\hline symptoms & $91 / 95(96)$ & $79 / 93(85)$ & $0.28(010-0.82)^{2}$ \\
\hline signs (physical examination) & $90 / 96(94)$ & $87 / 94(93)$ & $0.84(0.29-2.41)$ \\
\hline \multicolumn{4}{|l|}{ Absence of symptonis and signs } \\
\hline \multicolumn{4}{|l|}{ Day 10} \\
\hline symptoms & $18 / 96(19)$ & $22 / 95(23)$ & $1.06(0.91-1.22)$ \\
\hline signs (physical examination) & $68 / 98(69)$ & $76 / 95(80)$ & $1.53(0.93-2.53)$ \\
\hline \multicolumn{4}{|l|}{ Day 28 ( 340} \\
\hline symptoms & $59 / 95(62)$ & $50 / 93(54)$ & $0.82(0.581 .15)$ \\
\hline (4) signs (physical examination) & $82 / 96(85)$ & $80 / 94(85)$ & $0,98(0.49-1.94)$ \\
\hline Fexer $\left(238^{\circ} \mathrm{C}\right)$ gone, day 10 & $20 / 23(87)$ & $19 / 21 / 91)$ & $1.37(0.257 .41)$ \\
\hline Cure, final conclusion by physiclan, day 28 & $84 / 95(88)$ & $86 / 94(91)$ & $1.36(0.573 .23)$ \\
\hline
\end{tabular}

NOTE: Percentages are based on number of patients for each wariable.

1 Risk of no cure with amoxicillin ws roxithromycin. ${ }^{2} p<0.05$.

\section{Late follow-up}

According to the physicians" final assessments, the rate of clinical cure at 28 days was not significantly different between the two groups, although the percentage of patients who showed a decrease in symptoms was significantly higher in the amoxicillin group than in the roxithromycin group (Table 5.3). Again, cure rates were much lower when the strict definition of cure was used. Eleven patients in the amoxicillin group and eight in the roxithromycin group were not clinically cured after 28 days. Of these patients, 10 (five in each group) recovered shortly thereafter or did not consult their physician again for persisting symptoms of LRTI. Nine patients (six in the amoxicillin group, three in the roxithromycin group) with exacerbation of COPD slowly returned to their baseline clinical situation. Four patients (three in the amoxicillin group, one in the roxithromycin group) were found to have concomitant pulmonary cancer. Curative bilobectomy was performed in one of the patients. The others received palliative treatment.

\section{Self-reported response over time}

The time before resolution of symptoms according to the patients' diaries was similar for patients treated with amoxicillin and those treated with roxithromycin (Figures 5.2A and 5.2B). The percentage of patients who had abandoned daily activities was followed over time. At baseline, more than half of the patients in the amoxicillin group and fewer than $40 \%$ in the roxithromycin group reported that they 
had abandoned daily activities. At day 10 , this percentage had fallen to less than $20 \%$ in both groups and to less than $10 \%$ in both groups at day 27 . Differences between the amoxicillin and roxithromycin groups were not significant.

Furthermore, the patients' diaries revealed information about the time of impaired daily activities. The percentage of patients with impaired daily activities gradually decreased in both treatment groups from approximately $75 \%$ at baseline to $30 \%$ at day 10 and $20 \%$ at day 27 .

-... Amoxicilin Raxithromycin

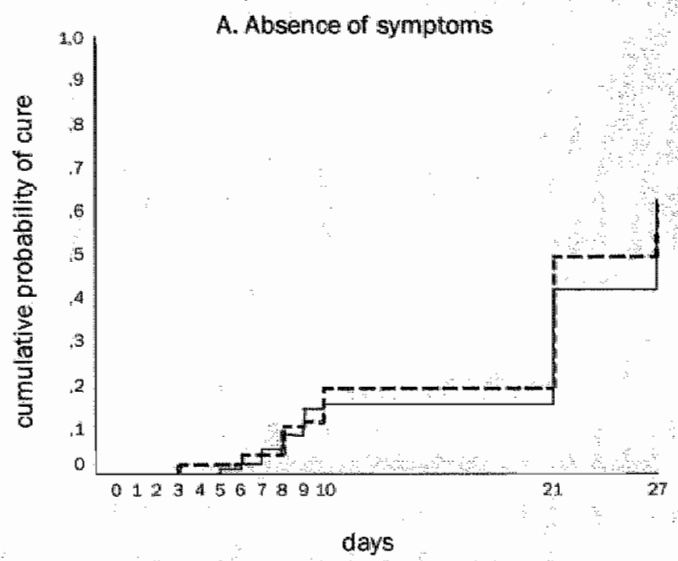

Owerall compartson of suminal experience using the Gehan statstic: $0.45(0 ; 0.50)$

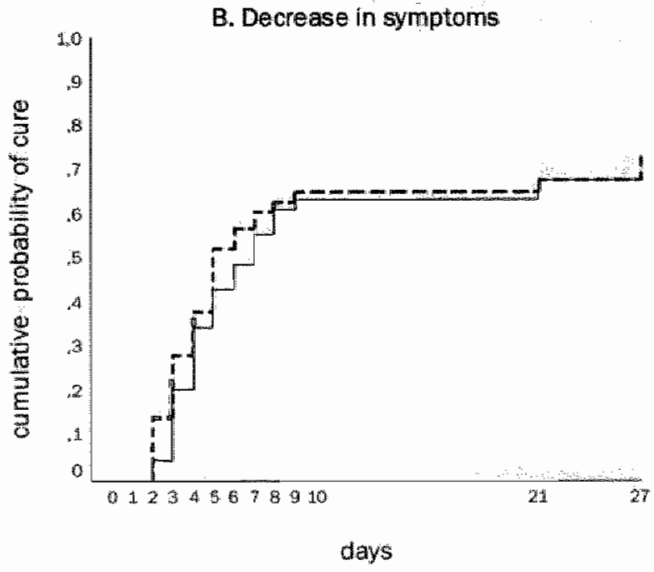

Overiall comparison of surviwal experimen using the Gehan statistic: $1.41(p)=0.24)$

Figure 5.2 Time to resolution of symptoms as described in patients' diaries. 


\section{Subgroup analyses}

The above analyses were repeated for a group of patients aged less than 65 years and a group aged 65 years and older. The trend in cure rates was the same. No differences were found between these age groups regarding the percentage of patlents with satisfactory clinical response. Furthermore, the same analyses were performed for each of the clinicall diagnoses made by the GPs at baseline (i.e., pneumonia, acute bronchitis, exacerbation of asthma or COPD, and unclassified LRTI). Overall, no significant differences were found between the amoxicillin and roxithromycin groups.

\section{Bacteriologic evaluation}

Pathogens were identified in 91 patients $(46 \%)$. Viruses were most frequent, followed by $H$ (para ) influenzae, S pneumoniae, and $M$ catarhalis (Table 5.4). Bacteriologic cure was achieved in 21 of the 23 patients (91\%) in the almoxicillin group and in 23 of the 27 patients $(85 \%)$ in the roxithromycin group (NS, Fisher's exact test). In nine patients of the amoxicillin group and eight patients of the roxithromycin group, only the sample obtained after 10 days showed the growth of a predominant bacterial pathogen (superinfection).

Table 5.4 Respiratory tract pathogens isolated

\begin{tabular}{|c|c|}
\hline 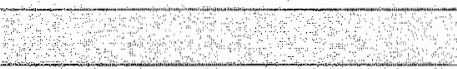 & $N(8)$ \\
\hline \multicolumn{2}{|l|}{ Typical Bacterial Pathogens } \\
\hline Haemophlus (para) influenzae & $34(17)$ \\
\hline Streptococcus pneumoniae & $12(6)$ \\
\hline Moraxella catarhalls & $6(3)$ \\
\hline Other & $5(3)$ \\
\hline \multicolumn{2}{|l|}{ Atypical Pathogens } \\
\hline Mycoplasma pneumoniae & $2(1)$ \\
\hline Legionella pneumophila & $1(0.5)$ \\
\hline \multicolumn{2}{|l|}{ Viruses } \\
\hline Mfluenza $\mathrm{A}$ & 29,161 \\
\hline Influenza $\mathrm{B}$ & $7(4)$ \\
\hline Parainfluenzae $1,2,3$ & $7(4)$ \\
\hline Adenovirus & $5(3)$ \\
\hline Respiratory syncyttal virus & $5(3)$ \\
\hline No organism (number of petients) & $105(54)$ \\
\hline
\end{tabular}

1. Enterobacteriaceae $(n=2)$. Staphylococcus aureus $(n=1)$. Streptococcus viridans $(n=1)$. Neisseria meningitialis $(n=1)$. 


\section{Safety and compliance}

Thirty possible or probable adverse events were reported in 19 of 99 patients $(19 \%)$ treated with amoxicillin: diarrhoea (13), stomach ache (3), headache (3), and 11 other side effects, including nausea, vomiting, and rash, once each. In the roxithromycin group, 24 events were reported in 16 patients (16\%): nausea (5), diarrhoea (4), vomiting (4), rash (2), headache (2), and seven others, including pruritus ani, dizziness, and mild bradycardia, once each.

Compliance with the medication regimen was high. Data from electronic monitoring were available for 160 patients (78 in the amoxicillin group, 82 in the roxithromycin group). The overall compliance rate for patients in both groups (i.e., the number of doses taken divided by the number of doses prescribed) was $98 \%$. In the amoxicillin group, the numbers of patients with less than $90 \%$ compliance in taking the tablets and capsules were seven and four, respectively. In the roxithromycin group, compliance in taking the tablets was at least $90 \%$ in all patients but compliance in taking the capsules was less than $90 \%$ in six patients.

\section{Discussion}

This community-based study shows that amoxicillin and roxithromycin are equally effective in the treatment of LRTI in the Netherlands. Clinical cure rates after 10 days of antibiotic treatment were approximately $90 \%$ in both study groups, although complete absence of symptoms was achieved in only a minority of cases. After 28 days of follow-up, cure rates remained high. The amoxicillin group had a significantly higher cure rate than the roxithromycin group as evidenced by the decrease in symptoms. However, this significant difference in favour of the amoxicillin group did not alter the GPS" overall conclusion after complete follow-up: that $90 \%$ of patients who received either drug had been effectively treated. Patients' diary entries agreed with that impression.

The time to resolution of symptoms, the cumulative cure rate per day, and the influence of the illness on daily activities were not significantly different between patients treated with amoxicillin versus those given roxithromycin. Adverse events were mild and were divided evenly over both groups with the exception of diarrhoea, which occurred more often in those taking amoxicillin.

In our study, complete absence of symptoms and signs after 28 days, as assessed by both physicians and patients, was achieved in only approximately half the patients. Complete remission of LRTI often takes more than four weeks.

Although LRT: is often managed in primary care, diagnostic and therapeutic decisions are usually based on the experiences of hospital-based specialists and on the results of trials conducted in hospital settings. Generalising these results to primary care is of limited value, since disease in patients recruited for these studies is often at a later stage and more serious. In our trial, patients were 
recruted, diagnosed, and treated by GPS in their natural setting, maintaining regular care as much as possible.

Nevertheless, generalisation of our findings to everyday care may not be valid. To explore the degree of selection in our recrutted patients, we compared the actual numbers of cases of LRTI in three practices (with a total of nine GPS and a total population of 13,269 ) with the numbers included in the present trial during one year of the inclusion period. Of the 463 presumably eligible patients, only $43(9 \%)$ were actually included. This proportion is similar to that in a recent study of randomised controlled trials in primary care in which less than $10 \%$ of the elligible population were recruited for the trial. ${ }^{3 i}$ Included patients did not differ from other eligible patients with regard to age, clinical diagnosis, severity of illness, and need for antibiotic treatment (according to the GPS).

Clinical studies, mostly in inpatient settings, on community-acquired pneumonia have identified causative pathogens in 50\% to $69 \%$ of patients. 14-17,21,23,32,33 Outpatient studies of acute bronchitis and LRTI have generally reported considerably lower percentages (16\% to 44\%).19,20,34-36 in our study, pathogens that presumably caused LRTI were found in $46 \%$ of patients.

Because atypical pathogens were the presumptive causative agent in only three cases (two $M$ pneumoniae, one $L$ pneumophila), the potential advantage of macrolide antibiotics over amoxicillin is minimal. Furthermore, bacteriall resistance to macrolide antibiotics is believed to be considerable. 37.38 in Finland, bacterial resistance to erythromycin has been shown to rise quickly after an increase in the consumption of macrolide antibiotics. 39 In contrast to alarming reports in the literature, $14,17,22,40,41$ the low incidence of $M$ pneumoniae and $L$ pneumophila found in the current study supports the conservative approach (i.e.. amoxicillin or doxycycline) to treating community-acquired LRTI in the Netherlands.

$M$ pneumoniae occurs at high rates in 4-year to 5 -year cycles. ${ }^{42}$ This timing implies that the frequency of $M$ pneumoniale might be higher if the same study were performed one year later. Because most $M$ pneumoniae infections are self-limiting and clinical cure rates of macrolide antibiotics compared with those of placebo are the same, ${ }^{43,44}$ however, this epidemiologic observation does not change the conclusions of the present study.

Compliance with medication was reliably measured and quantified by Medical Event Monitoring Systems. For both ethical and practical reasons, patients were informed about the monitoring mechanism. Their knowiedge about the monitoring may have slightly increased compliance as compared with daily practice, although this assumption has not been confirmed in other studies.45.46 Furthermore, compliance with antiblotic regimens is known to be greater than compliance with chronic medication regimens. 47,48 


\section{Conclusions}

General practitioners frequently diagnose LRTI in general or pneumonia and acute bronchitis in particular, including infectious episodes in patients with asthma or COPD. In many cases, treatment with antibiotics follows. The results of our randomised controlled trial did not confirm the potentially greater value of roxithromycin, which is often recommended as the drug of cholce for empirical treatment of community-acquired pneumonia, over amoxicillin. Because amoxicillin was as effective as roxithromycin, it remains a reliable first-choice antibiotic in the treatment of community-acquired LRTI. 


\section{References}

1. Bartett JG, Mundy LM. Community-acquired pneumonia. N Engl I Med. 1995;333: 161824.

2. Melbye $\mathrm{H}$, Straume $\mathrm{B}$, Aasebo U, Dale K. Diagnosis of pneumonia in aduits in general practice. Relative importance of typical symptoms and abnormal chest signs evaluated against a radiographic reference standard. Scand I Prim Health Care. 1992;10:226-33.

3. Melbye H, Straume B, Aasebo U, Brox J. The diagnosis of adult pneumonia in general practice. The diagnostic value of history "physical examination and some blood tests. Scand J Prim Health Care. 1988;6:111-7.

4. Wipf JE, Lipsky BA, Hirschmann JN, Boyko EJ, Takasugi J, Peugeot RL, Davis CL. Diagnosing pneumonia by physical examination - Relevant or relic? Arch Int Med. 1999; 159:1082-7.

5. Zaat JOM, Stalman WAB, Assendelft WJ. Hoort wie klopt daar? Een systematische literatuurstudie naar de waarde van anamnese en lichamelijk onderzoek bij verdenking op een pneumonie [Groaning, moaning and percussion. A systematic review on the diagnostic value of history and physical examination in patient with a suspicion of pneumonia]. Huisarts Wet. 1998;41:461-9.

6. Metlay JP, Kapoor WN, Fine MJ. Does this patient have community-acquired pneumonia? Diagnosing pneumonia by history and physical examination. JAMA. 1997; 278:1440-5.

7. Kuyvenhoven MM, Verheij TJ, de Melker RA, van der Velden J. Antimicrobial agents in lower respiratory tract infections in Dutch general practice. Br J Gen Pract. 2000;50: 133-4.

8. Macfarlane J, Lewis SA, Macfarlane R, Holmes W. Contemporary use of antibiotics in 1089 adults presenting with acute lower respiratory tract illness in general practice in the U.K.: implications for developing management guidelines. Respir Med. 1997;91: 427-34.

9. Oeffinger KC, Snell LM, Foster BM, Panico KG, Archer RK. Treatment of acute bronchitis in adults. A national survey of family physicians. J Fam Pract. 1998;46:469-75.

10. Ortqvist A. Antibiotic treatment of community-acquired pneumonia in clinical practice: a European perspective. J Antimicrob Chemother. 1995;35:205-12.

11. Janknegt $R$, Wijhands WJ, Stobberingh EE. Antibiotic policies in Dutch hospitals for the treatiment of pneumonia. J Antimicrob Chemother. 1994;34:431-42.

12. van der Werf GT, Smith RJA, Stewart RE, Meyboom-de Jong B. Spiegel op de huisarts: over registratie van ziekte, medicatie en verwijzingen in de geautomatiseerde huisartsenpraktijk. Groningen, Disciplinegroep Huisartsgeneeskunde, Rijksuniversiteit Groningen, 1998:1-181.

13. Stokx LU, Foets M. Het voorschrijven van geneesmiddelen in de huisartspraktijk. Deel II [Prescribing drugs in general practice]. Utrecht, NIVEL, 1994.

14. Marrie TJ, Peeling RW, Fine MJ, Singer DE, Coley CM, Kapoor WN. Ambulatory patients with community-acquired pneumonia: the frequency of atypical agents and clinical course Am J Med. 1996;101:508-15.

15. Berntsson $\mathbb{E}$, Lagergard $T$, Strannegard $O_{v}$ Trollfors $B$. Etiology of community-acquired pneumonia in out-patients. Eur J Clin Microbiol. 1986;5:446-7.

16. Bohte $\mathbb{R}$, van Furth $R$, van den Broek PJ. Aetiology of community-acquired pneumonia: a prospective study among adults requiring admission to hospital. Thorax. 1995;50: 543-7. 
17. Fang GD, Fine $M_{*}$ Orloff J, Arisumi $D_{v}$ Yu VL, Kapoor W, Grayston JT, Wang SP. Kohler $R$, Muder RR et al. Niew and emerging etiologies for community-acquired pneumonia with implications for therapy. A prospective multicenter studly of 359 cases. Medicine Baltimore. 1990;69:307-16.

18. Woodhead MA, Macfarlane JT, McCracken JS, Rose DH, Finch RG. Prospective study of the aetiology and outcome of pneumonia in the community. Lancet. 1987:1:671:4.

19. Jonsson JS, Sigurdsson JA, Kristinsson KG. Guthnadottir M, Magnusson S: Acute bronchitis in adults. How close do we come to its aetiology in general practice? Scand J Prim Health Care. 1997;15:156-60.

20. Macfarlane JT, Colville $A_{*}$ Guion $A$, Macfarlane RM, Rose DH. Prospective study of aetiology and outcome of adult lower-respiratory-tract infections in the community. Lancet. 1993;341:511-4.

21. Niederman MS, Bass JB, Jr., Campbell GD, Fein AM, Grossman RF, Mandell LA, Marrie TJ, Sarosi GA, Torres A, Yu VL. Guidelines for the initiall management of adults with community-acquired pneumonia: diagnosis, assessment of severity, and initial antimicrobial therapy. American Thoracic Society. Medical Section of the American Lung Association. Am Rev Respir Dis. 1993;148:1418-26.

22. Mandell LA, Niederman M. Antimicrobial treatment of community acquired pneumonia in adult: a conference report. Can IInfect Dis. 1993;4:25-8.

23. Marrie TJ. Community acquired pneumonia. Clin Infect Dis. 1994;18:501-15.

24. Poirier R. Comparative study of clarithromycin and roxithromycin in the treatment of community-acquired pneumonia. I Antimicrob Chemother. 1991;27:109-16.

25. Tilyard MW, Dovey SM. A randomized double-blind controlled trial of roxithromycin and cefaclor in the treatment of acute lower respiratory tract infections in general practice. Diagn Microbiol Infect Dis. 1992;15:S97-101.

26. Zeluff BJ, Lowe P, Koornhof HJ, Gentry LO: Evaluation of roxithromycin (RU-965) versus cephradine in pneumococcal pneumonia. Eur J Clin Microbiol Infect Dis. 1988;7:69-71.

27. Schonwald S, Barsic B Klinar I, Gunjaca M: Three-day azithromycin compared with tenday roxithromycin treatment of atypical pneumonia. Scand I Infect Dis. 1994;26: $706-10$.

28. Young RA, Gonzalez JP, Sorkin EM. Roxithromycin. A review of its antibacterial activity, pharmacokinetic properties and clinical efficacy. Drugs. 1989;37:8-41.

29. de Neeling AJ, Pelt van W. Hendrix MGR, Buiting AGM, Hal C, Ligtvoet EE, Petit PL, Sabbe LM, van Griethuysen AJA, Nohlmans-Paulssen MKE. Antibiotica resistentie in Nederland. Deel Ill: Gram-positieve bacteriën. Inf Bull. 1997;8:211.5.

30. Cramer JA, Mattson RH, Prevey ML, Scheyer RD, Ouellette VL. How often is medication taken as prescribed? A novel assessment technique. JAMA. 1989;261:3273-7.

31. Wilson $S$, Delaney $B C_{r}$ Roalfe $A$, Roberts $L_{r}$ Redman $V$, Wearn AM, Hobbs FD. Randomised controlled trials in primary care: case study. BMI. 2000;321:24-7.

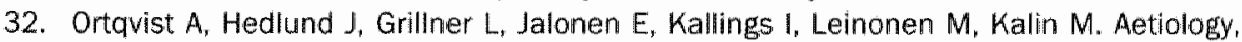
outcome and prognostic factors in community-acquired pneumonia requiring hospitalization. Eur Respir J. 1990;3:1105-13.

33. Ortqvist $A$, Valtonen $M$, Cars $O$, Wahl $M$, Saikku $P$, Jean $C$. Oral empiric treatment of community-acquired pneumonia. A multicenter, double-blind, randomized study comparing sparfloxacin with roxithromycim. The Scandinavian Sparfloxacin Study Group. Chest. 1996:110:1499-506.

34. Boldy DA, Skidmore SJ, Ayres JG. Acute bronchitis in the community: clinical features, infective factors, changes in pulmonary function and bronchial reactivity to histamine. Respir Med. 1990;84:377-85. 
35. Trigg $C J$, Wilks M, Herdman M. Clague JE, Tabachali $S$, Davies RJ. A double-blind comparison of the effects of cefaclor and amoxycilin on respiratory tract and oropharyngeal flora and clinical response in acute exacerbations of bronchitis. Respir Med. 1991;85:301-8.

36. Karalus NC, Garrett JE, Lang SD, Leng RA, Kostalas GN, Cursons RT, Cooper BC, Ryan C. Roxithromycin $150 \mathrm{mg}$ b.i.d. versus amoxycillin $500 \mathrm{mg} /$ clavulanic acid $125 \mathrm{mg}$ t.l.d. for the treatment of lower respiratory tract infections in general practice. Infection. $1995 ; 23: 515-20$.

37. Swartz MN. Use of antimicrobial agents and drug resistance. N Engl J Med. 1997;337: $491-2$

38. de Neeling AJ. Antibioticagebruik en het optreden var resistentie: Volksgezondheid Toekomst Verkenning 1997 l:de gezondheidstoestand: een actualisering, RIVM, 1997: $793-800$.

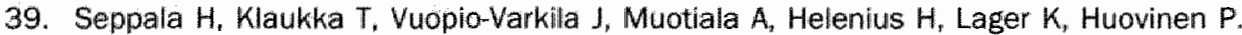
The effect of changes in the consumption of macrolide antibiotics on erythromycin resistance in group A streptococci in Finland. Finnish Study Group for Antimicrobial Resistance. N Engl J Med. 1997,337:441-6.

40. Wood MJ. More macrolides. BMJ. 1991;303:594-5.

41. Wort SJ, Rogers TR. Community acquired pneumonia in elderly people. Current British guidelines need revision. BMJ. 1998;316:1690.

42. Bartlett JB. Management of Respiratory tract infections. Baltimore, Williams\&Wilkins, 1997:1-117.

43. King DE, Williams $W C_{*}$ Bishop $L$, Shechter $A$. Effectiveness of erythromycin in the treatment of acute bronchitis. J Fam Pract. 1996;42:601-5.

44. Lode H, Garau J, Grassi $C$, Hosie J, Huchon $G$, Legakis $N$, Segev $S$, Wijnands G: Treatment of community-acquired pneumonia: a randomized comparison of sparfloxacin, amoxycillin-clavulanic acid and erythromycin. Eur Respir J. 1995;8: 1999-2007.

45. Urquhart J. Partial compllance in cardiovascular disease: risk implications. $\mathrm{Br} \rrbracket \mathrm{Clin}$ Pract Suppl: 1994:73:2-12.

46. Cramer JA, Ouelette VL, Mattson RH. Effect of microelectronic observation on compliance. Epilepsia. 1990;31:617-8.

47. Favre $O$, Delacretaz $E$, Badan M, Glauser M, Waeber B. Relationship between the prescriber's instructions and compliance with antibiotherapy in outpatients treated for an acute infectious disease. J Clin Pharmacol. 1997:37:175 8.

48. Urquhart J. Role of patient compliance in clinical pharmacokinetics. A review of recent research. Clin Pharmacokinet. 1994;27:202-15. 


\section{Chapter 6}

Do clinical findings in lower respiratory tract infection help general practitioners prescribe antibiotics appropriately? An observational cohort study in general practice

RM Hopstaken, CC Butler, JWM Muris, JA Knottnerus, ADM Kester, PELM Rinkens, GJ Dinant 


\section{Abstract}

\section{Objectives}

To directly assess the influence of general practitioners" history and examination findings on antibiotic prescribing for lower respiratory tract infection (LRT), and to explore the extent to which these clinical findings predict appropriate antibiotic prescribing.

\section{Patients and methods}

25 general practitioners (GP) in the Netherlands recruited during routine consultations 247 adult patients aged 1889 years with a clinical diagnosis of LRTI. The GPS, unaware of the study objectives and pesults of additional investigations, recorded clinical information. Odds ratios (OR) with $95 \%$ confidence intervals (Cl) for clinical variables predicting a prescription for an antibiotic were calculated. The relationship between antibiotic prescription and radiographic evidence of pneumonia was explored in order to gauge appropriateness of antibiotic prescribing.

\section{Results}

Auscultation abnormalities (OR 11.5; Cl 5.4-24.7), and diarnoea (OR>11) were strongly associated with antibiotic prescribing. An antibiotic was prescribed for $196(79 \%)$ patients. Assuming that an antibiotic definitely needs to be prescribed only for patients with pneumonia, antibiotics may have been inappropriately prescribed for $166 / 193(86 \%)$ of the patients. Antibiotics were not prescribed for 5 of the $32(16 \%)$ patients with a radiographic diagnosis of pneumonia.

\section{Conclusions}

Abnormal findings on auscultation in patients with LRTI strongly predict antibiotic prescribing and this is probably inappropriate for most patients. These results should prompt general practitioners to consider the extent to which finding 'crackles/rhonchi on auscultation' influences their decisions to prescribe antibiotics for their patients with LRTI, and to consider the predictive value of individual clinical signs in reaching evidence-based prescribing decisions. 


\section{Introduction}

Diagnosis for the vast majority of patients attending general practice with lower respiratory tract infection (LRTI) is based on history and clinical examination alone. General practitioners (GPs) often prescribe an antibiotic for these patients, and support their decision by recording abnormal findings on auscultation. However, the influence of GPS history and examination findings on antibiotic prescribing for LRTI has not been directly assessed, and the extent to which these clinical findings predict appropriate antibiotic prescribing is unknown. This gap in the evidence base is important because understanding the influence of clinical factors on antibiotic prescribing and identifying whether or not these factors influence prescribing appropriately, could lead to widespread changes in clinical decision making in the direction of more evidence-based antibiotic prescribing. This has wide potential impact: antibiotics are prescribed for about three quarters of patients with lower respiratory tract infections (LRTI): ${ }^{180 \%}$ of LRTI patients have acute bronchitis (incidence 24-46 per 1000 patients per year) and $20 \%$ have community-acquired pneumonia (incidence 5-11 per 1000 patients). ${ }^{2}$ Overprescribing continues despite growing evidence that acute bronchitis is self-limiting and rarely requires antibiotic treatment. Systematic reviews of randomised controlled trials of treatment for patients with acute bronchitis concluded that the possible modest beneficial effect is similar to the harm caused by antibiotic treatment. ${ }_{3} .4$ The studies included in these reviews recruited patients on the basis of clinical findings rather than etiologic agent, so findings are applicable to patients regardless of whether they are infected by a virus or bacterium. Antibiotic treatment is considered obligatory only for community-acquired pneumonia and may be clinically useful in more severe infectious exacerbations of chronic obstructive pulmonary disease (COPD). ${ }^{5}$ Few studies of antibiotic treatment in LRTI have been large enough to identify which subgroups of patients are more likely to benefit from antibiotic treatment.

Qualitative and questionnaire studies on respiratory tract infections ${ }^{6-8}$ revealled numerous factors that may contribute to inappropriate antibiotic prescribing. In order to gain insight in the actual diagnostic reasoning and therapeutic decision. making process, we therefore studied the influence of an array of clinical factors recorded in actual consultations on GPS decisions whether or not to prescribe an antibiotic in LRTI. We also explored whether or not these prescribing decisions were appropriate. 


\section{Methods}

\section{Patients}

Patlents aged 18 years and over were elligible if their GP made a diagnosis of LRTI and the patient had an acute (duration less than 29 days) or worsening cough. Additional inclusion criteria were the presence of at least one of the following four features: shortness of breath, wheezing, chest pain, auscultation abnormalities; and at least one of the following four: reported fever $\left(\geq 38^{\circ} \mathrm{C}\right)$, perspiring, headache, myalgia. Exclusions were pregnancy or lactation, history of hypersensitivity to penicillin or macrolide antibiotics, concomitant treatment with ergot alkaloids and/or terfenadine, severe disease requiring immediate hospitalisation, treatment with antibiotics within the preceding 14 days and hospital admission for a respiratory indication in the previous four weeks. Some of the exclusion criteria were relevant to a randomised clinical trial, which was run in parallel to the present study. ${ }^{g}$

\section{Procedures}

The 25 participating GPs performed and recorded a standardised medical history and physical examination on sequential, eligible consenting patients. GPs indicated their certainty of their clinical diagnosis (pneumonia or acute bronchitis) using a 5-point scale and their estimation of illness severity using a 4-point scale. Prescribing decisions and the reasons were then recorded. Those patients for who the GPs felt an antibiotic was indicated were entered into a randomised controlled trial comparing the efficacy of amoxicillin to that of a macrolide antibiotic (roxithromycin).9 All consenting patients were followed up in the same way, regardless of whether or not they were entered into the randomised trial aspect of this research program. Further management decisions were at the GPs" discretion. GPs were not informed of the aim underlying this aspect of the research, namely the identification of clinical influences on antibiotic prescribing. After the consultation, patients were asked to record their reasons for consulting their GP and whether or not, prior to the consultation, they had wanted a prescription for an antibiotic.

\section{Radiographic pneumonia}

Chest radiographs (lateral and pastero-anterior) were taken on the third day after recruitment.10 Two radiologists, blinded to all other information, independently assessed the radiographs for infiltrates. A third radiologist assessed the radiographs in the event of disagreement between the findings of the first two radiologists. The findings of this third assessment were considered final and accurate. Evidence of radiographic pulmonary infiltrates was regarded as evidence of pneumonia. 


\section{Statistical analysis}

The dichotomous outcomes of all recorded patient characteristics, symptoms and physical signs were compared with the dependent variable (antibiotic prescription yes or no) in two-by-two tables. Positive and negative predicted values (PVH. PV.) and diagnostic odds ratios (ORs) with $95 \%$ confidence intervals (Cl) were calculated.

To test the assumption that patients from the same GP are more allike in symptoms and signs than patients from different GPS the Intracluster Correlation Coefficient (ICC) was calculated. The independent contributions of the clinical items to predicting antibiotic prescribing was assessed using multiple logistic regression analysis, controlled for clustering at GP level (the random intercept model). To prevent excessive diagnostic variables being included for the available cases, three criteria had to be met before they were included in the analysis. First, each variable had to be present in at least ten patients. Second, each variable had to be positive in at least five patients who had an antibiotic prescribed. Third, the association of the variables with antibiotic prescription had to have a $p$-value $\leq 0.10\left(\chi^{2}\right.$ or Fisher's exact test). Backward elimination with $p>0.05$ was used to exclude variables in multiple logistic regression. Those variables remaining were considered as the most important clinical associations with antibiotic prescribing.

The univariate and multiple logistic regression analyses were repeated, but this time with the clinical diagnosis of pneumonia (yes or no) as the dependent variable. 'Absent pneumonia" represented the diagnosis of acute bronchitis.

Sensitivity, specificity, PV+, PV-, and OR with $\mathrm{Cl}$ were calculated from $2 \times 2$ tables, comparing antibiotic prescribing (yes or no) with the presence or absence of radiographic pneumonia.

\section{Results}

\section{Patients}

GPs recruited 247 LRTI patients with a mean age of 52 (range 18-89, 52\% female) years. History and physical examination data were not available for one patient. Chest radiography was not performed in three (two with and one without an antibiotic prescribed) of the remaining 246 patients. An antibiotic was prescribed for $195(79 \%)$ remaining patients. GPs did not prescribe an antibiotic for 51 patients because of mild symptoms $(n=33 ; 65 \%)$ and/or because a bacterial cause unlikely, was $(n=41 ; 80 \%)$. In 8 of these 41 patients $(20 \%)$ with 'bacterial infection unlikely', a bacterium was subsequently identified, which is slightly less than the remaining patients' average of $27 \%$.

When asked after the consultation, $34 \%$ of patients indicated that they had hoped, before the consultation, to receive a prescription for an antibiotic. GPS indicated 
that because of perceived patient pressure. they prescribed an antibiotic for $4 \%$ of patients for whom they felt an antibiotic was not indicated.

\section{Univariate analysis}

Table 6.1 shows the patients" wide range of respiratory and general symptoms and signs. Abnormal findings on auscultation were common (84\%). GPs prescribed antibiotics significantly less often to patients who had a dry cough, and more often to patients who had purulent sputum, moderate/severe illness, wheezing, and auscultation abnormalities. GPS prescribed an antibiotic to all patients with diarrhoea $(n=19)$, a high respiration rate $(>20 / \mathrm{min}, n=9)$ and crackles on auscultation $(n=50)$.

\section{Multilevel logistic regression analysis}

The features, dry cough, purulent sputum, moderate/severe illness, wheezing, and auscultation abnormalities were supplemented with clinical items not significantly correlated, but with $p<0.10$ on univariate analysis (male sex, thoracic pain, myalgia, vomiting, COPD and upper respiratory tract signs). These items were then selected for multiple logistic regression analysis, controlled for clustering at GP level, to assess the independent contribution of the variables on the decision whether or not to prescribe an antibiotic (Table 6.2). The ICC in this analysis was 0.44 . Although possibly of significance, high respiration rate $(>20 / \mathrm{min})$ was not selected for the analysis because of the low number of patients with this feature $(n=9)$. The variable 'auscultation abnormalities' was a strong predictor of antibiotic prescribing. The variable included bronchial breathing, crackles and rhonchi and was included in the regression analysis rather than the individual sub-items as it had a higher OR in univariate analysis. Patients with the sub-item 'crackles' and patients with diarhoea all received a prescription for an antibiotic and were therefore the strongest predictors of antibiotic prescribing. Because all patients with these features were prescribed antibiotics, the ORs of these variables could not be calculated exactly for methodological reasons, so were approximated by adding 0.5 to every cell of the $2 \times 2$ tables. The estimated OR was 35.7 for crackles and 1.1.4 for diarrhoea. The true OR will be higher than these estimated ORs. Vomiting also predicted prescribing an antibiotic, while the presence of chest pain predicted management without an antibiotic prescription. 
Table 6.1 Univariate comparison of age, symptoms and signs with Gist decision whether or not to prescribe an antibiotic in 246 patients with LRTI.

\begin{tabular}{|c|c|c|c|c|c|}
\hline & & & Antibiotic prescrip & $V=195 / 2$ & 9.3) \\
\hline & $\mathrm{N}$ & \% & $\mathrm{on} \mathrm{CH}$ & PVt $(\%)$ & PV (8) \\
\hline 1840 years & 60 & 24.4 & $0.7(0.4-1.4)$ & 75.0 & 19.4 \\
\hline 40,65 years & 115 & 467 & $12(0.6-22)$ & 809 & 221 \\
\hline 65 years or older & 71 & 289 & $1 \times(05-2,2)$ & 803 & 211 \\
\hline Male1 & 117 & 47.6 & $17(09-3)$ & 83.8 & 24.8 \\
\hline Recent cough 2 days & 11 & 4.5 & $12(0,2-5,6)$ & 818 & 20.8 \\
\hline Coughexacerbat on $\leq 2$ days & 35 & 233 & $1.6(0.6-4.5)$ & 857 & 209 \\
\hline Dr cought & 58 & 23.6 & $0.4(0.2,0.7)^{\circ}$ & 65.5 & 165 \\
\hline Purdent spintum, & 135 & 54.9 & $20(1,-3.8)$ & 844 & 270 \\
\hline Haemoptos & 14 & 5.7 & $16(0.3-7.4)$ & 857 & 24 \\
\hline Dysproea & 191 & 77.6 & $1.4(0,7-2,9)$ & 80.6 & 25,5 \\
\hline Thoracie paint & 147 & 59.8 & $0.6(0.3-11)$ & 756 & 152 \\
\hline Fever & 85 & 346 & $12(0,6,2,3)$ & 812 & 217 \\
\hline Perspiting & 184 & 74.8 & $0.8(0.4-1.6)$ & 783 & 172 \\
\hline Myalgia t & 151 & 614 & $0.5(03-1.0)$ & 75.5 & 14,2 \\
\hline Chills & 124 & 504 & $0.7(0.3-12)$ & 758 & 172 \\
\hline Headache & 153 & 62.2 & $0.9(0.5-1.7)$ & 78.4 & 10.4 \\
\hline Confusion & 8 & 3.3 & $0.4(0.1-1.8)$ & 625 & 20.2 \\
\hline Upper respiliatory tract symptoms & 168 & 68.3 & $0.8(0.4-15)$ & 78.0 & 179 \\
\hline Nausea & 39 & 159 & $15(0.6-399$ & 84.6 & 21, \\
\hline Vomiting' & 28 & 11.4 & $3.8(0.9-16.4)$ & 929 & 22.5 \\
\hline Dlarrhoea! & 19 & 7,7 & Pै। & 100 & 22.5 \\
\hline Stomach ache & 9 & 3,7 & $21103-17,5)$ & 889 & 211 \\
\hline Current smoking & 83 & 33.7 & $0.7(0.41 .4)$ & 759 & 19.0 \\
\hline Smoking past or present & 153 & 62.2 & $13(0,7-25)$ & 81.0 & 23,7 \\
\hline Commorbldity asthma & 48 & 195 & $1.4(0.6-3.2)$ & 833 & 217 \\
\hline$P(4+$ COPDI & 32 & 13.0 & $2.8(0.8-9.6)$ & 90.6 & 22.4 \\
\hline $44+$ Geart fallure & 8 & 3,3 & $1.9(0.2-15.5)$ & 87.5 & 210 \\
\hline $\begin{array}{l}\text { General impression: } \\
\text { noderate/seveire Illness }\end{array}$ & 65 & 26.4 & $27(4)=6.3)$ & 892 & 243 \\
\hline Upper respifatory tract signsi: & 136 & 55.3 & $0.5(0.3-1.0)$ & 750 & 15.5 \\
\hline Respliation rate $>20 / \mathrm{mins}^{3}$ & 9 & 37 & & 100 & 245 \\
\hline Wheezing & 105 & 427 & $3.4(1,6-7.0) 1$ & 895 & 28.4 \\
\hline Percussion dulliess & 11 & 4.5 & $12(02-57)$ & 818 & 20.9 \\
\hline Auscuitation abnormality & 206 & 83.7 & $115(5.4-24.7)$ & 874 & 62.5 \\
\hline bronohial breathing: & 66 & 26.4 & $33(1,3-80)$ & 90,6 & 249 \\
\hline crackles ${ }^{\prime}$ & 50 & 203 & Hets? & 100 & 26.0 \\
\hline nhonenil & 154 & 62.6 & $380.9772)$ & 877 & 34.8 \\
\hline Body lemperature $\geq 38^{\circ} \mathrm{C}$ & 58 & 23.6 & $12(0.5-2.4)$ & 81.0 & $21: 3$ \\
\hline Cinical diagnosis of preunonia & 21 & 85 & rా & 100 & 227 \\
\hline
\end{tabular}

"Variable with $p<0.10$ selected for multiple logistic regression analysis; 2 Measured less than 24 hours ago: 3 Not selected for multiple logistic regression analysis because of low number of cases $1<10$ patients with characteristic): " Statistically significant $(p<0.05)$;

$\mathrm{PV}+=$ positive predictive value; $\mathrm{PV}-=$ negative predictive value; $\mathrm{OR}=0 \mathrm{dds}$ ratio; $\mathrm{Cl}=95 \%$ confidence

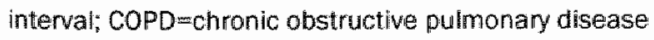


Table 6.2 Multiple logistic regression analysis, controlled for clustering at GP level. Odds ratios (OR) and $95 \%$ confidence intervals (C) for factors from history and physical examination that were statistlcally significantly assoclated, on univariate analysis, with general practitioners" antibiotic prescribing decision for $227^{\circ}$ patients with LRTI.

\begin{tabular}{|c|c|c|}
\hline \multirow{2}{*}{ Gilical iems } & \multicolumn{2}{|c|}{ Antibiotic us no antibiotie } \\
\hline & OR & +4 \\
\hline \multicolumn{3}{|l|}{ History } \\
\hline Chest pain & 0.3 & $01-09$ \\
\hline Vomiting & 296 & $22-3931$ \\
\hline Sex male & ins & \\
\hline Dry cough & ns & \\
\hline Sputum purulence & ns & \\
\hline Myalgia & ns & \\
\hline $\mathrm{COPD}+4$ & ns. & \\
\hline Physical examination & & \\
\hline Auscultation abnormalities & 28,8 & $6.3-1325$ \\
\hline General impression moderate/severe IIness & ns & \\
\hline Wheezing & ns & \\
\hline Upper respiratony tract signs & ns & \\
\hline
\end{tabular}

t patients with diarrhoea were not included because all patients with this clinical item were prescribed antibiotics, which precluded odlds ratios to be calculated; COPD $=$ chronic obstructive pulmonary disease; ns=non-significant test result

A clinical diagnosis of pneumonia was made in 21 of the 246 patients $(8.5 \%)^{11}$ GPs were at least moderately certain of this diagnosis in 20 (95\%) cases and judged $14(67 \%)$ as at least moderately severe (Table 6.3).

Table 6.3 Chinical diagnoses of pneumonia and acute bronchitis in 246 LRTI patients: GPS' estimation of their diagnostic certainty and the illness severity.

\begin{tabular}{|c|c|c|c|}
\hline & 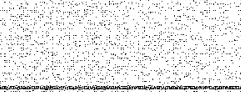 & $\begin{array}{l}\text { Preumonia } \\
\mathrm{N}=21(\% 1)\end{array}$ & $\begin{array}{c}\text { Acute branchitis } \\
N=225\left(\%^{1}\right)\end{array}$ \\
\hline \multirow[t]{5}{*}{ Clinical dagnosis } & verycentain & $4(19)$ & $24(11)$ \\
\hline & certain & $7(33)$ & $61(27)$ \\
\hline & pretty certain & $9(43)$ & $114(51)$ \\
\hline & uncertain & $1(5)$ & $21(9)$ \\
\hline & very uncertain & 010 & $5(2)$ \\
\hline \multirow[t]{4}{*}{ Ulness } & very severe & $0(0)$ & $0(0)$ \\
\hline & severe & $3(14)$ & $11(5)$ \\
\hline & moderately severe & $11 .(52)$ & $157(70)$ \\
\hline & mild & $7(33)$ & $57(25)$ \\
\hline
\end{tabular}

"column percentages per characteristic 
The finding of crackles and duliness to percussion were statistically significant predictors of a clinical diagnosis of pneumonia (Table 6.4). Auscultation abnormalities were present in all patients with a clinical diagnosis of preumonia. Productive cough was a clinical predictor of the diagnosis of acute bronchitis.

Table 6.4 Multiple logistic regression analysis odis ratios (OR) and $95 \%$ confidence interwals (C) for factors from history and physical examination that were statistically significant associated. on univariate analysis, with general practitioners' clinical diagnosis of pheumonia among a group of 246 patients with LRTI.

Clincal diagnosis of pneumonia ys, acute bronchitis

OR

Gl

History

Productive cough

01

000.4

chest pain

ns

Wheezing

ns

Perspiring

ns

Upper respiratory tract symptoms

ns

Phystcalexamination

crackles

41.0

95177,3

Percussion dulliness

341

39297,

ns=non-significant test result

\section{Appropriateness of the antibiotic prescriptions}

Lateral and postero-anterior chest radiographs were available in 243 patients, of whom 193 received an antibiotic. Radiographic pneumonia was diagnosed in 32 (13\%) patients. Based on the assumption that an antibiotic should definitely be prescribed only for patients with pneumonia, the appropriateness of the antibiotic was tested in a two-by-two table. We found that $166 / 193(86 \%)$ of the antibiotics were inappropriately prescribed according to this criterion (Figure 6.1).

Based on a less conservative assumption that both pneumonia patients and patients with co-morbidity of COPD needed to be prescribed an antiblotic, still $140 / 193(73 \%)$ of the antibiotics were inappropriately prescribed. An antibiotic was not prescribed in 5 of the $32(16 \%)$ patients with radiographic signs of pneumonia. An antibiotic was eventually prescribed in one of these 5 patients who reconsulted five days later. 


\begin{tabular}{|c|c|c|c|c|c|c|}
\hline & Pneumonla & No pneumonia & Total & Sensitivity & $27 / 32$ & $84.4 \%$ \\
\hline Antibiotic: & 27 & 166 & 193. & spedificity & $45 / 211$ & $213 \%$ \\
\hline & & & & Positive oredicted value & $27 / 193$ & $14,0 \%$ \\
\hline No antibiotic & 5 & 45 & & $\begin{array}{l}\text { Negative predicted value } \\
\text { Oddls ratio }\end{array}$ & $\begin{array}{l}45 / 50 \\
1.5 / 010\end{array}$ & \\
\hline Total: & 32 & 211 & 243 & & & \\
\hline
\end{tabular}

Figure 6.1 Sensitivity, specificity, positive predictive value, negative predictive value and odds ratio and $95 \%$ confidence interval of a prescription for an antibiotic predicting the presence of radiographic evidence of pneumonia in 243 LRTI patients.

\section{Discussion}

\section{Summary of main findings}

Auscultation abnormalities, especially crackles, and diarrhoea were the strongest predictors for GPs to prescribe an antibiotic. Abnormal findings on auscultation were strongly associated with unnecessary antibiotic prescribing. GPS prescribed an antibiotic for $79 \%$ of the patients with LRTI. Assuming that antibiotics should be prescribed only for patients with pneumonia and not for other cases of LRTI, antibiotics may have been prescribed inappropriately to $86 \%$ of the patients included in this study. These findings are important because acute respiratory tract infection is the commonest reason for patients to consult and for antibiotics to be prescribed. ${ }^{2.12}$ About $75 \%$ of all outpatient antibiotic prescriptions are for respiratory tract infections. ${ }^{13}$ Systematic reviews of therapeutic trials demonstrate that possible benefits of antibiotic treatment do not outweigh the disadvantages for most people with respiratory tract infections, regardless of whether the infecting agent is a virus or bacterium..$^{3,14}$ Unnecessary antibiotic use is assaciated with antimicrobial resistance, wastes resources and impacts negatively on help seeking behaviour. ${ }^{15.16}$ The Netherlands has the lowest antibiotic prescribing rate in Europe. ${ }^{17}$ Nevertheless, antibiotics are overprescribed and the unjustified prescription of broad-spectrum antibiotics including quinolones and second and third generation cephalosporins is rising. ${ }^{18}$ The greater understanding that this study has generated may prompt GPs to consider the clinical influences on their prescribing decisions.

\section{Strength and limitations of the study}

Adult patients with a wide range of lower respiratory tract symptoms were opportunistically recruited, diagnosed and treated by GPs in this pragmatic study. The sample included patients with acute bronchitis and pneumonia. Various 
symptoms and signs, like crackles and bronchial breathing on auscultation, are traditionally believed to be associated with pneumonia, but are also commonly observed in acute bronchitis. The presence of these signs in our study population was statistically not different from the patients with pneumonia and those with acute bronchitis. ${ }^{11}$ This sample is therefore likely to represent a group of patients in which there is diagnostic uncertainty and for whom there is a dilemma about antibiotic prescribing. The independent contribution of individual symptoms and signs to an often finely balanced and implicit prescribing decision was evaluated. Previous studies on the influences on prescribing have largely used either qualitative interview and/or questionnaire based methods that assessed GPS' perceptions of their management of mild respiratory tract infections. The GPS in the present study were unaware that this research would examine factors influencing prescribing, and the study involved direct assessments of these factors and prescribing decisions.

The decision to prescribe an antibiotic to the patient was left at the discretion of the GP, as in daily general practice. If an antibiotic was prescribed the patient entered into a randomised controlled trial. There were no advantages (diagnostically, mor financially, nor time) for the GPs and the patients to believe that this decision was made on other than medical grounds. The rate of antibiotic prescribing $(79 \%)$ in the present study was the same as in an epidemiological survey describing the prescription of antimicrobial agents in cases of LRTI in Dutch generall practice, 19 which supports our interpretation.

The high rate of antibiotic prescribing left a relatively small group of patients who did not receive a prescription for an antibiotic. Our restrictions for entering variables into the logistic regression analyses resulted in a satisfactory number of diagnostic variables. However, in the secondary diagnostic analyses of clinical features for diagnosing pneumonia, an even greater reduction of variables would have been better from a statistical point of view, given the small number of patients with clinically diagnosed pneumonia.

There is no internationally agreed definition of LRTI. We derived our definition from ane used in a previous study. ${ }^{20}$ Our wide, pragmatic inclusion criteria meant that patients with a range of aetiology and severity were included. Our focus was those patients GPS suspected of having a LRTI. As the main exclusions were for pregnancy and lactation, this is unlikely to have biased our sample.

Generalisation of our findings to everyday care may not be valid. To explore possible selection bias, we compared the actual numbers of patients presenting with LRTI in three practices (with a total of nine GPS and a combined patient list of 13,269) with the numbers included from those practices in the present study during one year of the recruitment periad. Of the 463 potentially eligible patients, 43. (9\%) were actually recruited. This proportion is not unusual for studies in primary care. ${ }^{21}$ Recruited patients did not differ from eligible patients who were not 
recruited with regard to age, clinical diagnosis, severity of illness, and GPS assessment of need for antibiotic treatment.

GPS in everyday practice may sometimes record diagnoses and clinical findings only after having made a decision to prescribe an antibiotic. ${ }^{7.22}$ Thus, recording: history and examination findings can be done selectively in order to justify a diagnosis that warrants antibiatic treatment. This may have occurred in the present study. However, the diagnosis of pneumonia, which would uncontroversially justify antibiotic prescription, was made at a rate no more frequent than expected. ${ }^{2}$

\section{Comparison with other studies}

Despite being set in the country with the overall lowest antibiotic prescribing rate in Europe, antiblotic prescribing in this study was high $(79 \%)$, and comparable to previous UK (72-76\%)1,23 and Europe-wide studies (83\%). ${ }^{24}$ This relatively high prescribing may have been because patients in this study presented with more severe illnesses and had a higher percentage of abnormal findings on auscultation $(84 \%)$ than in previous studies $\left(25 \%,{ }^{1}\right.$ and $\left.32 \%{ }^{23}\right)$. This may reflect both a high threshold for diagnosing LRTI among Dutch GPs and a high threshold for consulting. among Dutch patients with common infectious syndromes. GPs almost always prescribed antibiotics when crackles and bronchial breathing were found on auscultation. These findings are commonly associated with pneumonia. However, evidence is emerging that these signs are neither discriminative ${ }^{11,25}$ nor sufficient (crackles) to either rule in or rule out pneumonia in community settings. 26 The finding of rhonchi on auscultation - an acknowledged sign of acute bronchitis - was also commonly associated with a prescription for an antibiotic, despite the evidence that antibiotic treatment is not indicated for most cases of acute bronchitis. 3,4 GPs tended to prescribe an antibiotic to almost all patients with positive findings on auscultation. This was also the case in a study in which auscultation abnormalities were infrequently present. ${ }^{1}$. Antibiotics were prescribed for $80 \%$ of patients for whom GPs were unsure about the diagnosis and for $74 \%$ of patients for whom they were sure of the diagnosis. Non-clinical reasons like time and patient pressure are additional influences on GPs to prescribe an antibiotic, but these factors were not assessed in this study.

We previously showed that dry cough is one of the clinical predictors of radiographic pneumonia. $\$ 1$ In the present analysis, dry cough was associated with a clinical diagnosis of pneumonia. However, GPs prescribed an antibiotic less often if a dry cough was present (Table 6.1). All patients reporting a history of diarrhoea $(\mathrm{n}=19)$ received a prescription for antibiotics. Although an infrequent symptom, a history of diarrhoea statistically significantly predicted radiographic pneumonia in our previous study.11 Diarrhoea may well be a hitherto un-described symptom of 'serious" illmess for whilch GPS have developed "a sixth sense' which was expressed in the prescription of an antibiotic. To our knowledge, diarrhoea has never previously been considered as a diagnostic variable in studies on LRTI. 
GPS were confident in their clinical diagnosis of pneumonia $95 \%$ of the time. However, the predictive value of the clinical diagnosis of pneumonia, as previously: described, 11 turned out to be poor: radiographic evidence of pneumonia was found in only 4 of the 21 patients with a clinical diagnosis of pneumonia (PV+19\%, prior probability of pneumonia $13 \%)$, and 28 of the $32(87 \%)$ cases of radiographic pneumonia were diagnosed as acute bronchitis by the GPs. The discrepancy between the GPS' confidences in their diagnosis compared with radiographically confirmed diagnoses is striking. Our secondary analysis of clinical reasons for diagnosing pneumonia suggests that this confidence is based on a belief in the diagnostic accuracy of finding crackles on auscultation and dullness to percussion.

\section{Conclusion}

Abnormal findings on auscultation, identified as possibly relevant in previous quallitative and questionnaire studies, were an important clinical reason for GPS to prescribe antibiotics in this practice-based, diagnostic study that explored the relationship between actual clinical findings (as opposed to general recall and perception) and actual antibiotic prescribing. The influence of abnormall auscultation appears to be over-estimated and is associated with inappropriate antibiotic prescribing. GPS appeared overmconfident in their diagnosis of pneumonia. In addition, we confirmed that GPs overprescribe antibiotics for LRTI, and that more patients were prescribed an antibiotic than wished to receive one. This study provides better insight in the clinical factors associated with GPs' decisions to prescribe an antibiatic for patients with LRTI. This clearer insight is an essential precondition for developing successful, future strategies to reduce antibiotic prescribing. These results should prompt GPs to consider the extent to which finding 'crackles/rhanchi on auscultation' influences their decisions to prescribe antibiotics for patients with LRTI, and to consider the predictive value of individual clinical signs in reaching evidence-based prescribing decisions. 


\section{References}

1. Holmes WF Macfarlane JT, Macfarlane RM, Hubbard R. Symptoms, signs, and prescribing for acute lower respiratory tract illness. Br J Gen Pract 2001;51:177-81.

2. Okkes IM, Oskam $S K$, Lamberts $H$. Wan Klacht naar diagnose: episodegegevens uit de huisartspraktijk. [From complaint to diagnosis: Disease episodes in general practice]. Bussum: Couthino, 1998.

3. Smucny J Fahey T, Becker $\mathbb{L}$, Glazier R. Antibiotics for acute bronchitis (Cochrane review). The Cochrane Library. Issue 1, 2004. Chichester, UK: John Wiley \& Sons, Ltd., 2004.

4. Fahey T, Stocks $N$, Thomas $T$. Quantitative systematic review of randomised controlled trials comparing antibiotic with placebo for acute cough in adults. BMJ 1998;316:90610.

5. The COPD Guidelines Group of the Standards of Care Committee of the BTS. BTS guidelines for the management of chronic obstructive pulmonary disease. 1997;52 S5:\$128.

6. Butller CC, Rollnick S, Pil R, Maggs Rapport F, Stott N. Undlerstanding the culture of prescribing: qualitative study of general practitioners' and patients' perceptions of antibiotics for sore throats. BMJ 1998;317:637-42.

7. Coenen S, Van Royen P, Vermeire E, Hermann I, Denekens J. Antibiotics for coughing in general practice: a qualitative decision analysis. Fam Pract 2000;17:380-5.

8. Macfarlane J, Holmes W, Macfarlane R, Britten N. Influence of patients' expectations on antibiotic management of acute lower respiratory tract illness in general practice: questionnaire study. BMJ 1997;315:1211-4.

9. Hopstaken RM, Nelemans P, Stobberingh EE, Muris JWM, Rinkens PELM, Dinant GJ. Is roxithromycin better than amoxicillin in the treatment of acute lower respiratory tract infections in primary care? A doulble-blind randomized controlled trial. J Fam Pract 2002:51:329-36.

10. Bartlett $J G$, Mundy LM. Community acquired pneumonia. N Engl J Med 1995;333: 1618-24.

11. Hopstaken RM, Muris JWM, Knottnerus JA, Kester ADM, Rinkens PELM, Dinant G. Contributions of symptoms, signs, enthrocyte sedinentation rate and Coreactive protein to a diagnosis of pneumonia in acute lower respiratory tract infection. $\mathrm{Br} J \mathrm{Gen}$ Pract 2003:53:358-64.

12. Offlce of Population Censuses and Surveys. Morbidity statistics from general practice: 4th National Study 1991-1992 Series MB5, 3. London: HMSO, 1995.

13. Gonzales R, Bartlett JG, Besser RE, Cooper RJ, Hickner JM, Hoffman JR, et al. Principles of appropriate antibiotic use for treatment of acute respiratory tract infections in adults: background, specific aims, and methods. Ann Intern Med 2001;134:479-86.

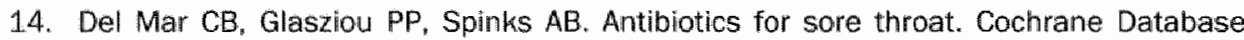
Syst Rev 2000(2):Cd000023.

15. Swartz MN. Use of antimicrobial agents and drug resistance. $N$ Engl J Med 1997;337: $491-2$.

16. Butler $\mathrm{CC}_{\mathrm{n}}$, Rollnick $\mathrm{S}$, Kinnersley $\mathrm{P}$, Jones $\mathrm{A}$, Stott $\mathrm{N}$. Reducing antibiotics for respiratory tract symptoms in primary care: consolidating 'why' and considering 'how'. Br J Gen Pract 1998:48:1865*70.

17. Cars O, Molstad S, Melander A. Variation in antibiotic use in the European Union. Lancet 2001;357:1851-3.

18. Kuyvenhoven MM, Van Balen FA, Verheij TJ. Outpatient antibiotic prescriptions from 1992 to 2001 in The Netherlands. A Antimicrob Chemother 2003;52:675-8. 


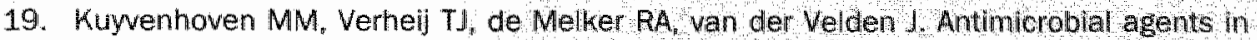
lower respiratory tract infections in Dutch general practice. Br I Gen Pract 2000;50: $133-4$.

20. Macfarlane IT, Colville A, Guion A, Mactarlane RM, Rose DH. Prospective study of aetiology and outcome of adult lower-respiratory-tract infections in the community. Lancet $1993 ; 341: 5114$.

21. Wilson $S$, Delaney $B C$, Roalfe A, Roberts L, Redman V, Wearn AM, et al Randomised controlled trials in primary care: case study BMJ 2000;321:247.

22. Vinson DC, Lutz $U$. The effect of parental expectations on treatment of children with a cough: a report from ASPN. J Fam Pract 1993,37,23-7.

23. Macfarlane JT, Holmes WF, Macfarlane RM. Recuicing reconsultations for acute lower respiratory tract iliness with an information leaflet: a randomized controlled study of patients in primary care. Br J Gen Pract 1997\%47:719-22.

24. Huchon G., Gialdroni Grassi G, Leophonte P, Manresa F, Schaberg T, Woodhead M. Initial antibiotic therapy for lower respiratory tract infection in the community: a European survey. Eur Respir J 1996;9:1590-5.

25. Melbye $H$. Straume $B$, Aasebo U, Dale $K$. Diagnosis of pneumonia in adults in general practice. Relative importance of typical symptoms and abnormal chest signs evaluated against a radiographic reference standard. Scand J Prim Health Care 1992;10:226-33.

26. Heckerling PS, Tape TG, Wigton RS, Hissong KK, Leikin JB, Ornato JP, et al. Clinical prediction rule for pulmonary infiltrates. Ann Intern Med 1990;113:664-70. 


\section{Chapter 7}

Prognostic factors and clinical outcome in acute lower respiratory tract infections; a prospective study in general practice

RM Hopstaken, S Coenen, CC Butler, P Nelemans, JWM Muris, PELM Rinkens, ADM Kester, GJ Dinant

Submitted for publication 


\section{Abstract}

\section{Backgrounds}

Unrealistic expectations about illness duration are likely to result in reconsultations and associated unnecessary antibiotic presicriptions. An evidence-based account of clinical outcomes in patients with LRTI may help avoid unnecessary antibiotic prescriptions and reconsultations.

\section{Objectives}

We aimed to identify clinical factors that may predict a prolonged clinical course or poor outcome for patients with LRTI and to provide evidence-based account of duration of a LRTI and the impact of the iliness on daily activities in patients consulting in general practice.

\section{Methods}

A prospective cohort study of 247 adult patients with a clinical diagnosis of LRTI presenting to twenty-five general practitioners (GP) in the Netherlands was carried out. Clinical data and infection parameters were collected at baseline. Multivariable Cox regression analysis was used to identify the clinical items that predicted the time taken for symptoms to resolve. Symptom resolution and the proportion of patients whose symptoms still affected their usual daily activities were calculated for the days $\mathbb{1}-10,21$, and 27 . Kaplan-Maier curves were used to analyse time to symptom resolution. Clinical cure was recorded by the GPs at 28 days after the initial consultation, and by the patients at 27 days.

\section{Results}

Comorbidity of asthma was a statistically significant predictor of delayed symptom resolution, whereas the presence of fever, perspiring, and the prescription of an antibiotic weakly predicted enhanced symptom resolution. The GPS considered $89 \%$ of the patients clinically cured at 28 days, but $43 \%$ of these nevertheless reported ongoing symptoms. Patient-reported cure was much lower ( $51 \%$ ), and usual daily activities were limited in $73 \%$ of the patients at baseline, and $19 \%$ at final follow-up. Five patients with pneumonia not prescribed an antibiotic at the initial assessment recovered without specific treatment.

\section{Conclusions}

The course of LRTI was generally uncomplicated, but the morbidity of this illness was considerable with a longer duration than generally reported especially for patients with asthma. Antibiotic treatment enhanced symptom resolution in the patients with pneumania. but not in other LRTI patients. Although the GPs considered most patients cured at 28 days. considerable numbers of patients had ongoing symptoms and/or limited usual dally activities, thus focussing attention once again on the importance of enhancing GPS" communication skills within the consultation and providing GPS with an evidence-based account of outcomes to share with patients in order to set realistic expectations. 


\section{Introduction}

Most acute lower respiratory tract infections (LRTIs) in adults are managed within primary care and are self-limiting. 1,2 However, LRTI is a broad diagnostic category and important numbers of these patients will have evidence of pneumonia and/or infection with certain organisms that may put them at higher risk for a prolonged clinical course or poorer outcome. Studies have generally failed to identify robust clinical tools for predicting outcomes in patients consulting in general practice with LRTI. Accurate identification of higher risk patients may allow for the earlier and more appropriate interventions. Similarly, a clinical tool that was able to accurately identify low risk patients could help avoid unnecessary antibiotic prescriptions and reconsultations. We studied a cohort of adult patients with LRTI recruited in general practice and identified clinical factors that helped predict pneumonia. ${ }^{3}$ However, we could not identify any clinical factors that helped predict bacterial and viral infections. In addition, routine chest radiography was not an effective tool for identifying individual patients with pneumonia in routine general practice settings. ${ }^{4}$ These analyses were, in effect, attempts to use clinical assessment variables to identify surrogate markers among LRTI patients at higher risk of a poor prognosis. However, the most important clinical question is not which features predict diagnoses of pneumonia or microbiological evidence of bacterial infection. Busy clinicians would be helped most by a tool that could accurately differentiate a subgroup of patients who are likelly to have a prolonged clinical course from those at low risk. Such a tool would help clinicians target additional interventions, including setting realistic expectations about recovery times. Two-thirds of the patients initially treated with an antibiotic who reconsult receive another antibiotic, despite the lack of evidence of infection. 5

Previous studies have found associations between diagnostic uncertainty, overestimated value of abnormal auscultation, and various non=medical factors like time and patient pressure, patient expectations, and perceived patient expectations, with antibiotic overprescribing. ${ }^{3,6-9}$ An additional potential explanation for unnecessary antibiotic prescribing in LRTI may be a general underestimation of the duration of LRTI. ${ }^{10}$ Clinicians underestimate the duration of cough in children. ${ }^{11}$ The aim of the present study was therefore two-fold. Firstly, we planned to conduct an analysis of the data from our cohort of primary care patients with LRTI to evaluate the contribution a broad range of patient characteristics, clinical items, infection parameters and antibiotic prescription at presentation on subsequent clinical outcomes. Secondly, we set out to provide an evidence-based account of the duration of a LRTI course and the impact of the illness on daily activities in patients in patients consulting in general practice who were and who were not prescribed an antibiotic, subdivided by radiographic evidence of pneumonia and microbiological aetiology. Such a description of the clinical course of the condition may help clinicians communicate more effectively with LRTI patients treated with 
and without an antibiotic to help set realistic expectations about likely duration of symptoms.

\section{Methods}

\section{Eligibility criteria}

Patients aged 18 years and over with a new (i.e., less than 29 days) or worsening cough, combined with at least one of the following four features: shortness of breath, wheezing, chest pain, auscultation abnormalities; and at least one of the following four: reported fever $\left(\geq 38^{\circ} \mathrm{C}\right)$, perspiring, headache, myalgia; were eligible to enter the study, if the GP was convinced of the diagnosis LRTI. Exclusion criteria were: pregnancy and lactation, history of hypersensitivity to penicillin or macrolide antibiotics, concomitant treatment with ergot alkaloids and/or terfenadine during the study period, other severe clinical disease, treatment with an antibiotic within the preceding 14 days and hospital stay for respiratory complaints in the previous four weeks. Some of the exclusion criteria were relevant to a randomised clinical trial, which was running in parallel to the present study. ${ }^{12}$

\section{Baseline characteristics}

The GPs performed and recorded an extensive, standardised medical history, physical examination and clinical diagnosis. GPs then decided on the basis of their own assessment whether or not to prescribe an antibiotic for the patient. If a decision was made to prescribe an antibiotic, the patient was entered into a randomised controlled trial in which the efficacy of amoxicillin was compared to that of a macrolide antibiotic (roxithromycin). ${ }^{12}$ Additional management decisions were at the GPS' discretion.

\section{Infection parameters}

GPS measured and recorded body temperature. Venous blood samples were taken for white cell count, erythrocyte sedimentation rate (ESR), C-reactive protein (CRP), and for determination of sero-conversion for the viral pathogens Influenza $A$, Influenza $B$, Parainfluenza 1/2/3, Adenovirus and Respiratory syncytial virus, and the bacteria Mycoplasma pneumoniae and Legionella pneumophila. The blood samples were analysed on the same day, using standard procedures. ${ }^{13}$ The GPS were informed of the haematology results if ESR was higher than $80 \mathrm{~mm} /$ hour.

Sputum samples and oral washings were taken for standard microbiological analysis for all patients. This was done before commencing antibiotic treatment in those patients who received an antibiotic prescription. ${ }^{13}$ Oral washings were included in analyses only if sputum samples could not be obtained. ${ }^{14}$ Isolation of Streptococcus pneumoniae, Haemophilus influenzae, Moraxella catarrhalis and 
other bacteria as predominant micro-organisms were considered indicative of a laboratory diagnosis of infection. Nasopharyngeal swabs were taken for detection of Chlamydia pneumoniae using polymerase chain reaction (PCR). ${ }^{\text {t5 }}$ Susceptibilities of the cultured bacteria for the antibiotic prescribed were recorded. If no viral or bacterial pathogens were isolated, the infection was considered of unexplained aetiology.

Chest radiographs (lateral and postero-anterior) were performed on the third day after inclusion to increase the chance of detection of infiltrates. ${ }^{.6}$ The radiographs were assessed for the presence or absence of infiltrates by two independent radiologists in a blinded fashion. If there was disagreement between the findings of the two radiologists, a third radiologist conducted an independent assessment that was considered definitive. The conclusive finding of a pulmonary infiltrate was regarded as evidence of pneumonia.

\section{Follow-up and outcome measures}

The final follow-up point was at 28 days after entry into the study. GPs took a history and conducted a physical examination at this point and made a decision regarding whether or not the patient was cured. Patient assessment of cure, defined as the absence of self-reported symptoms, was obtained the night before, at 27 days after entry into the study. We calculated the proportion of patients whose symptoms had resolved and the proportion of patients whose symptoms still affected their usual daily activities for days 1-10,21, and 27 after the initial consultation. Data on patients who were not cured according to the GPs at 28 days were followed-up until cure or another outcome was established.

\section{Statistical analysis}

We used Cox regression analysis, relative risk (RR) and $95 \%$ confidence intervals $(\mathrm{Cl})$, to identify the contribution that all patient characteristics, symptoms and physical signs recorded at the initial assessment made to predicting the time taken for symptoms to resolve. Variables with $p<0.10$ were used for the multivariable analysis. Backward elimination with $p>0.05$ was then used for exclusion of the variables. The remaining variables represented the final prognostic factors for clinical cure.

Differences in clinical cure rate between patients with and without antibiotic treatment were tested with two-sided chi square analysis $(\alpha=0.05)$ and expressed in RR and $95 \% \mathrm{Cl}$. Time to symptom resolution was analysed using Kaplan-Meier curves. Differences between subgroups in time to clinical cure were tested using the Mantel-Cox-Savage log rank test. The statistical analyses were performed with (SPSS) version 11.0. 


\section{Results}

\section{Patients and characteristics at baseline}

25 GPs in the Netherlands recruited 247 patients with a mean age of 52 (range 18-89) years. Clinical data from the initial assessment were not available for one patient who was prescribed an antibiotic. Most patients suffered from acute cough $(92 \%)$ and dyspnoea $(78 \%)$ and showed abnormallities on auscultation (84\%; Table 7.1).

Table 7.1 Findings on presentation for $246^{1}$ patients presenting to the GP with LRTI.

\begin{tabular}{|c|c|}
\hline 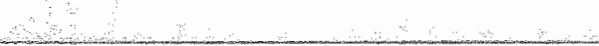 & $N(\%)^{2}$ \\
\hline \multicolumn{2}{|l|}{ Demographic data } \\
\hline Male & $117(47.6)$ \\
\hline Mean age in years (SD) & $52 \pm 16$ \\
\hline \multicolumn{2}{|l|}{ Symptoms } \\
\hline Acute cough (new or increasing) & $226(91.9)$ \\
\hline Dyspnoea & $191(77.6)$ \\
\hline \multicolumn{2}{|l|}{ Rlisk factors } \\
\hline Smaking cigarettes, past or present & $153(62.2)$ \\
\hline Asthma & $48(19.5)$ \\
\hline COPD & $32(13.0)$ \\
\hline \multicolumn{2}{|l|}{ Signs } \\
\hline \multicolumn{2}{|l|}{ Auscultation abnormalities } \\
\hline crackles & $50(20.3)$ \\
\hline rhonchi & $154(62.6)$ \\
\hline Body temperature $\geq 38.0^{\circ} \mathrm{C}$ & $58(23.6)$ \\
\hline \multicolumn{2}{|l|}{ Infection: } \\
\hline mild & $64(26.0)$ \\
\hline moderate & $168(68.3)$ \\
\hline severe & $14(5.7)$ \\
\hline Antibiotic prescription & $196(79.7)$ \\
\hline \multicolumn{2}{|l|}{ Daily activitles } \\
\hline Impaired & $166(72.8)$ \\
\hline Stopped & $97(42.2)$ \\
\hline \multicolumn{2}{|l|}{ Laboratory tests } \\
\hline C-reactive protein, median (range) & $22.5 \cdot(2-312)$ \\
\hline Erythrocyte sedimentation rate, median (range) & $19.0(1.121)$ \\
\hline Leucocytes, median (range) & $8.3(3.8-19.7)$ \\
\hline Bacterial infection & $47(19)$ \\
\hline Viral infection & $49(19.8)$ \\
\hline Mixed viral-bacterial infection & $16(6.5)$ \\
\hline \multicolumn{2}{|l|}{ Chest radiographs } \\
\hline Pneumonia & $32(13.2)$ \\
\hline
\end{tabular}

${ }^{1}$ no data avallable for one patient; 2 percentage based on number of patients for each variable (valid percentage): ${ }^{3}$ Chronic abstructive pulmonary disease 
Patients suffered from LRTI symptoms for an average of nine (range 1-28) days before consulting. An antibiotic was prescribed for 196 patients. Conservative treatment or reassurance was given to the remaining 51 patlients. Nine of these 51 patients did however recelve a prescription for an antibiotic at a subsequent consultation, which took place a mean of 10.8 (range 4-21) days after the first presentation. Evaluation of GP reported outcome was missing in eight patients. Five of these patients did not attend for the scheduled consultation at 28 days, two patients were admitted to hospital at the time of this assessment, one for heart failure and the other for exacerbation of chronic obstructive pulmonary disease (COPD), and in one other patient the outcome measure reported by the GP was missing. A complete data set for both assessment and outcome was thus available for 239 patients. Patient reported cure and the analysis of prognostic factors were assessed in 240 patients, since patient reported data were available for one extra patient.

\section{Infection parameters}

Recorded fever, presence of a bacterial or a viral infection, mean ESR, mean leucocytes and radiographic pneumonia were not significantly different between those for whom an antibiotic was prescribed and those who were not prescribed an antibiotic. However, the mean CRP level was significantly higher in the group who was prescribed an antibiotic $(p=0.03)$.

51 Patients with a positive bacterial culture, including 57 bacterial strains, received an antibiotic. In vitro resistance to the antibiotic prescribed was found in 22 (39\%) strains: $12 / 28 \mathrm{H}$ influenzae, $1 / 11 \mathrm{~S}$ pneumoniae, $2 / 7 \mathrm{H}$ para-influenzae, 4/6 $\mathrm{M}$ catarrhalis, and $3 / 5$ (various) other bacteria.

Radiographic pneumonia was identified in 32 patients (13\%). Five pneumonia patients did not receive an antibiotic prescription at baseline. One of them received a prescription for amoxicillin five days later.

\section{Predicting outcomes}

Based on univariate analysis, the following clinical variables were eligible for multivariable testing in Cox regression analysis: co-morbidity of asthma, present smoking, reported fever, perspiring, cough less than two days, crackles, pneumonia, ESR, CRP and antibiotic prescribed. CRP and ESR, both measuring inflammation, were sequentially tested with identical results. Fever, perspiring, and antibiotic prescribed were statistically significant predictors of enhanced symptom resolution (Table 7.2). Co-morbidity of asthma was a statistically significant predictor of delayed symptom resolution. Kaplan-Meier curves were constructed for each clinical predictor in order to compare the time to symptom resolution between groups with and without the particular factor (Figure 7.1 ). 
Table 7.2 cinical predictors of enhanced symptom resolution in 240 patients with LRT. Cox regression analysis:

\begin{tabular}{|c|c|c|}
\hline Selededitems & $\begin{array}{l}\text { Prediotors of enthan } \\
\text { Relative ris K (RR) }\end{array}$ & $95 \mathrm{mes}$ olution \\
\hline Co-niololuly of asthma & 0,5 & $0,30,9$ \\
\hline Fevert? & 1,5 & 1,122 \\
\hline Antlbiollo pireseribed & 17 & 1,028 \\
\hline Perspining $\mathrm{s}^{\mathrm{s}} \mathrm{s}$ & 11 & $1,02,8$ \\
\hline Counh 2 days & & \\
\hline Smoking & & 2 \\
\hline Crackles & & \\
\hline ESA $/ \mathrm{PAPI}$ & & \\
\hline Pneumonia: & 3 & 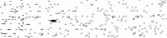 \\
\hline
\end{tabular}

${ }^{1}$ analysis once performed with ESR and once with CRP resulting in the same RR and CIS.

\section{Cure; GP assessment and self report}

GPS considered $213 / 239(89 \%)$ of the patients cured at complete follow-up (28 days), although 76 of these $213(36 \%)$ patients considered to be cured by their GPs still reported symptoms to their GP at this point, and physical signs were identified in $13(6 \%)$ of these 239 patients. 16 of the 26 patients not clinically cured at 28 days recovered shortly after and did not reconsult their GP. Ten patients with an exacerbation of COPD slowly returned to their baseline clinical condition. Four patients, all clinically cured for the LRTI episode, were found to have concomitant pulmonary cancer. Curative lobectomy was performed in one of the patients. The others received palliative treatment.

Twenty patients turned out to be infected with a bacterium that, on laboratory analysis, was found to be insensitive to the antibiotic that was prescribed for them: $18(90 \%)$ of these patients were considered cured by GPs assessment at 28 days and $10(50 \%)$ considered themselves to be cured at day 27 .

The patient reported cure rate gradually increased (days 1-10, 21, and 27), but only $123 / 240(51 \%)$ of the patients reported themselves cured at day 27 (Figure 7.2). Cough $(n=82 ; 74 \%)$ and dyspnoea $(n=59 ; 53 \%)$ were the most common remaining symptoms in the patients who considered themselves not cured (Table 7.3). Moreover, 37 (34\%) of patients were limited in terms of performing usual daily activities, and $12(11 \%)$ had abandoned their usual daily activities, while 30 (29\%) patients still performed no significant physical activity whatsoever. 
A

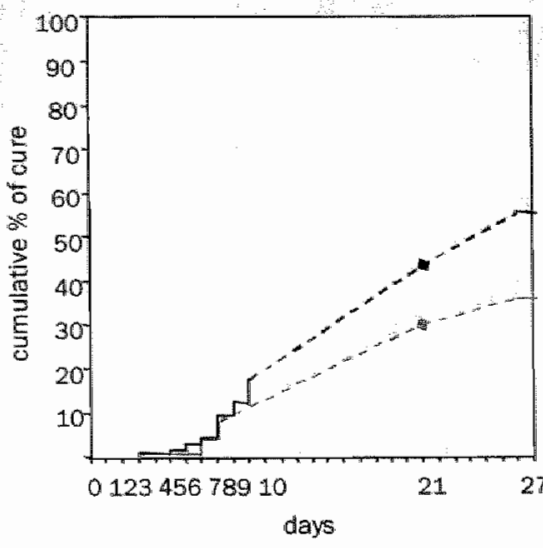

L fever

C

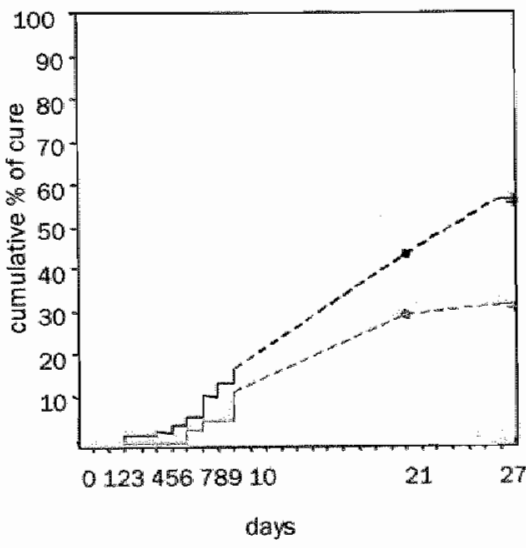

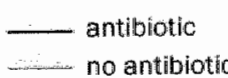

logrank test
$p=0.0183$

B

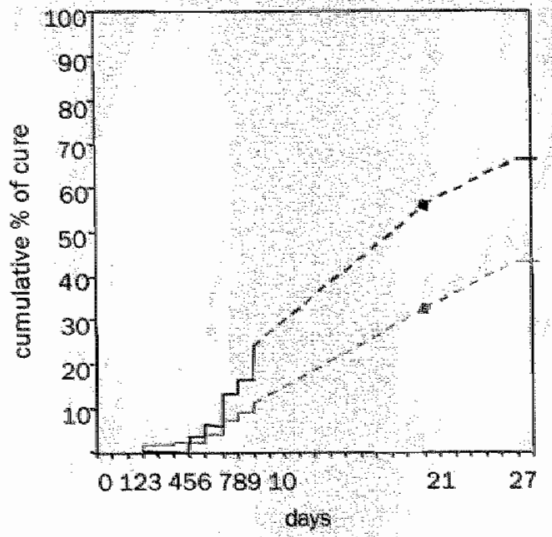

no asthma

logrank test $p=0.006$

D

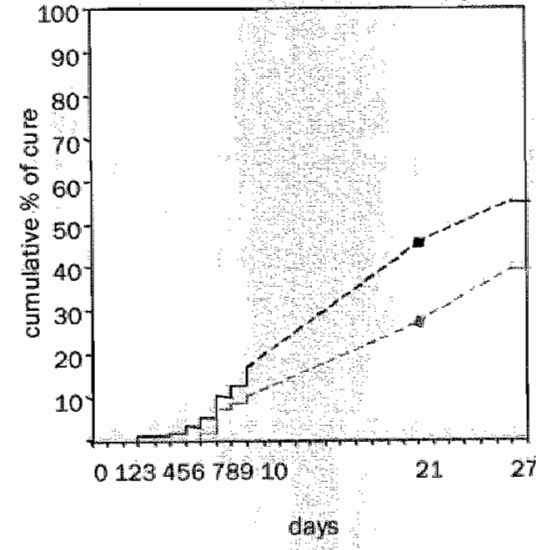

perspiring

no perspiring logrank test

$p=0.0257$

Figure 7.1 Cumulative percentage of cure during 27 days of follow-up for patients with and without (A) co-morbidity of asthma, (B) reported fever, (C) antibiotic prescribed, and (D) perspiring. Kaplan-Meier curves. Since clinical cure was recorded on days 1-10, 21 and 27, curves were assumed to be linear in between (dotted in the curves). 


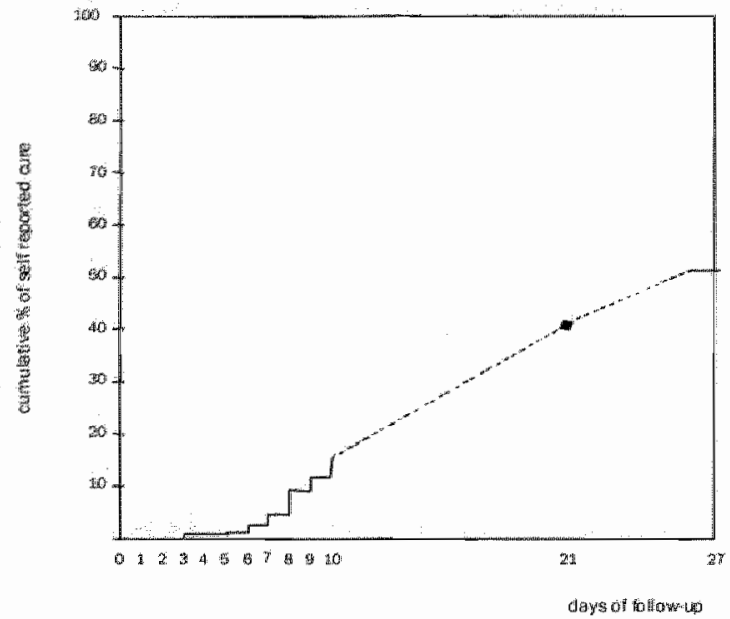

Figure 7.2 Cumulative percentage of seif reported cure for 240 LRT/ patients during 27 days of follow. up. Kaplan-Meier curve. Since clinical cure was recorded on days 1-10, 21 and 28, curves were assumed to be linear in between (dotted in the curves?.

Table 7.3 Persisting symptoms and influence on dally activities for $117^{1}$ patients not cured after 27 days of follow-up.

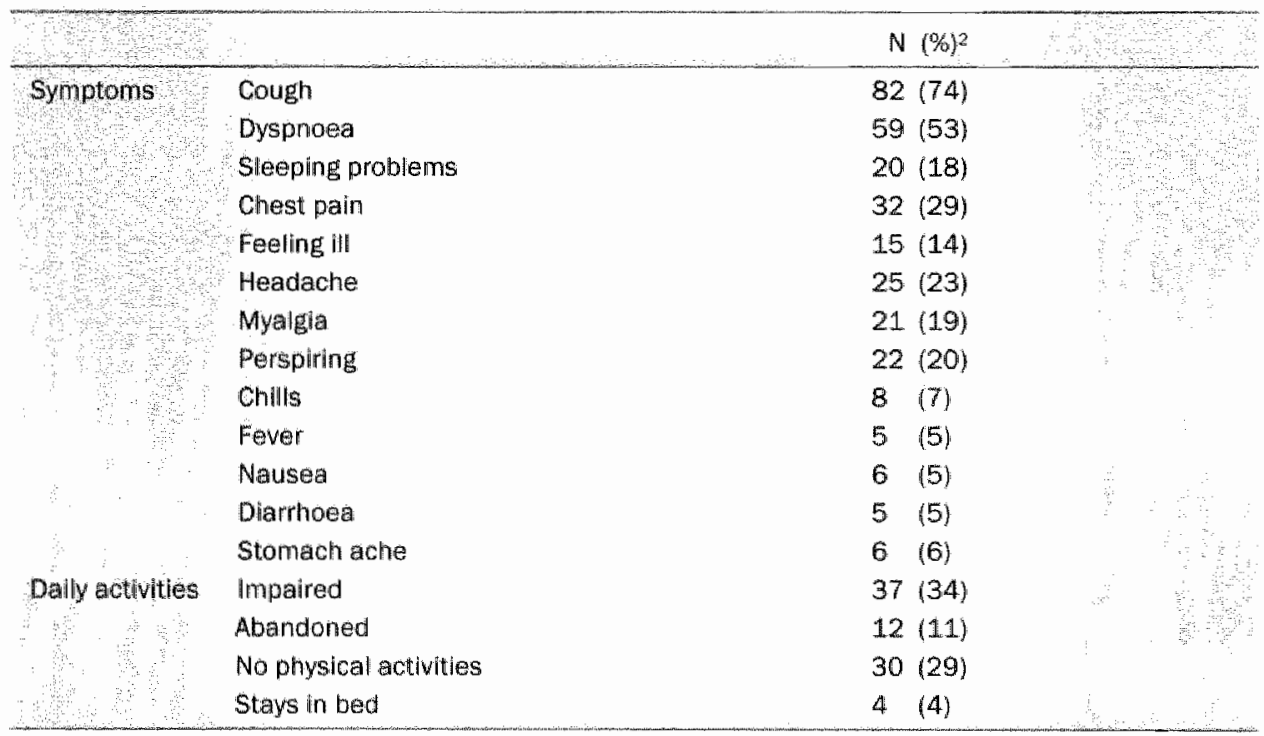

\footnotetext{
${ }^{1}$ no data avallable for 7 patients; " valid percentage
}

Table 7.4 provides and overview of the cure rates according to GPs' assessment and patient self repont for patients who were prescribed an antibiotic, for patients who recelved a radiographic diagnosis of pneumonia, and for patients with a microbiological diagnosis of viral or bacterial infection. Rates for GP assessment of 
cure were simllarly high $(168 / 187$ (90\%) vs. 42/49 (89\%); RR 1.33 ol 0.67-2.65) for patients who were and who were not prescribed an antibiotic. However, patient reported cure was statistically significantly higher for those that were prescribed an antibiotic (102/187 (55\%) vs. $18 / 49$ (37\%); RR 1.87 Cl 1.11-3.14). This difference was confined to and explained by the higher cure rate in patients with a radiographic diagnosis of pneumonia who were prescribed an antibiotic $(20 / 26$ $(77 \%)$ vs. $0 / 5(0 \%) ; p=0.003)$. The five patients (mean age 56 years) who were found to have radiographic evidence of pneumonia were not prescribed an antibiotic at baseline, because the GPS considered the patients to be suffering from mild or moderately severe acute bronchitis and thus not requiring antibiotic treatment (Box 7.1). They all recovered without antimicrobial treatment that would have been considered appropriate according to radiological or microbiological findings, although a persisting cough in one patient took 42 days to resolve. The patient with adenoviral pneumonia who received amoxicillin five days after the initial consultation was not secondarily infected with a bacterium according to repeat microbiological testing. She was therefore considered cured without treatment specific to her radiographic or microbiological assessment.

\section{Limited and abandoned usual daily activities}

Usual daily activities at baseline were limited by the illness in $164(73 \%$, walid $\%)$ of the patients, while $95(42 \%)$ had abandoned all usual daily activities (Figure 7.3). These numbers gradually decreased to $42(19 \%)$ and $13(6 \%)$ respectively by day 27. The same pattern was found for both the patients prescribed an antibiotic, and those who were not prescribed an antibiotic, although the proportion of the latter group was somewhat lower at baseline.

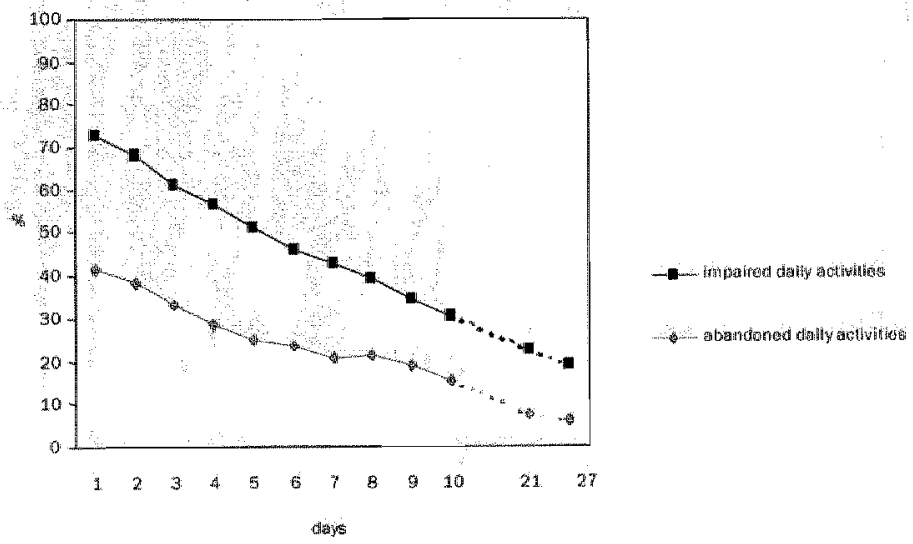

Figure 7.3 Ampaired and abandonad daily activities for 240 LRT patients during 27 days of follow-up. Average decrease in impaired and abandoned daily activities per day. 


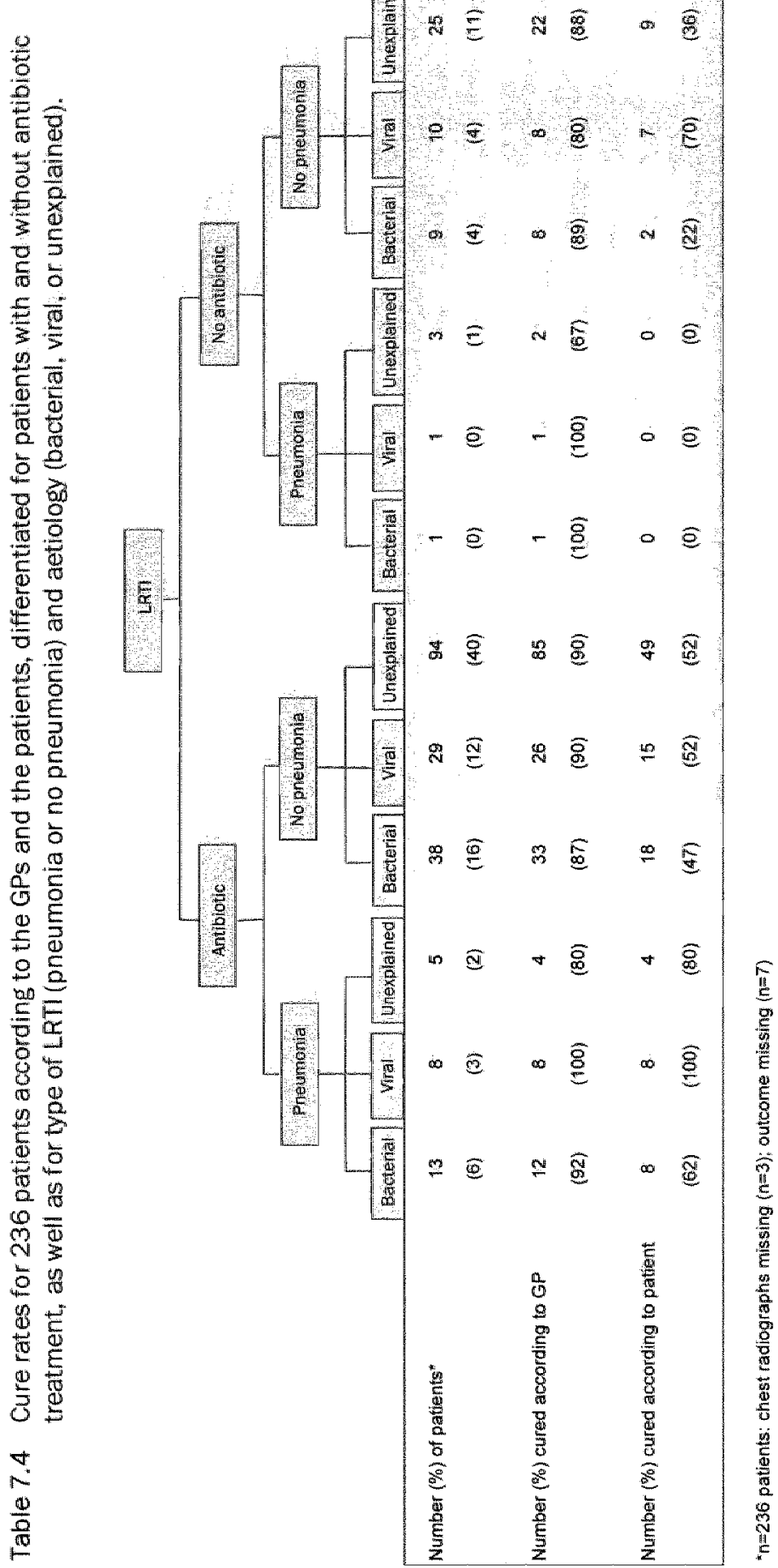


A 40 year old woman presented with a 5 day history of dro cough, dysphoee, chest pain, and fever (recorded temperature $39.5 \%$ ). Her ESR was 93 mm/ hour and CRP 207 ng/l she had radiographic evidence of pneumonia and adenoviras was cultured. After 5 days of follow up stie was preschibed amoxicillin because of worsening symptoms. Her GP coinsidered her fully recovered 28 days after the initial consultation

A 76 year old woman presented with a 28 dey histor of productive cough and dyspnoea. Her ESR was $88 \mathrm{~mm} /$ hour and CRP $58 \mathrm{mgl}$, she had radiagraphic evidence of pnelumonla, and Streptocaccus group B was cultured. Her GP considered her fully recovered 28 days of ter the initial consultation.

A 69 year old man with histon of asthma oresented after 5 days of productive cough. His ESR was $20 \mathrm{~mm} / \mathrm{hour}$ and CRP $80 \mathrm{mg} / \mathrm{l}$. He had radiographis evidence of pneumonia w/th hegative cultures. He was treated with oral corticosteroids, and his GP considered him fully recovered 28 days after the initial con sultation.

A 68 year old woman presented with a 28 day history of dry coughi and dyspnoea, Her GP found ronchi on auscultation. Her ESR was 14 mm/houl and CRP $12 \mathrm{mg} / \mathrm{s}$. She had radiographic evdence: of pneumonia with negative cultures. Her GP considered her fully recovered 28 cavs after the initial consultation.

A 25 year old woman presented with a 4 day history of dry cough and rever (recorded temperature $39.3^{\circ} \mathrm{C}$. She had radiographic evidence of preumonia with negative cultures. Her ESR was 29 mm/hour and CRP $94 \mathrm{mg} /$. Her GP did not consider her fully recovered 28 days after consulting because of persisting cough (which became productive after 10 days) and impaired dally adivities. which disappeared after two more weeks.

Box 7.1 LRTI course and outcome in five patients with pneumonia, clinically diagnosed as acute bronchitis, who did not receive antibiatic treatment at baseline:

\section{Discussion}

\section{Summary of main findings}

Our first aim was to identify findings available to climicians at the initial assessment of patients consulting with LRTI that would predict an abnormal or prolonged clinical course. We found that co-morbidity with asthma was correlated with a slow resolution of symptoms, whereas the presence of fever, perspiring, and the prescription of an antibiotic at the initial assessment weakly predicted symptom resolution by day 27 .

Our second aim was to describe the (natural) history of LRTI for patients who were and were not prescribed an antibiotic at the initial consultation. Most patients (89\%) were clinically cured according to the GPS 28 days after first consulting, irrespective of whether or not they were prescribed an antibiotic. However, $43 \%$ of 
the patients GPS considered cured nevertheless reported ongoing symptoms (mainly cough and dyspnoea) to their GPs at this point. Five patients not prescribed an antibiotic at the initial assessment were found to have radiographic evidence of pneumonia. They all recovered without treatment that would normally have been considered specific to their radiographic or microbiological diagnoses. Self-reported cure was much lower $(51 \%)$ and usuall dally activities were limited according to $19 \%$ of the patients at the 27 day follow-up. Self-reported cure was not achieved for the five pneumonia patients who were not prescribed an antibiotic at the initial assessment:

Duration of symptoms and the considerable impact of the LRTI course on daily activities lasted much longer than has thus far been suggested. The difference in assessment of cure between GPS and patients underlines the importance of communication in managing LRTI in general practice in appropriately modifying patient's help seeking behaviour. ${ }^{17.18}$ if, for example, GPS reassure patients that the illness is 'just a self-limiting viral bronchitis that will disappear in a week or so', this may trigger the patient to reconsult if the illmess lasts longer or if a bothersome cough remains present. Expectations for antibiotic treatment may be higher in a second consultation.

\section{Strength and limitations of the study}

The eligibility criteria for our LRTI study were adapted from the first prospective study on LRTI in the community by Macfarlane and colleagues. ${ }^{19}$ Our definition required the presence of acute cough, together with at least one focal and one general symptom and sign of LRTI. The wide inclusion criteria reflect the variety and complexity of clinical presentations that characterize daily general practice and ensured inclusion of patients with comorbidity of asthma and chronic obstructive pulmonary disease with an infectious exacerbation. This study is therefore likely to have included important numbers of patients in whom clinical doubt and lack of evidence on diagnosis, management and prognosis is most profound.

In this pragmatic study, the process of diagnosis and deciding whether or not to prescribe an antibiotic for LRTI was left up to the GPs analogous to usuall care. Despite this diagnostic reasoning and the effort to accurately select only those patients on clinical grounds who are likely to benefit from antibiatic treatment, microbiological, haematological and radiographic findings indicative of infection were almost evenly distributed among patients who received a prescription for an antibiotic and those who did not. Therefore, it was (ethically) possible to study the natural course of five of the $32(16 \%)$ cases of radiographic pneumonia, not clinically diagnosed with pneumonia, and not treated with an antibiotic by the GPS at baseline. These cases all resolved without specific treatment. Although the numbers are small, these cases may suggest that 'missing pneumonia' in general practice may not always be the serious matter that this is sometimes made out to be. Two retrospective studies suggest that reducing antibiotic treatment may be 
associated with more complicated respiratory tract infections, but the sizes of the effects were modest, 20 and possibly confounded by other (unidentified) factors. 21 However, the need for finding better methods of targeting antibiotics to patients at risk for poor outcome is confirmed by the results of these studies. The high resolution rate in patients who were infected by an organism that was resistant to the antibiotic that the patient received is also striking.

The results of the prognostic analysis need to be carefully interpreted. The prescription of an antibiotic was a (weak) factor predicting enhanced symptom resolution. Antibiotic treatment in a large number of these patients may have affected outcome and thus limited the power of this study to identify clinical factors associated with outcome. The analysis could therefore have been subject to confounding by treatment. ${ }^{22}$ However, systematically studying the natural course of untreated LRTI, including pneumonia, is not possible for ethical reasons. On the other hand, the prognostic value of 'antibiotic prescribed' may be overestimated, since patients who were not treated with an antibiotic may have expressed (implicitly or explicitly) their dissatisfaction by recording ongoing symptoms. The modest prognostic value of 'antibiotic prescribed' to enhanced resalution of symptoms turned out to be confined to the patients with radiographic evidence of pneumonia. This finding supports the view that it is only these patients who are likely to benefit form antibiotic treatment.

To explore possible selection bias, we compared the actual numbers of patients presenting with LRTI in three of the participating practices (with a total of nine GPS and a combined patient list of 13,269 ) with the numbers recruited to the cohort from those practices during one of the study years. Of the 463 potentially eligible patients, $43(9 \%)$ were actually recruited. This proportion is not unusual for studies in primary care. ${ }^{23}$ Recruited patients did not differ from eligible patients who were not recruited for age, clinical diagnosis, severity of illness, and GPs' decisions about the need for antibiotic treatment.

\section{Comparison with other studies}

Prospective studies on the outcome and prognosis of LRTI in primary care are rare and have generally been medication trials on acute bronchitis. Hospital studies generally focus on the biomedical evaluation of pneumonia and do not usually capture outcome that are important to patients, other than mortality.24.25 Pneumonia is a sub-diagnosis of LRTI, and so studies of pneumonia alone do not reflect the complexity of clinical presentation in daily general practice.

In an important series of UK studies on $\|$ ower respiratory tract illness, treatment was at the GPS' discretion, as in our study.1,5,26 Reconsultations for the same illness within a month was also common in these studies (16-20\%) and not influenced by microbiological evidence of infection or antibiotic use. However, reconsultations were more common in those with persisting cough and functional impairment. Cough was present in $58 \%$ of the patients and $29 \%$ had not resumed 
normal activities after ten days of follow-up. ${ }^{26}$. Two thirds of the patients who reconsulted received another antibiotic. 5 Our study provides longer-term follow up. However, the general pattern we found at 28 days (frequent, ongoing symptoms, regardless of microbiological diagnosis and antibiotic treatment) is similar to the findings of other researchers at 10 days. The (natural) course and outcome of untreated pneumonia cases has, to our knowledge, never been described in previous studies. However, in a prospective, non-randomised cohort study, Macfarlane identified a group of LRTI patients with changes on the chest radiograph" who recovered without antibiotic treatment. ${ }^{1}$

A large prospective study on LRTI, including possible pneumonia, in primary care is needed to confirm the results of our study and to narrow the gap to a possible next phase in LRTI research: a placebo-controlled study design on outcome and prognosis of community-acquired LRTI, uncluding (mild) pneumonia cases, under the safety net of multiple clinical evaluation moments and proper monitoring of the illness with repeated near-patient CRP testing. ${ }^{27}$ Furthermore, strategies for changing physician and patient behaviour regarding the limited value of antibiotics in self-limiting diseases like most respiratory tract infections need to be systematically studied to increase chances of successful implementation. ${ }^{17}$ The effect of providing a clear, evidence-based account of expected duration of symptoms to patients with LRTI also needs prospective evaluation.

\section{Conculusion}

The course of LRTI was generally uncomplicated, but the morbidity of this illness was considerable with a longer duration than generally reported, in particular in patients with co-morbidity of asthma. Antibiotic treatment enhanced symptom resolution in patients with pneumonia only. Although the GPs considered most patients cured at 28 days, considerable numbers of patients had remaining symptoms and/or limited usuall daily activities, thus focussing attention once again on the importance of enhancing GPs' communication skills within the consultation. With this evidence-based account of outcomes in patients with LRTI, GPs may be able to set realistic expectations about illness duration and thus help avoid reconsultations and associated unnecessary antibiotics. 


\section{References}

1. Macfarlane J, Holmes W, Gard P, Macfarlane R, Rose D, Weston V. Leinonen M, Saikku $P$. Myint S. Prospective study of the incidence, aetiology and outcome of adult lower" respiratory tract illness in the community. Thorax. 2001;56:109-14.

2. Fahey $T$, Stocks $\mathbb{N}$. Thomas $T$. Quantitative systematic review of randomised controlled trials comparing antibiotic with placebo for acute cough in adults. BMJ. 1998;316: 906-10.

3. Hopstaken RM, Muris JWM, Knottnerus JA, Kester ADM, Rinkens PELM, Dinant GJ. Contributions of symptoms, sigins, erythrocyte sedimentation rate and C-reactive protein to a diagnosis of pneumonia in acute lower respiratory tract infection. Br J Gen Pract. 2003;53:358-64.

4. Hopstaken RM, Witbraad T, van Engelshowen JMA, Dinant GJ, Interobserver variation in the interpretation of chest radiographs for pneumonia in community-acquired lower respiratory tract infections. Clin Radiol. Volume 2004;59:743-52.

5. Macfarlane J, Prewett J, Rose D, Gard P, Cunningham $\mathbb{R}$, Saikku P, Euden S, Myint $S$. Prospective case-control study of role of infection in patients who reconsult after initial antibiotic treatment for lower respiratory tract infection in primary care. BMJ. 1997; 315:1206-10.

6. Melbye $H$, Straume $B$, Aasebo U, Dale $K$ : Diagnosis of pneumonia in adults in generall practice. Relative importance of typical symptoms and abnormal chest signs evaluated against a radiographic reference standard. Scand J Prim Health Care. 1992;10:226-33.

7. Coenen S, Van Royen $P_{n}$ Vermeire $E_{8}$ Hermann I, Denelkens J. Antibiatics for coughing in general practice: a qualitative decision analysis. Fam Pract. 2000:17:380-5.

8. Butler CC, Rollnick S, Pill R, Maggs Rapport F, Stott $N$. Understanding the culture of prescribing: qualitative study of general practitioners" and patients' perceptions of antibiotics for sore throats. BMJ. 1998;317:637-42.

9. Coenen S, Michiels B, Van Royen P, Van Der Auwera JC, Denekens J. Antibiotics for coughing in general practice: a questionnaire study to quantify and condense the reasons for prescribing. BMC Fam Pract. 2002;3:16.

10. Little P. Where next with antibiotics and respiratory tract infections? J Fam Pract. 2002; 51:337-8.

11. Hay AD, Wilson A, Fahey T, Peters Tl. The duration of acute cough in pre-school children presenting to primary care: a prospective cohort studly. Fam Pract. 2003;20:696-705.

12. Hopstaken RM, Nelemans P, Stabberingh EE, Muris JWM, Rinkens PELM, Dinant GJ. Is roxithromycin better than amoxicillin in the treatment of acute lower respiratory tract infections in primary care? A double-blind randomized controlled trial. J Fam Pract. 2002;51:329-36.

13. Isenberg HD. Clinical microbialogy procedures handbook. Washington, D.C., American Society for Microbiology, 1994.

14. Sachs AP, van der Waaij $D_{0}$ Groenier KH, Koeter GH, Schiphuis J. Oropharyngeal flora in asthma and in chronic obstructive pulmonary disease. Indigenous oropharyngeal microorganisms in outpatients with asthma or chronic obstructive pulmonary disease. Am Rev Respir Dis. 1993:148:1302-7.

15. Tong $C Y$, Sillis $M$. Detection of Chlamydia pneumoniae and Chlamydla psittaci in sputum samples by PCR. J Clin Patholl. 1993;46:313-7.

16. Bartlett $\rfloor G$, Mundy LM. Community-acquired pneumonia. N Engl J Med. 1995;333: 1618-24. 
17. Butler $C C_{\text {, }}$ Rollnick $S$, Kinnersjey $P$, Jones $A$, Stott $N$. Reducing antibiotics for respiratory tract symptoms in primary care: consolidating "why' and considering 'how'. Br J Gen Pract. $1998 ; 48: 1865-70$.

18. Butler CC, Rollnick S, Kinnersley $P$, Tapper-Jones $L$, Houston $H$. Communicating about expected course and re-consultation for respiratory tract infections in children: an exploratory study: Br J Gen Pract. 2004:54:536-8.

19. Mactarlane JT, Colville A, Guion A, Macfarlane RM, Rose DH. Prospective study of aetiology and outcome of adult lower-respiratory-tract infections in the community. Lancet $1993 ; 341: 51144$.

20. Little $\mathrm{P}$, Watson $L$, Morgan $S$, Williamson I. Antibiotic prescribing and admissions with major suppurative complications of respiratory tract infections: a data linkage study. Bir $J$ Gen Pract. 2002;52: 187-90,193.

21. Price $\mathrm{DB}_{n}$ Honeybourne $\mathrm{D}$, Little $\mathrm{P}$, Mayon White RT, Read RC, Thomas M, Wale MC, FitzGerald P, Weston AR, Winchester CC. Community-acquired pneumonia mortality: a potential link to antibiotic prescribing trends in general practice. Respir Med. 2004;98: $17-24$.

22. Doust J Del Mar C. Diagnosing coughs and colds. Br J Gein Pract. 2004;54:5-6.

23. Wilson $S$, Delaney $B C_{v}$ Roalfe $A$, Roberts $L$, Redman $V$, Wearn AM, Hobbs FD. Randomised controlled trials in primary care: case study. BMAJ. 321: 24-7, 2000.

24. Barlow GD, Lamping DL, Davey $P$ G and Nathwani D: Evaluation of outcomes in community-acquired pneumonia: a guide for patients, physicians, and policy-makers. Lancet Infect Dis. 2003:3:476-88.

25. British Thoraclc Society Standards of Care Committee. BTS Guidelines for the Management of Community Acquired Pneumonia in Adults. Thorax. 2001;56 Suppl 4: $1-64$.

26. Holmes WF, Macfarlane JT, Macfarlane RM, Hubbard R. Symptoms, signs, and prescribing for acute lower respiratory tract illness. Br J Gen Pract. 2001;51:177-81.

27. Pepys $M B, B e r g e r ~ A$. The renaissance of $C$ reactive protein. $B M J .2001 ; 322: 4-5$. 


\section{Chapter}

\section{Implementing findings of diagnostic research in everyday general practice; the paradox of evidence and practice in the example of lower respiratory tract infections}

RM Hopstaken, MA van Bokhoven, GJ Dinant

Published in an altered version as:

Dinant GJ, Hopstaken RM and Bokhoven MA: Implementatie van diagnostisch onderzoek in de dagelijkse praktijk. De paradox tussen evidence en practice. Huisarts en Wetenschap 2004;47:99-103 


\section{Abstract}

Atthough diagnostic research is nowadays accepted as an important research area, the uttimate goal of improving patient care by the primary health care workers in the field is often not achieved. Various factors determining the (lack of) successful implementation of diagnostic research findings in dally general practice are discussed in this paper. A recent research project on lower respiratory tract infections in general practice is used to illustrate important issues of this paradox of evidence and practice. 


\section{Evidence based diagnosis in general practice}

Diagnostic research has a relatively short history. The expertise required to design and perform diagnostic research is limited, and the relevant methodology has not yet been fully developed. ${ }^{1}$ Interpreting its findings requires a theoretical understanding of diagnostic principles (as proposed by Bayes), as well as an understanding of the everyday activities doctors engage in, to allow the relevance of the research findings for everyday practice to be assessed. Comparisons with previous studies (if at all available) is often hampered by differences between study populations and reference tests. For example, abnormal auscultation findings for a particular patient will undoubtedly have predictive value for the presence of pneumonia if the study population includes many healthy persons. If, however, the population consists entirely of patients suffering from lower respiratory tract infection (LRTI), in whom abnormal auscultation findings are very common, abnormal auscultation will not undoubtly be helpful to distinguish between patients with pneumonia and those with acute bronchitis. These subtleties and distinctions mean that readers have to be very perceptive in interpreting reported research findings.

Nevertheless, the lack of great interest in diagnostic research in general practice is striking, all the more so as a general practitioner (GP)'s work consists largely of establishing diagnoses and testing diagnostic hypotheses, which also involves excluding serious pathology. It is therefore essential for GPs to be aware of the diagnostic value of findings from the patient's history, physical examination and additional tests for common disorders. Although progress is being made in assessing this value, such newly developed knowledge is not always applied in everyday general practice. Apparently, GPs tend to continue working with the knowledge they were taught during their training, knowledge which was often derived from research among highly selected populations (often in hospital settings), anecdotal evidence and the GP's own experience (sound or otherwise) based on patient contacts.

It is not easy to ascertain to what extent lack of knowledge about the real diagnostic value of clinical data - in addition to the practical problems, like costs and lack of time, that are experienced in implementing this knowledge in everyday practice - leads to underdiagnosis or overdiagnosis. The former means that certain disorders may be diagnosed late, even too late, while the latter means that the likelihood of false-positive test results for healthy patients increases significantly as the number of tests and other supplementary tests rises. The latter is a particularly common problem in general practice, since many of these patients have disorders that resolve spontaneously and the likelihood of finding a serious disorder is relatively low.

In the case of lower respiratory tract infections (LRTI), GPS frequently turn to the therapeutic equivalent of overdiagnosis, that is, overtreatment. Notwithstanding 
the low probability of pneumonia, GPs often prescribe antibiotics in spite of diagnostic findings. Important reasons for such actions include not only non-clinical factors (pressure of time, patient expectations and what GPs think patients expect) but also uncertainty about the diagnostic value of clinical findings (like overestimating the value of abnormal auscultation findings). As a result, patients are unnecessarily exposed to adverse effects of the medication, and bacterial resistance is promoted.

Well-designed research can ensure that any conclusions are based on the acknowledged principles of diagnostic research. ${ }^{2}$ This allows important steps towards successful implementation of the research findings to be made even at the design stage of a study. Nevertheless, application in everyday general practice (the "practice") of sound, diagnostic studies (the 'evidence') is often hampered.

\section{Near patient testing for acute lower respiratory tract infections}

LRTI can be subdivided into acute bronchitis (covering the large majority of cases) and pneumonia. Whereas antibiotics are rarely indicated in acute bronchitis, withholding antibiotic treatment from patients with pneumonia would be regarded as bad practice. In order not to contribute to the growing problem of bacterial resistance, GPs should prescribe antibiotics only if there is a clear indication for their use. It must be remembered, however, that pneumonia patients seen in the hospital setting have symptoms that differ to some extent from those of patients presenting at the GP's surgery with a (suspected) pneumonia. Norwegian as well as Dutch research found that percussion dullness and crackles and bronchial breath sounds on auscultation were not predictive of the presence of pneumonia in patients with LRTI. ${ }^{3.4}$ If the findings of a physical examination do not provide diagnostic certainty, supplementary tests are a logical next step. In view of its accepted value as a diagnostic 'gold standard', chest radiographs could be the next diagnostic step. However, this option has considerable drawbacks, such as the delay in obtaining the outcome, transport problems and radiation exposure. Moreover, the inter-observer reliability in the interpretation of chest radiographs turns out to be rather poor ${ }^{5,6}$ An alternative for most GPS in the Netherlands is to measure the erythrocyte sedimentation rate (ESR) at their own practice. Since, however, this requires an hour's waiting time. GPs tend to opt for a practice-based solution: they prescribe antibiotics to patients with LRTI. Prescribing unnecessary antibiotics causes less 'chagrin' than unjustified withholding of antibiotics treatment. ${ }^{7}$ Not only does this option eliminate the fear of leaving a case of pneumonia untreated, but both patients and doctors tend to be pleased with the approach, the former because they have been given an apparently effective medicine and the latter because they have gained time. ${ }^{8}$ The evidence that 
excessive use of antibiotics results in high rates of bacterial resistance does not visibly affect the approach opted for at the GP's surgeny and will thus not commony induce GPs to adopt an evidence-based approach.9

Serum C-reactive protein (CRP) level is a better predictor of pneumonia than any finding from history taking or physical examination.4,10 A combination of low CRP and other predictive clinical data adequately allows GPS to exclude pneumonia.

How could the likelihood of this knowledge being successfully implemented in everyday general practice be improved? Scandinavian GPs commonly use the reliable CRP point of care test to diagnose $L R T I$, with good results. ${ }^{11} \mathrm{~A}$ finger prick blood sample and a few simple analytical procedures allow patients to be reassured within minutes that they do not have pneumonia or to be told that in cases of high CRP values antibiotic treatment may be warranted. In view of the favourable diagnostic characteristics and practical advantages of the CRP point of care test relative to the ESR test, the former should be made available to all GPS. A logical further step would be follow-up studies to assess other aspects of the CRP test, like its cost-effectiveness and the reduction of the number of antibiotic prescriptions. Ultimately, successful implementation will require adequate education and financial compensation by the health insurers for the equipment and test strips.

\section{Towards successful implementation}

Various interrelated factors determine the successful implementation of research findings. ${ }^{12-14}$ Some of the findings of our own study of LRTI can be used to illustrate these factors.

Availability and practical relevance of scientific knowledge

The level of evidence provided by scientific research is not only determined by the quality of the research effort but also by the setting in which it takes place. This determines to a considerable extent whether the results can be generalised for everyday general practice. Until recently, very few studies of LRTI had been done in a general practice setting. Our research questions were prompted by knowledge gaps and problems perceived by practicing GPS. The study was developed and implemented by GPs and was done entirely in a GP setting.

\section{Access to new knowledge}

Publishing the results of research is the obvious duty of any researcher. For strategic reasons, however, they aften prefer to publish in English in prestigious international journals. The majority of the articles published in these joumals are not directly relevant or valuable for everyday general practice. And even the few 
international journals that concentrate on general practice research tend to be rarely read by Dutch GPS. Fortunately, the Dutch journal Huisarts en Wetenschap has recently adopted the policy of stimulating researchers explicitly to submit their international publications on well-designed and carefully performed studies that are relevant to general practice for repeat publication in Dutch. As a result, the report on the above study of the diagnostic value of clinical findings, ESR and CRP for pneumonia was first published in the British Journall of General Practice, ${ }^{4}$ then in Huisarts en Wetenschap ${ }^{15}$ and finally in journals on evidence-based medicine like Minerva ${ }^{16}$ and Evidence-Based Medicine. ${ }^{17}$ Researchers working on general practice issues should always keep in mind that GPs are only able to read a limited number of scientific journals regularly, and that they tend to prefer journals in their own mother tongue. Successful implementation of research findings thus requires them to be published in journals as such.

\section{Involving GPS in research and implementation}

Although in many cases, the researcher is the obvious person to guide the process of implementation, this also implies that he or she should be familiar with the everyday work of GPS. Hence, both researchers and GPS involved in such studies should ideally contribute actively to the dissemination of its findings, including the development of practice guidelines like those published by the Dutch College of General Practitioners (NHG). Working parties preparing such guidelines should therefore make every effort to track down any research done in a general practice setting, including ongoing research projects. The results of such studies could replace more traditional insights, which were often derived from research among selected populations in secondary care. Involving practising GPS in the design and implementation of research from an early stage promotes the subsequent implementation of the findings.

\section{Applicability of new knowledge}

Successful implementation of findings is more likely if they fit in closely with existing practice routines. If new equipment or a new test llike the CRP point of care test) is to be introduced, it is important to assess any factors that could impede its utilisation. These could include lack of office space, lack of adequate technical training, pressure of work, costs, lack of confidence among GPs about the added value of the new diagnostic option and the fear of having to invest more time. In addition, indications for using the new test must be made perfectly clear and users must be told what their response should be to finding abnormal test results. For example, a CRP finding of $15 \mathrm{mg} / \mathrm{l}$ for a patient suffering from a cold should, in the absence of signs of pneumonia, not imply that an antibiotic is to be prescribed. 


\section{New knowledge as an element of continuous quality improvement}

Successful implementation of research findings is not the end of the story. Over time, new questions and problems tend to arise. Research will be needed to show whether the CRP test is actually being used for the right indications in everyday general practice and whether its use does indeed lead to a permanent reduction in the number of unnecessary antibiotics prescriptions. In addition, the CRP test equipment will need to be carefully serviced and recalibrated in accordance with the manufacturer's instructions, and operating skills will have to be maintained. Growing experience with the new diagnostic tool will then result in new research questions that are relevant to everyday general practice. Thus, rather being an end result, new knowledge is actually a starting point for further quality improvement.

\section{The role of policy-makers in implementation}

Authorities within the health care system have considerable influence on the success of any implementation effort. Thus, our study of LRTI ties in closely with EU initiatives aimed at reducing antibiotics resistance in primary and secondary care. In addition, policy advisory bodies and professional associations obviously play an important part as well, not only by developing and disseminating evidence based guidelines, but also by developing products that facilitate the application of new knowledge. The Dutch College of General Practitioners, for instance, has its own department of product development and implementation, which is responsible for developing continued education materials and individual training packages after the College has published a new guideline. Obviously, this can only be done after the new knowledge has been incorporated in such a guideline.

\section{Favourable effects of applying new knowledge}

GPs themselves have to be able to percelve the favourable effects of applying the new knowledge, and in this respect, short-term advantages are often more decisive than long-term effects. The CRP point of care test, for instance, allows the GP to largely eliminate the diagnostic uncertainty within the duration of a normal consultation, unlike the ESR test, which used to be the diagnostic option for inflammatory diseases.

\section{Conclusion}

Although GPs tend to spend a large proportion of their time on diagnostics, the value of their diagnostic procedures is often not yet sufficiently clear. Traditionally, new knowledge has been derived from research among selected populations in a hospital setting. Fortunately, clinical-diagnostic research is increasingly taking place in generall practice settings. It is however not enough merely to produce new 
evidence: such knowledge will also have to be implemented in practice. It is not just a matter of disseminating knowledge etther. Clinical-diagnostic research in modern general practice will need to take account of the process of implementation of research findings in the GP's everyday practice. Conditions determining the successful implementation of diagnostic research do not differ essentially from those for the findings of therapeutic research. The actual process, however, is often different, since there are no powerful pharmaceutical companies that are willing to take upon themselves the process of disseminating knowledge and developing implementation strategies for the findings of diagnostic research. In addition, accepting new diagnostic skills seems to be more difficult for GPs than trying a new medicine (I have relied on history taking and physical examination for the past 25 years' versus 'we now have an even better drug'). While it is essential to emphasise the need for continuous quality improvement in our diagnostic procedures, this implies not only improvements to the quality of patient care: successful implementation of well-designed and carefully carried out diagnostic research will also be invaluable in terms of reducing uncertainty and creating greater job satisfaction for GPS. 


\section{References}

1. Knottnerus JA. The evidence base of clinical diagnosis. Londion, BM. Books, BMA House, Tavistock Square, 2002.

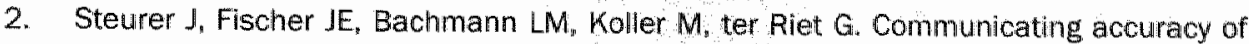
tests to general practitioners: a controlled study. BMJ. 2002:324:824-6.

3. Melbye $H$, Straume B, Aasebo U, Dale K. Diagnosis of pneumonia in adults in general practice. Relative importance of typical symptoms and abnormal chest signs evaluated against a radiographic reference standard. Scand I Prim Health Care. 1992;10:226-33.

4. Hopstaken RM, Muris JWM, Knottnerus JA, Kester ADM, Rinkens PELM, Dinant GJ. Contributions of symptoms, signs, erythrocyte sedimentation rate and C-reactive protein to a diagnosis of pneumonia in acute lower respiratory tract infection. $\mathrm{Br} J \mathrm{Gen}$ Pract. 2003;53:358-64.

5. Hopstaken RM, Witbraad T, van Engelshoven JMA, Dinant GJ. Interobserver variation in the interpretation of chest radiographs for pneumonia in community-acquired lower respiratory tract infections. Clin Radiol. Volume 2004:59:743-52.

6. Melbye $H$, Dale $K$. Interobserver variability in the radiographic diagnosis of adult outpatient pneumonia. Acta Radiol. 1992;33:79.81.

7. Feinstein AR. The 'chagrin factor" and qualitative decision analysis. Arch Intern Med. 1985;145:1257-9.

8. Coenen S, Van Royen P, Vermeire E, Hermann I, Denekens J. Antibiotics for coughing in general practice: a qualitative decision analysis. Fam Pract. 2000;17:380-5.

9. Felmingham D, Gruneberg RN. The Alexander Project 1996-1997: latest susceptibility data from this international study of bacterial pathogens from community-acquired lower respiratory tract infections. J Antimicrob Chemother. 2000;45:191-203.

10. Melbye $H_{,}$Straume B, Brox J. Laboratory tests for pneumonia in general practice: the diagnostic values depend an the duration of illness. Scand J Prim Health Care. 1992; 10:234-40.

11. Dahler Eriksen BS, Lassen JF, Petersen PH, Lund ED, Lauritzen T, Brandslund I. Evaluation of a near-patient test for $C$-reactive protein used in daily routine in primary healthcare by use of difference plots. Clin Chem. 1997;43:2064-75.

12. Meurs PL, van Splunteren PT, van der Werf WTPF. De uitdagingen van effectieve implementatie. Het verspreiden en toepassen van kennis. Med Contact. 1999:54.. 199-200.

13. Grol R. Improving the quality of medical care. Building bridges among professional pride , payer profit, and patient satisfaction. JAMA. 2001;286:2578-85.

14. Ravensbergen J, de Jong $R$, van Splunteren $P$. Implementeren valt te leren. Mediator. 1999;10:8-10.

15. Hopstaken RM, Muris JWM, Knottnerus JA, Kester ADM, Rinkens PELM, Dinant GJ. De waarde wan anamnese, lichamelijk onderzoek, BSE en CRP voor de diagnose pneumonie bij acute lage-luchtweginfecties. Huisarts Wet. 2004;47:9-15.

16. Coenen S. Diagnostiek van pneumonie [abstract]. Minerva. 2004;3:7-8.

17. Hopstaken RM, Muris JWM, Knottmerus JA, Kester ADM, Rinkens PELM, Dinant GJ. Symptoms and signs plus erythrocyte sedimentation rate or C-reactive protein predicted pneumonia in lower respiratory tract infection. Evidence Based Medicine. 2004;9:55. 


\section{Chapter 9}

General discussion

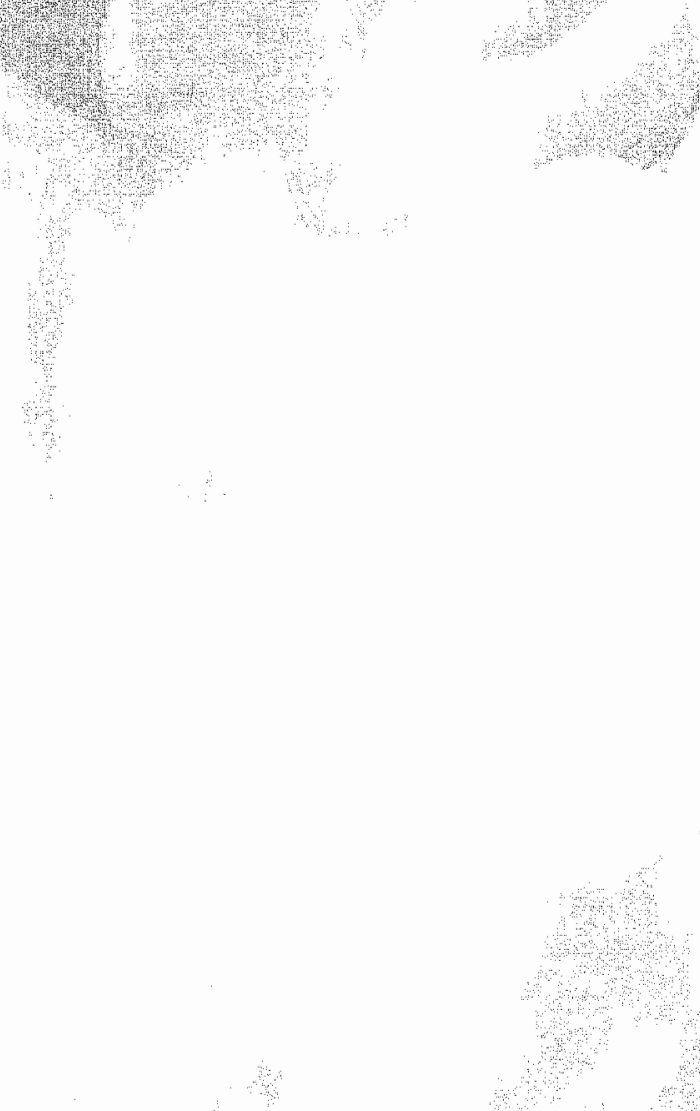




\section{General discussion}

The most important results of the various studies in our LRTI project are presented in the Summary of this thesis, in the form of answers to the research questions. Specific strengths and limitations of these studies are addressed in Chapters $2-8$. The present chapter discusses overall methodological aspects of the LRTI project. This is followed by a discussion of the role of CRP in the diagnostic work-up of LRTI, outcome and prognosis, antibiotic overprescribing, practical implications for general practice and future research challenges in LRTI.

\section{Methodological considerations}

\section{A practice-based approach of acknowledged clinical problems}

The questions this project tried to answer were formulated on the basis of frequently encountered clinical dilemmas in daily general practice. Insecurity about diagnostic and therapeutic strategies and discontent about current management of LRTI was acknowledged and expressed by the participating GPS and will be recognised by most practicing physicians in primary care. Clinically useful answers to this type of research questions can best be provided if the actual clinical problem is incorporated in the study design and methods. To meet this requirement, we have tried to define the clinically most sensible study criteria and, most importantly, we chose LRTI as the clinical condition of interest, rather than pneumonia or acute bronchitis. The reason was that GPs are known to have great difficulty diagnosing pneumonia in patients with LRTI. ${ }^{1}$ Thus, GPs do not 'see' patients with pneumonia or acute bronchitis. Instead, they are consulted by patients with (possible) LRTI. It is particularly in this group of patients that unjustified antibiotic prescribing is a huge problem. GPs need evidence-based information that helps them to prescribe antibiotics more appropriately, thereby both reducing the societal problem of growing bacterial resistance and improving patient care in general. Remarkably, most previous studies have failed to address these needs.

Many therapeutic trials on community-acquired pneumonia have been published, mostly assessing whether one antibiotic is more effective than the other. They have almost exclusively been performed in selected groups of patients, mostly from emergency or inpatient departments. The higher prevalence and greater severity of the disease in these studies has hampered generalisation of their results to daily general practice. Moreover, these trials do not give answers to the most important questions GPS are facing: Which patients with lower respiratory tract symptoms need antibiotic treatment? Should $\|$ order chest radiography for this patient? Whom should I monitor more carefully? What should I tell the patient about the duration, impact and prognosis of the illness? The same shortcoming is found in the numerous, but often small-sized, placebo-controlled therapeutic trials on acute bronchitis, despite the fact that they are mostly performed in primary care settings. 
Fortunately, Melbye in Norway and Mactarlane in the LK have adopted the GPS perspective in several important studies on LRTI, addressing a range of issues. 14 These studies were the main source for generating new research questions for the project described in this thesis. The inclusion criteria used in our studies were the presence of acute cough, together with various optional clinical symptoms and signs of LRTI. The broadly defined inclusion criteria reflect the variety of clinical presentations and differential diagnostic considerations that characterise daily general practice. To some extent, asthma and COPD often present with similar symptoms and signs, but these patients are also more susceptible to LRTI. Excluding these patients would mean that we would not do justice to the actual complexity of daily general practice. Therefore, we added the criterion that the GPs needed to be convinced of the diagnosis of LRTI, whether or not in patients with coexistent asthma or COPD. In order to approximate actual clinical behaviour, the participating GPs were not specifically trained in theoretical or practical aspects (e.g interpretation of pulmonary sounds) of LRTI. Feedback from additional diagnostic testing was not supplied to prevent selection and work-up bias.

\section{Chest radiography}

Chest radiography was the reference standard of our diagnostic study on clinical prediction of pneumonia. The conclusive finding of an infiltrate after assessment by two - or in case of disagreement three - independent radiologists was regarded as evidence of pneumonia. This reference standard is widely acknowledged for studies on community-acquired pneumonia. As in most diagnostic studies, reference standards are not 'gold'. The results of our study of inter-observer agreement in the interpretation of chest radiographs for pneumonia are therefore of particular interest for a better understanding of the limitations of this reference standard. Whereas the moderate agreement found is considered clinically sufficient by radiologists, it confirms that the validity of chest radiography for diagnosing pneumonia is not optimal. By adding a third radiologist, who performed a third and decisive reassessment of the chest radiographs in case of disagreement, we believe to have gone some way towards solving this validity problem. However, the results of our diagnostic study should be cautiously interpreted and the study should be repeated in new study populations to get a better idea of their value for daily general practice.

\section{Only one project'}

The different studies of the LRTI project were performed within one geographic area of approximately 300 square kilometres, in the south of the Dutch province of Limburg. It is possible that studies in different geographic regions would have revealled local spreads of specific bacterial or viral outbreaks, which would have represented variations in the frequency distributions of pathogens responsible for the LRTI episodes. It is also possible that these distributions differ from year to year. This is especially true for Mycoplasma pneumoniae, which usually occurs in five- 
year cycles. This is why we recruited patients during two consecutive whters ffrom January until April 1998, and from November 1998 until April 1999).

The studies included in this thesis are derived from one body of work, including 247 patients for the diagnostic and prognostic studies. After the GPs had selected 196 of them for antibiotic treatment, these patients participated in the randomised controlled trial. To increase the power of our studies, the diagnostic studies in particular, we would have preferred to include more patients. However, the relatively high expenses per recruited patient prevented us from doing so. Twenty-five GPS, varying in age, work experience and type of practice organisation, participated in our studies. Although we have no evidence to the contrary, they may not be fully representative of GPS in the Netherlands. It would have been preferable to thave more than 25 GPs, especially for our study on antibiotic prescribing behaviour. The logistics of the study, however, were not simple. Various biological samples were taken at the GPs' surgery and had to be transported by our own couriers to the nearest hospital for further analysis. Delays had to be restricted as much as possible, especially to limit false-negative microbiological test results. To allow us to adhere to the strict diagnostic standards, both the geographical region and the number of participating GPs had to be limited.

Patients were recruited during regular, mostly busy, consultation hours. They suffered from an acute illness with serious morbidity, requiring immediate care. Accu rate and extensive recording of thistory and physical examination, assessing eligibility, explaining the study and obtaining informed consent, as well as additional diagnostic testing, were all time consuming. These circumstances are not optimal for the GPS' motivation to invite every eligible patient for participation in a research project. Indeed, we estimate that they actually recruited only $9 \%$ of the eligible patients for the randomised controlled trial (see also the Discussion to Chapter 5), which is not unusual in general practice research." Selection bias may have been present, although, according to the GPs, recruited patients did not differ from other eligible patients in terms of age clinical diagnosis, severity of the illness and the need for antibiotic treatment.

\section{C-reactive protein}

\section{Previous studies}

Tillet and Francis discovered in 1930 that a protein in the sera of patients with pneumococcal pneumonia was able to bind to the C-polysaccharide derived from the cell wall of the pneumococcus. ${ }^{6}$ Because the reaction between the protein and the polysaccharide was so specific, they named the protein C-reactive protein (CRP). CRP was soon recognised as a marker of inflammatory activity, following closely the course of the acute phase response to inflammation or tissue necrosis. The production of CRP, which is synthesised in the liver, increases within 4-6 hours after the onset of inflammation or acute tissue injury, and peaks at 36 to 50 hours. CRP levels remain elevated with ongoing inflammation and tissue destruction, but 
drop rapidly after their resolution, because of its short half-life offour to seven houts. ${ }^{8}$

It was only in the 1980 s that analytically sensitive and specific immunoassays became avallable. ${ }^{9 t}$ took another ten years before the additional value of CRP for the diagnosis and follow-up of adult pneumonia was acknowledged in hospitalbased studies. $10-15$ Some of these studies focussed on the value of CRP in differentiating between bacterial and viral infections. CRP was usually higher in severe bacterial infections, particularly if they were caused by Streptococcus pneumoniae and Legionella pneumophila. ${ }^{23,16-18}$ in less severe infections, the additional value of CRP in predicting bacterial infection was often not confirmed. ${ }^{19-24}$

Since primary care usually lags behind hospital settings in the development of new diagnostic and therapeutic strategies, it is striking that Melbye realised as early as 1988 that CRP analysis could be of importance for differentiating between pneumonia and other respiratory tract infections. In his pilot study on clinical predictors of pneumonia in 71 adult patients with suspected pneumonia in general practice, CRP turned out to be the strongest predictor ${ }^{2}$ These findings were confirmed in one other, relatively small study. ${ }^{25}$ Subsequently, Melbye designed a larger study to test the diagnostic value of ESR, white blood cell count and CRP for pneumonia in 402 adult patients with a respiratory tract infection. Again, CRP was found to be the most valuable supplementary tool in the diagnosis of pneumonia in general practice, in particular if the illness lasted one week or more. ${ }^{26}$

From that time, the use of CRP tests requested by GPs increased steadily in Scandinavian countries. In Denmark, the CRP test was ordered in $4 \%$ of all GP consultations and for $34 \%$ of all patients whose blood samples were analysed at the central laboratory.27 Unexpectedly, however, the use of ESR did not decrease correspondingly. A CRP test is only useful in general practice if the result has consequences for the management of the illness. This is mostly not the case if the blood sample is taken in hospitals, since it usually takes a few days before the test result is available. By that time, most patients have alleady started an - often unnecessary course of antibiotics. A reliable CRP near-patient or point of care test that could be easily used in primary care settings coull overcome this problem. ${ }^{28}$ A quantitative, immunometric assay was soon developed. In this test, blood from a finger prick is diluted and applied to a test device, after which one drop of CRP binding conjugate and one drop of washing solution are added. Subsequently, the test result is obtained with an electronic reader. The whole procedure is easy to perform and takes two minutes. This rapid test was found to be reliable compared to a laboratory test. as well as feasible for use by GPS and practice nurses, 29.33 and proved to yield more useful clinical information than ESR, ${ }^{32,33}$ although one study found an older version of the test to be useful only if the GP wanted to be informed about the test result during the same consultation. ${ }^{34}$

The introduction of the CRP point of care test soon led to its widespread adoption in general practice in Norway and Denmark. Dahler-Eriksen found that the CRP 
point of care test was cost-effective in terms of a reduction in the use of hospital laboratory services. He concluded that further implementation would create opportunities for the reduction of unjustified antibiotics use. Lindbaek found that CRP analysis in general practice resulted in a change of diagnosis in $30 \%$ of the patients, and a reduction of antibiotics prescriptions in $25 \%$ of the patients. 35 However, another Norweglan study on LRTI and a Danish study on respiratory tract infections failed to confirm this. ${ }^{36,37}$ These studies found non-significant reductions of antibiotics prescriptions of $4 \%$ and $3 \%$, respectively, in patients whose CRP level was tested, compared to a control group.

\section{What do our studies on the value of CRP add to current knowledge?}

GPs are generally capable of clinically differentiating between upper respiratory tract infections (i.e., rhinitis, sinusitis, pharyngitis and tonsillitis) and LRTI (acute bronchitis and pneumonia). GPs will admit frankly that they have much greater problems differentiating between acute bronchitis and pneumonia, as was already shown in Melbye's diagnostic study on clinical predictors of pneumonia. $₫$ Only 7 of 20 radiographic pneumonia cases were clinically diaginosed as such (sensitivity of $35 \%$ ), and 7 of 29 chinical diagnoses of pneumonia were actually pneumonia according to the radiographic reference standard (positive predictive value of $24 \%$, with a prior probability of pneumonia of $5 \%$ ).

These striking results increased our eagerness to perform a new practice-based study on LRTI in the Netherlands. We recruited those patients for whom the uncertainty about the diagnosis was greatest, i.e., patients with clinical LRT! including those with coexisting asthma or COPD. In our study, GPs had even more difficulty in differentiating between acute bronchitis and pneumonia: the sensitivity of a pneumonia diagnosis was $13 \%$ and the positive predictive value was $19 \%$, with a $13 \%$ prior probability of pneumonia. These results are of clinical importance particularly because the management of acute bronchitis and pneumonia differs. Systematic reviews of randomised controlled trials of treatment for patients with acute bronchitis have concluded that the modest possible beneficial effect is similar in size to the harm caused by antibiotic treatment. ${ }^{38.39}$ Antibiotic treatment is considered obligatory only for pneumonia. The need for new, easily obtainable diagnostic tests was therefore urgent. In our diagnostic study of the value of symptoms, signs and blood tests for the diagnosis of pneumonia, CRP turned out to be the strongest clinical predictor of pneumonia (Chapter 2).40 Pneumonia could be safely excluded if a low CRP ( $<20 \mathrm{mg} / \mathrm{l})$ was found in the presence of at most one of the other clinil. cal predictors: acute cough, recorded body temperature of $\geq 38^{\circ} \mathrm{C}$ and diarrhoea.

The value of CRP in predicting bacterial LRTI has often been suggested, but had never been systematically studied in general practice. In our study of the clinical predictors of viral and bacterial LRTI (Chapter 4), CRP was not found to be of clinical use in differentiating between viral and bacterial LRTI. This was confirmed in a comparable Dutch study, which ran in parallel to our study. ${ }^{41}$ In contrast to our findings, this study found some clinical items that were considered to help predict 
bacterial LRTI, but - contrary to the authors' conclusions - these were not clinically relevarit. 42 un view of the results of these two studies, we believe that it is time to shift the focus away from the effort to use CRP testing (and other diagnostics) to identify bacterial infections or specific etiologic diagnoses in general practice. Even if it had been possible to differentiate between bacterial and viral LRTI, the therapeutic consequences of this knowledge would have been restricted to the small proportion of patients with bacterial pneumonia. There is no evidence of the additional value of antibiotics in acute bacterial bronchitis.38 This ties in with the conclusions from an important qualitative study on the culture of prescribing, which found that emphasising the positive aspects of non-antibiotic treatment and the lack of efficacy of antibiotics in general might be more helpful than communicating with patients about the bacterial or viral nature of their illness, which rather seems to cause confusion. 43 Patients are better off with proper advice on the expected self-limiting course of the illness and the mostly long-lasting complaints, and might be helped with symptomatic treatment that reduces the burden of the illness.

In our prognostic study (Chapter 7) the CRP level at the initial consultation did not predict poor outcome or a prolonged clinical course. Although the rise in CRP levels may be associated with the severity of the infection and the duration of symptoms before consultation, ${ }^{18.26}$ this does not automatically mean that patients with high levels of CRP are worse off than others. CRP levels fall rapidly if the patient recovers, whether or not influenced by proper treatment. This may imply that repeated measurements of CRP may be of greater clinicall use than a single recording. A definitive answer to the question whether or not CRP may help to predict poor outcome in LRTI in general practice can only be given if its value is recorded in a study population with untreated, non-severe LRTI, including pneumonia patients. So far, however, it has not been possible to conduct such a study, for ethical reasons, though I believe it may be possible to perform such a study in the future, under controlled circumstances. In our study we may have taken the first step: five patients who turned out to have radiographic evidence of pneumonia recovered without the aid of antibiotic treatment.

\section{CRP point of care test in general practice: yes or no?}

The potential value of CRP anallysis for the diagnosis and management of LRTI is acknowledged in various guidelines. It is particularly useful for GPS, whose work consists largely of establishing diagnoses and testing diagnostic hypotheses, which also involves excluding serious pathology. It is especially in LRTI, where diagnostic insecurity is greatest, and differentiation between acute bronchitis and pneumonia has important therapeutic consequences, that CRP analysis can be of great help. This will only be so if CRP point of care testing is available and refunded by insurers. This has been the case for many years in Norway, Denmark, Sweden and Finland, but not in the UK and the Netherlands. Even CRP analysis in central laboratories, routinely requested at hospital wards, is not often requested by GPs in the Netherlands. This difference between Scandinavia on the one hand and the UK 
and the Netherlands on the other is striking, all the more so since there are otherwise many similarities between these countries in the organisation of and views on general practice. The following causes may contribute to the hesitation to use CRP point of care test analysis in the Netherlands and the UK.

1. Hesitation to implement CRP point of care testing in daily general practice most probably concerns the insufficient evidence that the results of these tests do improve patient care and/or decrease antibiotic overprescribing. More evidence is indeed needed to enlarge the evidence base for recommendations to use CRP point of care testing in the routine diagnostic work-up for LRTI. Despite the promising results from general practice studies and the experience with CRP point of care test use in Scandinavian countries over many years, these studies haven not been undertaken.

2. Another reason may be the concern that the results of the CRP point of care test will be inappropriately interpreted. CRP is a sensitive, non-specific test, which may show CRP values up to 100 times higher than the normal values $(<8-10 \mathrm{mg} / \mathrm{l})$ in healthy subjects. The advantage is that serious illnesses like pneumonia or, in other areas, acute appendicitis or acute myocardial infarction will be easily detected. On the other hand, minor illnesses like pharyngitis or rhinitis may also lead to CRP values above normal, and these results should not lead the GP to conclude that the illness is severe or bacterial and, thus, requires antibiotic treatment. This may occur quite frequently in Scandinavian countries, where the GPs show a tendency to take an active approach (i.e., prescribe an antibiotic) in cases with abnormal CRP test results. This is especially true for consultations on respiratory infections, in which the 'chagrin' factor plays an important role: prescribing unnecessary antibiotics causes less chagrin than unjustified withholding of antibiotic treatment. 44

3. A related point is that introduction of the CRP point of care test in Scandinavian countries may have been too premature and on too large a scale. Introduction in general practice was not planned by health care authorities, nor guided by official guidelines from professional general practice associations. Moreover, it is doubtful whether GPs and their assistants were properly instructed on how to interpret the test results.

4. The simple fact that many of the Scandinavian reports were not in English or were published in journals with low scientific impact may be another reason why CRP point of care test analysis is not a topic of interest in the UK and the Nether* lands.

5. GPs are generally reticent about adopting new technologies or diagnostic instruments that may change daily general practice. They feel comfortable with the consultation skills and procedures that they are familiar with. 
6. Last but not least, the overprescribing of antibiotics does not yet directly harm daily practice situations. For the time being, it is mostly seen as a societal problem that will interest microbiologists more than practicing GPS. The need to change diagnostic behaviour may not be felt by GPS and their professional organisations. On the contrary: many GPs do still welcome the short consultation with a patient with respiratory tract symptoms that ends with the generally accepted prescription of an antibiotic.

Recently, Scandinavian researchers expressed their concern about the excessive use of point of care CRP testing in general practice. A large Swedish study described the use and results of CRP testing in relation to the duration of symptoms and antibiotic prescribing in patients assigned a diagnosis of respiratory tract infection.45 One of the authors' conclusions was that CRP test analysis had been overused in upper respiratory tract infections, with the possible consequence that GPS in this study eagerly prescribe antibiotics when CRP levels are above normal. Unfortunately, the GPs seem to have diagnosed the illness after having read the CRP point of care test result, which means that the authors' conclusion that too many CRP tests were being performed for viral upper respiratory tract infections was not valid. Despite this, they did find that CRP tests were performed in almost half of the study population (mostly upper respiratory tract infections), leading to a statistically significant decrease in antibiotic prescribing. Although the authors merely stressed the excessive use of the CRP point of care test in Swedish general practice, the number of antibiotic prescriptions for LRTI was low (34\%) if a CRP test result of $<25$ $\mathrm{mg} / \mathrm{l}$ was recorded. A similar, retrospective study concluded that the CRP test for upper respiratory tract infections made little contribution to relevant management. ${ }^{46}$ Both studies show that the CRP point of care test is widely used in Sweden. It is reasonable to conclude that the introduction of the CRP point of care test in Scandinavian general practice has taken place before sufficient knowledge about indications and interpretation of the test results was available. The value of the CRP point of care test lies in its high accuracy in discriminating between pneumonia and acute bronchitis. It is not rational to use it for upper respiratory tract infections, since the test results will rarely have consequences for the management of the illness. In LRTI, it may lead, if properly used and interpreted, to considerable reduction of unnecessary antibiotic prescribing. It is regretfut that scepticism about. the use of the CRP point of care test is fed by studies including all kinds of respiratory tract infections, as well as by GPs who have never been told how to use the CRP point of care test in daily practice.

\section{CRP and the Dutch guidelines on acute cough}

In 2003, the Dutch College of General Practitioners published its practice guidelines (NHG-Standaard) for patients with acute cough. The steering committee preparing the text for the guidelines eventually hesitated to add information on the diagnostic value of CRP to the text. This is surprising for more than one reason. 
Convincing evidence of the great difficulties GPS have in discriminating between pneumonia and acute bronchitis is avallable. 1,40 Moreover, diagnostic tests that help discriminate between these two are important, since therapeutic decisions differ for pneumonia (antibiotics required) and acute bronchitis (antibiotics rarely required). The chapter of the guidelines on 'additional diagnostic testing' is based on the assumption that GPs generally diagnose properly on the basis of history and physical examination. The value of CRP testing is not discussed in the official text, but has only been added to the notes, with seven references. Other GPs have also noted this shortcoming after publication of the guidelines. 47 Instead, the guidelines advocate the use of chest radiography if there is clinical doubt about the presence of pneumonia, which - according to the authors - is the case when severely ill patients do not have any signs of pneumonia, or when focal chest abnormalities are found in non-severe illness. If GPs were to follow these guidelines, this would lead to the use of chest radiography in almost every LRTI patient, and in patients with acute bronchitis in particular, since clinical doubt occurs with most LRTI patients, and focal chest abnormalities are an obligatory criterion to diagnose acute bronchitis. Moreover, the value of routine chest radiography for cliagnosing pneumonia has proved disappointing in a previous, community-based study. 48 Since the publication of the guidelines, this limited value has been confirmed by our study of inter-observer variation in interpretation of chest radiographs for pneumonia. ${ }^{49}$

In 2004, other studies were published that supported our findings that CRP is strongly associated with pneumonia. In an American study of patients with acute cough at emergency departments, including $12 \%$ pneumonia patients, the CRP point of care test turned out to be a clinically useful diagnostic test for predicting pneumonia. ${ }^{50}$ The same conclusion was drawn in a population-based case-control study in Spain, which compared the CRP test results of pneumonia patients, suspected pneumania patients and healthy subjects. 18 Hopefully, these new studies will help to overcome the current hesitations about adding CRP test analysis to the diagnostic work-up of LRTI in general practice.

\section{Prognostic considerations}

\section{Outcome}

Patients generally do not take a great deal of interest in diagnoses, test results or insights into GPs" clinical decisions; they usually want to be cured as quickly as possible. Furthermore, they want to know how long symptoms will last. Physicians often respond with undifferentiated answers like 'consult me again if symptoms get worse, or if the illness lasts longer than one or two weeks'. Strikingly, data on outcome and prognosis are the least available in LRTI research. We have shown that clinical cure takes much longer than generally suggested, irrespective of whether or not the patient is prescribed an antibiotic. Although most patients in our study were considered cured by the GPs after 28 days, half of the patients still reported a variety of symptoms at this time, which in a considerable number of cases impaired 
their usual daily activities. GPS need to be aware of the long duration of symptoms in LRTI, and the possible differences in the interpretation of cure by GPS and patients. GPS therefore need to communicate expectations about the course of the illness to their patients, and need to be aware of differences in the interpretations of cure, if we are to reduce the large number of unnecessary reconsultations and first or second antibiotic courses in the future. 51,52

In our pragmatic study, the process of establishing a diagnosis and deciding whether or not to prescribe an antibiotic for LRTI was left to the GPS, as it is in usual care. This resulted in the unique opportunity to study the natural course of five pneumonia cases not treated with an antibiotic. The illness was uncomplicated and self-limiting in all five cases, indicating that antibiotic treatment might play a minor role in the management of LRTI in the community. Moreover, diagnostic labelling seems to be of less importance than knowing which patients are at risk of a prolonged clinical course or poor prognosis.

\section{Prognosis}

We evaluated the contribution of a broad range of patient characteristics, clinical items, infection parameters and antibiotic prescription at presentation on subsequent clinical outcome, but we found no important predictors of a poor outcome. However, the majority of the recruited patients received antibiotic treatment, which may have prevented us from detecting possible factors leading to poor outcome. This problem could not be overcome, since it is ethically impossible to study the natural course of a cohort of LRTI patients. It is also very well possible that the prognosis of LRTI managed in general practice is simply good. The GPs' expertise and sixth sense may well help to detect the few patients who need (immediate) antibiotic treatment or hospitalisation. The others will most probably recover from the illness in due time, irrespective of treatment decisions. Both patients and GPS should allow themselves time for recovery.

\section{Opportunities for future reseairch}

\section{Bacterial resistance, a societal problem}

The global problem of increasing bacterial resistance due to overprescribing of antibiotics is becoming a major societal problem. Many researchers throughout the world are aware that denial of this problem may have catastrophic consequences. If bacterial infections no longer respond to regular antibiatic treatment, the costs of managing patients" illnesses (e.g. expensive antimicrobial therapy, additional diagnostic procedures, isolation of the patient) and providing primary or secondary prevention strategies may soon spiral out of control. Individual patients may be forced to fall back on pre-antibiotic treatment strategies. The first cases of untreatable, multi-resistant bacterial infections have already been found. Policy-makers throughout the world are rarely confronted with the actuall problem and often seem to be reluctant to anticipate its potentially far-reaching consequences. The same 
may be true for practicing GPS, who prefer the 'easy' consultation that ends with handing over the antibiotic prescription, as long as they do not feel the negative consequences of unnecessary prescriptions. Fortunately, primary care researchers have increasingly translated their awareness of the current situation into scientific studies on antibiotic prescribing.

\section{Cooperative research efforts}

In the last 15 years, valuable studies on respiratory tract infections in general practice have been performed in many countries, including the Scandinavian countries, the United Kingdom, Belgium and the Netherlands. Expertise is increasingly being exchanged between these researchers, often within the General practice Respiratory tract Infections Network (GRIN). This has resulted in fruitful cooperation, including co-authorships in the present thesis. More importantly, it provides opportunities to join forces in designing, performing and finding funds for the necessary further studies.

In Belgium, Coenen has collected about 1500 patients with acute cough, of whom a considerable number had LRTI. Cooperation in the earlier phases of our respective studies has led to the decision to use comparable study criteria. This will give us the opportunity to try and validate the results of some of the analyses presented in this thesis in the near future. The important diagnostic value of CRP testing in LRTI has been found in various studies in general practice. Despite the consistently positive outcomes, guidelines still consider CRP onlly of potential value for the diagnosis of pneumonia in LRTI cases. It is therefore time for a systematic evaluation of the availablle evidence on CRP in LRTI. CRP test analysis is only useful if the results are available before the GP makes the decision whether to prescribe an antibiotic for the illness. Since the results of CRP point of care tests are available within three minutes, they can influence management decisions. If CRP levels found in the point of care test are low $(<20 \mathrm{mg} / \mathrm{l})$, the test may help the GP to safely reduce unneces. sary antibiotics prescriptions. However, the chances of successful use of CRP point of care test analysis in general practice will be increased if its introduction is accompanied by skills trainings to ensure the proper use of the test, and improve communication aspects.

It is time to test these assumptions. We have therefore developed a clusterrandomised controlled trial that should answer the following research questions. To what extent will the introduction of the CRP point of care test and enhanced communication skills for managing LRTI in general practice, either separately or combined, lead to improved patient recovery, a reduction in the use of other diagnostic tests and a reduction in antibiotic prescribing? To what extent are these reductions cost-effective? The intended trial may result in convincing evidence of the additional value of the CRP point of care test for the diagnosis and management of LRTI. With the results of a CRP point of care test at hand, GPS will then be able to manage LRTI better than ever before. 
Future studies are necessary to confirm or disprove the findings presented in this thesis. In all modesty, however, I believe that it may already be more sensible to adopt the consequences of the most convincing findings of our studies than to rely on anecdotal evidence, personal experience or results from research among highly selected populations. 


\section{References}

1. Melbye $H$, Straume $B$, Aasebo $U$, Dale $K$. Diagnosis of pneumonia in adults in general practice. Rellative importance of typical symptoms and abnormal chest signs evaluated against a radiographic reference standard. Scand J Prim Heatth Care. 1992;10:226-33.

2. Melbye $H$, Straume B, Aasebo $U$, Brox J. The diagnosis of adult pneumonia in general practice. The diagnostic value of history, physical examination and some blood tests. Scand J Prim Health Care. 1988;6:111-7.

3. Macfarlane JT, Prewitt J, Gard P, Guion A. Comparison of amoxycillin and clarithromycin as initial treatment of community-acquired lower respiratory tract infections. Br J Gen Pract. 1996;46:357-60.

4. Macfarlane JT, Colville A, Guion A, Macfarlane RM, Rose DH: Prospective study of aetiology and outcome of adult lower-respiratory-tract infections in the community. Lancet. 1993;341:511-4.

5. Wilsan $S$, Delaney BC, Roalfe A, Roberts $L$, Redman 'V, Wearn AM, Hobbs FD. Randomised controlled trials in primary care: case study. BMJ. 2000;321:24-7.

6. Tillett WS, Francis T. Serological reactions in pneumonia with a non-protein somatic fraction of pneumococcus, 1930:561-71.

7. Pepys MB. C-reactive protein fifty years on. Lancet. 1981;1:653-7.

8. Young $B$, Gleeson $M$, Cripps AW: Creactive protein: a critical review. Pathology. 1991;:23:118-24.

9. Gambino R. C-reactive protein-undervalued, underutilized. Clin Chem. 1997:43: $2017-8$.

10. Lehtomaki K. Clinical diagnosis of pneumococcal, adenoviral, mycoplasmal and mixed pneumonias in young men. Eur Respir J. 1988;1:324-9.

11. Smith RP, Lipworth $\mathrm{BJ}$. C-reactive protein in simple community-acquired pneumonia. Chest. 1995;107:1028-31.

12. Smith RP, Lipworth BJ, Cree IA, Spiers EM, Winter JH. C-reactive protein. A clinical marker in community-acquired pneumonia. Chest. 1995;108:1288-91.

13. Ortqvist $A$, Hedlund J, Wretlind B, Carlstrom A, Kalin M. Diagnostic and proginostic value of interleukin-6 and C-reactive protein in community-acquired pneumonia. Scand J Infect Dis. 1995;27;457-62.

14. Babu G, Ganguly NK, Singhi $S$, Walia BN. Value of C-reactive protein concentration in diagnosis and management of acute lower respiratory infections. Trop Geogr Med. 1989:41:309-15.

15. Lehtomaki K, Leinonen M, Takala A, Hovi T, Herva E, Koskela M. Etiological diagnósis of pneumonia in military conscripts by combimed use of bacterial culture and serological methods. Eur J Clin Microbiol Infect Dis. 1988;7:348-54.

16. Korppi M, Heiskanen Kosma T, Leinonen M. White blood cells, C-reactive protein and erythrocyte sedimentation rate in pneumococcal pneumonia in childiren. Eur Respir $J$. $1997: 10: 1125-9$

17. Garcia Vazquez E, Martinez JA, Mensa J, Sanchez F, Marcos MA, de Roux A, Torres A. Creactive protein levells in communityacquired pneumonia. Eur Respir J. 2003;21: $702-5$.

18. Almirall J, Bolibar I, Toran P, Pera G, Boquet X, Balanzo X, Sauca G. Contribution of Creactive protein to the diagnosis and assessment of severity of community-acquired pneumonia. Chest. 2004;125:1335-42.

19. Nohynek $H$, Valkeila $E$, Leinonen $M$, Eskola J. Erythrocyte sedimentation rate, white blood cell count and serum C-reactive protein in assessing etiologic diagnosis of acute lower respiratory infections in children. Pediatr Infect Dis J. 1995;14:484-90. 
20. Korppi $\mathrm{M}_{\text {; Kroger } L} \mathrm{C}$ Creactive protein in viral and bacterial respiratory infection in children. Scand J infect Dis. 1992;25:207-13.

21. Soderstrom $M$, Blomberg J, Christensen $P$. Hovelius $B$. Enythromycin and phenoxymethy/penicilin (penicilin $V$ ) in the treatment of respiratory tract infections as related to microbiological findings and serum creactive protein. Scand I Infect Dis. 1991;23:347-54:

22. Jonsson JS, Sigurdsson JA, Kristinsson KG, Guthnadottir M, Magnusson S. Acute bronchitis in adults. How close do we come to its aetiology in general practice? Scand I Prim Health Care. 1997;15:156:60.

23. Ruuskanen $O$, Putto $A$, Sarkkinen $H$, Meurman 0 , Irjala $K$. C-reactive protein in respira. tony virus infections. J Pediatr 1985;107:97-100.

24. Heiskanen Kosma $T$, Korppi M. Serum C-reactive protein cannot differentiate bacterial and wiral aetiology of community-acquired pneumonia in children in primary healthcare settings. Scand J Infect Dis. 2000;32:399-402.

25. Ritland $N$, Melbye H. Crreaktivt protein, SR og hvite blodlegemer ved akutte nedre luftveislidelser. Nytten av blodprover i diagnostisering av pneumoni. Tidsskr Nor Laegeforen. 1991:111:2249.52.

26. Melbye $H$, Straume $B$, Brox $J$. Laboratory tests for pneumonia in general practice: the diagnostic values depend on the duration of illness. Scand J Prim Health Care. 1992;10:234440.

27. Dahler Eriksen BS, Lassen JF, Lund ED, Lauritzen T, Brandslund I. C-reactive protein in general practice-how commonly is it used and why? Scand J Prim Health Care. $1997 ; 15: 35-8$.

28. Dahler Eriksen BS, Lassen JF, Lauritzen T, Lund ED, Brandslund I. Forskelle I brugen af C-reaktivt protein og saenkningsreaktion i almen praksis og pa sygehus. Udwikling fra 1986 til 1995. Ugeskr Laeger. 1998;160:4868-72.

29. Hobbs FD, Kenkre JE, Carter $\mathrm{YH}$, Thorpe GH. Holder RL. Reliability and feasibility of a near patient test for C-reactive protein in primary care. $\mathrm{Br} / \mathrm{Gen}$ Pract. 1996;46: $395-400$.

30. Urdlal P, Borch SM, Landaas S, Krutnes MB, Gogstad GO, Hjortdahl P. Rapid ilmmunometric measurement of C-reactive protein in whole blood. Clin Chem. 1992;38: 5804.

31. Dahler Eriksen BS, Lassen JF, Petersen PH, Lund ED, Lauritzen T, Brandslund I. Evaluation of a near-patient test for C-reactive protein used in daily routine in primary healthcare by use of difference plots. Clin Chem. 1997;43:2064-75.

32. Hjortdahl $P$, Landaas $S$, Urdal $P$, Steinbakk $M$, Fuglerud $P$, Nygaard $B$. C-reactive protein: a new rapid assay for managing infectious disease in primary health care. Scand J Prim Health Care. 1991;9:3-10.

33. Hansison LO, Carlsson I, Hansson E, Hovelius B, Svenssom P, Tryding N. Measurement of C-reactive protein and the erythrocyte sedimentation rate in general practice. Scand J Prin Health Care 1995:13:39-45.

34. Dinant GJ, de Kock CA, van Wersch JW. Diagnostic value of C-reactive protein measurement does not justify replacement of the erythrocyte sedimentation rate in daily general practice. Eur J Clin Invest. 1995;25:353-9.

35. Lindbaek M, Hjortdahl P. C-reaktivt protein i allmennpraksis. Et viktig diagnostisk helpemiddel ved infeksjoner. Tidsskir Nor Laegeforen. 1998;118:1176-9.

36. Melbye $H_{1}$, Aaraas I, Fleten N, Kolstrup N, Mikalsen Jl. Nytten av a teste C-reaktivt protein ved mulig nedre luftveisinfeksjon. En undersokelse fra allmennpraksis av en hurtigtests innvirkning pa antibiotikaforskrivning og sykdomsforlop hos voksne. Tidsskr Nor Laegeforen. 1995;115:1610-5. 
37. Diederichsen $H Z$, Skaming $M$, Diederichsen $A$, Grinsted $P$, Antonsen $S$, Petersen $P H$, Munck AP, Kragstrup J. Randomised controlled trial of CRP rapid test as a guide treatment of respiratory infections in general practice. Scand I Prim Health Care. 2000; 18:39-43.

38. Smucny J, Fahey T, Becker L, Glazier R. Antibiotics for acute bronchitis /Cochrane review): The Cochrane Library. Issue 1, 2004. Chichester, UK, John Wiley \& Sons, Ltd., 2004.

39. Fahey $T$, Stocks $N$, Thomas $T$. Quantitative systematic review of randomised controlled trials comparing antibiotic with placebo for acute cough in adults. BMJ. 1998;316: 906-10.

40. Hopstaken RM, Muris JWM, Knottnerus JA, Kester ADM, Rinkens PELM, Dinant GJ. Contributions of symptoms, signs, erythrocyte sedimentation rate and C-reactive protein to a diagnosis of pneumonia in acute lower respiratory tract infection. $\mathrm{Br} J \mathrm{Gen}$ Pract. 2003;53:358-64.

41. Graffelman AW, Knuistingh Neven A, le Cessie S, Kroes ACM, Springer MP, van den Broek PJ. A diagnostic rule for the aetiology of lower respiratory tract infections as guidance for antimicrobial treatment. Br J Gen Pract. 2004;54:20-4.

42. Hopstaken R, Hay AD, Butler CC. Diagnosis of bacterial LRTI. Br J Gen Pract. 2004; $54: 216$.

43. Butler CC, Rollnick S, Pill R, Maggs Rapport F, Stott N. Understanding the culture of prescribing: qualitative study of general practitioners' and patients ${ }^{\prime}$ perceptions of antibiotics for sore throats. BMJ. 1998,317:637-42.

44. Feinstein AR. The 'chagrin factor' and qualitative decision analysis. Arch Intern Med. 1985;145:1257-9.

45. Andre $M$, Schwan $A$, Odenholt $\mathbb{I}$. The use of CRP tests in patients with respiratory tract infections in primary care in Sweden can be questioned. Scand J Infect Dis. 2004;36" 192-7.

46. Engstrom $S_{v}$ Molstad $S_{4}$ Lindstrom $K_{n}$ Nilsson $G$, Borgquist L. Excessive use of rapid tests in respiratory tract infections in Swedish primary health care. Scand J Infect Dis. $2004 ; 36: 213-8$.

47. van de Lisdonk EH, van den Bosch WI. De standaard 'Acuut hoesten' van het Nederlands Huisartsen Genootschap; reactie vanuit de huisartsgeneeskunde. Ned Tijdischr Geneeskd. 2004;148:700-2.

48. Melbye $H$, Dale $K$. Interobserver variability in the radiographic diagnosis of adult outpatient pneumonia. Acta Radial. 1992;33:79-81.

49. Hopstaken RM. Witbraad T, van Engelshoven JMA, Dinant GJ. Interobserver variation in the interpretation of chest radiographs for pneumonia in community-acquired lower respiratory tract infections. Clin Radiol. 2004;59:743-52.

50. Flanders SA, Stein J, Shochat G, Sellers K, Holland M, Maselli J, Drew WL, Reingold AL, Gonzales R. Performance of a bedside C-reactive protein test in the diagnosis of community acquired pneumonia in adults with acute cough. Am ل Med. 2004:116:529-35.

51. Butler CC, Rollnick S, Kinnersley P, Tapper-Jones L, Houston H. Communicating about expected course and re-consultation for respiratory tract infections in children: an exploratory study. Br J Gen Pract. 2004;54:536-8.

52. Macfarlane J, Prewett J, Rose $D$, Gard $P$, Cunningham $R$, Saikku P. Euden $S$, Myint $S$. Prospective case-control study of role of infection in patients who reconsult after iniliall antibiotic treatment for lower respiratory tract infection in primary care. BMJ "1997* 315:1206-10. 
Summary 


\section{Summary}

Lower respiratony tract infections (LRT) are mostly presented, diagnosed and managed in general practice. Antibiotics are easily prescribed, despite their questionable additional value in many cases. Practice-based studies are of eminent importance to assess the occurrence and presentation of LRTI in primary care and to provide answers that may help to slow down the pace of the emerging problem of growing bacterial resistance worldwide. The many unanswered research questions have stimulated us to initiate this LRTI project. The aim of our study was to examine the aetiology, diagnosis, antibiotic prescribing behaviour, outcome and prognosis of LRTI in general practice, which is essential for the development of rational diagnostic and therapeutic strategies, including a possible reduction of unnecessary antibiotic prescribing.

The studies presented in this thesis were derived from one intervention study and one observational study, with a range of study objectives. The studies were performed in daily general practice with the aid of 25 GPS and their practice assistants in the Dutch province of Limburg, in the years 1998 and 1999. Data of 247 adult patients with acute cough and additional symptoms and signs of LRTI were recorded during regular consultation hours. Additional study procedures, including the collection of biological samples, took place at the GPs' surgeries on the same day. The analysis of biological samples took place at the Haematology, Clinical Chemistry and Medical Microbiology laboratories of the University Hospital Maastricht. Chest radiography was performed and assessed at the Hospital in Sittard and Geleen and at the University Hospital Maastricht.

The contents of the chapters of this thesis are summarized below, followed by specific answers to the research questions addressed in the thesis.

The subject of lower resplratory tract infections in general practice is introduced in chapter 1 , and is followed by descriptions of the general aim of the study and the research questions addressed in this thesis.

The diagnostic value for pneumonia of a large set of clinical items, as well as ESR and CRP, was assessed in 247 patients consulting their GP with symptoms and signs of LRTI. As a reference standard for pneumonia we used the finding of a pulmonary infiltrate on chest radiographs after repeated assessment by two or three radiologists. This study is presented in chapter 2. Dry cough, diarrhoea, recorded temperature $\geq 38^{\circ} \mathrm{C}$, ESR and CRP were independent and statistically significant predictors of pneumonia, whereas abnormal pulmonary auscultation and the clinical diagnosis of pneumonia by the GPs were not. A large group of patients with a low risk of having pneumonia was identified, comprising patients with a CRP test result of $<20 \mathrm{mg} /$ and a maximum of one of the three identified clinical predictors of pneumonia. They could have been safely treated without antibiotics if a CRP point-of-care test had been available in the GPs" offices, which, however, is currently not the case in general practice in the Netherlands. 
The radiologists of three hospitals routinely assessed a pair of chest radiographs for each recruited LRTI patient. The radiographis were then blindly reassessed for the presence or absence of infiltrates by one independent radiologist. The interobserver variation in the interpretation of chest radiographs for patients with pneumonia versus those without pneumonia is reported in chapter 3 . The interobserver agreement adjusted for chance was moderate, and was considerably lower if chronic obstructive pulmonary disease or an infection with Streptococcus pneumoniae was present. Since the agreement in pneumonia cases was much poorer than the agreement in non-pneumonia cases, it was concluded that stricter selection for chest radiography of patients with a higher risk of having pneumonia by GPS would not improve, and probably even decrease, observer agreement. Guidelines on indications for chest radiography in LRTI need to be reconsidered, since the additional value of chest radiography after diagnostic work-up by the GP is questionable.

Whether or not viral LRTI can be differentiated from bacterial LRTI had never been systematically studied before. In chapter 4 findings on history-taking, physical examination and relevant blood tests are evaluated for their ability to predict viral or bacterial LRTI. After a thorough analysis of the data, including repeated testing in various subpopulations, the answer was simple: extensive history-taking and physical examination did not yield any items that predict viral or bacterial LRTI. Although often suggested, we could not confirm the view that CRP can differentiate between wiral and bacterial LRTI, but elevated CRP and ESR were valuable in distinguishing between microbiologically proven LRTI and microbiollogically unexplained LRTI.

This chapter also presents frequencies of the respiratory tract pathogens isolated in community-acquired LRTI. Viral pathogens were found as often as bacterial pathogens. Haemophilus (para-) influenzae was most frequently found, followed by Influenza $A_{1}$ Streptococcus pneumoniae, Influenza B and Adenovirus. Roughly the same frequency distribution was found in the subgroup of pneumonia patients. We were unable to confirm the common belief that the aetiology of acute bronchitis is mostly viral, and that of pneumonia mostly bacterial.

It is often questioned whether amoxicillin is still the drug of choice if antibiotic treatment is required (or believed to be required) in LRTI. In light of a possible rise of bacterial infections caused by Legionella pneumophila, Chlamydia pneumonia and Mycoplasma pneumoniae, a macrolide antibiotic may be a better choice. Chapter 5 reports the results of a double-blind randomised controlled medication trial in 196 LRTI patients who needed antibiotic treatment according to their GP. The efficacy and safety of roxithromycin were compared with those of amoxicillin in a 10 day treatment regimen. The possible additional value of roxithromycin was not confirmed. No infections with Chlamydia pneumoniae were found. Mycoplasma pneumoniae was found in two patients, and Legionella pneumophila in one patient only. Clinical cure rates after the completion of antibiotic treatment ( 10 days) were 
not significantly different for the two groups. After complete follow-up ( 28 days), the GPs concluded that $90 \%$ of the patients had been effectively and safely treated with either amoxicillin or roxithromycin. We concluded that amoxicillin remains a reliable first-choice antibiotic in the treatment of LRTI in general practice in the Netherlands.

The negative consequences of the overprescription of antibiotics for LRTI are wellknown, and questionnaire-based and qualitative studies have asked clinicians about their perceptions of the reasons behind this overprescription. Chapter 6 describes the findings on history and physical examination that predict antibiotic prescribing for LRTI, and explores the appropriateness or otherwise of these prescribing decisions. Auscultation abnormalities and diarrhoea strongly predicted antibiotic prescribing. Antibiotics were prescribed for $79 \%$ of the 247 patients. Assuming that antibiotics need to be prescribed only for patients with pneumonia, they were inappropriately prescribed in most patients. Despite this overprescription, antibiotics were not prescribed for $16 \%$ of the patients with a radiographic diagnosis of pneumonia. Although not well-known as a predictor of pneumonia, GPs (implicitly) acknowledged diarrhoea as an important reason for (appropriately) prescribing antibiotics. The importance of abnormal auscultation, however, was overestimated and was associated with inappropriate antibiotic prescribing. GPS were overconfident about their diagnostic skills. The results should prompt them to consider the low predictive value of abnormal auscultation in reaching evidence-based prescribing decisions in patients with LRTI.

Chapter 7 presents the contribution of patient characteristics and history and examination findings to delayed and enhanced symptom resolution. Coexistent asthma was correlated with delayed symptom resolution, whereas fever, perspiring and the prescription of antibiotics were identified as (weak) prognostic factors for enhanced symptom resolution. The chapter also describes the duration of the clinical course and the clinical outcome of LRTI, as reported by GPS and patients. as well as the impact of LRTI on impairment of daily activities. The course of LRTI was generally uncomplicated, but the morbidity was considerable and lasted longer than generally reported, in particular in patients with coexisting asthma. According to the GPS, most LRTI patients were clinically cured after a 28-day follow-up. irrespective of whether the patients were prescribed antibiotics. However, half of the study population still reported symptoms (most commonly cough and dyspnoea) after 28 days of follow-up, and considerable numbers of patients still reported limitations to their usual daily activities at that time. With this evidencebased account of outcomes in patients with LRTI, GPS may be able to offer their patients realistic expectations about illness duration and thus help avold reconsultations and associated unnecessary antibiotics.

GPs are often afraid that they may miss pneumonia cases, a fear which contributes to high levels of antibiotic prescribing in LRTI. This practice-based study gave us the opportunity to follow the clinical courses of five pneumonia patients who had not 
received antibiotics. Their illnesses were all self-limiting. It should be reassuring for GPS to know that not all pneumonia cases require antibiotic treatment.

Issues relating to the implementation of diagnostic research findings in daily general practice, and its attendant difficulties, are discussed in chapter 8. Our research project on LRTI in general practice is used to illustrate important issues of the paradox of evidence and practice. Researchers doing clinical-diagnostic studies in general practice will need to be aware of factors promoting successful implementation strategies before the study is even started. Chances of successful implementation of diagnostic research are higher, when GPs are involved in all phases of the project, when the results are published in national journals, and when the GPS' professional colleges actively support the implementation strategies. Successful implementation of the results of well-designed and carefully carried out diagnostic research is invaluable in terms of reducing uncertainty and creating greater job satisfaction for GPS.

Chapter 9 provides a general discussion of the research underlying this thesis. The questions this project tried to answer were formulated on the basis of acknowledged clinical dilemmas encountered by practicing GPs. A practice-based approach was chosen to help fill the gaps in our primary care knowledge and to increase the chances of successful implementation of the study results in daily general practice, and the chapter also discusses methodological aspects of this approach. GPs are generally not familiar with the use of CRP testing, which turned out to be a highly relevant test in the diagnostic work-up of LRTI. For this reason, the chapter discusses relevant previous studies and reasons why GPs hesitate to use CRP point-of-care testing. This is followed by a discussion of the prognosis and outcome of LRTi. Clinical cure often takes much longer than generally suggested, and GPS regard their patients as cured sooner than the patients themselves. Communicating expectations about the course of the illness and awareness of differences in the interpretation of 'cure' between GPs and patients are therefore necessary to reduce the large number of unnecessary reconsultations and first or second antibiotics courses in the future.

To fight the growing problem of increasing bacterial resistance, researchers around the world need to join forces in performing much-needed further studies. Cooperation has already resulted in the development of a cluster-randomised controlled trial, which will try to answer the following research questions: To what extent will the introduction of the CRP point-of-care test and enhanced communication skills for managing LRTI in general practice, either separately or combined, lead to improved patient recovery, a reduction in other diagnostic testing and a reduction in antibiotic prescribing? To what extent are these reductions cost-effective?

Although new studies are necessary to confirm or disprove the findings presented in this thesis, it may already be more sensible to adopt the most convincing results 
of our studies than to rely on anecdotal evidence, personal experience or results from research among highly selected (hospital) populations.

\section{Answers to the research questions}

1. What is the diagnostic value of clinical symptoms, signs and additional blood tests for the diagnosis of pneumonia in LRTI?

Dry cough, diarrhoea, recorded temperature $\geq 38^{\circ} \mathrm{C}$. ESR and CRP were independent and statistically significant predictors of pneumonia, whereas abnormal pulmonary auscultation and clinical diagnosis of pneumonia by the GPS were not. CRP had higher diagnostic odds ratios than any of the symptoms and signs. If a prediction rule for low-risk patients, including $C R P<20 \mathrm{mg} / \mathrm{l}$, had been applied, 80 of the 193 antibiotic prescriptions could have been prevented, with a maximum risk of $2.5 \%$ of missing a pneumonia case.

2. What is the inter-observer agreement in the interpretation of chest radiographs for pneumonia in community-acquired LRTI?

The observed proportional agreement was 218 in 243 patients $(89.7 \%)$. However, the inter-observer agreement adjusted for chance was moderate (kappa $0.53 ; 95 \%$ $\mathrm{Cl}$ 0.37-0.69). The agreement in pneumonia cases was much poorer than the agreement in non-pneumonia cases (59\% versus 94\%). Kappa was considerably lower if chronic obstructive pulmonary disease $(0.20)$ or Streptococcus pneumoniae infection $(-0.29)$ was present.

3. What is the frequency distribution of the microorganisms most frequently involved in LRTI in the community?

Viral pathogens were found as often as bacterial pathogens. Haemophilus (para-) influenzae was most frequently found $(16 \%)$, followed by Influenza $A(14 \%)$, Streptococcus pneumoniae $(6 \%)$ and Influenza B and Adenovirus (both $5 \%$ ). The so-called atypical bacteria were present in less than $2 \%$ of the LRTI patients. Roughly the same frequency distribution was found in the subgroup of pneumonia patients.

4. Is the macrolide antibiotic roxithromycin more effective than amoxicillin in the treatment of LRTI?

The possible additional value of roxithromycin was not confirmed. Clinical cure rates after the completion of antibiatic treatment (10 days) were not significantly different for the two groups. After complete follow-up (28 days), the GPs concluded that $90 \%$ of the patients had been effectively and safely treated with either amoxicillin or roxithromycin. 
5. What is the diagnostic value of clinical symptoms, signs and additional blood tests for the diagnosis of viral and bacterial LRT?

Extensive history-taking and physical examination did not yield items that predicted viral or bacterial LRTI. In addition, we were unable to confirm that CRP differentiates between viral and bacterial LRTI. CRP and ESR values were significantly higher in microbiologically proven LRTI than in microbiologically unexplained LRTI.

6. How do the general practitioners' history and examination findings influence antibiotic prescribing rates for LRTI, and to what extent do these clinical findings predict appropriate antibiotic prescribing?

Auscultation abnormalities and diarrhoea strongly predlicted antibiotic prescribing. Antibiotics were prescribed for $196(79 \%)$ patients. Assuming that antibiotics need to be prescribed only for patients with pneumonia, they may have been inappropriately prescribed in up to $86 \%$ of the patients. Antibiotics were not prescribed for $16 \%$ of the patients with a radiographic diagnosis of pneumonia.

7. How long does it take to recover from LRTI according to GPS and patients, taking possible antibiotic treatment and various subgroups into consideration? Eighty-nine percent of the LRTI patients were clinically cured after a 28-day followup, irrespective of whether the patients had received antibiotics. However, symptoms (mainly cough and dyspnoea) were still present in $43 \%$ of the LRTI patients considered to be cured. The self-reported cure rate was much lower $(51 \%)$. The clinical courses of five pneumonia patients who had not received antibiotics were all self-limiting, although one patient took more than 28 days to recover.

8. To what extent does LRTI impair the patients' daily activities?

At baseline, daily activities were impaired in $73 \%$, and abandoned in $42 \%$ of the patients. These percentages were 19 and 6 , respectively, after a 28 -day follow-up.

9. Is it possible to identify subgroups of patients with patient and clinical characteristics indicating that they are prone to a poor prognosis or a prolonged clinical course?

Coexisting asthma was correlated with delayed symptom resolution, whereas fever, perspiring and the prescription of antibiotics were identified as (weak) prognostic factors for enhanced symptom resolution. Poor prognosis, in the sense of mortality or persistent morbidity resulting from the acute LRTI course, did not occur. 
10. Why is implementation of diagnastic research in dally general practice often not achieved, and how can it be improved?

The key issues and messages are:

- General practice research should be done in general practice, and GPS need to be involved in all phases of a diagnostic research project to increase the chances of successful implementation afterwards.

- Whereas researchers are often obliged to publish their study results in international journals, most general practitioners read national journals only; new diagnostic evidence should be published in these journals.

- Since diagnostic implementation strategies are hampered by the lack of backup by the kinds of powerful (pharmaceutical) companies that support therapeutic research, they should be supported by the GPs' professional colleges and be incorporated in evidence-based guidelines. 
Samenvatting 


\section{Samenvatting}

Lageluchtweginfecties (LLWI) worden meestal in de huisartsenpraktijk gepresenteerd, gediagnosticeerd en behandeld. Antibiotica worden vaak voorgeschreven, ondanks het feit dat dit in veel gevallen niet helpt. Bovendien leidt de hoge consumptie van antibiotica tot een groeiend, wereldwijd probleem van bacteriële resistentie tegen antibiotica. Het streven bij te dragen aan een rationeel gebruik van antibiotica heeft ons geïnspireerd tot het bestuderen van etiologie, diagnose, voorschrijfgedrag, genezing en prognose van LLWI in de huisartsenpraktijk. Daarbij was het doel rationele diagnostische en therapeutische strategieën te ontwikkelen die kunnen leiden tot een vermindering van onnadig antibioticagebruik bij LLWI.

De in dit proefschrift beschreven hoofdstukken komen voort uit een interventieonderzoek en een observationeel onderzoek. De onderzoeken zijn uitgevoerd in de dagelijkse huisartsenpraktijk. 25 Huisartsen in de provincie Limburg verleenden in 1998 en 1999 hun medewerking. De anamnestische gegevens en bevindingen van het lichamelijk onderzoek van 247 volwassen patiënten met acute hoest werden tijdens het dagelijkse spreekuur verzameld en geregistreerd. Aanvullend onderzoek, waaronder het verzamelen van bloed-en sputummonsters, vond - op dezelfde dag - plaats in de praktijk. Ze werden geanalyseerd in de laboratoria voor hematologie, klinische chemie en medische microbiologie van het academisch ziekenhuis Maastricht. Thoraxfoto's werden gemaakt en beoordeeld in het Maaslandziekenhuis te Sittard en Geleen en in het academisch ziekenhuis Maastricht. De inhoud van de hoofdstukken van het proefschrift worden hieronder samengevat, waarna wordt afgesloten met de specifieke antwoorden op de verschillende onderzoeksvragen.

Het onderwerp lageluchtweginfecties in de huisartsenpraktijk wordt geïntroduceerd in hoofdstuk 1. Daarna volgt een beschrijving van het algemene doel van het onderzoek en de specifieke onderzoeksvragen die in het proefschrift aan bod komen.

We onderzochten de waarde van een uitgebreide anamnese, bevindingen bij lichamelijk onderzoek, de bezinkingssnelheid van erytrocyten (BSE) en C-reactief proteïne (CRP) voor de diagnose pneumonie bij patiënten met een LLWI. Dit onderzoek is beschreven in hoofdstuk 2. 247 Patiënten die hun huisarts consulteerden met klachten en ziekteverschijnselen van LLWI verleenden hun medewerking. Thoraxfoto's werden door twee of drie radiologen beoordeeld op de aan- of afwezigheid van infiltraten. De uiteindelijke vaststelling van een infiltraat werd beschouwd als bewijs voor pneumonie en fungeerde als referentiestandaard voor de diagnostische parameters. Droge hoest, diarree, gemeten temperatuur van $\geq 38^{\circ} \mathrm{C}$, BSE en CRP waren onafhankelijke en statistisch significante voorspellers van pneumonie. Afwijkingen bij auscultatie van de longen en de klinische diagnose pneumonie door de huisarts waren (onder meer) niet voorspellend voor pneumonie. Een grote groep patiënten met een laag risico op pneumonie kon worden 
geidentificeerd. Deze groep bestond uit patiënten met een CRP testuitslag van $<20 \mathrm{mg} / \mathrm{l}$ en maximaal éen positieve score op de drie variabelen droge hoest, diarree en temperatuur $\geq 38^{\circ} \mathrm{C}$. Als huisartsen een CRP sneltest in de praktijk tot hun beschikking hadden, wat in Nederland momenteel niet het geval is, dan hadden de patiënten in deze laagrisicogroep veilig behandeld kunnen worden zonder een antibioticum.

De radiologen van drie ziekenhuizen hebben van elke deelnemende patiènt die zich in het ziekenhuis meldde twee thoraxfoto's beoordeeld op infiltraten. Deze foto's werden vervolgens opnieuw geblindeerd beoordeeld door een andere radioloog. De overeenstemming tussen de beoordelaars in de interpretatie van de longfoto's van patiënten met en zonder pneumonie is beschreven in hoofdstuk 3 . De overeenstemming - gecorrigeerd voor toeval - was matig, en aanzienlijk lager bij patiënten met chronisch obstructieve longziekte (COPD) en bij patiënten met LLWI door Streptococcus pneumoniae. De overeenstemming was aanzienlijk lager bij patiënten met pneumonie dan bij patiënten zonder pneumonie. Als huisartsen in de dagelijkse praktijk alleen patiënten met een hoger risico op pneumonie zouden verwijzen voar een thoraxfoto, dan zou de interbeoordelaars-overeenstemming niet verbeteren, mogelijk zelfs verslechteren. Richtlijinen voor het vervaardigen van thoraxfoto's moeten genuanceerd worden voor wat betreft de indicaties, aangezien de aanvullende waarde na een volledige diagnostische inventarisatie door de huisarts twijfelachtig is.

Adequaat onderzoek naar het klinisch onderscheid tussen virale en bacteriële LLWI bij volwassenen was ten tijde van de start van ons onderzoek niet eerder verricht. In hoofdstuk 4 hebben we onderzocht of bevindingen uit anamnese, lichamelijk onderzoek en bloedonderzoek het mogelijk maken virale en bacteriële LLWI van elkaar te onderscheiden. Na een uitgebreide statistische analyse van de gegevens, inclusief het herhaald testen in subpopulaties, was het antwoord eenvoudig: uitgebreide anamnese en lichamelijk onderzoek leverden geen gegevens op die virale of bacteriële LLWW konden voorspellen. Ook konden we niet bevestigen dat CRP van waarde is bij dit onderscheid. Verhoogde CRP en BSE waren wel van waarde in het onderscheiden van microbiologisch bewezen LLWI ten opzichte van microbiologisch onverklaarde LLWI.

Het voorkomen van verwekkers van LLWI in de algemene praktijk is ook in dit hoofdstuk beschreven. Virale verwekkers van LLWI werden even vaak gevonden als bacteriële verwekkers. Haemophilus (para) influenzae kwam het vaakst voor, gevolgd door Influenza A, Streptococcus pneumoniae, Influenza B en het Adenovirus. In de patiënten met pneumonie werd grofweg dezelfde frequentieverdeling gevonden. De veronderstelling dat acute bronchitis meestal viraal en pneumonie meestall bacterieel is bleek niet waar te zijn.

Steeds vaker wordt betwijfeld of amoxicilline het middel van eerste keuze zou moeten zijn bij LLW1, indien men behandeling met een antibioticum noodzakelijk acht. Als het waar is dat bacteriële infecties door Legionella pneumophila, Chlamy- 
dia pneumonia en Mycoplasma pneumoniae tegenwoordig vaker voorkomen zoals vaak wordt beweerd - zou een antibioticum uit de macroliden-groep een betere keuze kunnen zijn. In hoofdstuk 5 worden de resultaten van een dubbelblind, gerandomiseerd geneesmiddelenonderzoek beschreven. 196 Patienten met LLWI, die volgens de huisarts een antibioticum nodig hadden, deden mee met dit onderzoek. De werkzaamheid en de veiligheid van 10 dagen behandelen met roxitromycine werd vergeleken met amoxicilline. De toegevoegde waarde van roxitromycine werd niet bevestigd. Infecties met Chlamydia pneumoniae werden niet gevonden. Mycoplasma pneumoniae werd aangetoond bij twee patienten en Legionella pneumophila slechts bij een patiënt. Het klinische genezingspercentage na afloop van de behandeling was identiek in de twee groepen. Na afloop van de volledige follow-up van 28 dagen concludeerden de huisartsen dat $90 \%$ van de patiënten effectief en veilig was behandeld, onafhankelijk van het voorgeschreven antibioticum. We concluderen dat amoxicilline nog altijd een betrouwbaar eerstekeuze antibioticum is voor de behandeling van LLWI in de Nederlandse huisartsenpraktijk.

De negatieve gevolgen van onnodig antibiotica voorschrijven zijn bekend. In enquêtes en kwalitatief onderzoek zijn huisartsen vaker bevraagd over hun perceptie van de redenen voor het overmatig voorschrijven van antibiotica. Het is echter niet goed bekend wat de huilsarts nu daadwerkelijk - in de dagelijkse praktijk - doet besluiten antibiotica voor te schrijven. Hoofdstuk 6 beschrijft de gegevens uit anamnese en lichamelijk onderzoek die voorspellend zijn voor het voorschrijven van een antibioticum. Bovendien wordt beschreven in hoeverre beslissingen om een antibioticum voor te schrijven voor de betreffende patiënten adequaat waren. $79 \%$ van de patiënten ontving een antibioticumvoorschrift van de huisarts. Afwijkingen bij auscultatie en diarree waren zeer sterke voorspellers van de beslissing om een antibioticum voor te schrijven. Uitgaande van de huidige wetenschappelij* ke bewijswoering dat alleen patiënten met pneumonie een antibioticum nodig hebben, kregen de meeste patiënten ten on rechte een antibioticum. Ondanks het grote percentage onnodige voorschriften, kreeg $16 \%$ van de patiënten met radialogisch bewezen pneumonie ten onrechte geen antibioticum. Opvallend was dat - het weinig frequent voorkomende - diarree bij patiënten steeds leidde tot het voorschrijven van antibioticum. We vermoeden dat de huisarts op grond van de klinische presentatie van de patiënt impliciet - en vaak terecht - heeft geoordeeld dat de patiënt behandeling met een antibioticum nodig had. Daarentegen werd het belang van afwijkende auscultatie overschat. Dit was geassocieerd met een hoog aantal onnodige antibioticumvoorschriften. Huisartsen bleken bovendien vaak ten onrechte zelfverzekerd over de juistheid van hun diagnostische beslissingen. Men dient zich bewust te zijn van de beperkte waarde van afwijkende auscultatie als het gaat om het nemen van een beslissing wel of geen antibiotica voor te schrijven aan patiënten met LLWI. 
In hoofdstuk 7 worden diverse onderzoeksvragen beantwoord. Allereerst wordt stilgestaan bij de bijdrage van patiëntkenmerken, anamnese en bevindingen van lichamelijk onderzoek voor vertraagde en snelle genezing van de patiënt. Astma als comorbiditeit was de enige factor die statistisch significant correleerde met vertraagde klachtenafname, zoals door de patiënt geregistreerd. Koorts, transpireren en het voorschrijven van een antibioticum waren zwakke voorspellers van snelle klachtenafname. Hoofdstuk 7 geeft tevens inzicht in de totale duur en de beperkingen in dagelijkse activiteiten van een die LLWI veroorzaakt. De huisartsen en de patiënten hebben bovendien op de laatste dag van de follow-up, na 28 dagen, onafhankelijk van elkaar bepaald of de patiënt was genezen. Het verloop van LLWI was ongecompliceerd, maar duurde veel langer dan meestal gerapporteerd wordt, in het bijzonder bij patiënten met astma als co-morbiditeit. De ziektelast was aanzienlijk. De huisartsen beschouwden de meeste patiënten genezen na 28 dagen, onafhankelijk van behandeling met of zonder een antibioticum. Daarentegen rapporteerde de helft van de patiënten na 28 dagen nog klachten van LLWI, vooral hoest en benauwdheid. Bovendien was op dit laatste evaluatiemoment nog. een aanzienlijk aantal patiënten beperkt in hun dagelijkse activiteiten. Meer realistische verwachtingen over de vaak lange ziekteduur en ziektelast van LLWI kunnen bijdragen aan een reductie van het aantal onnodige herhaalde bezoeken aan de huisarts, en het daarmee geassocieerde grote aantal onnodige antibioticumvoorschriften. Goede communicatie tussen arts en patiënt is daarbij een essentiële voorwaarde.

De vrees pneumonie over het hoofd te zien draagt bij aan het onnodig voorschrijven van antibiotica. De pragmatische studieopzet gaf ons de unieke kans het klinische beloop van pneumonie te volgen bij vijf patiënten die geen antibioticum hadden ontvangen. De ziekte genas steeds spontaan. Het moet een geruststellende gedachte zijn voor huisartsen dat niet elke patiënt met pneumonie een antibioticum nodig heeft om te genezen.

In hoofdstuk 8 wordt aandacht besteed aan kwesties rondom de implementatie van resultaten van diagnostisch onderzoek in de huisartsenpraktijk. We gebruikten het LLWI-project als voorbeeld om de paradox tussen evidence en practice te illustreren. De kans op succesvolle implementatie van diagnostisch onderzoek neemt toe als huisartsen in alle fasen van het onderzoek betrokken zijn, als de resultaten gepubliceerd worden in nationale vakbladen, en als de beroepsgroep implementatiestrategieën concreet ondersteunt. Minder onzekerheid en meer plezier ervaren in het dagelijkse werk zijn onschatbare resultaten van succesvolle implementatie van goed uitgevoerd diagnostisch onderzoek.

De onderzoeksvragen in dit proefschrift komen voort uit dilemma's die praktiserende huisartsen dagelijks ondervinden. We hebben dan ook gekozen voor een op de dagelijkse praktijk geënte methodologie met als doel kennislacunes te verkleinen en de kans op succesvolle implementatie te vergroten. In hoofdstuk 9, de algemene discussie van het proefschrift, worden methodologische aspecten van 
deze keuze aan de orde gesteld. Ook wordt nader ingegaan op huisantsgeneeskundig relevante wetenschappelijke inzichten over LLWI. CRP bleek een relevante, diagnostische test in ons onderzoek. Echter, huisartsen hebben over het algemeen nog weinig ervaring met deze test. Daarom wordt in dit hoofdstuk bestaande literatuur over CRP geëvalueerd en worden redenen gegeven voor de gereserveerdheid van huisartsen om de CRP-sneltest als aanvulling op het diagnostisch arsenaal in de huisartsenpraktijk te gaan gebruiken. Vervolgens wordt in de dis cussie de aandacht gericht op genezing van LLWI. Volledig herstellen van een episode van LLWI blijkt dus over het algemeen veel langer te duren dan tot op heden is aangenomen. De verwachting dat de ziekte een gunstig beloop heeft, maar vaak lang duurt moet met de patiënt worden besproken. Bovendien dient men zich bewust te zijn van de verschillen in de interpretatie van genezing tussen de huisarts en de patiënt.

Nieuwe studies zijn nodig om het groeiende probleem van bacteriële resistentie het hoofd te bieden. Onderzoekers wereldwijd zullen daarbij de handen ineen moeten slaan. Internationale samenwerking heeft reeds geleid tot de start van een gerandomiseerd interventieonderzoek in de regio Zuidoost-Brabant met de volgende onderzoeksvragen: In hoeverre zal de introductie van de CRP-sneltest en specifieke communicatievaardigheden (al of niet gecombineerd) in de huisartsenpraktijk leiden tot snellere genezing, vermindering van aanvullende diagnostiek en vermindering van het voorschrijven van antiblotica? In hoeverre zijn deze reducties kosteneffectief?

Nieuwe studies zijn nodig om de resultaten van de onderzoeken uit dit proefschrift te bevestigen of te weerleggen. Tot die tijd is het verstandiger om de meest over. tuigende resultaten uit deze onderzoeken te aanvaarden dan te vertrouwen op anekdotische informatie, persoonlijke ervaring of resultaten uit onderzoeken verricht in geselecteerde (ziekenhuis)populaties.

\section{Antwoorden op de onderzoeksvragen}

1. Wat is de waarde van anamnese, lichamelijk onderzoek en bloedonderzoek voor de diagnose pneumonie bij patiënten met een LLWI?

Droge hoest, diarree en gemeten temperatuur $\geq 38^{\circ} \mathrm{C}$. BSE en CRP waren onafhankelijke en statistisch significante voorspellers van pneumonie. Afwijkende bevindingen bij auscultatie van de longen en de klinische diagnose pneumonie door de huisarts gesteld waren niet voorspellend voor pneumonie. CRP had hogere diagnostische odds ratio's dan alle andere testen, symptomen en ziekte. verschijnselen. Als een predictieregel voor laagrisicopatiënten (met o.a. CRP<20 $\mathrm{mg} /$ ) zoul zijn toegepast op de onderzoekspopulatie, dan hadden 80 van de 193 antibioticavoorschriften voorkomen kunnen worden met " ten opzichte van de voorafkans van $13.2 \%$ - een risico op het missen van pneumonie van maximaal $2.5 \%$ 
2. Hoe groot is de overeenstemming tussen radiologen bij de beoordeling van longfoto's op pneumonie bij patiënten met LLWI?

Er was overeenstemming bij 218 van de 243 patiënten ( $89.7 \%$ ). De geobserveerde overeenstemming gecorrigeerd voor toeval was echter matig (kappa 0.53 ; $95 \%$ betrouwbaarheidsinterval $0.37-0.69$ ). De overeenstemming bij patiënten met pneumonie was aanzienlijk lager dan bij patiènten zonder pneumonie (59\% versus 94\%). Kappa was veel lager bij patiënten met chronisch obstructieve longziekte (COPD) en indien Streptococcus pneumoniae $(-0.29)$ was aangetoond.

3. Wat is de frequentieverdeling van de micro-organismen die bij de patiënten met $L L W I$ zijn gevonden?

Virale verwekkers werden even vaak gevonden als bacteriële. Haemophilus (para-) influenzae kwam het vaakst voor (16\%), gevolgd door Influenza A $(14 \%)$, Streptococcus pneumoniae (6\%), Influenza B en het Adenovirus (beide 5\%). De zogenaamde atypische bacteriën kwamen in minder dan $2 \%$ van de patiënten met een LLWI voor. In de subgroep van patiënten met pneumonie werd grofweg dezelfde frequentieverdeling gevonden.

4. Is het macrolide-antibioticum roxitromycine effectiever dan amoxicilline in de behandeling van LLWI?

De toegevoegde waarde van roxitromycine werd niet bevestigd. Het klinische genezingspercentage na afloop van de behandeling was hetzelfde voor de twee groepen. $\mathrm{Na}$ afloop van de volledige follow-up van 28 dagen concludeerden de huisartsen dat $90 \%$ van de patiënten effectief en veilig was behandeld, onafhankelijk van het voorgeschreven antibioticum.

5. Wat is de waarde van anamnese, lichamelijk ondezoek en bloedonderzoek voor de diaghose virale versus bacteriële LLWI?

Uitgebreide anamnese en lichamelijk onderzoek leverden geen gegevens op die virale of bacteriële LLWI konden voorspellen. Ook konden we niet bevestigen dat CRP van waarde is bij dit onderscheid. Verhoogde CRP en BSE waren well waardevol in het onderscheiden van microbiologisch bewezen LLWI ten opzichte van microbiologisch onverklaarde LLWI.

6. Welke gegevens uit anamnese en lichamelijk onderzoek zijn bepalend voor de keuze wel of geen antibioticum voor te schrijven bij LLWI, en hoeverre is deze keuze de meest adequate?

Afwijkingen bij auscultatie en diarree waren zeer sterke voorspellers voor de beslissing van de huisarts om een antibioticum voor te schrijen. $79 \%$ van de 
patienten ontving een antibioticumvoorschrift van de huisants. Uitgaande van de huidige wetenschappelijke bewijsvoering dat alleen patienten met pheumonie een antibioticum nadig hebben; kreeg $86 \%$ van de patienten ten onrechte een antibioticum. Ondanks het grote percentage onnodige voorschriften, kreeg $16 \%$ van de patiënten met radiologisch bewezen pneumonie ten onrechte geen antibioticum.

\section{Hoe lang duurt het om te genezen van LLWI?}

$89 \%$ van de patiënten met LLWI was volgens de huisartsen genezen na 28 dagen. $49 \%$ van de patiënten rapporteerde na 28 dagen echter nog klachten van LLWI, het meest hoest en benauwdheid. Bovendien was op dit laatste evaluatiemoment nog een aanzienlijk aantal patiënten beperkt in de dagelijkse activiteiten. Het klinische beloop van vijf patiënten met pneumonie die geen antibioticum hadden ontvangen was steeds gunstig, al duurde het bij êén patiënt langer dan 28 dagen alvorens hij was genezen.

8. In welke mate beinvloedt een episode van $L L W I$ de dagelijkse activiteiten van de patiënt?

Ten tijde van het eerste bezoek aan de huisarts meldde $73 \%$ van de patiënten beperkingen in de dagelijkse activiteiten. $42 \%$ van de patiënten had deze activiteiten gestopt. Na 28 dagen was $19 \%$ van de patiẻnten nog beperkt in de activiteiten en had $6 \%$ van de patiënten de meeste activiteiten nog altijd gestopt.

9. Is het mogelijk subgroepen van patiënten te selecteren die een groter risico hebben op een slechtere prognose of langduriger zjektebeloop?

Astma als co-morbiditeit was de enige factor die statistisch significant correleerde met vertraagde klachtenafname. Koorts, transpireren en het voorschrijven van een antibioticum waren zwakke voorspellers van snellere klachtenafname. Een slechte uitkomst, in de zin van overlijden of persisterende ziekte als gevolg van de acute episode van LLWI, kwam niet voor.

10. Hoe kan implementatie van diagnostisch onderzoek naar de dagelijkse huisartsenpraktijk worden bevorderd?

Kernboodschappen zijn:

- Huisartsgeneeskundig, diagnostisch onderzoek dient zo veel mogelijk te worden verricht in de dagelijkse huisartsenpraktijk en huisartsen moeten in het gehele onderzoeksproces betrokken blijven. Hiermee wordt de kans op succesvolle implementatie van de onderzoeksresultaten vergroot.

- Van onderzoekers wordt verwacht dat $\mathrm{zij}$ in internationale tijdschriften publiceren. De meeste huisartsen lezen echter nationale vakbladen. Nieuwe (diagnostische) kennis dient dan ook juist in deze bladen te worden gepubliceerd. 
- In tegenstelling tot bij therapeutisch onderzoek ontbreken bij diagnostisch onderzoek vaak machtige organisaties die implementatiestrategieẻn ondersteunen. De beroepsgroep kan dan ook - onder meer via richtlijnen en nascholingsactiviteiten - juist op dit onderzoeksdomein een voorname rol spelen. 
Dankwoord 


\section{Dankwoord}

"Het wordt eens tijd dat je dat project afmaakt, dan kun je eindelijk eens gaan werken", zei mijn moeder me laatst nog, op de haar wel vertrouwde toon. Goed nieuws dus. Mijn hobby-kunstwerkje is af. Het was heerlijk hoor, een beetje

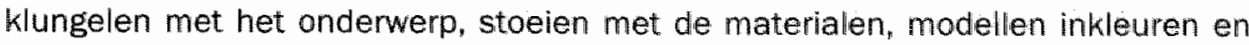
bijschaven, een rijk geschakeerd palet aan resultaten. Ik kon er alle emoties in kwijt. Nu ik ook de diepere betekenis van het geheel heb vastgelegd, ben ik klaar voor mijn eerste openbare expositie. Het zal op 9 september geen prijsuitreiking met dankwoord worden, dus dat kan ik beter nu doen.

Al hoestende, ziek, zwak en misselijk je toestemming geven om aan een onderzoek deel te nemen, terwijl je niet weet of je daar nu zelf bij gebaat bent, is bewonderenswaardig. En dan te weten dat men afstand moest doen van o.a. vijf buisjes bloed, een paar goede fluimen, en neus-keel secreet dat afgenomen werd met een stok die na binnenkomst in de neus toch wel verdacht ver richting kleine hersenen gestoken werd. $U$ deed toch mee, fantastisch! Hartelijk dank.

$\mathrm{Tja}$, en deze lichaamsvochten moesten dus ook verzameld worden. De praktijkassistenten kregen dit voor elkaar. Hulde! De LRTI Rocheldoos is door jullie een geaccepteerd begrip geworden. Jullie waren ook onmisbaar voor het complexe logistieke traject, zoals het plannen van herhaalconsulten, registratie en snelle verwerking van de biologische samples.

De huisartsen Berendsen, van den Berg, Bergmans, Boesten, Boode, Croughs, Dinant, Dirckx, Goossen, Hellemons, Huijbers, Jochems, Koppes, Kuypers, Leclercq, Muijsken, Muris, Peeters, van Proosdij, de Ree, van Rooy, van Stijn, Swinkels, Vissers, Vijgen, Vijgen-Hamers, Wiertz, de Wolf en Wolfs hebben ervoor gezorgd dat we het onderzoek hebben kunnen doen. Jullie zijn de uitdaging aangegaan: tijdens een druk spreekuur acuut zieke patiënten insluiten voor het onderzoek, hen informatie verschaffen, het consult en overwegingen uitgebreid registreren, aanvullende diagnostiek inzetten en behandeling (al of niet gerandomiseerd) opstarten. I $\mathrm{k}$ ben me ervam bewust dat er veel gevraagd is van de dokter in dit onderzoek. Ik merk nu zelf dat het zelfs zonder deelname aan onderzoek een hele opgave is binnen de gestelde praktijkuren patiënten de tijd en aandacht te geven die ze verdienen. Hartelijk dank voor jullie bijdragen!

Dei, dat was spannend: studenten vragen om formulieren en biologische samples per acuut op te halen uit de huisartspraktijk en tijdig af te leveren in het ziekenhuis. Studenten, tijdig, en een betrouwbare auto. Het lijkt onmogelijk, maar het lukte. Nou ja, niet toen het dienst-mobieltje (koelkastmodel) een ritje op het dak van de auto had gemaakt, en ook niet toen het in een afgesloten kluis was 
blijen liggen. Dank aan Danny Hikman, Jan Olif, Eugène Hendriks, Pascal Gorissen, Anika Dam, Angelo Luja, Roel Koch. Nadia Bertelli, Sabine Snieders, Spencer Schipper, Patrick Maas en Daniëlle Bischoff Tulleken.

Ik dank de medewerkers van de afdelingen Kinische Chemie, Radiologie en Medische Microbiologie van het Academisch Ziekenhuis Maastricht, het Maaslandziekenhuis te Sittard en Geleen voor de belangenloze en deskundige hulp. In het bijzonder gaat mijn dank uit naar Ruud Deurenberg en Melanie Schnijderberg voor hun tomeloze inzet, hun precisie en het overzicht in de wereld van dozen, buisjes, sputummonsters, stickers, formulieren en patiëntennummers. $\mathrm{Nu}$ je het zegt, dat hele microbiologische gebeuren heeft me naast enkele grijze haren toch ook een hoop bedankjes opgeleverd.

Vanuit het basiskamp (affeling Huisartsgeneeskunde) hebben Ramon Ottenheim, Josephine Asberg (destijds huisartsen in opleiding). Alexander Thissen. Tessa Witbraad (destijds studenten geneeskunde) en Hilde Sielhorst (onderzoeksassistente) me op wisselende momenten enorm geholpen het onderzoek draaiende te houden als ik uren voor de huisartsopleiding volgde. En het gesjouw met ruim 500 longfoto's heeft toch maar mool een publicatie opgeleverd, Tessa. Dank voor jullie geweldige hulp.

Het is al weer lang geleden dat we onze medicatiestudie hebben gedaan. Francine de Stoppelaar, je hielp me vakkundig met de uitvoer, blinderingen, verpakkingen en controles, waarvoor mijn dank.

Phile Govaert, je hebt het onderzoek goed op gang geholpen: pragmatisch, recht door zee, zo nodig paternalistisch als je die jonkies-van-huisartsen vertelde dat ze gewoon mee moesten doen met het onderzoek. Enorm fijn dat je mij als groentje op het goede spoor hebt gezet.

Jan van Wersch, de fibrinogeenbuisjes staan koud, we kunnen gaan beginnen... Dank voor je enthousiasme en ideeër.

Arnold Kester loodste me door het drassige en geaccidenteerde terrein van de statistiek. Hartelijk dank hiervoor.

Jos van Engelshoven dank ik hartelijk voor de leerzame fotosessies en de hulp bij het radiologische artikel.

Virus of niet? Catrien Bruggeman, je hebt me goed op weg geholpen met de interpretatie van de serologische monsters. 
Tussen analyse 1 en 102F, op zoek naar een weggelopen bacterie of virus, hebben we de dingen des levens regelmatig de revue laten passeren. Opperviakkigheid in diagnostiek en persoon werd niet getolereerd. Het is simpel. Zonder Paula Rinkens was er geen proefschrift. Het woord "dank" past niet op het papier.

1 would like to thank the members of the General practice Respiratory tract Infections Network for the stimulating discussions and the joy of working together.

Hasse Melbye. Long before I was even aware of the importance of studying LRTI you were already disclosing important LRTI matters. Happily, these days, we are jointly referenced. It takes (at least) two to tango. Thanks for your important work, your advices on CRP and appropriate wine choices for dinner.

Christopher Butler, what to say? $\|$ am afraid to write, because you will probably have a better sentence in mind. Thanks a lot for the fruitful cooperation in the second (or third?) half of my research project. I am very happy we will continue working together in the IMPAC ${ }^{3}$ T study, together with Kerenza Hood, Geert-Jan Dinant and Jochen Cals, amongst others. Man, we already had the most efficient meetings I can think of. But this time I also have a serious comment for you: please clean your car so now and then, the inside in particular.

Raiph Gonzales from over-the-big-ocean, thanks for sharing your ideas. Let us continue, we are on the same and right track. Yes, I want antibiotic reduction advertisements on our public buses tool

Willy Graffelman, we hebben van start to finish een vergelijkbaar doel gehad. Het Graffelman-Hopstaken model ligt in het verschiet.

Samuel Coenen, LRTI-krijger van het eerste uur. Onze gelijkgestemde visie en open vizier maakten onze samenwerking tot een feest. Hartelijk dank! De interessante verschillen tussen onze landjes beloven nog veel samenwerkingsgenot.

Patty Nelemans, je scherpe blik, je persoonlijke interesse en je MEMS-dekseltjes voor de medicijnenpotjes. Zo maar een voyeuristisch element in het onderzoek: een kijkje in het privéleven van de patiënt, althans in zijn/haar medicijninnameritme en therapietrouw. We moeten dat artikeltje toch nog maar eens gaan schrijven.

Jean Muris, ook begeleider van het eerste uur. Ondanks je dubbelrol als huisarts en begeleider bespeurde ik nooit hectiek, onrust of druk bij onze besprekingen. De laatste jaren heb je je werkgebied wat meer moeten verschuiven, maar wellicht dat het in "LRTI-3" toch weer meer samenvalt. 
Ellen Stobberingh, microbioloog en leider van het LRTI-project. Je vakvrouwschap, fabuleuze dosis energie en geweldige steun, gecombineerd met een vleugje chaos, zijh nog altijd hartverwarmend. Wat een luxe, drie co-promotoren!

Geert-Jan Dinant, rode draad door mijn wetenschappelijke werk. Het woord diarree is in dit proefschrift regelmatig gevallen. Ruim 10 jaar geleden is onze samenwerking daar ook mee begonnen: een stageverslag (mooi ouderwets ingebonden met harde kaft en bijpassend lintje) naar diarree bij kinderen in Indonesië kon je goedkeuring wegdragen. $\mathrm{Na}$ een plezierige wetenschapsstage volgde spoedig het aiotho-traject, waarin je altijd mijn persoonlijke mentor bent gebleven. Je bereidheid 24 uur per dag klaar te staan voor werkinhoudelijke en persoonlijke adviezen heb ik bijzonder gewaardeerd. Je snelle en adequate beoordeling en correctie van manuscripten is een zege voor elke promovendus. Het is goed dat we nu op losgeharkte ondergrond verder gaan. Het biedt perspectief voor nieuwe ideeën en projecten. De onlangs gestarte Impact-studie is een geweldig mooi begin.

André Knottnerus, veel van de hoofdstukken uit dit proefschrift zouden slechts schetsen zijn als jij geen grondlegger was geweest van diagnostisch onderzoek in de huisartsgeneeskunde. Naast architect van een aantal studies was je ook steeds bereid als metselaar de laatste oneffenheden en gaatjes dicht te strijken. Ik dank je hartelijk hiervoor.

Op mijn eerste werkdag werd ik nog bruut van mijn werkplek verstoten door een astmatische collega, maar daarna was het een groot feest met aardige en gezellige kamergenoten: Jan-Joost Rethans, Cathelijne van Hasselt, Ben van Steenkiste, Wim Verstappen, Sandra Kuiper en Loes van Bokhoven. En natuurlijk hadden we op den duur ook allemaal nog wel een aanzittende student-assistent. Niet allemaal tegelijk, hoor... maar wel bijna. Het blijft een frappante ervaring om op vrijdagmiddag bij Huisartsgeneeskunde twee lange lege gangen door te wandelen en te eindigen in een wat muffe kamer met een verspreide allegaar aan artikelen over onbegrepen klachten, astma, cholesterol en luchtweginfecties en daartussen. zij aan zij, vier zwoegende promovendi. Ach ja, als de computers het maar doen (...) Gelukkig hebben we wel een onafhankelijk opererende kamer-unit met hoog gekwalificeerd personeel: concierge, teddybeer, systeembeheerder en psycholoog in één persoon: Ben, je bent een kanjer. Dank voor alle hulp! Je zou eigenlijk zelf ook eens een onderzoekje moeten gaan doen.

De collega's van Revalidatiecentrum Hoensbroeck, de medewerkers van het RDB Chronische Pijn in het bijzonder, dank ik hartelijk voor de fijne samenwerking, ooit, aan het begin van dit promotietraject. 
Pascale Nelissen, dank voor je interesse, ondersteuning en hulp bij de lay-out van dit boekje. Het stokje werd soepel overgedragen aan Tiny Wouters, redder in nood! Jouw ervaring en liefde voor de opmaak hebben mijn nachten goed gedaan. Ojee, je leest dit natuurlijk als het boekje nog afgemaakt moet worden... Tiny, je bent de bestel

Dan mijn lotgenoten, de artsen in opleiding tot huisarts en onderzoeker (aiotho's): Loes van Bokhoven, Katinka Prince, Marjolein de Vries, Annemiek Nijholt, Wemke Veldhuizen, Patrick van Limpt, Roelf Norg, Niels Chavannes, Paul Houben, en eerder aok Cyril Schreurs. We hebben op momenten hard moeten knokken voor ons bestaan, maar tegenwoordig hebben we toch regelmatig wat te vieren. De volgende ronde gaat beginnen. Ik wens vanaf nu met $U$ te worden aangesproken door jullie. Yvonne van Leeuwen, Paul Ram en Geert-Jan Dinant hebben hun vertrouwen in de alotho-opleiding omgezet in daadkracht. Hartelijk dank!

Aiotho zijn betekende dus ook het vak van huisarts leren. De steun en wijsheid van de huisartsbegelelders Bert ten Berge, Jos Slijpen, Mark Brueren, Gerard van Mierla en Carla Stuurman hebben me geholpen in deze ontwikkeling. De huisartsen - diestijds in opleiding - van de drie haio-groepen dank ik hartelijk voor de boeiende discussies en de gezelligheild tijdens de terugkomdagen. Math Hundscheid en Harry Huijben, huisartsopleiders, bij jullie was ik in goede handen. Een groter contrast in persoonlijkheid, praktijk en omgeving was haast niet denkbaar en mede daarom is het me zo goed bevallen. Betty, Willy, Yvonne en de anderen, de sfeer was ongekend, ik kom het gauw weer eens opsnuiven.

In barre tijden is het immer Ine Siegelaer die je eens diep in de ogen kijkt, oordeelt en de arm om je heen slaat. Dank, Ine.

Mark Spigt, collega, vriend, hardloopmaatje. Ik heb je steun bilizonder gewaardeerd. Maud, hoe langer het stukje... Zodra Ik een nieuwe enkel heb, ga ik de sportieve strijd weer met je aan.

Ook anderen hebben me in een woelige fase van mijn leven enorm geholpen. Jullie weten je naam well te vinden in dit dankwoord. Zij die wat langer stilstaan bij dit: stukje dank ik voor de levenslessen.

Jim Tatipata, Marga van de Aa, Karin Vaessen, Frits Ruijters, Sandrine Tuerlinckx, en Sjoerd Hobma bij Huisartsgeneeskunde dank ik voor de ondersteuning en gezelligheid. Sjoerd, je bent net voor me gefinisht, maar zolang het met de belangrijke dingen in het leven - zoals de Parelloop - andersom is, malk ik me geen zorgen. 
Jan Klerk, thank you wery much.

In Noorwegen hebben de "CRP-guys from Holland" elkaar leren kennen, jij nog sportgekker dan ik. Onze bedden bleken al jaren 25 meter van elkaar vandaan te staan in een van de betere achterbuurten van Maastricht. Jochen Cals, de future is bright, maar bovenal, "ge zèt unne goeie vent". Gelukkig kan ik je met squashen nog verslaan. In de wetenschap heb je de ronde achterstand als een lichtvoetige Bekele al bijna ingehald.

De Stichting Gezondheidscentra Eindhoven straalt professionaliteit en ambitie uit. Ik dank directeur Ernst van Voorst en de medewerkers van het Stedelijk Buro voor het vertrouwen, de ondersteuning en de positieve attitude ten aanzien van mijn wetenschappelijke werk. Het is een weelde dat nagenoeg alle gezondheidscentra van de SGE zullen gaan deelnemen aan ons nieuwe project.

De derde huisarts in Gezondheidscentrum Meerhoven is lange tijd een 'mystery guest" geweest. Het doet me enorm veel deugd dat ik deze plek nu definitief heb mogen innemen. Ik ben nu een echte dokter geworden. En dat is leuk, man, want er zijn aardige patiënten en er is ook nog eens een hele club enthousiaste eerstelijnsprofessionals die het werken in het centrum tot een feest maken. Robert Vening dank ilk voor zijn mentorrol, zijn enthousiasme en vertrouwen. Caroline Thijssen en Liedewei van Waes, jullie zijn super-collega's. Caroline van Vroenhoven, Annalies Hamers, Astrid Mangé en Inge Helmonds, het is fijn om met jullie samen te werken. En dan zijn er ook nog alle andere warme en gezellige collega's in het gezondheidscentrum. Dank voor de superstart die ik door jullie heb mogen maken!

Annemarie, Joep, Liliane en Nicole hebben een tijdje op mijn geboorte moeten wachten. Nog attijd' loop ik een paar levensfases achter, maar "broertje" bijuven is bij jullie wel leuk, hoor! Zwagers Douwe, Benoît en Rob, jullie zijn altijd welkom... om te klussen in huis. A.u.b. niet meezingen als de Hopstakens a-capella voor me gaan zingen. Riekie, warmhartige schoonzus, met warme stem mag dat wel. Tja, en dan mijn lieve nichtjes Ellian, Karen, Jana, Alies, Jelyn en Veerle. Jullie herhaalde, steeds wanhopiger klinkende, sollicitaties naar de functie van bruidsmeisje hebben we in goede orde ontvangen. We houden uw brief in ons bestand. Sebas en Mathieu, echte kerels, het wordt weer eens tijd voor een stevig partijtje voetbal. FC Utrecht en Helmond Sport... ach ja, een transfer naar Willem II kan altijd nog:

De familie Leckle-Sendar dank ik hartelijk voor de steun, het vertrouwen en de Surinaamse warmte.

Mam, ik zal eens gaan werken. Ik dank jou en pap voor een geweldige jeugd en opvoeding. I $\mathrm{k}$ ben trots op jullie! I k koester de warme gedachten aan mijn vader. 
De inwoners van Tibet dank ik voor de inspiratie, Rosanne, René, Anita en Martijn voor de gezelligheid aldaar en de wriendschap. Rene, supermaat Je gaat van flora naar fauna, op weg om een witstekende huisarts worden, het kan niet anders.

AV Dikke Stella, vereniging van ex-top (of tob?)sporters... gaat goedl Edgar van Mil, Steven Olde Damink, Dennis Bergmans, Michiel Marcar. Wanhopig trachten we onze lijven de glorieuze aanblik van weleer terug te geven. De een lukt dit beter dan de ander. Sorry, kan ik ook niets aan doen. Ik kijk wit naal de cup met de kleine oren. En Sandra, Marja, Irma en Maartje, zwanger of niet, buiken als wasbordjes wil ik zien op 9 september. Dennis man, we bouwen een aardig staaltje overeenkomsten in onze levens op: jongste van viff, samen in selectie ZuidNedierland, de wonderlijke Herman, MVV, dokter spelen, de liefde voor Van The Man, promoveren op pneumonie en nu dus ook het beroep van paranimf.

Ralph Laven, rots in de branding, samen met Astrid. Sinds wij de marathonvoorbereiding hebben gedaan, is het vak van huisarts enorm aan het veranderen. Dat moet door al onze gesprekken komen, toch? Wij denken dat het beter kan, bijvoorbeeld met de volgende openingszin van het consult: "Mevrouw, luister eens even, ik heb drie banen, ik heb $u$ niet gekozen, $u$ heeft mij niet gekozen, maar er moet wel brood op de plank komen, dus vertel maar eens waarvoor u komt."

Wij delen een onophoudelijk tweestemmig duet van school, voetbal, vakantie, schaatsen, het vak, liften, zang, ik noem maar eens wat. Lol en kwaliteit, altijd weer, Daan van Baar. Isabel, succesvolle allochtoon in Nederland, je bent een toffe meid. Kan ik Daan gauw weer eens lenen voor een ouderwets nachtje 'klooien' met Cubase, zang en gitaar?

Alla dey ju e presiri mi ati Vanessa.

wan gran sula fu lobi,

krakti nanga satisfacti

mi lobi ju

A boto mus kon lusu now fu na shoro

ma ini a denki ai tan didon

Ook ik ga er maar eens een dikke, vette, doch vrolijke punt achter zetten 
Publications 


\section{Publications}

Hopstaken RM, Stabberingh EE, Knottmerus IA, Muris JWM, Nelemans P, Rinkens PELM, Dinant GJ. Zijn virale en bacteriële lageluchtweginfecties in de dagelijkse praktijk van elkaar te onderscheiden? Een explorerend onderzoek. Huisarts Wet. 2005; accepted for publication.

Hopstaken RM, Cals JWL, Dinant GJ. CRP helps to exclude pneumonia. BMJ.com 2005.

Hopstaken RM. Spricht Husten plus Diarthoe für Pneumonie? Der Hausarzt. 2005;6(5):13.

Hopstaken RM. Diagnostisch onderzoek naar lageluchtweginfecties in de huisartsenpraktijk. Huisarts Wet. 2005:48:192.

Hopstaken RM, Stobberingh EE, Knottnerus JA, Muris JWM, Nelemans P. Rinkens PELM, Dinant GJ. Clinical items not helpful in differentiating viral from bacterial lower respiratory tract infections in general practice. J Clin Epidemiol. 2005; 58:175-83.

Hopstaken RM, Hay AD, Butler CC. Diagnosis of bacterial LRTI. Br J Gen Pract. 2004:54: 216.

Hopstaken RM, Witbraad T, van Engelshoven JMA, Dinant GI. Interobserver variation in the interpretation of chest radiographs for pneumonia in community-acquired lower respiratory tract infections. Clin Radiol. 2004;59:743-52.

Hopstaken RM, Muris JWM, Knottnerus JA, Kester ADM, Rinkens PELM, Dinant GJ. Symptoms and signs plus erythrocyte sedimentation rate or C-neactive protein predicted pneumonia in lower respiratory tract infection. [Abstract of: Hopstaken RM, Muris IW, Knottnerus JA, et al. Contributions of symptoms, signs, erythrocyte sedimentation rate, and C-reactive protein to a diagnosis of pneumonia in acute lower respiratory tract infection. $\mathrm{Br} J$ Gen Pract 2003;53:358-64.] Evidence-Based Medicine 2004;9:55.

Hopstaken RM. Diagnose pneumonie bij lage-luchtweginfecties. Huisarts Wet 2004;47:205.

Hopstaken RM, Muris JWM, Knottnerus JA, Kester ADM, Rinkens PELM, Dinant GJ. De waarde van anamnese, lichamelijk onderzoek, BSE en CRP voor de diagnose pneumonie bij acute lage-luchtweginfecties. Huisarts Wet 2004;47:9-15.

Hopstaken RM, Muris JWM, Knottnerus JA, Kester ADM, Rinkens PELM, Dinant GJ. Contributions of symptoms, signs, erythrocyte sedimentation rate and C-reactive protein to a diagnosis of pneumonia in acute lower respiratory tract infection. $\mathrm{Br} I$ Gen Pract 2003;53:358-64.

Hopstaken RM, Nelemans P, Stobberingh EE, Muris JWM. Rinkens PELM, Dinant Gע. Behandeling van acute lage-luchtweginfecties in de huisartsenpraktik. Een dubbelblind. gerandomiseerd anderzoek met amoxicilline versus roxitromycine. Huisarts Wet $2003 ; 46: 73-9$. 
Hopstaken RM, Nelemans P, Stobberingh EE, Muris JWM, Rinkens PELM, Dinant GJ. Is roxithromycin better than amoxicillin in the treatment of acute lower respiratory tract infections in primary care? A double-blind randomized controlled trial. I Fam Pract $2002 ; 51: 329-36$

Dinant GJ "Hopstaken RM, van Bokhoven MA. Implementatie van diagnostisch onderzoek in de dagelijkse praktik. De paradox tussen evidence en practice. Huisarts Wet 2004,47 : 99103 .

\section{Publication related acknowledgments}

The CAPHRI 2004 Philipsen Award for best publication 2003; Maastricht University.

Award for Best Paper By A Fesident at the 30 th Annual Meeting of the North American Primary Care Research Group, 2002, New Orleans, USA.

Nomination for best article Extramural and Transmural Research Institute (ExTra) and Health in 2002; Maastricht University.

Nomination for Heert Dokterprijs for best article in Huisarts en Wetenschap 2003.

\section{Manuscripts submitted for publication:}

Hopstaken RM, Coenen S, Butler CC. Treating patients not diagnoses; challenging assumptions underlying the irvestigation and management of LRTI in general practice.

Hopstaken RM, Coenen $S_{\text {n }}$ Butler CC, Nelemans P, Muris JWM, Rinkens PELM, Kester ADM* Dinant GJ. Prognostic factors and clinical outcome in acute lower respiratory tract infections; a prospective study in general practice.

Hopstaken RM, Butler CC, Muris JWM, Knottmerus JA, Kester ADM, Rinkens PELM, Dinant GJ. Do clinical findings in lower respiratory tract Infection help general practitioners prescribe antibiotics appropriately? An observational cohort study in general practice. 
About the author 


\section{About the author}

Rogier Hopstaken was born in Tilburg, the Netherlands, on 11 November, 1969. He grew up in Goirle, where he completed his secondary education at the Mill-Hill College in 1988. Although a possible career in soccer was tempting, he chose to study health sciences at Maastricht University for two years and then started medical school at the same university. During his studies, he did various small research projects at the Department of General Practice and attended family medicine courses in Yogyakarta, Indonesia and Montreal, Canada. After graduation in 1997, he started to work as a researcher at the Department of General Practice, which he combined with a job as team manager for a multidisciplinary treatment programme for patients with chronic pain at the Institution of Rehabilitation Centres Limburg in Hoensbroek. From 1998 to 2002, he participated in the combined vocational training and research programme at the Department of General Practice at Maastricht University. The studies on which this thesis is based were prepared and conducted in the same period. From 2002 to 2004 , he worked as a general practitioner at various locations in the Netherlands. Since 2004, he has been a general practitioner at the Institution of Health Centres in Eindhoven (SGE), where he has been attached to the Meerhoven Health Centre since 2005. $\mathrm{He}$ is the supervisor of a PhD project on point of care C-reactive protein testing and enhanced communication skills training in lower respiratory tract infections in general practice, which is about to start in the Eindhoven region. 
Appendix 


\section{The Stethoscope Song}

A professional ballad by Oliver Wendell Holmes (1848)

There was a young man in Boston town, He bought him a stethoscope nice and new. All mounted and finished and polished down, With an ivory cap and a stopper too.

It happened a spider within did crawl, And spun him a web of ample size, Wherein there chanced one day to fall A couple of very imprudent flies.

The first was a bottle-fly, big and blue, The second was smaller, and thin and long; So there was a concert between the two, Like an octave flute and a tavern gong.

Now being from Paris but recently, This fine young man would show his skill; And so they gave him, his hand to try, A hospital patient extremely ill.

Some said that his liver was short of bile, And some that his heart was over size, While some kept arguing, all the while, He was crammed with tubercles up to his eyes.

This fine young man then up stepped he, And all the doctors made a pause;

Said he, The man must die, you see, By the fifty-seventh of Louis's laws.

But since the case is a desperate one, To explore his chest it may be well; For if he should die and it were not done, You know the autopsy would not tell.

Then out his stethoscope he took, And on it placed his curious ear; Mon Dieu! said he, with a knowing look, Why, here is a sound that's mighty queer! 
The bourdonnement is very clear,Amphoric buzzing, as I 'm alive!

Five doctors took their turn to hear;

Amphoric buzzing, said all the five.

There's empyema beyond a doubt

We'll plunge a trocar in his side.

The diagnosis was made out,-

They tapped the patient; so he died.

Now such as hate new-fashioned toys

Began to look extremely glum;

They said that rattles were made for boys,

And vowed that his buzzing was all a hum.

There was an old lady had long been sick, And what was the matter none did know:

Her pulse was slow, though her tongue was quick;

To her this knowing youth must go.

So there the nice old lady sat,

With phials and boxes all in a row;

She asked the young doctor what he was at,

To thump her and tumble her ruffles so.

Now, when the stethoscope came out,

The flies began to buzz and whiz:

Oh, hol the matter is clear, no doubt;

An aneurism there plainly is.

The bruit de râpe and the bruit de scie

And the bruit de diable are all combined;

How happy Bouillaud would be,

If he a case like this could find!

Now, when the neighboring doctors found

A case so rare had been descried,

They every day her ribs did pound

In squads of twenty; so she died.

Then six young damsels, slight and frail, Received this kind young doctor's cares;

They all were getting slim and pale,

And short of breath on mounting stairs. 
They all made rhymes with "sighs" and "skies," And loathed their puddings and buttered rolls, And dieted, much to their friends' surprise, On pickles and pencils and chalk and coals.

So fast their little hearts did bound, The frightened insects buzzed the more;

So over all their chests he found

The râle sifflant and the râle sonore.

He shook his head. There's grave disease,-I greatly fear you all must die;

A slight post-mortem, if you please, Surviving friends would gratify.

The six young damsels wept aloud, Which so prevailed on six young men That each his honest love avowed, Whereat they all got well again.

This poor young man was all aghast;

The price of stethoscopes came down;

And so he was reduced at last

To practise in a country town.

The doctors being very sore, A stethoscope they did devise That had a rammer to clear the bore With a knob at the end to kill the flies.

Now use your ears, all you that can, But don't forget to mind your eyes, Or you may be cheated, like this young man, By a couple of silly, abnormal flies. 